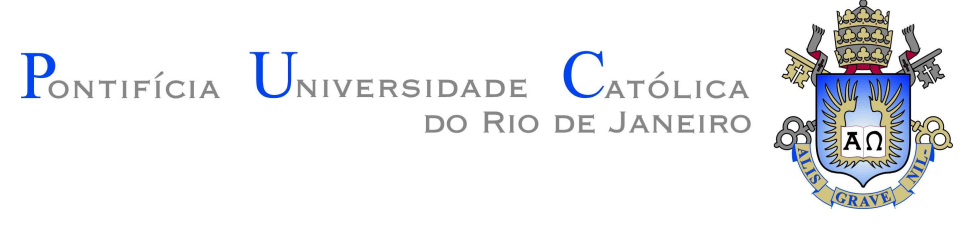

Ricardo Dória Loyola-Camorim

\title{
Análise de sensibilidade de variáveis de reservatório em simulador de escoamento em meio poroso de dupla porosidade e permeabilidade
}

Dissertação de Mestrado

Dissertação apresentada como requisito parcial para obtenção do grau de Mestre pelo Programa de Pós-Graduação em Engenharia Mecânica, do Departamento de Engenharia Mecânica da PUC-Rio.

Orientador: Prof. Ivan Fábio Mota de Menezes Coorientador: Dr. Marcos Vitor Barbosa Machado 
Ricardo Dória Loyola-Camorim

\section{Análise de sensibilidade de variáveis de reservatório em simulador de escoamento em meio poroso de dupla porosidade e permeabilidade}

Dissertação apresentada como requisito parcial para obtenção do grau de Mestre pelo Programa de Pós-Graduação em Engenharia Mecânica da PUC-Rio. Aprovada pela Comissão Examinadora abaixo:

Prof. Ivan Fábio Mota de Menezes

Orientador

Departamento de Engenharia Mecânica - PUC-Rio

Dr. Marcos Vitor Barbosa Machado

Coorientador

Petróleo Brasileiro S/A - Petrobras

Prof. Arthur Martins Barbosa Braga

Departamento de Engenharia Mecânica - PUC-Rio

Dr. Daniel Nunes de Miranda Filho Petróleo Brasileiro S/A - Petrobras

Dr. José Sérgio de Araújo Cavalcante Filho

Petróleo Brasileiro S/A - Petrobras 
Todos os direitos reservados. É proibida a reprodução total ou parcial do trabalho sem autorização da universidade, do autor e do orientador.

\section{Ricardo Dória Loyola-Camorim}

Graduou-se em Engenharia Eletrônica e de Computação em 2010 pela Universidade Federal do Rio de Janeiro (UFRJ). Ingressou na Petrobras no mesmo ano como engenheiro de petróleo e, desde então, concentra sua atuação na área de engenharia de reservatórios. Desde o início de sua trajetória na companhia, trabalha com modelagem de campos de petróleo do pré-sal.

Ficha Catalográfica

Loyola-Camorim, Ricardo Dória

Análise de sensibilidade de variáveis de reservatório em simulador de escoamento em meio poroso de dupla porosidade e permeabilidade / Ricardo Dória Loyola-Camorim ; orientador: Ivan Fábio Mota de Menezes ; coorientador: Marcos Vitor Barbosa Machado. - 2020.

155 f. : il. color. ; $30 \mathrm{~cm}$

Dissertação (mestrado)-Pontifícia Universidade Católica do Rio de Janeiro, Departamento de Engenharia Mecânica, 2020.

Inclui bibliografia

1. Engenharia Mecânica - Teses. 2. Dupla permeabilidade. 3. Reservatório. 4. Carste. 5. Fratura. 6. Vug. I. Menezes, Ivan Fábio Mota de. II. Machado, Marcos Vitor Barbosa. III. Pontifícia Universidade Católica do Rio de Janeiro. Departamento de Engenharia Mecânica. IV. Título. 
Dedico esse trabalho a meu pai e a minha mãe que sempre me deram a base para eu atingir meus objetivos. 


\section{Agradecimentos}

Gostaria de agradecer aos meus orientadores Ivan Menezes e Marcos Machado pelo apoio na elaboração dessa dissertação.

Também agradeço à PUC-Rio, à CAPES e à Petrobras por terem permitido meu desenvolvimento.

Aos meus pais e família por sempre terem me incentivado na busca pelo conhecimento.

À minha esposa Ilana pelo apoio incondicional, mesmo em uma época difícil como a quarentena devido ao COVID-19.

E a todos os meus amigos, colegas e professores que de alguma forma contribuíram para o término desse trabalho.

O presente trabalho foi realizado com apoio da Coordenação de Aperfeiçoamento de Pessoal de Nível Superior - Brasil (CAPES) - Código de Financiamento 001. 


\section{Resumo}

Dória Loyola-Camorim, Ricardo; Mota de Menezes, Ivan Fábio; Barbosa Machado, Marcos Vitor. Análise de sensibilidade de variáveis de reservatório em simulador de escoamento em meio poroso de dupla porosidade e permeabilidade. Rio de Janeiro, 2020. 155p. Dissertação de Mestrado Departamento de Engenharia Mecânica, Pontifícia Universidade Católica do Rio de Janeiro.

Os reservatórios de petróleo do pré-sal brasileiro são encontrados em rochas carbonáticas localizadas em ambiente offshore na borda da plataforma continental. Com o fim de explorar essas jazidas de forma mais segura e rentável, é essencial representá-las corretamente nos modelos de simulação de escoamento. Entretanto, esta não é uma tarefa simples. Essas rochas carbonáticas recorrentemente apresentam fraturas e carstes nos quais o escoamento se comporta de forma diferente da simulação tradicional utilizando porosidade única. Para solucionar o problema, existem técnicas que representam o escoamento através dos diversos meios porosos. No entanto, essas modelagens inserem diversas complexidades para a correta caracterização das formações geológicas e da previsão da produção. Nesse trabalho são analisados os impactos que algumas das características das fraturas, da matriz e da malha de poços têm no resultado das simulações com dupla porosidade e permeabilidade.

\section{Palavras-chave}

Dupla permeabilidade; Reservatório; Carste; Fratura; Vug. 


\section{Abstract}

Dória Loyola-Camorim, Ricardo; Mota de Menezes, Ivan Fábio (Advisor); Barbosa Machado, Marcos Vitor (Co-Advisor). Sensitivity analysis of reservoir variables on a dual porosity and permeability simulator. Rio de Janeiro, 2020. 155p. Dissertação de mestrado - Departamento de Engenharia Mecânica, Pontifícia Universidade Católica do Rio de Janeiro.

Petroleum reservoirs of the Brazilian pre-salt are found in carbonate rocks located offshore at the edge of the continental shelf. To optimize the exploitation of these reservoirs, it is of paramount importance to properly represent them in the flow simulation models. Nevertheless, this is not a straightforward task. Carbonate rocks usually present fractures and karsts, where flow differs from what is traditionally represented by single porosity reservoir simulators. With the purpose of better modelling the fluid flow behavior through multiple media, alternative techniques exist. However, these alternatives require additional complexities and variables for the adequate characterization of the geologic formations and production forecast. In this work, the impact that some of the fracture and matrix characteristics and the well positioning have on the results of dual-porosity and dualpermeability simulations is addressed.

\section{Keywords}

Dual Permeability; Reservoir; Karsts; Fracture; Vug. 


\section{Sumário}

1 Introdução 21

1.1 Contexto Geológico 21

1.2 Contexto de Simulação 24

1.3 Motivação 26

1.4 Objetivos 27

1.5 Estrutura do Trabalho 28

2 Revisão Bibliográfica 29

2.1 Reservatórios Naturalmente Fraturados 29

2.1.1 Classificação 30

2.1.2 Modelagem de Escoamento 31

3 Fundamentação Teórica 38

3.1 Conceitos e Definições 38

3.1.1 Conceitos Básicos 38

3.1.2 Reservatórios Fraturados 39

3.1.3 Função Logística $\quad 41$

3.2 Simulador de Escoamento $\quad 42$

3.2.1 Simulação Numérica de Reservatórios 42

3.2.2 Simulação Composicional $\quad 45$

3.2.3 Simulação de Dupla Porosidade e Dupla Permeabilidade 54

4 Metodologia 58

4.1 Organização do Trabalho 58

4.1.1 Simulação 58

4.1.2 Variáveis Estudadas $\quad 59$

4.1.2.1 Homogeneidade/Heterogeneidade da Matriz da Rocha 60

4.1.2.2 Posicionamento dos Poços 61 
$\begin{array}{lll}\text { 4.1.2.3 Corredor de Fraturas } & 62\end{array}$

4.1.2.4 Permeabilidade Efetiva das Fraturas 63

$\begin{array}{lll}4.1 .3 & \text { Resultados Avaliados } & 64\end{array}$

4.1.3.1 Previsão de Produção $\quad 64$

4.1.3.2 Resultados Numéricos 66

4.2 Modelo de Reservatório $\quad 70$

4.2.1 Condições Iniciais do Modelo 70

4.2.2 Estrutural 71

$\begin{array}{lll}4.2 .3 \text { Fluido } & 73\end{array}$

4.2.4 Distribuição das Propriedades $\quad 74$

$\begin{array}{lll}4.2 .5 & \text { Fraturas } & 75\end{array}$

4.2.6 Permeabilidade Relativa 76

$5 \quad$ Resultados e Análises $\quad 78$

5.1 Simulações sem Injeção $\quad 79$

5.1.1 Controle de Qualidade da Solução Numérica 80

5.1.2 Homogeneidade da Matriz 82

5.1.3 Aspectos Geométricos do Corredor de Fraturas 83

5.2 Simulações com Injeção $\quad 87$

5.2.1 Controle de Qualidade da Solução Numérica 88

5.2.2 Homogeneidade da Matriz 88

5.2.3 Direção da Malha de Poços em Relação à Malha do Modelo 95

5.2.4 Aspectos Geométricos do Corredor de Fraturas 97

5.2.5 Comportamento das Previsões de Produção em Relação à Permeabilidade Efetiva de Fraturas

6 Conclusões 110

6.1 Ajuste dos Parâmetros Numéricos 110

6.2 Cenários sem Injeção 111

6.3 Cenários com Injeção 111

$\begin{array}{lll}6.4 & \text { Sugestões para Trabalhos Futuros } & 112\end{array}$ 
Referências Bibliográficas

Apêndice A. Tabelas com os Resultados das Simulações

Apêndice B. Tabelas com os Ajustes da Curva Logística 


\section{Lista de Figuras}

Figura 1.1: Província do Pré-sal.

Figura 1.2: Exemplos de lâmina petrográfica de rocha do pré-sal: (a) com polarizadores paralelos e (b) com polarizadores cruzados. Porosidade em azul; seta vermelha aponta para esférulas de calcita; seta branca, shrub; seta verde, argila.

Figura 1.3: Lâminas petrográficas com (a)fratura e (b)vug e imagem de raio-X de plugue de rocha com (c)matriz, (d)fratura e (e)vug.

Figura 1.4: (a) e (b) Rochas carbonáticas no afloramento da Formação Yacoraite, Salta, Argentina; (c) visão lateral das fraturas com aberturas métricas entre blocos carbonáticos no afloramento da Formação Salitre, Bahia, Brasil (d) vista de cima de carbonatos carstificados no afloramento da Formação Jandaíra, Rio Grande do Norte, Brasil.

Figura 1.5: Esquemático do escoamento unidirecional em um simulador de porosidade simples, dupla porosidade e dupla permeabilidade.

Figura 2.1: Classificação de reservatórios fraturados.

Figura 2.2: Modelo de reservatório fraturado.

Figura 3.1: Esquemático de uma falha geológica apresentando a zona de dano. 40

Figura 3.2: Função Logística $P(z)$.

Figura 3.3: Esquemáticos das formulações (a) explícita e (b) implícita. 43

Figura 3.4: Exemplo de modelo unidimensional de três células. 52

Figura 3.5: Esquema da sobreposição de malhas na simulação de dupla porosidade e dupla permeabilidade.

Figura 4.1: (a) Porosidade do modelo e (b) permeabilidade horizontal do modelo. 60

Figura 4.2: Mapas com o coeficiente de Dykstra-Parsons: (a) modelo utilizado e (b) ajuste à curva log-normal. 
Figura 4.3: Localização dos poços.

Figura 4.4: Exemplos de corredores de fraturas com diferentes geometrias.

Figura 4.5: Histogramas do erro de balanço de massa acumulado dos cenários com controle numérico default a) com injeção e b) sem injeção.

Figura 4.6: Histogramas do erro de balanço de massa acumulado dos cenários com controle numérico final a) com injeção e b) sem injeção

Figura 4.7: Modelo proxy original - $H \times \varphi \times S_{o}(m) . \quad 71$

Figura 4.8: Modelo final $-H \times \varphi \times S_{o}(m)$ após multiplicação por NTG. $\quad 72$

Figura 4.9: Modelo final - NTG $\quad 72$

Figura 4.10: Envelope de Fases do Fluido Utilizado com Pressão Original do Reservatório (P0); Pressão de Saturação do Reservatório (Psat) e Ponto Crítico do Fluido $(\mathrm{Pc})$.

Figura 4.11: Histogramas de propriedades da rocha: (a) porosidade efetiva e (b) permeabilidade absoluta horizontal. 75

Figura 4.12: Curvas de permeabilidade relativa da matriz e da fratura.

Figura 5.1: Exemplo de curva de produção de óleo e gás sem manutenção da pressão por injeção de água.

Figura 5.2: (a) Fator de recuperação e (b) $t_{D p b}$ das simulações sem injeção, com matriz heterogênea e corredor de fraturas com largura=2 e distância $=0$.

Figura 5.3: (a) Tempo de simulação, (b) número de timesteps, de (c) iterações do solver e de (d) ciclos newtonianos das simulações sem injeção, com matriz heterogênea e corredor de fraturas com largura $=2$ e distância $=0$.

Figura 5.4: (a) Erro de balanço de materiais e (b) implicitude média das simulações sem injeção, com matriz heterogênea e corredor de fraturas com largura $=2$ e distância $=0$.

Figura 5.5: Fator de recuperação das simulações sem injeção e corredor de fraturas com largura=1 e distância $=1$.

Figura 5.6: Implicitude média das simulações sem injeção e corredor de fraturas com largura $=3$ e distância $=0$. 
Figura 5.7: Tempo de simulação dos cenários sem injeção, matriz heterogênea e com largura $=2$.

Figura 5.8: Tempo de simulação dos cenários sem injeção, matriz heterogênea e com distância $=0$.

Figura 5.9: (a) Fator de recuperação e (b) $t_{D p b}$ nos cenários sem injeção e com matriz heterogênea.

Figura 5.10: Exemplo de curva de produção com injeção.

Figura 5.11: (a) Tempo de simulação, (b) número de timesteps, (c) número de iterações do solver e (d) número de ciclos newtonianos das simulações com malha paralela à grade, com injeção e corredor de fraturas com largura $=1$ e distância $=0$.

Figura 5.12: Implicitude média das simulações com malha paralela à grade, com injeção e corredor de fraturas com largura $=1$ e distância $=0$.

Figura 5.13: (a) Fator de recuperação e (b) $t_{D w}$ das simulações com injeção em malha paralela à grade, distância $=0$ e com largura $=1$.

Figura 5.14: $t_{D w}$ versus FR, colorido pela homogeneidade da matriz e com pontos de tamanho proporcional a $K_{\text {frat. }}$

Figura 5.15: Corte de água para os cenários com distância $=1$, largura $=2$ e $K_{\text {frat }}=$ $1.000 \mathrm{mD}$.

Figura 5.16: Resultados de produção das simulações com injeção em malha paralela à grade, distância= 5 e com largura=3: (a) FR; (b) $t_{D w}$.

Figura 5.17: Seção na direção dos poços comparando a saturação de água nos casos de matriz heterogênea e homogênea.

Figura 5.18: Representação esquemática de escoamento não alinhado com um dos eixos coordenados da malha de simulação.

Figura 5.19: $t_{D w}$ das simulações com injeção em matriz homogênea, distância=0 e com: (a) largura=2; (b) largura=1.

Figura 5.20: Mapa das células fraturadas no caso poços diagonais à grade, distância=0 e largura=1.

Figura 5.21: Média do tempo de simulação por $\log _{10}\left(K_{\text {frat }}\right)$ e distância do corredor de fraturas.

Figura 5.22: Implicitude média das simulações com injeção em matriz heterogênea, malha paralela à grade e com largura $=1$. 
Figura 5.23: Resultados de produção das simulações com injeção em matriz heterogênea, malha paralela à grade e com largura=1: (a) FR; (b) $t_{D w} .101$

Figura 5.24: Mapas de $S_{w}$ na matriz da camada $k=10$ no instante $t=3.000$ dias, do cenário de malha paralela, matriz heterogênea, $\mathrm{L}=1$ e $K_{\text {frat }}=32.000 \mathrm{mD}$, comparando os cenários

Figura 5.25: Número de cortes de timestep das simulações com injeção em matriz heterogênea, malha paralela à grade e com $D=1$.

Figura 5.26: (a)Tempo de simulação, (b) número de timesteps, (c) de iterações do solver e (d) de ciclos newtonianos das simulações com injeção em matriz heterogênea, malha paralela à grade e com $\mathrm{D}=0$.

Figura 5.27: (a)FR e (b) $t_{D w}$ das simulações com injeção em matriz heterogênea, malha paralela à grade e com $\mathrm{D}=0$.

Figura 5.28: $F R$ médio $x \log _{10}\left(K_{\text {frat }}\right)$. 105

Figura 5.29: $t_{D w}$ médio $x \log _{10}\left(K_{\text {frat }}\right)$. 105

Figura 5.30: Exemplos de ajustes de $t_{D w}$ e de $F R$ por $K_{\text {frat. }}$. 108

Figura 5.31: xa de $t_{D w}$ por xa de $F R$ colorido pela distância entre poços e fraturas.109 


\section{Lista de Tabelas}

Tabela 4.1: Parâmetros Numéricos Finais 68

Tabela 4.2: Características dos fluidos utilizados.

Tabela 4.3: Percentuais molares dos pseudo-componentes. 73

Tabela 4.4: Características das distribuições de $\varphi$ e de $K_{\text {matriz }}$ do modelo. $\quad 74$

Tabela 4.5: Parâmetros das curvas de permeabilidade relativa da matriz. $\quad 76$

Tabela 5.1: Resumo das características dos modelos de reservatório a serem $\begin{array}{ll}\text { combinadas } & 78\end{array}$

Tabela 5.2: Convergência da equação logística $(\alpha \times \beta)$

Tabela A.1: Resultados das simulações - numérico 1

Tabela A.2: Resultados das simulações - numérico 2

Tabela A.3: Resultados de Simulaçao - Produção 142

Tabela B.1: Ajustes da curva logística do FR. 154

Tabela B.2: Ajustes da curva logística do $t_{D w}$. 


\section{Lista de Abreviaturas}

ADTSC - Adaptative Time Step Control

AIM - Adaptative Implicit Method

CBM - Coal-Bed Methane

CFL - Courant-Friedrichs-Lewy

CMG - Computer Modelling Group

EBM - Erro de Balanço de Materiais

EOR - Enhanced Oil Recovery

FIP - Fluid In Place

$F R$ - Fator de Recuperação

IMPECS - Implicit Pressure, Explicit Compositions and Saturations

IMPES - Implicit Pressure, Explicit Saturations

MINC - Multiple Interacting Continua

NTG - Net-To-Gross

$\mathrm{PC}$ - Pseudo-Componente

$\mathrm{RC}$ - Reservoir Conditions

RGO - Razão Gás-Óleo

STD - Standard Conditions

VOIP - Volume de Óleo In Place

WAG - Water Alternating Gas 


\section{Lista de Símbolos}

\section{Letras latinas}

$A_{x, y, z}$ - área transversal ao fluxo

$A_{w, g}$ - matriz dos termos de pressão capilar

$B_{o, g, w}$ - fator volume de formação

$C$ - compressibilidade

D - distância entre o corredor de fraturas e os poços

$f$ - fugacidade

$F$ - função genérica

$h$ - inclinação da curva logística no ponto de inflexão

$H$ - espessura

$i, j, k$ - três direções no espaço discretizado

[J] - matriz Jacobiana

$k$ - permeabilidade

$K_{\text {frat }}$ - permeabilidade efetiva da fratura

$K_{\text {matriz }}$ - permeabilidade efetiva da matriz

$l$ - largura da célula

$\mathrm{L}$ - largura do corredor de fraturas em número de células

$n_{c}$ - número de componentes

$N$ - concentração molar do componente

$N_{p}$ - volume acumulado de óleo produzido

$p$ - pressão

$p_{i}$ - ponto de inflexão da curva logística

$\mathrm{P}_{0}$ - pressão inicial do reservatório

$q$ - vazão volumétrica

$r$ - resíduo

$R_{S}$ - razão de solubilidade

$S$ - saturação

$t$ - tempo

$T$ - transmissibilidade

$\Delta t$ - passo de tempo (timestep) 
$v$ - velocidade

$V_{b}$ - volume total da célula

$V_{p}$ - volume poroso do reservatório

$x, y, z$ - três direções no espaço contínuo

$\boldsymbol{x}$ - fração molar do componente na fase oleica

$x_{a}$ - valor de permeabilidade em que se atinge a assintocidade

$X$ - matriz dos termos gravitacionais

$\boldsymbol{y}$ - fração molar do componente na fase gasosa

$y_{m i ́ n}$ - valor mínimo da curva logística

$y_{\text {máx }}$ - valor máximo da curva logística

$Z$ - profundidade do ponto no espaço

\section{Letras Gregas}

$\gamma$ - peso específico

$\mu$ - viscosidade

$v$ - identificador do ciclo newtoniano

$[\delta \xi]$ - vetor de variação das incógnitas

$\rho$ - volume específico

$\sigma-$ fator de forma

$\tau$ - termo de transferência matriz-fratura

$\varphi$ - porosidade

$\Phi$ - potencial

$[\psi]$ - vetor dos resíduos

\section{Subscrito}

c-capilar

$D$ - adimensional

$f$ - fratura

$g$ - gás

$h$ - horizontal

$i$ - identificador da célula

$m$ - matriz

$m$ - identificador do componente

$o-$ óleo 
$p$ - pressão

$p b$ - pressão de bolha

$r$ - relativa

$v$ - vertical

$w$-água

\section{Sobrescrito}

$L$ - líquido

$n$ - identificador do timestep

$V$ - vapor

$v$ - identificador do ciclo newtoniano 
Ora et labora.

São Bento, Regula Benedicti. 


\section{Introdução}

Os reservatórios de petróleo do pré-sal são importantes fontes de produção de hidrocarbonetos do Brasil. Para desenvolver esse polo de produção offshore foi necessário superar diversos desafios, tais como ambiente em águas ultraprofundas (acima de $1500 \mathrm{~m}$ de profundidade), presença de $\mathrm{CO}_{2}$ no gás associado, problemas de garantia de escoamento e perfuração de poços atravessando camadas espessas de sal (DA COSTA FRAGA et al., 2015).

Desde as primeiras descobertas da área até a atualidade, um dos principais desafios que se enfrenta é o novo contexto de modelagem de reservatório. Antes dos anos 2000, os grandes campos produtores brasileiros eram compostos por rochas siliciclásticas. Todavia, os prospectos descobertos no polo pré-sal foram formados em um contexto geológico diferente, resultando em formações de natureza carbonática. As repercussões dessa origem diversa não recaem apenas na modelagem geológica. O modelo de escoamento em meio poroso deve ser capaz de representar corretamente as características dessas rochas.

\subsection{Contexto Geológico}

As formações carbonáticas do pré-sal se originaram em um ambiente criado pela separação das placas tectônicas da América do Sul e África. Esse evento ocorreu durante o período geológico denominado Cretáceo (145 a 66 milhões de anos atrás) (CHABOUREAU, 2013). Com essa cisão, se formou uma bacia sedimentar ( rift) paralela à costa brasileira, a qual foi preenchida inicialmente por rochas sedimentares siliciclásticas finas com variável teor de matéria orgânica. Posteriormente, essas rochas se tornariam a fonte para a geração dos hidrocarbonetos presentes nessa região.

Em seguida, as condições climáticas áridas favoreceram a formação de um lago alcalino. Nesse ambiente, as rochas carbonáticas foram precipitadas e, cerca de 120 milhões de anos depois (MOREIRA et al., 2007), se tornariam os principais reservatórios do pré-sal. Subsequentemente, inicia-se uma conexão entre esse lago e o mar. A consequente entrada de águas salinas na bacia, até então isolada, favoreceu a deposição de extensa e espessa camada de sal, seguida pela formação de folhelhos e turbiditos marinhos (MOREIRA et al., 2007). O depósito de sal serve como selo para os reservatórios que são o foco desse trabalho.

Nesse contexto, já existem diversas descobertas dentro do que é conhecido como a província do pré-sal. A Figura 1.1 apresenta os campos descobertos nessa área. 


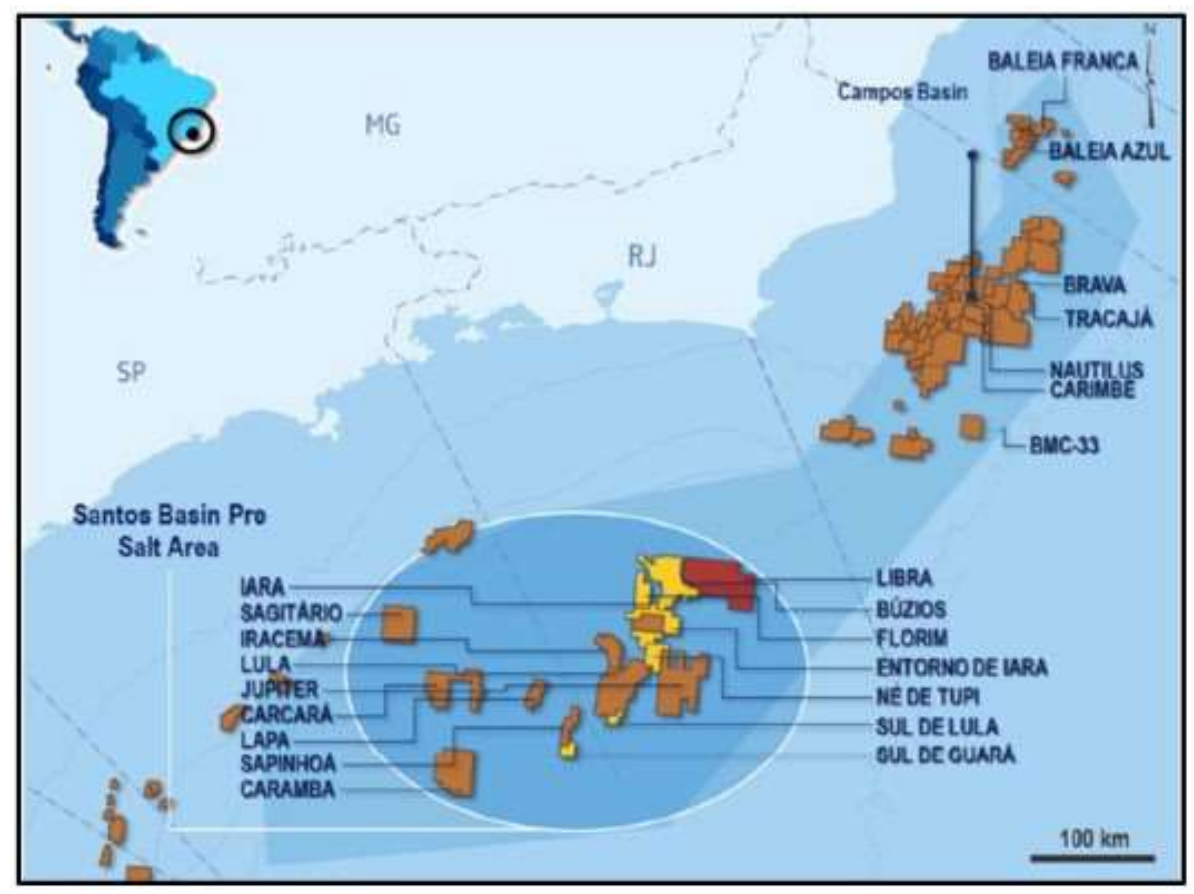

Figura 1.1: Província do Pré-sal. Fonte: PIZARRO et al. (2017).

É importante ressaltar que não há um análogo conhecido para as rochas reservatório do pré-sal (MOCZYDLOWER et al., 2012). Elas foram formadas durante o Aptiano (125 a 113 milhões de anos atrás) em um grande lago (MOREIRA et al., 2007). Todavia, diferem em vários aspectos dos depósitos clássicos de lagos com predomínio de fácies microbianas (LIMA e DE ROS, 2019). Estas rochas são compostas pela combinação de diferentes proporções de três componentes gerados in situ (GOMES et al., 2020): lama (micrita e argila); calcita em formato de esférulas (spherulite); e calcita fascicular em forma de arbusto (shrub). A Figura 1.2 apresenta alguns exemplos em imagens de lâminas petrográficas. Além dos componentes que são precipitados, os mesmos podem ser quebrados e deslocados lateralmente, formando os calcarenitos.

Logicamente, cada reservatório tem suas particularidades. Porém, há uma característica que está presente em todos os casos do pré-sal, que é uma intensa heterogeneidade vertical das formações devido à complexa geração dos elementos citados. Além disso, devido às propriedades congênitas dos carbonatos, é praticamente inevitável o surgimento de fraturas, vugs e outros tipos de carstes. A carstificação é um fenômeno que ocorre em um momento posterior à gênese da rocha, ou seja, um processo diagenético. Através de atuação química e/ou mecânica, a diagênese altera as propriedades permoporosas da formação. Vugs são poros de dimensão macroscópica que funcionam como armazenadores de fluido com grande permeabilidade. Fraturas são canais de pequena porosidade, mas altas permeabilidades que permitem um rápido escoamento. A Figura 1.3 exemplifica essas duas estruturas. 

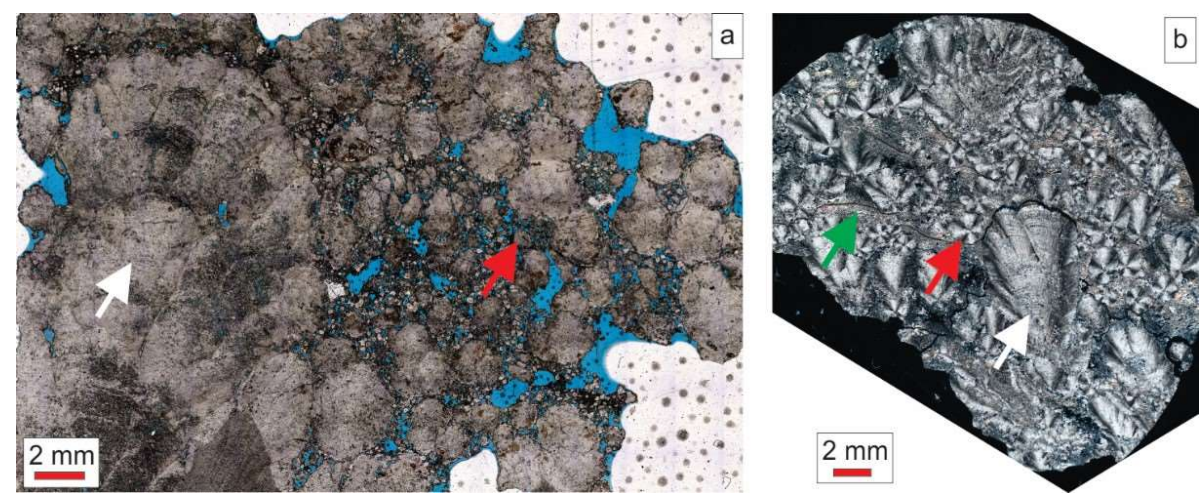

Figura 1.2: Exemplos de lâmina petrográfica de rocha do pré-sal: (a) com polarizadores paralelos e (b) com polarizadores cruzados. Porosidade em azul; seta vermelha aponta para esférulas de calcita; seta branca, shrub; seta verde, argila.

Fonte: Modificado de GOMES et al. (2020).

Lâminas petrográficas

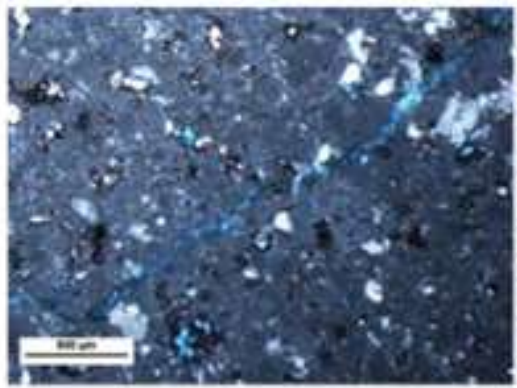

(a)Fratura

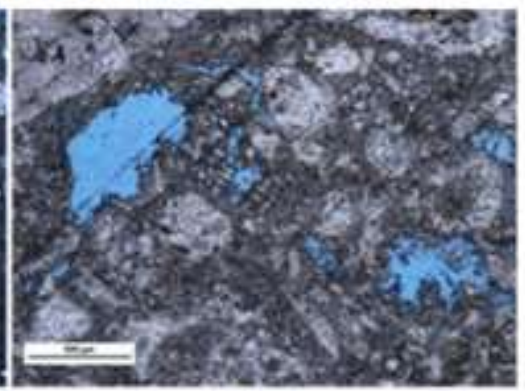

(b)Vug

Raio-x de plugues

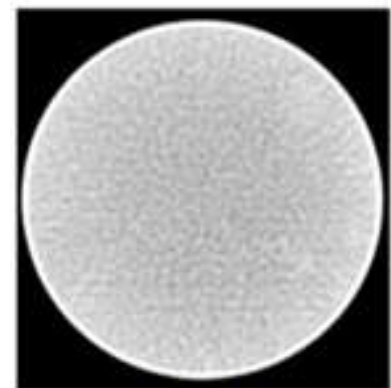

(c)Matriz

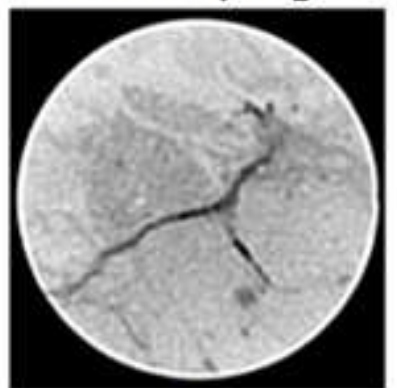

(d)Fratura

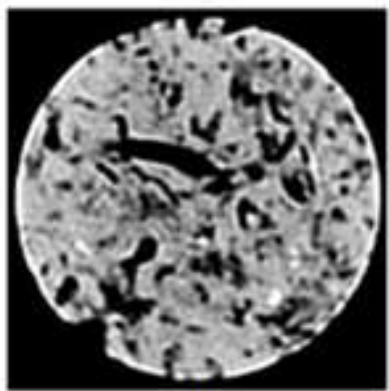

(e)Vug

Figura 1.3: Lâminas petrográficas com (a)fratura e (b)vug e imagem de raio-X de plugue de rocha com (c)matriz, (d)fratura e (e)vug.

Fonte: Modificado de WANG et al. (2015).

As características descritas são bastante discrepantes daquelas dos arenitos que compõem os principais campos brasileiros nas décadas anteriores. Portanto, faz-se necessária uma modelagem também diferente para se atingir resultados confiáveis. 
$\mathrm{Na}$ Figura 1.4, são apresentados alguns exemplos de rochas carbonáticas e de carstificação. Observam-se: (a) complexidades das formações de estromatólitos; (b) continuidade lateral contrastando com a heterogeneidade vertical; (c) geração de caminhos preferenciais através de carstificação; e (d) intenso fraturamento comum nessas rochas que pode ser intensificado pelos processos diagenéticos.

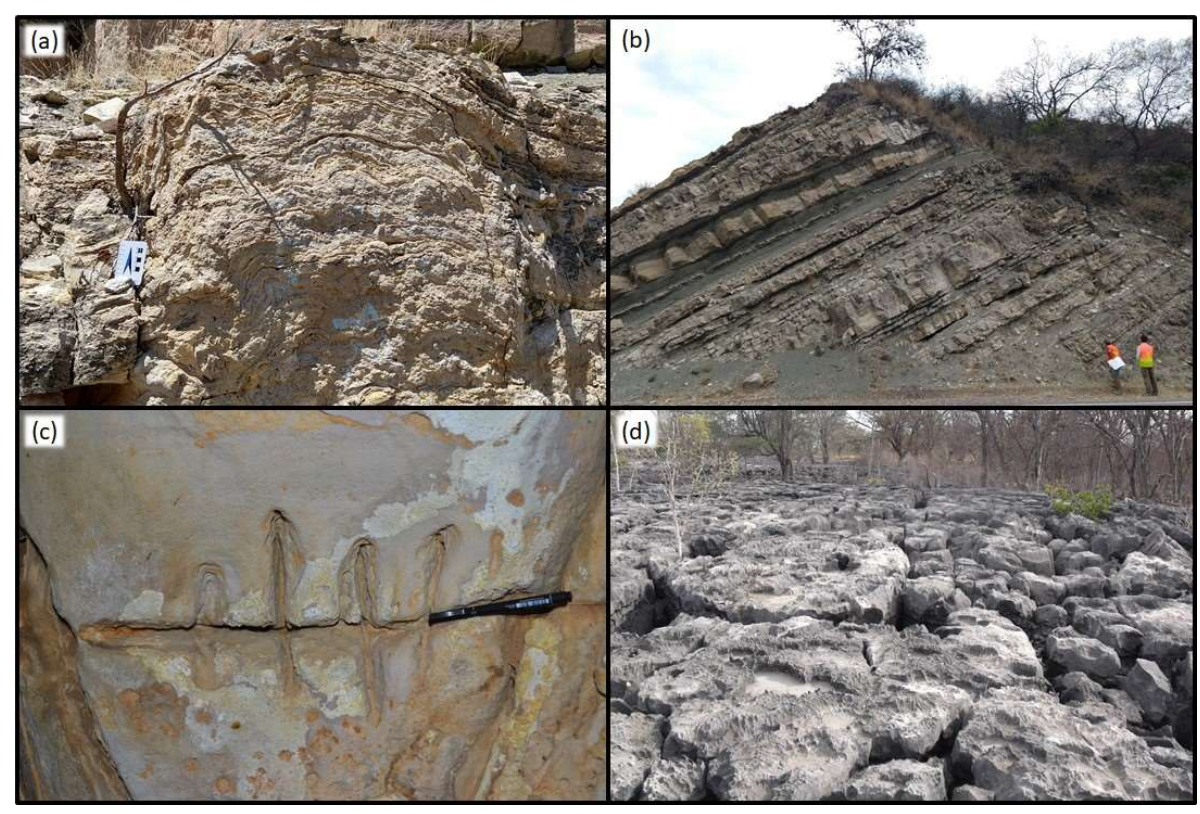

Figura 1.4: (a) e (b) Rochas carbonáticas no afloramento da Formação Yacoraite, Salta, Argentina; (c) visão lateral das fraturas com aberturas métricas entre blocos carbonáticos no afloramento da Formação Salitre, Bahia, Brasil (d) vista de cima de carbonatos carstificados no afloramento da Formação Jandaíra, Rio Grande do Norte, Brasil. Fonte: Do autor (arquivo pessoal).

\subsection{Contexto de Simulação}

SALOMÃO et al. (2015) abordam as estratégias que são adotadas para a melhor explotação de um campo de petróleo como os do pré-sal. Todas essas avaliações apresentadas tomam como base resultados de simulações numéricas. Para se obter um plano de drenagem verdadeiramente robusto, uma modelagem confiável é imprescindível.

Em reservatórios siliciclásticos não fraturados, típicos dos campos brasileiros explotados previamente ao pré-sal, a simulação de escoamento normalmente adota a modelagem de porosidade simples. Nesse caso, se assume que os fluidos são transportados através de um mesmo meio, discretizado espacialmente para contemplar as heterogeneidades e anisotropia. Normalmente, devido às grandes dimensões dos reservatórios, essa metodologia não incorre em erros relevantes, sobretudo no cenário de rochas siliciclásticas. Entretanto, em casos de reservatórios com presença relevante de outros tipos de porosidade, essa modelagem passa a se mostrar equivocada. Reservatórios carstificados, como os observados 
no pré-sal, não respeitam as premissas do modelo de porosidade simples uma vez que, devido às suas severas heterogeneidades, a representação do escoamento pela lei de Darcy não pode ser aplicada com alto grau de confiabilidade.

O principal impacto dessas discrepâncias ocorre quando é considerada a injeção de água ou gás. Nos projetos do pré-sal, a injeção é utilizada tanto para fins de recuperação secundária como para descarte de gás e $\mathrm{CO}_{2}$ (ALMEIDA et al., 2010). Dentro de um escopo de EOR (Enhanced Oil Recovery), são encontrados casos de injeção de água e, também, de injeção WAG (Water Alternating Gas) (PIZARRO e BRANCO, 2012). A depender de regulações ambientais futuras, é possível, inclusive, que a reinjeção de água produzida venha a se tornar mandatória (BARRETO e SCHIOZER, 2012).

O escoamento do óleo em meios porosos pode ser drasticamente afetado por canalizações que prejudiquem o deslocamento do óleo em direção aos poços produtores. As heterogeneidades naturais das rochas, as fraturas e os vugs são estruturas capazes de criar essas canalizações, ou seja, caminhos preferenciais que não são corretamente caracterizados pela modelagem de porosidade simples. Portanto, fez-se necessário mudar a representação do escoamento através de feições carstificadas, passando-se a utilizar modelos de múltiplos meios.

BARENBLATT et al. (1960) já identificam a necessidade de uma formulação específica para o problema de dupla permeabilidade. Desde então, já foram propostas diversas soluções diferentes para a representação dessas formações. Não obstante, poucas são implementadas em simuladores comerciais, dada a complexidade numérica que elas representam. A Figura 1.5 apresenta um esquemático unidimensional das diferenças entre a simulação de porosidade simples, dupla porosidade e dupla permeabilidade mais utilizadas. 


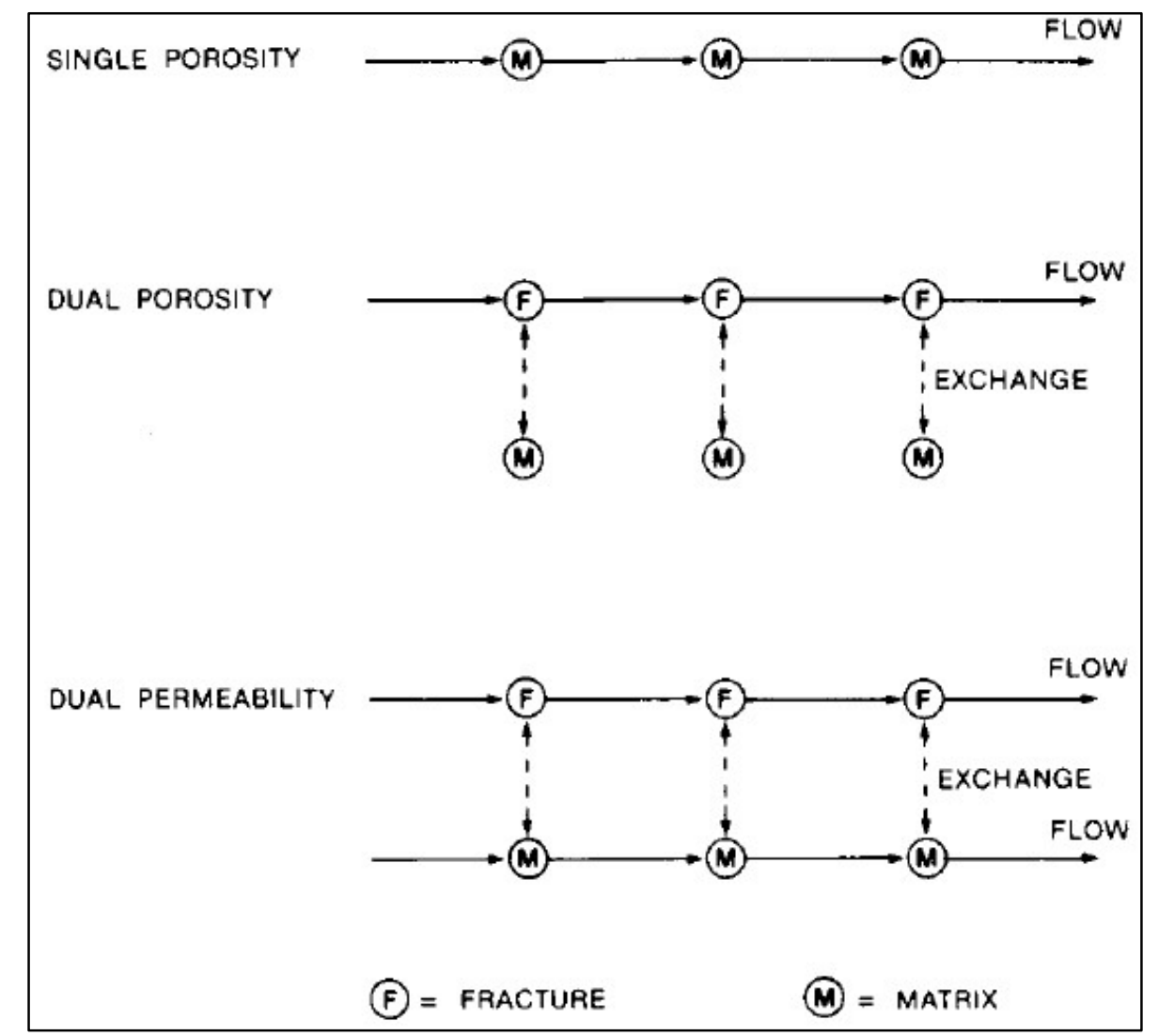

Figura 1.5: Esquemático do escoamento unidirecional em um simulador de porosidade simples, dupla porosidade e dupla permeabilidade.

Fonte: DEAN e LO (1988).

No contexto de previsão de produção para campos do pré-sal, utiliza-se quase que exclusivamente modelos de dupla porosidade e permeabilidade, também conhecidos como $2 \varphi 2 k$. Entre os profissionais que trabalham com esses projetos há bastante conhecimento empírico, devido à adoção das melhores práticas de simulação. Contudo, pouca documentação existe registrando detalhadamente essas práticas. As principais dificuldades estão associadas à confidencialidade e baixa prioridade frente às demais demandas da indústria.

\subsection{Motivação}

A modelagem do escoamento em reservatórios é uma área da Engenharia de Petróleo que requer a compreensão de diversos fenômenos que ocorrem em ambientes complexos e difíceis de serem reproduzidos em laboratório. Contudo, é uma atividade essencial para a indústria, haja vista que serve de base para todo o dimensionamento dos projetos que serão realizados.

Já foi citado que os principais campos do Brasil, na atualidade, são compostos por carbonatos carstificados. Outrossim, estima-se que mais de $20 \%$ das reservas de petróleo do mundo se encontram em reservatórios naturalmente fraturados (FIROOZABADI, 2000). Há 
avaliações que elevam esse percentual a até 50\% (BOURBIAUX, 2010). Logo, uma representação acurada dessas formações é crucial para que elas proporcionem bons projetos.

O primeiro passo para uma boa caracterização é a aquisição de informações. ROSA et al. (2018) ressaltam como os dados adquiridos impactam nas definições dos projetos do campo de Lula. Testes de interferência entre poços, injeção de traçadores e sísmica 4D, entre outros, trazem excelentes informações sobre como os fluidos se comportam no reservatório (PIZARRO et al., 2017). Contudo, a importância dessas informações reside na sua utilização para a modelagem, uma vez que os dados só são valiosos se eles puderem afetar a qualidade das decisões tomadas. Por conseguinte, a motivação para esse estudo é a melhor compreensão dos mecanismos que regem a simulação de reservatórios de múltipla permeabilidade. Assim, consegue-se melhor modelar o comportamento os campos de petróleo estudados. Ou seja, gerar um modelo que, em um tempo computacional razoável, reproduza os padrões de escoamento esperados, dentro de uma faixa de incertezas aceitável. Por fim, com essa representação do reservatório, é possível otimizar projetos de explotação de petróleo e diminuir ou mitigar os riscos inerentes ao processo de produção.

\subsection{Objetivos}

De forma geral, este trabalho visa a melhor compreensão dos impactos das variáveis do reservatório na simulação de escoamento em meio poroso, em cenários representativos do pré-sal brasileiro, ou seja, reservatórios carbonáticos com alto grau de heterogeneidades.

Assim, serão submetidos diversos cenários a um simulador de escoamento em meio poroso composicional multifásico 3D de dupla porosidade e dupla permeabilidade, variandose os parâmetros de entrada. Os efeitos dos seguintes itens serão avaliados:

- Fraturas no reservatório em cenários de depleção;

- Fraturas no reservatório em cenários de injeção de água;

- Direção das fraturas em relação à grade do modelo;

- Distância dos poços em relação às fraturas;

- Largura dos corredores de fraturas;

- Fraturas em reservatórios com diferentes níveis de heterogeneidade;

- Interação entre o meio fraturado e matriz do modelo.

Ao se analisar os efeitos dessas variáveis, o profissional que desejar realizar simulações de reservatórios fraturados pode construir seu modelo de forma mais otimizada. As características das fraturas modeladas (permeabilidade efetiva, orientação em relação à malha do modelo, largura do corredor) e o posicionamento dos poços em relação a elas 
poderão ser definidos tal que representem satisfatoriamente o escoamento através desse meio, porém sem aumentar em demasia o custo computacional da simulação.

\subsection{Estrutura do Trabalho}

Esse trabalho está dividido em cinco seções. A primeira corresponde à presente introdução. A segunda apresenta a revisão bibliográfica, com as motivações e a evolução da modelagem de reservatórios fraturados. Em seguida, na terceira seção, é exposta a fundamentação teórica do simulador utilizado para os estudos desenvolvidos, iniciando com conceitos básicos até chegar nas formulações aplicadas. A metodologia aplicada é mostrada na quarta seção, primeiramente explicando as características do simulador, em seguida, apresentando as variáveis e os resultados que serão avaliados e, por fim, detalhando o modelo utilizado. Os resultados são apresentados na quinta seção, incluindo análises comparativas entre os casos estudados. Finalmente, na sexta seção são relatadas as conclusões da dissertação e propostos trabalhos futuros de aprofundamento no tema pesquisado. 


\section{Revisão Bibliográfica}

A simulação numérica do escoamento em meios porosos constitui importante ferramenta para a concepção de projetos e gerenciamento para a produção de campos de petróleo. Dentre seus objetivos específicos, pode-se citar os principais:

- Estudo de alternativas de projetos;

- Definição de malha de drenagem;

- Ajuste do histórico de produção;

- Gerenciamento da produção;

- Análise de Incertezas;

- Previsão de produção;

- Estimativa de Reservas.

As primeiras formulações da simulação numérica de reservatórios foram propostas nos artigos de COATS et al. (1967) e ODEH (1969). As formulações implementadas em softwares comerciais têm origem em teorias consolidadas na indústria do petróleo, tais como a lei de conservação de massa, Equação de Buckley-Leverett, teorema de Stokes, lei de Darcy etc. Vários livros e artigos que descrevem de forma mais detalhada os conceitos e formulações subjacentes. Como bons exemplos, tem-se: PEACEMAN (1977); THOMAS (1981); ROSA et al. (2006); SANTOS (2013). O foco da revisão bibliográfica estará na discussão sobre reservatórios naturalmente fraturados e sua modelagem.

\subsection{Reservatórios Naturalmente Fraturados}

NELSON (2001) define uma fratura como descontinuidades planares presentes em rochas devido à deformação ou diagênese física. As fraturas naturais ocorrem em praticamente qualquer formação geológica. Há três principais fatores que podem influenciar sua geração (BOURBIAUX, 2010):

- Tectônica: A movimentação da crosta terrestre resulta em dobramentos e falhas;

- Litologia: Formações carbonáticas são mais propícias a fraturamento do que as siliciclásticas; 
- Idade: Formações mais antigas e profundas tendem a ser menos porosas e permeáveis, o que aumenta a suscetibilidade ao fraturamento, além de haver mais tempo para os efeitos tectônicos agirem.

Apesar da abundância de reservatórios que sofreram fraturamento, nem sempre eles podem ser classificados como fraturados. Essa denominação compete somente aos casos nos quais as fraturas afetam os padrões de escoamento da formação (NELSON, 2001), ou seja, apenas se ocorrerem anisotropias, canalizações, aumentos de porosidade e/ou permeabilidade decorrentes do fraturamento. Caso o reservatório se comporte conforme uma rocha íntegra, não há necessidade de designá-lo fraturado. Esses efeitos podem ocorrer mesmo em cenários nos quais os dados adquiridos não apresentem fraturas diretamente. Isto é, ainda que não haja indícios comprovando a presença de fraturamento, ele pode existir e ser atuante.

\subsubsection{Classificação}

NELSON (2001) categorizou os reservatórios fraturados em quatro grupos. Sua classificação foi elaborada segundo as relações da porosidade e da permeabilidade da matriz e das fraturas.

- Tipo 1: Matriz sem Porosidade:

São reservatórios fechados em que os hidrocarbonetos estão todos localizados nas fraturas e o escoamento também ocorre por elas. Um caso seriam rochas ígneas, sem porosidade, que sofrem fraturamento e, eventualmente, se tornam reservatórios. Exemplos: Amal (Líbia), Edison (EUA).

- Tipo 2: Matriz Porosa, mas sem Permeabilidade:

Essas formações possuem boas porosidades, mas, devido ao tipo de porosidade pouco interconectada, o fluido não escoa com facilidade. As fraturas auxiliam esse aspecto. Exemplos: Agha Jari (Irã), Mara (Venezuela).

- Tipo 3: Qualidade Permoporosa da Matriz Comparável à das Fraturas:

São bons reservatórios que sofrem alterações no seu comportamento dinâmico devido ao fraturamento. Podem ocorrer canalizações, forte anisotropia e/ou aumento de permeabilidade localizado. Exemplos: Kirkuk (Iraque), Sapinhoá (Brasil). 
- Tipo 4: Qualidade Permoporosa da Matriz Superior à das Fraturas:

Ocorrem quando a presença de fraturas é discreta e as formações são de boa qualidade. Assim, o impacto é restrito a anisotropias e barreiras.

BRATTON et al. (2006) adicionam duas subclassificações: os tipos M e G. O primeiro (M) são reservatórios semelhantes ao tipo 4. Contudo, as fraturas obliteradas atrapalham o escoamento na forma de barreiras e compartimentação. O segundo subgrupo (G) é similar ao tipo 2. É composto de reservatórios não convencionais como metano de carvão (CBMcoal-bed methane) e reservatórios fraturados de gás condensado. A Figura 2.1 resume a classificação apresentada.

A importância dessa classificação é determinar quais são os parâmetros das fraturas que são relevantes para determinado reservatório. Uma segunda vantagem é saber quais são os comportamentos típicos que o campo deve apresentar. O foco dessa dissertação está centrado em reservatórios semelhantes aos do pré-sal brasileiro, os quais são classificados como do tipo 3.

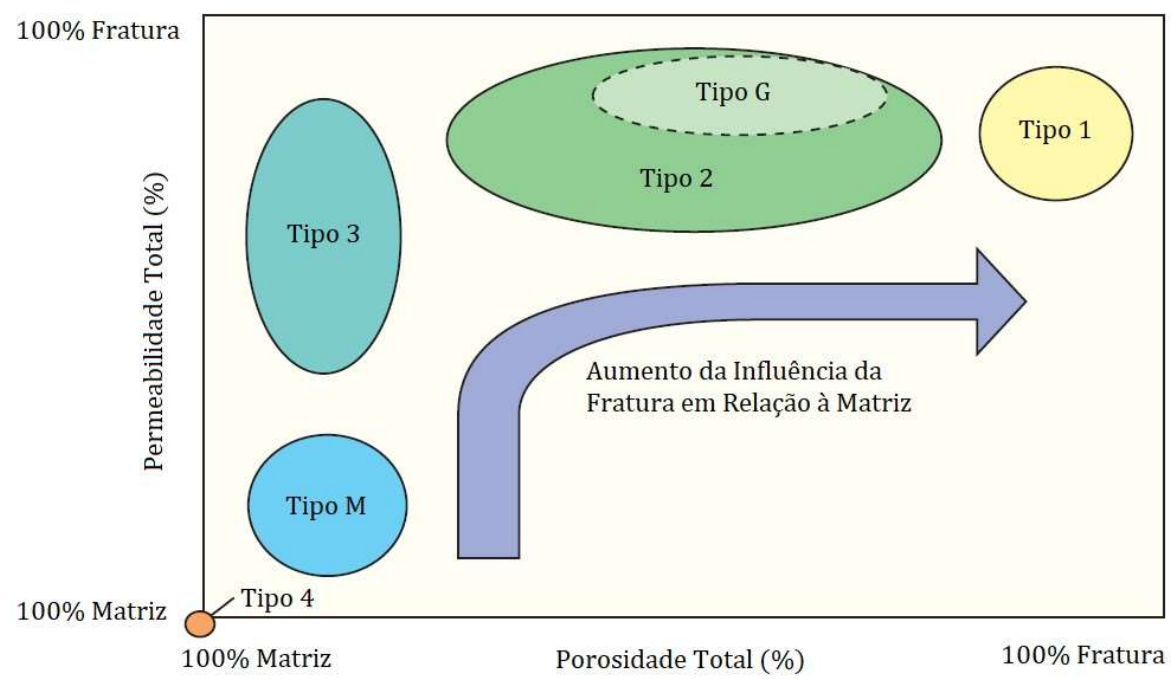

Figura 2.1: Classificação de reservatórios fraturados. Fonte: Modificado de BRATTON et al. (2006).

\subsubsection{Modelagem de Escoamento}

A caracterização dos reservatórios fraturados apresenta numerosos desafios. A complexidade decorre da representação do escoamento na matriz e nas fraturas, além da interação entre os meios (BAKER e KUPPE, 2000). No entanto, não é simples obter dados diretos da formação. Portanto, são necessárias medidas indiretas das propriedades do meio poroso. 
A primeira formulação para um meio fraturado é feita por BARENBLATT et al. (1960). Eles assumem que em rochas fraturadas, o escoamento ocorre majoritariamente pelas fraturas, desprezando, por conseguinte, o escoamento entre poros. Então, considera-se que o sistema de fraturas, respeita as condições de escoamento da lei de Darcy, chegando à Equação 2-1, que representa a velocidade de escoamento nas fraturas.

$$
v_{f}=\frac{k_{f}}{\mu} \operatorname{grad} p_{f}
$$

onde o subscrito $f$ representa as propriedades da fratura.

Em seguida, para calcular o escoamento entre os poros e as fraturas, faz-se uma análise dimensional, chegando na Equação 2-2:

$$
v=\frac{\alpha}{\mu}\left(p_{m}-p_{f}\right)
$$

onde $\alpha$ é alguma característica adimensional da rocha fraturada e o subscrito $m$ se refere às propriedades da matriz. Por fim, para se chegar à vazão entre a matriz e as fraturas, dividese a Equação 2-2 pelo volume específico do líquido, resultando em:

$$
q=\frac{\rho \alpha}{\mu}\left(p_{m}-p_{f}\right)
$$

Nesse ponto é pertinente observar que o termo adimensional $\alpha$ representa a transferência de fluidos entre matriz e fratura. Seu equacionamento será tema de diversos trabalhos posteriores ao de BARENBLATT et al. (1960). Através de análise dimensional, chega-se à Equação 2-4.

$$
\alpha \propto k_{m} \sigma^{2}
$$

onde $\sigma$ é um fator geométrico correspondente ao inverso da largura do bloco:

$$
\sigma=\frac{1}{l}
$$


Esse conceito é utilizado por WARREN e ROOT (1963). Eles propõem um modelo unidimensional radial para fins de testes de formação. Entretanto, esse exemplo serve de base para as simulações realizadas atualmente. Nele, é idealizado um volume de reservatório composto por paralelepípedos de matriz separados por corredores planares e ortogonais de fraturas, conforme apresentado na Figura 2.2.
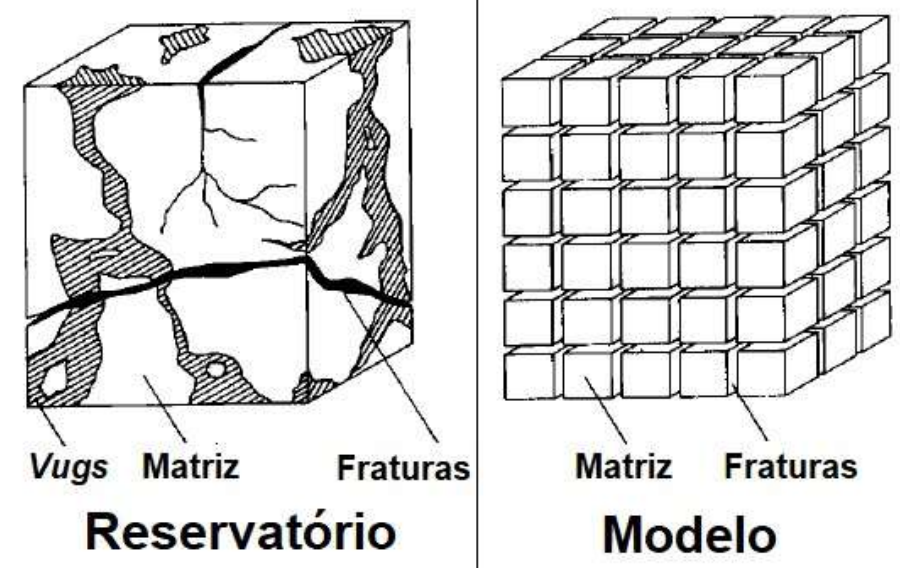

Figura 2.2: Modelo de reservatório fraturado. Fonte: Modificado de WARREN e ROOT (1963).

A porosidade primária, composta pela matriz, é caracterizada por blocos homogêneos e isotrópicos do modelo. A porosidade secundária, constituída por todas as demais estruturas da rocha, é representada no sistema ortogonal de fraturas entre os blocos. É previsto escoamento de fluidos entre os dois meios, mas não entre os blocos de matriz.

A partir dessas premissas, Warren e Root se propõem a desenvolver métodos para determinar a porosidade secundária e o fator de forma, parâmetro que controla a comunicação entre os dois meios.

Primeiramente, são definidas duas pressões em um determinado ponto, segundo as Equações 2-6 e 2-7.

$$
\begin{gathered}
p_{m}(x, y, z, t)=\frac{\int_{V} p(x, y, z, t) \cdot g_{m}(V) d V}{\int_{V} g_{m}(V) d V} \\
p_{f}(x, y, z, t)=\frac{\int_{V} p(x, y, z, t) \cdot g_{f}(V) d V}{\int_{V} g_{f}(V) d V}
\end{gathered}
$$


onde

$$
g_{m}(V)=1 \text { para porosidade primária e } g_{m}(V)=0 \text { para porosidade secundária }
$$

e

$g_{f}(V)=0$ para porosidade primária e $g_{f}(V)=1$ para porosidade secundária

Então, assumindo volumes de dimensões muito menores do que o do reservatório, mas maiores do que as estruturas da matriz da rocha e desprezando a saturação de água conata presente na porosidade secundária, aplicou-se o teorema de Green no volume $V$, chegando-se à Equação 2-8.

$$
\frac{k_{f x}}{\mu} \cdot \frac{\partial^{2} p_{f}}{\partial x^{2}}+\frac{k_{f y}}{\mu} \cdot \frac{\partial^{2} p_{f}}{\partial y^{2}}-\varphi_{m} C_{m} \cdot \frac{\partial p_{m}}{\partial t}=\varphi_{f} C_{f} \cdot \frac{\partial p_{f}}{\partial t}
$$

onde os eixos $x$ e $y$ são os eixos de maior permeabilidade e $C_{m}$ e $C_{f}$ são a compressibilidade total do meio da matriz e da fratura, respectivamente.

Assume-se, em seguida, que as regiões dos dois meios são independentes $\left(\varphi_{f}\right.$ independe de $p_{m}$ e $\varphi_{m}$ independe de $p_{f}$ ), a variação de $\varphi_{f}$ em relação a $p_{f}$ é desprezível e que as forças externas são constantes. Também se faz a aproximação de um estado semiestacionário, chegando à Equação 2-9.

$$
\varphi_{m} C_{m} \cdot \frac{\partial p_{m}}{\partial t}=\frac{\alpha k_{m}}{\mu} \cdot\left(p_{f}-p_{m}\right)
$$

onde $\alpha$ é o fator de forma que reflete a geometria dos elementos do modelo e controla o escoamento entre os meios. A formulação sugerida por Warren e Root para o caso de fraturas espaçadas uniformemente é:

$$
\alpha=\frac{4 n \cdot(n+2)}{l^{2}}
$$

onde $n$ é o número de direções do eixo com fraturas $(1 \leq n \leq 3)$ e $l$ é dado pela Equação 2-11, no caso tridimensional:

$$
l=\frac{3 l_{x} l_{y} l_{z}}{l_{x} l_{y}+l_{x} l_{z}+l_{y} l_{z}}
$$


sendo $l_{i}$ o espaçamento das fraturas na direção i.

A partir dessas premissas, alguns avanços foram feitos no estudo de escoamento em meios fraturados. ODEH (1965) desenvolve equações matemáticas para modelar o comportamento de reservatórios fraturados em estado transiente. KAZEMI et al. (1969) apresentam soluções numéricas e analíticas para interpretar testes de interferência. BRAESTER (1972) proporciona uma solução analítica para o escoamento bifásico.

KAZEMI et al. (1976) são os primeiros a desenvolver um simulador numérico capaz de modelar escoamento bifásico em dupla porosidade e dupla permeabilidade. Com isso, permitem que o problema possa ser tratado em escala de reservatório. Adicionalmente, introduzem uma nova proposta para o fator de forma, apresentado na Equação 2-12:

$$
\sigma=4\left(\frac{1}{l_{x}^{2}}+\frac{1}{l_{y}^{2}}+\frac{1}{l_{z}^{2}}\right)
$$

Essa é a formulação mais utilizada em simuladores comerciais e, também, a que será aplicada no presente trabalho.

DEAN e LO (1988) descreveram um simulador black-oil tridimensional, trifásico para modelos de dupla porosidade e dupla permeabilidade. As equações utilizadas foram:

- Para a fratura:

$$
\begin{gathered}
\Delta_{x, y, z}\left[T_{o f}\left(\Delta p_{o f}-\gamma_{o f} \Delta Z\right)\right]+T_{o m}\left(p_{o m}-p_{o f}\right)+q_{o f}= \\
\frac{V_{b}}{\Delta t} \Delta_{t}\left(\frac{\varphi_{f} s_{o f}}{B_{o f}}\right)
\end{gathered}
$$

$$
\begin{gathered}
\Delta_{x, y, z}\left[T_{w f}\left(\Delta p_{w f}-\gamma_{w f} \Delta Z\right)\right]+T_{w m}\left(p_{w m}-p_{w f}\right)+q_{w f}= \\
\frac{V_{b}}{\Delta t} \Delta_{t}\left(\frac{\varphi_{f} S_{w f}}{B_{w f}}\right) ;
\end{gathered}
$$




$$
\begin{gathered}
\Delta_{x, y, z}\left[T_{g f}\left(\Delta p_{g f}-\gamma_{g f} \Delta Z\right)\right]+\Delta_{x, y, z}\left[R_{s f} T_{o f}\left(\Delta p_{o f}-\gamma_{o f} \Delta Z\right)\right]+ \\
T_{g m}\left(p_{g m}-p_{g f}\right)+R_{s m} T_{o m}\left(p_{o m}-p_{o f}\right)+q_{g f}= \\
\frac{V_{b}}{\Delta t} \Delta_{t}\left(\frac{\varphi_{f} S_{g f}}{B_{g f}}\right)\left(\frac{R_{s f} \varphi_{f} S_{o f}}{B_{o f}}\right) .
\end{gathered}
$$

- Para a matriz:

$$
\begin{gathered}
\Delta_{x, y, z}\left[T_{o m}\left(\Delta p_{o m}-\gamma_{o m} \Delta Z\right)\right]-T_{o m}\left(p_{o m}-p_{o f}\right)= \\
\frac{V_{b}}{\Delta t} \Delta_{t}\left(\frac{\varphi_{m} S_{o m}}{B_{o m}}\right)
\end{gathered}
$$

$$
\begin{gathered}
\Delta_{x, y, z}\left[T_{w m}\left(\Delta p-\gamma_{w m} \Delta Z\right)\right]-T_{w m}\left(p_{w m}-p_{w f}\right)= \\
\frac{V_{b}}{\Delta t} \Delta_{t}\left(\frac{\varphi_{m} S_{w m}}{B_{w m}}\right) ;
\end{gathered}
$$

$$
\begin{gathered}
\Delta_{x, y, z}\left[T_{g m}\left(\Delta p_{g m}-\gamma_{g m} \Delta Z\right)\right]+\Delta_{x, y, z}\left[R _ { s m } T _ { o m } \left(\Delta p_{o m}-\right.\right. \\
\left.\left.\gamma_{o m} \Delta Z\right)\right]-T_{g m}\left(p_{g m}-p_{g f}\right)-R_{s m} T_{o m}\left(p_{o m}-p_{o f}\right)= \\
\frac{V_{b}}{\Delta t} \Delta_{t}\left(\frac{\varphi_{m} S_{g m}}{B_{g m}}\right)\left(\frac{R_{s m} \varphi_{m} S_{o m}}{B_{o m}}\right) .
\end{gathered}
$$

Para as Equações 2-13 a 2-18, tem-se:

$T$ é a transmissibilidade do meio

$\gamma$ é o gradiente do fluido;

$p$ é a pressão;

$Z$ é a profundidade do bloco;

$V$ é o volume do bloco;

$\Delta t$ é o timestep;

$S$ é a saturação do fluido;

$B$ é o fator volume de formação do fluido; 
$\varphi$ é a porosidade;

$R_{S}$ é a razão de solubilidade;

$\Delta_{x, y, z}$ é o operador de diferenças finitas no espaço;

$\Delta_{t}$ é o operador de diferenças finitas no tempo.

Além dessas formulações apresentadas, diversos outros autores já propuseram melhorias e alternativas a esses modelos. SONLER et al. (1988) incluem o efeito gravitacional no fluxo entre matriz e fratura. GILMAN e KAZEMI (1988) propõem novas considerações sobre o fator de forma, corrigindo efeitos gravitacionais e de deslocamento viscoso. Por fim, WU et al. (2004) propõem uma formulação de tripla porosidade e YAN et al. (2016) desenvolvem uma generalização para modelos de múltiplas porosidades. Esses trabalhos vão além do escopo aqui estudado. No entanto, dão uma perspectiva sobre novas teses a serem produzidas futuramente.

Academicamente foram obtidos diversos avanços na teoria de simulação de reservatórios fraturados. Assim, atualmente, tem-se uma boa fundamentação teórica implementada em diversos simuladores comerciais. No presente trabalho, foi utilizado o software GEM da Computer Modelling Group (CMG), cujas especificações e formulação serão apresentadas no capítulo 3. 


\section{Fundamentação Teórica}

Nesse capítulo, são apresentados e definidos os termos e variáveis necessários para a compreensão da metodologia, resultados e conclusões. Também são apresentados os conceitos teóricos de simulação numérica de reservatórios e a formulação utilizada no simulador escolhido para os estudos que são o tema desse trabalho.

\subsection{Conceitos e Definições}

\subsubsection{Conceitos Básicos}

Antes de apresentar formulações do simulador e iniciar discussões sobre os estudos, é necessário definir alguns conceitos que são utilizados no decorrer do trabalho.

O petróleo é uma mistura de hidrocarbonetos e impurezas complexa de forma que são necessárias algumas simplificações para modelá-lo. A formulação black-oil supõe que a mistura de hidrocarbonetos é composta somente pelos componentes denominados óleo e gás, correspondentes às fases oleica e gasosa, respectivamente. Logo, considera-se que, em condições de reservatório, o componente gás se encontra solubilizado no componente óleo, se a mistura estiver subsaturada. Ao levar o petróleo para as condições denominadas standard (temperatura de $15,6^{\circ} \mathrm{C}$ e pressão de $1 \mathrm{~atm}$ ), esse gás é liberado. A razão de solubilidade $\left(R_{s}\right)$ de um fluido é a relação entre os volumes de gás e de óleo nessas condições. Ao ser levado para a superfície, o volume dos fluidos é alterado. A relação entre o volume do fluido no reservatório e na superfície é o fator volume de formação ( $B_{\circ}$ para óleo e $B_{w}$ para água).

Muitas vezes o óleo encontrado nos reservatórios está subsaturado. Ou seja, há menos gás solubilizado do que poderia haver em solução. Todavia, a capacidade de solubilização diminui conforme a pressão também diminui, pressupondo uma temperatura constante. Assim, há um valor de pressão no reservatório no qual a capacidade de solubilização do gás no óleo chega ao limite. Esse valor é denominado pressão de saturação $\left(P_{\text {sat }}\right)$ ou ponto de bolha. Esse valor é de extrema importância pois, abaixo dessa pressão, começa a se formar a fase gasosa dentro do reservatório, o que pode ser indesejável para a produção de óleo.

A explotação de um campo de petróleo é feita através de poços produtores e injetores de água ou de gás. Os primeiros têm o objetivo de extrair o óleo enquanto os outros visam aumentar a recuperação de hidrocarbonetos através do deslocamento viscoso e da manutenção da pressão, além de outros efeitos benéficos. Infelizmente, os produtores não 
extraem apenas óleo do reservatório. Eles podem também produzir água injetada ou originalmente existente no reservatório. A produção de gás sempre ocorre, seja decorrente de gás em solução, gás livre no reservatório ou gás injetado. Para medir esses fluidos produzidos, utilizam-se as seguintes taxas de produção: corte de água (wcut) que é a relação entre a vazão de água e a de líquidos (óleo e água) produzidos; razão gás-óleo (RGO) que é a relação entre a vazão de gás e de óleo produzidos. Normalmente, o corte de água inicial de um poço é próximo de zero, enquanto a RGO é igual a $R_{s}$. $O$ aumento dessas taxas de produção decorre da irrupção (breakthrough) de água ou de gás, respectivamente.

Conforme foi explicado, uma das formas dos poços injetores auxiliarem no aumento da produção de um campo é através da manutenção de pressão. Isso é feito por meio da manutenção do balanço de massa. Esse balanço é uma consequência do princípio de conservação de massa. Ou seja, o volume de fluido produzido deve ser igual ao volume injetado, considerando a redução do volume poroso da rocha, em uma mesma condição de pressão e temperatura do reservatório. Como o volume poroso do reservatório é diretamente relacionado com a pressão, o balanço de massa em condições de reservatório permite produzir o reservatório em condição controlada de pressão.

Por fim, a quantificação da produção de um campo é comumente feita através do fator de recuperação $(F R)$. Esse parâmetro é a relação entre o volume de óleo produzido e o volume original da jazida, ambos em condições standard.

\subsubsection{Reservatórios Fraturados}

A modelagem do escoamento em meio poroso fraturado possui dois principais obstáculos: (i) não há ferramenta capaz de especificar as descontinuidades presentes no reservatório; e (ii) mesmo que houvesse essa especificação, não há modelos capazes de simular a produção de um campo em tempo computacional aceitável, levando em consideração estruturas tão pequenas como as fraturas e vugs. Portanto, faz-se necessária a simplificação da modelagem a fim de se considerar os efeitos dessas estruturas de forma viável.

Os modelos de dupla porosidade e de dupla permeabilidade levam em consideração três premissas:

- As fraturas possuem permeabilidades muito maiores do que a matriz;

- As fraturas possuem porosidade muito menores do que a matriz;

- Há troca de fluidos entre fratura e matriz.

Como corolário das duas primeiras premissas, assume-se que o escoamento no meio fraturado é muito mais intenso do que na matriz. 
As fraturas podem ser caracterizadas pelos seguintes parâmetros (BAKER e KUPPE, 2000):

- Espaçamento: indica, em média, qual é a distância entre duas fraturas. Seu inverso equivale à densidade de fraturas.

- Orientação: demonstra a direção majoritária das fraturas. É importante para representar a anisotropia durante a modelagem.

- Altura, Comprimento e Abertura: são as características geométricas das fraturas. Esses são os dados utilizados para se estimar a porosidade e a permeabilidade que serão utilizadas durante a simulação de fluxo.

Após a determinação dessas propriedades, é necessário fazer a sua distribuição pelo reservatório. Para isso, há diversas técnicas que fazem esse mapeamento (TRAN, 2004). No entanto, para esse trabalho, foi assumida uma simplificação que tem como base a zona de dano, que é a região próxima ao plano de falha onde ocorre o fraturamento mecânico da rocha. A Figura 3.1 mostra que as falhas geológicas não ocorrem simplesmente com um deslizamento da estrutura por uma superfície. O que ocorre é uma série de pequenas rupturas, que provocam um deslocamento da camada geológica. Essas pequenas rupturas geram as fraturas que formam a zona de dano.

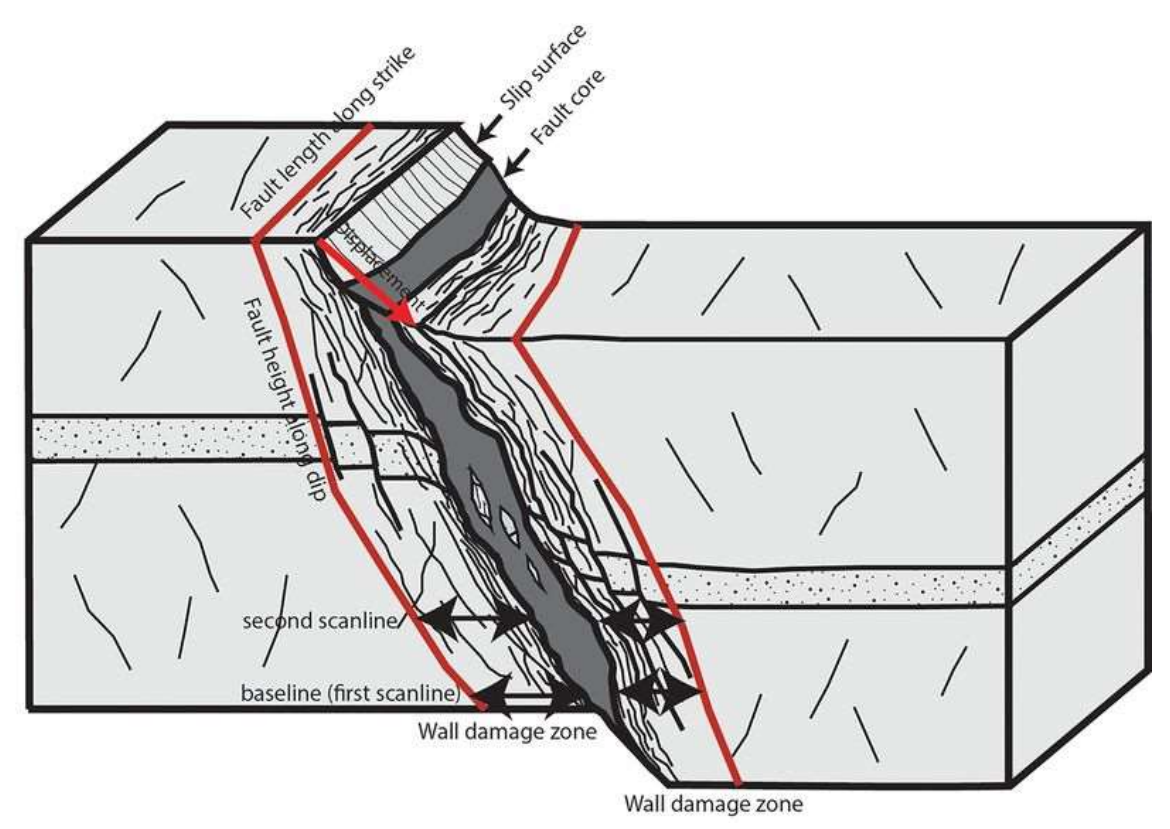

Figura 3.1: Esquemático de uma falha geológica apresentando a zona de dano.

Fonte: TORABI (2020). 


\subsubsection{Função Logística}

A função logística não é normalmente utilizada em estudos de reservatório. Essa função foi primeiramente proposta por Pierre François Verhulst em 1838 (CRAMER, 2002). Ele tinha por objetivo modelar o crescimento populacional de alguns países europeus. A escolha do nome não é bem explicada, mas acredita-se que foi uma tentativa de se fazer uma referência ao termo logarítmico uma vez que tem relação com o crescimento aritmético e geométrico. Assim, no idioma original francês, os termos seriam arithmétique, géométrique e logistique. Atualmente, a função é utilizada em diversas áreas, tais como redes neurais, modelagem de pandemias, linguística etc.

A Equação 3-1 apresenta sua fórmula e a Figura 3.2 mostra um exemplo.

$$
P(z)=\frac{e^{z}}{1+e^{z}}
$$

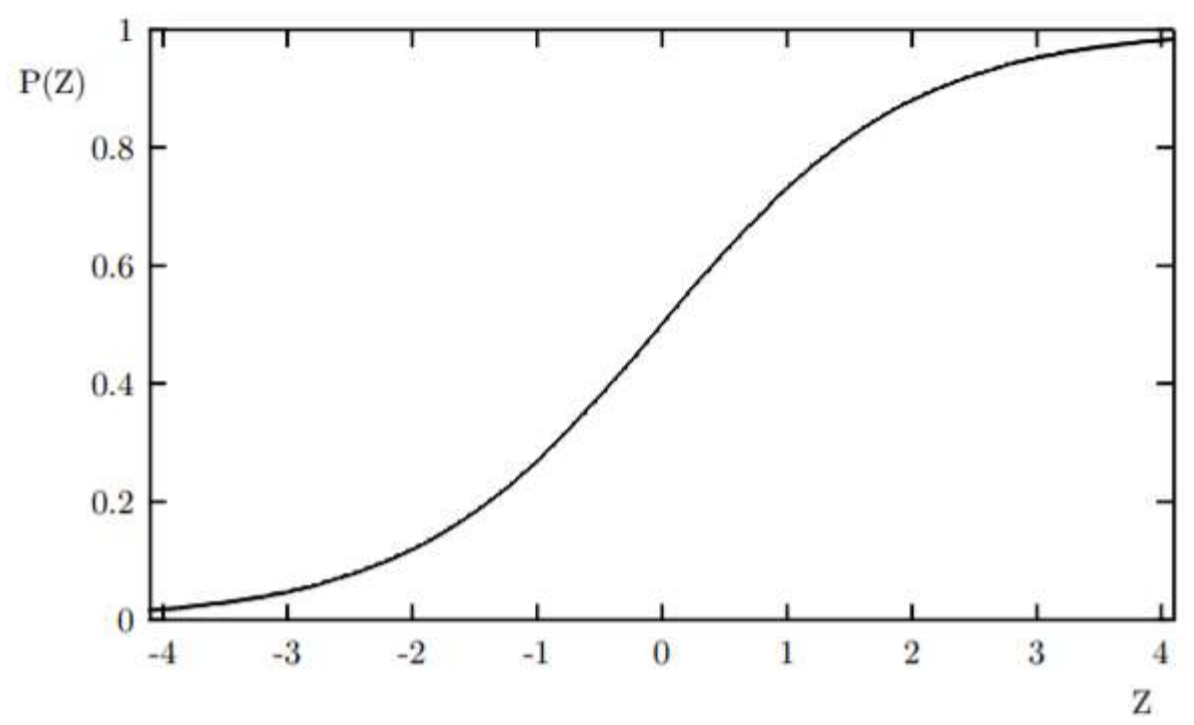

Figura 3.2: Função Logística $\mathrm{P}(\mathrm{z})$.

Fonte: CRAMER (2002).

Nesse trabalho, será utilizada uma versão generalizada da fórmula:

$$
y(x)=y_{\min }+\frac{y_{\text {máx }}-y_{\min }}{1+\left(10^{h\left(p_{i}-x\right)}\right)^{\prime}}
$$

onde $y_{\text {mín }}$ e $y_{\text {máx }}$ são os limites inferior e superior da função; $h$ é a inclinação da curva no ponto de inflexão, representado por $p_{i}$. 


\subsection{Simulador de Escoamento}

O GEM é um simulador de escoamento composicional desenvolvido pela CMG. No presente trabalho, foi utilizada a versão 2019.10. Além de simulações de reservatórios com porosidade simples, o GEM também possui soluções de múltiplas porosidades e permeabilidades implementadas.

\subsubsection{Simulação Numérica de Reservatórios}

Os simuladores de escoamento são modelos numéricos que, para resolver a equação da difusividade hidráulica em reservatórios complexos, utiliza discretizações temporal e espacial.

A discretização espacial consiste em selecionar uma malha capaz de subdividir o reservatório em pequenas células e, dessa forma, simplificar o equacionamento do balanço de massa em cada célula de simulação. Em contrapartida, o aumento do número de células na malha faz crescer o sistema de equações para a solução simultânea do balanço de massa em cada célula do reservatório a ser modelado. É possível realizar discretização unidimensional, bidimensional ou tridimensional. Usualmente, as direções espaciais nos eixos contínuos são denominadas $x$, y e z enquanto nos eixos discretos são i, j e k.

A discretização temporal consiste no método de diferenças finitas para resolver as derivadas presentes no equacionamento. Com isso, segmenta-se o tempo em períodos denominados de timesteps $(\Delta t)$. Tradicionalmente, há duas formas de implementar a discretização temporal: formulação explícita ou implícita. Para se explicar a diferença entre as duas, é importante ressaltar que as equações que estão sendo solucionadas possuem não linearidades no tempo e, por conseguinte, as variáveis que as compõem não são constantes.

A formulação explícita assume que as variáveis calculadas em $t_{i}$ se mantém constantes até o próximo timestep $\left(t_{i}+\Delta t\right)$. Assim, para não incorrer em grandes erros, são necessários passos de tempo pequenos. Caso contrário, a simulação se torna instável.

A formulação implícita calcula o valor das variáveis no tempo futuro através de aproximação por série de Taylor. Essa aproximação gera um erro que será abordado posteriormente. Todavia, esse método é incondicionalmente estável, de forma que se torna possível aumentar a dimensão dos timesteps.

Na Figura 3.3 encontra-se um desenho esquemático demonstrando a diferença entre as duas formulações: dado que se tem as propriedades em $t_{i}$ e se deseja calculá-las em $t_{i+1}$, ambas utilizam propriedades de $t_{i}$. Mas a implícita também utiliza propriedades em $t_{i+1}$. 


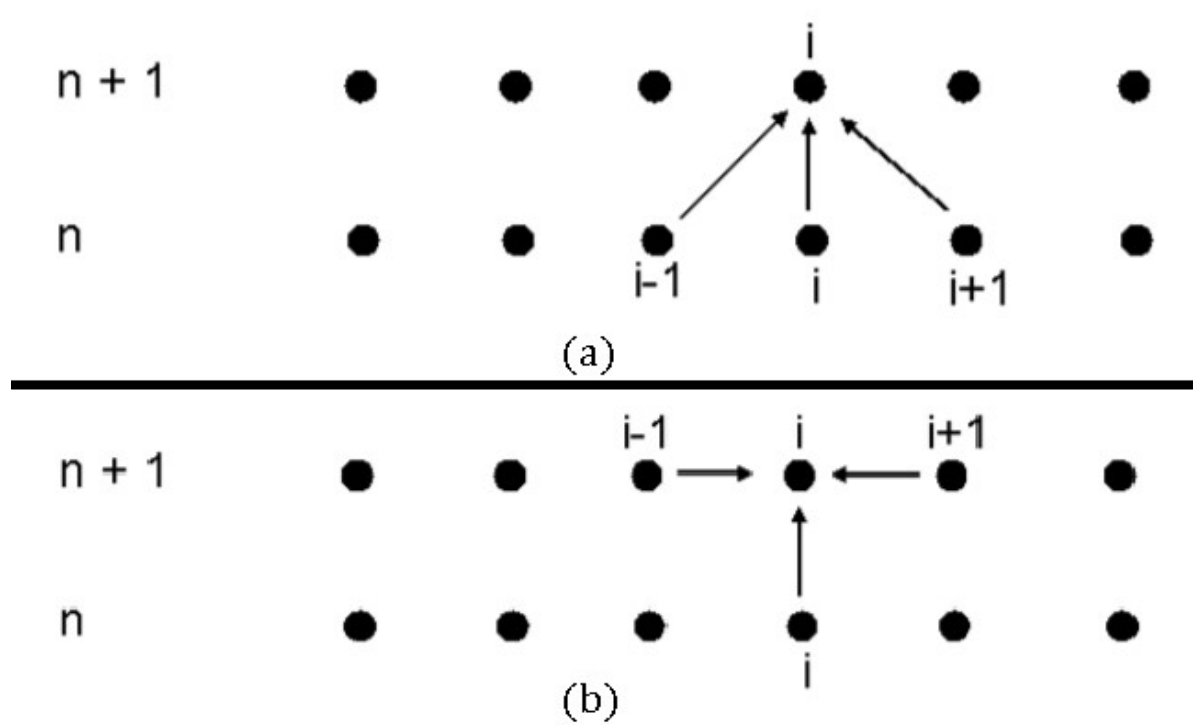

Figura 3.3: Esquemáticos das formulações (a) explícita e (b) implícita.

Devido à maior complexidade inerente à formulação implícita, é necessário significativo esforço computacional para chegar à convergência das equações. A fim de acelerar esse processo, utiliza-se o método denominado totalmente implícito que, através de iterações de Newton-Raphson, lineariza as equações, acelerando a convergência. Cada iteração desse processo é nomeada iteração newtoniana.

O algoritmo que modela as equações linearizadas é denominado solver linear enquanto o solver não-linear é o que lineariza as equações por Newton-Raphson ao longo de um timestep.

Há ainda outros métodos que buscam diminuir o tempo de simulação. Um deles é o IMPES (Implicit Pressure, Explicit Saturations), cuja formulação foi apresentada por SHELDON et al. (1959) e STONE e GARGNER (1961). Essa metodologia consiste em se calcular os valores de pressão de forma implícita e os de saturação de forma explícita. Para isso, se reduz o sistema de equações implícitas, excluindo as incógnitas de saturação. Em seguida, calcula-se a pressão de forma implícita. Com esse dado, o cálculo das saturações é feito de forma explícita. Segue um esquemático de um caso com modelagem black-oil para facilitar a compreensão do método (MACHADO, 2019):

$$
\begin{aligned}
& F_{o}\left(p_{o}^{n+1}, S_{w}^{n+1}, S_{g}^{n+1}\right)=0 \\
& F_{w}\left(p_{o}^{n+1}, S_{w}^{n+1}, S_{g}^{n+1}\right)=0 \\
& F_{g}\left(p_{o}^{n+1}, S_{w}^{n+1}, S_{g}^{n+1}\right)=0
\end{aligned}
$$


onde $F_{o, w, g}$ são as equações que modelam o escoamento no reservatório.

Explicitando $S_{g}^{n+1}$ da Equação 3-5, tem-se:

$$
F_{g_{2}}\left(p_{o}^{n+1}, S_{w}^{n+1},\right)=S_{g}^{n+1}
$$

Substituindo $S_{g}^{n+1}$ por $F_{g_{2}}$ nas outras equações, chega-se a:

$$
\begin{aligned}
& F_{o_{2}}\left(p_{o}^{n+1}, S_{w}^{n+1}\right)=0 \\
& F_{w_{2}}\left(p_{o}^{n+1}, S_{w}^{n+1}\right)=0
\end{aligned}
$$

Repetindo por fim, o procedimento para $S_{w}^{n+1}$ o resultado é:

$$
F_{o_{3}}\left(p_{o}^{n+1}\right)=0
$$

Logo, através do método IMPES, se calcula $p_{o}^{n+1}$ implicitamente para, em seguida, as saturações serem calculadas de forma explícita.

O IMPES é aplicado em formulações black-oil. Para o caso composicional, utiliza-se o método análogo, chamado de IMPECS (Implicit Pressure, Explicit Compositions and Saturations). De forma semelhante que explicado para o IMPES, são isoladas as variáveis relativas aos pseudo-componentes globais da mistura e a pressão para solução implícita. Em seguida, as saturações e as composições de cada pseudo-componente em cada fase são avaliadas de forma explícita.

Ambas as metodologias (IMPES e IMPECS) ainda podem gerar instabilidade na simulação. Para mitigar esse problema, utiliza-se a técnica conhecida como AIM (Adaptative Implicit Method). Esse método identifica os blocos do modelo cujas variações são expressivas e Ihes aplica a formulação totalmente implícita. Para as demais células, nas quais o risco de instabilidade é reduzido, a solução é obtida através do IMPES ou IMPECS, mais rápidos. Há algumas técnicas para determinar o critério de estabilidade. Nesse trabalho, foi utilizado o critério combinado CFL (Courant-Friedrichs-Lewy) e de limite (threshold).

Diversos parâmetros são necessários para controlar a convergência das soluções e o tamanho dos timesteps utilizados durante a simulação. Destacam-se as tolerâncias para a convergência dos solvers linear e não-linear; variações típicas e máximas de pressão, saturação e composição molar; valores máximo e mínimo de timestep. 
O simulador busca adaptar o tamanho do timestep para respeitar os parâmetros determinados pelo usuário. Uma técnica comumente usada para isso é a seleção automática de timestep (TODD, 1972).

Nesse caso utiliza-se, para $n=0$ :

$$
\Delta t^{n+1}=\Delta t_{m i n}
$$

e para $n>0$ :

$$
\Delta t^{n+1}=\operatorname{mín}\left(\Delta t^{n} \cdot\left(\frac{\Delta t^{n+1}}{\Delta t^{n}}\right)_{\text {máx }}, \Delta t_{p}^{n+1}, \Delta t_{S}^{n+1}, \Delta t_{R_{S}}^{n+1}\right),
$$

onde:

$$
\begin{aligned}
& \Delta t_{p}^{n+1}=\Delta t^{n} \frac{\Delta p_{\text {máx }}}{\operatorname{máx}_{i, j, k}\left(\left|p_{i, j, k}^{n+1}-p_{i, j, k}^{n}\right|\right)} ;
\end{aligned}
$$

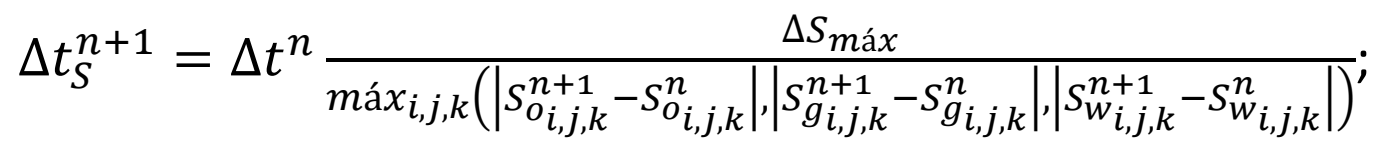

$$
\begin{aligned}
& \Delta t_{R_{S}}^{n+1}=\Delta t^{n} \frac{\Delta R_{S_{\text {máx }}}}{{\text { máx } x_{i, j, k}\left(\left|R_{S i, j, k}^{n+1}-R_{S i, j, k}^{n}\right|\right.}^{n+1}},
\end{aligned}
$$

e o usuário determina os valores máximos de variação $\left(\frac{\Delta t^{n+1}}{\Delta t^{n}}\right)_{\text {máx }}, \Delta p_{\text {máx }}, \Delta S_{\text {máx }}$ e $\Delta R_{S_{\text {máx }}}$. Caso o solver não convirja com o timestep determinado, ele é reduzido e inicia-se o processo de solução das equações novamente. No entanto, se o solver chegar à solução rapidamente e as restrições impostas permitirem, o timestep é aumentado.

Normalmente, esses parâmetros são definidos no início da simulação e se mantém constantes até o final. Todavia, foi implementado no GEM o ADTSC (Adaptative Time Step Control). Esse algoritmo permite a otimização automática desses parâmetros de controle de forma iterativa, a fim de se acelerar a simulação.

\subsubsection{Simulação Composicional}

A simulação composicional procura modelar o comportamento dos componentes dos hidrocarbonetos e demais fluidos presentes no reservatório. Através de equações de estado, 
o simulador é capaz de determinar as propriedades e fases dos fluidos resultantes, necessárias para os equacionamentos relativos ao escoamento. Logo, difere das simulações black-oil que assumem uma simplificação, na qual o petróleo é representado apenas por um componente óleo e um componente gás, correspondendo às respectivas fases, e cujas características são determinadas por tabelas relacionando as propriedades desses componentes à pressão. A formulação composicional aumenta a complexidade do sistema de equações a serem resolvidas, uma vez que, para cada componente utilizado, é necessária uma equação extra, em cada bloco da malha. Como os fluidos do pré-sal brasileiro são majoritariamente modelados com formulação composicional, faz-se necessário descrevê-la nesse trabalho.

SANTOS et al. (2015) apresentam detalhadamente a formulação de um simulador composicional de porosidade simples. São assumidas as seguintes premissas:

- Sistema isotérmico;

- Não há interação entre a rocha e os fluidos;

- Não há reação entre os fluidos injetados e os fluidos do reservatório;

- Meio poroso pouco compressível;

- Não há transferência de massa entre a água e os hidrocarbonetos;

- A viscosidade da água é constante;

- O efeito de pressão capilar é desprezível;

- Não há barreiras para o escoamento.

Para cada componente de hidrocarboneto tem-se a seguinte equação de balanço de massa:

$$
\begin{gathered}
\frac{\partial}{\partial x}\left(\frac{A_{x} k_{x} k_{r o}}{\mu_{o}} \cdot \rho_{o} \boldsymbol{x}_{m} \cdot \frac{\partial \Phi_{o}}{\partial x}+\frac{A_{x} k_{x} k_{r g}}{\mu_{g}} \cdot \rho_{g} \boldsymbol{y}_{m} \cdot \frac{\partial \Phi_{g}}{\partial x}\right) \Delta x \\
+\frac{\partial}{\partial y}\left(\frac{A_{y} k_{y} k_{r o}}{\mu_{o}} \cdot \rho_{o} \boldsymbol{x}_{m} \cdot \frac{\partial \Phi_{o}}{\partial y}+\frac{A_{y} k_{y} k_{r g}}{\mu_{g}} \cdot \rho_{g} \boldsymbol{y}_{m} \cdot \frac{\partial \Phi_{g}}{\partial y}\right) \Delta y \\
+\frac{\partial}{\partial z}\left(\frac{A_{z} k_{z} k_{r o}}{\mu_{o}} \cdot \rho_{o} \boldsymbol{x}_{m} \cdot \frac{\partial \Phi_{o}}{\partial z}+\frac{A_{z} k_{z} k_{r g}}{\mu_{g}} \cdot \rho_{g} \boldsymbol{y}_{m} \cdot \frac{\partial \Phi_{g}}{\partial z}\right) \Delta z+q_{m} \\
=V_{b} \frac{\partial}{\partial t}\left(\varphi \rho_{o} \boldsymbol{x}_{m} S_{o}+\varphi \rho_{g} \boldsymbol{y}_{m} S_{g}\right),
\end{gathered}
$$

onde $A$ representa a área transversal ao escoamento, $k$ é a permeabilidade absoluta em determinada direção, $k_{r}$ é a permeabilidade relativa ao fluido, $\mu$ é a viscosidade do fluido, $\rho$ 
corresponde à densidade molar do fluido, $\boldsymbol{x}_{m}$ e $\boldsymbol{y}_{m}$ representam as frações molares do componente $m$ na fase líquida e gasosa, respectivamente, $\Phi$ é o potencial do fluido, $q$ é o termo sumidouro de cada componente, $V_{b}$ é o volume total da célula, $\varphi$ é a porosidade da célula, $S$ é a saturação da fase, $t$ representa o tempo e $x, y$ e $z$ representam as três direções do espaço. Os índices $o$ e $g$ representam as fases óleo e gás, respectivamente enquanto $m$ representa o componente, que pode ir de 1 até $n_{c}$ (número de componentes).

Para a fase água, o balanço de massa é representado pela Equação 3-16:

$$
\begin{gathered}
\frac{\partial}{\partial x}\left(\frac{A_{x} k_{x} k_{r w}}{\mu_{w}} \cdot \rho_{w} \cdot \frac{\partial \Phi_{w}}{\partial x}\right) \Delta x \\
+\frac{\partial}{\partial y}\left(\frac{A_{y} k_{y} k_{r w}}{\mu_{w}} \cdot \rho_{w} \cdot \frac{\partial \Phi_{w}}{\partial y}\right) \Delta y \\
+\frac{\partial}{\partial z}\left(\frac{A_{z} k_{z} k_{r w}}{\mu_{w}} \cdot \rho_{w} \cdot \frac{\partial \Phi_{w}}{\partial z}\right) \Delta z+q_{w} \\
=V_{b} \frac{\partial}{\partial t}\left(\varphi \rho_{w} S_{w}\right) .
\end{gathered}
$$

Para simplificar a escrita, adota-se o conceito de transmissibilidade:

$$
T_{o x}=\frac{A_{x} k_{x} k_{r o}}{\mu_{o} \Delta x}
$$

Nesse exemplo, a transmissibilidade está definida em relação à direção $x$ e à fase óleo. Contudo, a mesma formulação se aplica às demais direções e fases.

Também é adotada a simplificação das equações 3-18 e 3-19.

$$
\begin{gathered}
N_{m}=\varphi\left(\rho_{o} \boldsymbol{x}_{m} S_{o}+\rho_{g} \boldsymbol{y}_{m} S_{g}\right), \\
N_{w}=\varphi \rho_{w} S_{w} .
\end{gathered}
$$

Por fim, os potenciais são descritos como:

$$
\begin{gathered}
\Phi_{o}=p_{o}-\gamma_{o} Z \\
\Phi_{g}=p_{o}-p_{c o g}-\gamma_{g} Z \\
\Phi_{w}=p_{o}-p_{c o w}-\gamma_{w} Z
\end{gathered}
$$


onde o índice $w$ se refere à água, $P_{o}$ representa a pressão da fase óleo, $P_{c o w}$ é a pressão capilar óleo-água, $P_{c o g}$ é a pressão capilar óleo-gás, $\gamma$ corresponde ao peso específico da fase e $Z$, à profundidade do ponto no espaço.

Dessa forma, as equações 3-15 e 3-16 são reescritas:

$$
\begin{gathered}
\frac{\partial}{\partial x}\left(T_{o x} \cdot \Delta x \rho_{o} \boldsymbol{x}_{m} \cdot\left(\frac{\partial p_{o}}{\partial x}-\gamma_{o} \frac{\partial Z}{\partial x}\right)\right. \\
\left.+T_{g x} \cdot \Delta x \rho_{g} \boldsymbol{y}_{m} \cdot\left(\frac{\partial p_{o}}{\partial x}-\frac{\partial p_{c o g}}{\partial x}-\gamma_{g} \frac{\partial Z}{\partial x}\right)\right) \Delta x \\
+\frac{\partial}{\partial y}\left(T_{o y} \cdot \Delta y \rho_{o} \boldsymbol{x}_{m} \cdot\left(\frac{\partial p_{o}}{\partial y}-\gamma_{o} \frac{\partial Z}{\partial y}\right)\right. \\
\left.+T_{g y} \cdot \Delta y \rho_{g} \boldsymbol{y}_{m} \cdot\left(\frac{\partial p_{o}}{\partial y}-\frac{\partial p_{c o g}}{\partial y}-\gamma_{g} \frac{\partial Z}{\partial y}\right)\right) \Delta y \\
+\frac{\partial}{\partial z}\left(T_{o z} \cdot \Delta z \rho_{o} \boldsymbol{x}_{m} \cdot\left(\frac{\partial p_{o}}{\partial z}-\gamma_{o} \frac{\partial Z}{\partial z}\right)\right. \\
+\frac{\partial}{\partial z}\left[T_{w z} \cdot \Delta z \rho_{w}\left(\frac{\partial p_{o}}{\partial z}-\frac{\partial p_{c o w}}{\partial z}-\gamma_{w} \frac{\partial Z}{\partial z}\right)\right] \Delta z+q_{w} \\
+\frac{\partial}{\partial y}\left[T_{w y} \cdot \Delta y \rho_{w}\left(\frac{\partial p_{o}}{\partial y}-\frac{\partial p_{c o g}}{\partial z}-\gamma_{g} \frac{\partial Z}{\partial z}\right)\right) \Delta z+q_{m} \\
\frac{\partial}{\partial x}\left[T_{w x} \cdot \Delta x \rho_{w}\left(\frac{\partial p_{o}}{\partial x}-\frac{\partial p_{c o w}}{\partial x}-\gamma_{w} \frac{\partial z}{\partial x}\right)\right] \Delta x \\
+\frac{\partial N_{m}}{\partial t}
\end{gathered}
$$


Dessa forma, totalizam-se $n_{c}+1$ equações. A elas, se adicionam $n_{c}+3$ restrições do sistema, que são apresentadas nas Equações 3-25 a 3-28.

$$
\begin{gathered}
S_{o}+S_{g}+S_{w}=1 ; \\
\sum_{i=1}^{n_{c}} \boldsymbol{x}_{m}=1 ; \\
\sum_{i=1}^{n_{c}} \boldsymbol{y}_{m}=1 ; \\
f_{m}^{L}=f_{m}^{V},
\end{gathered}
$$

onde $f_{m}^{L}$ e $f_{m}^{V}$ representam as fugacidades de cada componente $m$ nas fases líquido e vapor, respectivamente.

A solução das equações de equilíbrio de fases é uma tarefa já demasiado complexa, denominada, comumente de flash (COLLINS et al., 1992). Por conseguinte, é sugerido que as Equações 3-26, 3-27 e 3-28 sejam resolvidas separadamente das Equações 3-23, 3-24 e 3-25. Ou seja, que as equações de fluxo sejam tratadas de forma isolada das de equilíbrio de fases. Logo, primeiramente, o simulador calcula as pressões e frações molares de cada componente em cada célula do modelo. Em seguida, as frações molares de cada componente em cada fase é calculada. Esse processo é feito em cada iteração newtoniana.

O próximo passo é realizar a discretização geométrica e temporal das equações. Para isso, utilizou-se a mesma técnica de MACHADO (2019), adaptando-se a formulação para o caso composicional.

Primeiramente, apresenta-se a transmissibilidade entre células, que segue a Equação 3-29.

$$
T_{i+1 / 2}=\frac{2 k_{i} k_{i+1} A_{i} A_{i+1}}{\mu_{i} \Delta x_{i} k_{x i+1} A_{i+1}+\mu_{i+1} \Delta x_{i+1} k_{i} A_{i}}
$$

onde o conceito pode ser levado para outras direções e para o outro sentido $\left(T_{i-1 / 2}\right)$.

Também é necessário simplificar os termos gravitacionais com as Equações 3-30 a 332 e de pressão capilar com as Equações 3-33 e 3-34.

$$
\begin{gathered}
X_{o}=\frac{\partial}{\partial x}\left(T_{o x} \cdot \Delta x \cdot \boldsymbol{x}_{m} \cdot \gamma_{o} \cdot \frac{\partial Z}{\partial x}\right) \cdot \Delta x+\frac{\partial}{\partial y}\left(T_{o y} \cdot \Delta y \cdot \boldsymbol{x}_{m} \cdot \gamma_{o} \cdot \frac{\partial z}{\partial y}\right) \cdot \Delta y+ \\
\frac{\partial}{\partial z}\left(T_{o z} \cdot \Delta z \cdot \boldsymbol{x}_{m} \cdot \gamma_{o} \cdot \frac{\partial Z}{\partial z}\right) \cdot \Delta z
\end{gathered}
$$




$$
\begin{gathered}
X_{g}=\frac{\partial}{\partial x}\left(T_{g x} \cdot \Delta x \cdot \boldsymbol{y}_{m} \cdot \gamma_{g} \cdot \frac{\partial z}{\partial x}\right) \cdot \Delta x+\frac{\partial}{\partial y}\left(T_{g y} \cdot \Delta y \cdot \boldsymbol{y}_{m} \cdot \gamma_{g} \cdot \frac{\partial z}{\partial y}\right) \cdot \Delta y+ \\
\frac{\partial}{\partial z}\left(T_{g z} \cdot \Delta z \cdot \boldsymbol{y}_{m} \cdot \gamma_{g} \cdot \frac{\partial z}{\partial z}\right) \cdot \Delta z \\
X_{w}=\frac{\partial}{\partial x}\left(T_{w x} \cdot \Delta x \cdot \gamma_{w} \cdot \frac{\partial z}{\partial x}\right) \cdot \Delta x+\frac{\partial}{\partial y}\left(T_{w y} \cdot \Delta y \cdot \gamma_{w} \cdot \frac{\partial z}{\partial y}\right) \cdot \Delta y+ \\
\frac{\partial}{\partial z}\left(T_{w z} \cdot \Delta z \cdot \gamma_{w} \cdot \frac{\partial z}{\partial z}\right) \cdot \Delta z ; \\
A_{g}=\frac{\partial}{\partial x}\left(T_{g x} \cdot \Delta x \cdot \boldsymbol{y}_{m} \cdot \frac{\partial p_{c o g}}{\partial x}\right) \cdot \Delta x+\frac{\partial}{\partial y}\left(T_{g y} \cdot \Delta y \cdot \boldsymbol{y}_{m \cdot} \frac{\partial p_{c o g}}{\partial y}\right) \cdot \Delta y+ \\
\frac{\partial}{\partial z}\left(T_{g z} \cdot \Delta z \cdot \boldsymbol{y}_{m \cdot} \frac{\partial p_{c o g}}{\partial z}\right) \cdot \Delta z ; \\
\begin{array}{c}
\frac{\partial}{\partial z}\left(T_{w z} \cdot \Delta z \cdot \frac{\partial p_{c o w}}{\partial z}\right) \cdot \Delta z . \\
\frac{\partial}{\partial x}\left(T_{w x} \cdot \Delta x \cdot \frac{\partial p_{c o w}}{\partial x}\right) \cdot \Delta x+\frac{\partial}{\partial y}\left(T_{w y} \cdot \Delta y \cdot \frac{\partial p_{c o w}}{\partial y}\right) \cdot \Delta y+
\end{array}
\end{gathered}
$$

Realizando as discretizações, as fórmulas resultantes para os hidrocarbonetos e para a água são, respectivamente:

$$
\begin{aligned}
& T_{o x}^{n+1} \rho_{\left(i+\frac{1}{2}\right)}^{n+1} \rho_{\left(i+\frac{1}{2}\right)}^{n+1} x_{\left(i+\frac{1}{2}\right)}^{n+1}\left(p_{i+1}-p_{i}\right)^{n+1} \\
& -T_{o x_{\left(i-\frac{1}{2}\right)}^{n+1}}^{\rho_{o}^{n+1}} \boldsymbol{x}_{\left(i-\frac{1}{2}\right)}^{n+1}\left(p_{\left.i-\frac{1}{2}\right)}-p_{i-1}\right)^{n+1} \\
& +T_{g x_{\left(i+\frac{1}{2}\right)}^{n+1}}^{n} \rho_{g_{\left(i+\frac{1}{2}\right)}^{n+1}} y_{m}^{n+1}\left(p_{i+1}-p_{i}\right)^{n+1} \\
& -T_{g x_{\left(i-\frac{1}{2}\right)}^{n+1}}^{n \rho_{g}^{n+1}} \boldsymbol{y}_{m\left(i-\frac{1}{2}\right)}^{n+1}\left(p_{i}-p_{i-1}\right)^{n+1} \\
& +q_{o}^{n+1}+q_{g_{i}}^{n+1}=\frac{V_{b}}{\Delta t}\left(N_{m}^{n+1}-N_{m}^{n}\right)-T_{o x_{i}}^{n+1}+X_{o}^{n+1}+X_{g}^{n+1}-A_{g}^{n+1} \text {; }
\end{aligned}
$$




$$
\begin{gathered}
T_{w x_{\left(i+\frac{1}{2}\right)}^{n+1}} \rho_{w\left(i+\frac{1}{2}\right)}^{n+1}\left(p_{i+1}-p_{i}\right)^{n+1}-T_{w x_{\left(i-\frac{1}{2}\right)}^{n+1}}^{n} \rho_{\left(i-\frac{1}{2}\right)}^{n+1}\left(p_{i}-p_{i-1}\right)^{n+1} \\
+q_{w i}^{n+1}=\frac{V_{b i}}{\Delta t}\left(N_{w}^{n+1}-N_{w}^{n}\right)+X_{w}^{n+1}+A_{w}^{n+1}
\end{gathered}
$$

onde os subscritos $i$ se referem à cada célula da discretização geométrica, o $n$ corresponde ao timestep da discretização temporal e as demais direções podem ser descritas analogamente.

Conforme comentado na seção 3.2.1, a linearização dessas equações é feita através do método totalmente implícito que utiliza um termo denominado resíduo para realizar as iterações newtonianas. Logo, as formulações podem ser reescritas em formato desse resíduo $r:$

$$
\begin{aligned}
& r_{i_{m}}^{n+1}=T_{o x}^{n+1}{ }_{\left(i+\frac{1}{2}\right)}^{n+1} \rho_{o\left(i+\frac{1}{2}\right)}^{n+1} x_{\left(i+\frac{1}{2}\right)}^{n+1}\left(p_{i+1}-p_{i}\right)^{n+1} \\
& -T_{o x_{\left(i-\frac{1}{2}\right)}^{n+1}} \rho_{o}^{n+1} x_{\left(i-\frac{1}{2}\right)}^{n+1} x_{\left(i-\frac{1}{2}\right)}\left(p_{i}-p_{i-1}\right)^{n+1} \\
& +T_{g x_{\left(i+\frac{1}{2}\right)}^{n+1}}^{n \rho_{g}^{n+1}} \boldsymbol{y}_{\left(i+\frac{1}{2}\right)}^{n+1}\left(p_{i+1}-p_{i}\right)^{n+1} \\
& -T_{g x_{\left(i-\frac{1}{2}\right)}^{n+1}}^{n} \rho_{g_{\left(i-\frac{1}{2}\right)}^{n+1}} y_{m}^{n+1}\left(p_{\left.i-\frac{1}{2}\right)}-p_{i-1}\right)^{n+1} \\
& +q_{o_{i}}^{n+1}+q_{g_{i}}^{n+1}+X_{m}^{n+1}+A_{m}^{n+1}-\frac{V_{b}}{\Delta t}\left(N_{m}^{n+1}-N_{m}^{n}\right),
\end{aligned}
$$

e o sistema de equações pode ser reescrito com a seguinte equação, repetida para cada componente, incluindo a água e para cada célula da malha:

$$
\begin{gathered}
\left(\frac{\partial r_{i_{m}}}{\partial p_{i+1}}\right)^{n+1^{v}} \delta p_{i+1}^{n+1^{v+1}}+\left(\frac{\partial r_{i_{m}}}{\partial p_{i}}\right)^{n+1^{v}} \delta p_{i}^{n+1^{v+1}} \\
+\left(\frac{\partial r_{i_{m}}}{\partial p_{i-1}}\right)^{n+1^{v}} \delta p_{i-1}^{n+1^{v+1}}+\sum_{m=1}^{n_{c}+1}\left(\frac{\partial r_{i_{m}}}{\partial N_{i_{m}}}\right)^{n+1^{v}} \delta N_{i_{m}^{n+1^{v+1}}}^{n}=-r_{i_{m}^{n+1^{v}}}
\end{gathered}
$$

onde o sobrescrito $v$ ou $v+1$ representam a iteração newtoniana atual ou subsequente, respectivamente e o componente $n_{c}+1$ representa a água. 
Com isso, são obtidos $n_{c}+1$ equações. No entanto, estamos buscando resolver $n_{c}+$ 2 incógnitas: $p, N_{w}, N_{1}, N_{2}, \ldots, N_{n_{c}}$. Logo é necessária mais uma equação que é chamada de equação de consistência de volume, a qual consiste na equação de soma das saturações igual a unidade, reorganizada.

$$
r_{p}^{n+1}=\frac{N_{o}^{n+1}}{\rho_{o}^{n+1}}+\frac{N_{g}^{n+1}}{\rho_{g}^{n+1}}+\frac{N_{w}^{n+1}}{\rho_{w}^{n+1}}-\varphi^{n+1}
$$

Reescrevendo o sistema de equações no formato matricial, chega-se à Equação 3-40.

$$
[J]^{n+1^{v}}[\delta \xi]^{n+1^{v+1}}=-[\psi]^{n+1^{v}}
$$

onde $[J]$ é a matriz Jacobiana que consiste nas derivadas dos resíduos (3-37) e (3-39) para cada bloco da malha, $[\delta \xi]$ indica o vetor das variações das incógnitas, composto pelos termos infinitesimais relativos à pressão de cada bloco e aos componentes, inclusive a água, e o vetor $[\psi]$ representa os resíduos de cada componente mais $r_{p}$.

Para deixar mais claro o entendimento da formação desse sistema matricial, segue um exemplo, para um caso unidimensional, com dois componentes de hidrocarbonetos mais a água e composto por apenas três células, conforme mostrado na Figura 3.4:

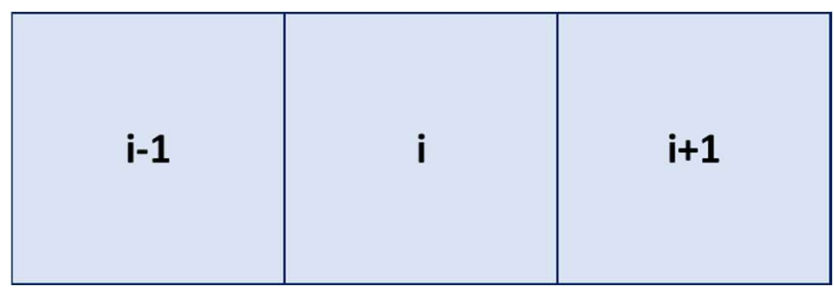

Figura 3.4: Exemplo de modelo unidimensional de três células. 


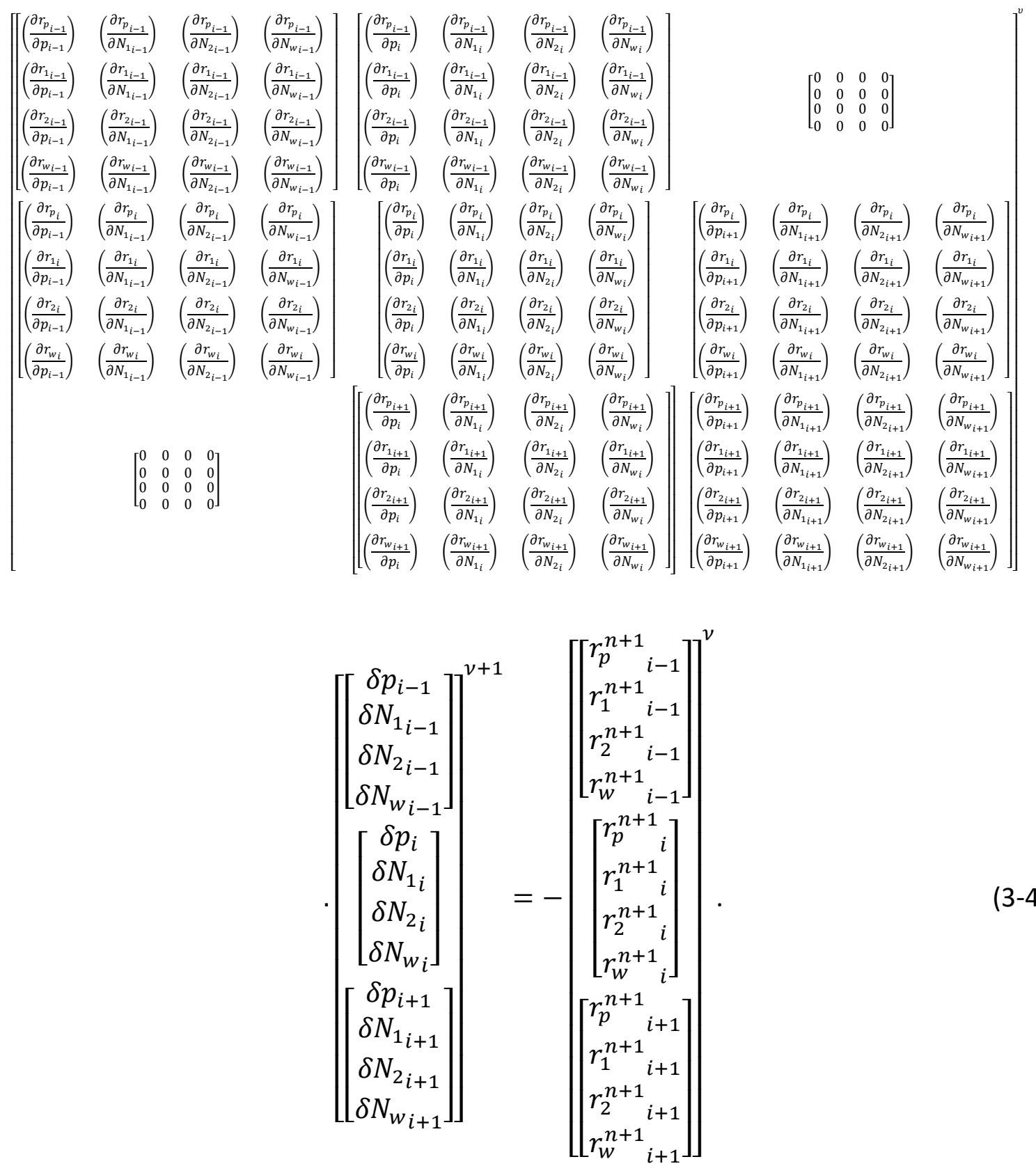

Na metodologia adotada pelo GEM, esse sistema é resolvido para as incógnitas denominadas variáveis primárias $\left(N_{m}\right.$ 's, $N_{w}$ e $p$ ) para cada bloco e, em cada iteração newtoniana, é realizado um cálculo flash para se determinar o equilíbrio de fases (termos $\boldsymbol{x}_{m}$ e $\boldsymbol{y}_{m}$ ). SANTOS (2013) descreve algumas das metodologias utilizadas para se solucionar as equações de estado.

Por fim, as diversas aproximações foram feitas, de forma que há um erro cumulativo que ocorre em cada iteração do simulador. Portanto, uma das formas de se fazer um controle de qualidade dos resultados é realizar o balanço de materiais. Esse método consiste, simplesmente, em calcular a massa presente no início da simulação e compará-la com a 
presente no final, subtraindo os fluidos produzidos e somando os injetados. Portanto, o erro de balanço de materiais $(E B M)$ é definido por:

$$
E B M=\frac{F I P_{t}}{F I P_{0}-F_{p}+F_{i}}
$$

onde $F I P_{t}$ é o volume de fluido no tempo $t$ no reservatório, $F I P_{0}$ é o volume de fluido inicialmente no reservatório, $F_{p}$ é o volume de fluido produzido e $F_{i}$ é o volume de fluido injetado.

\subsubsection{Simulação de Dupla Porosidade e Dupla Permeabilidade}

Para representar o meio fraturado são necessárias algumas adaptações em relação ao que foi apresentado anteriormente. A primeira alteração ocorre na malha de simulação. São utilizadas duas malhas idênticas sobrepostas, uma representando a matriz e a outra, o meio fraturado, conforme apresentado na Figura 3.5.

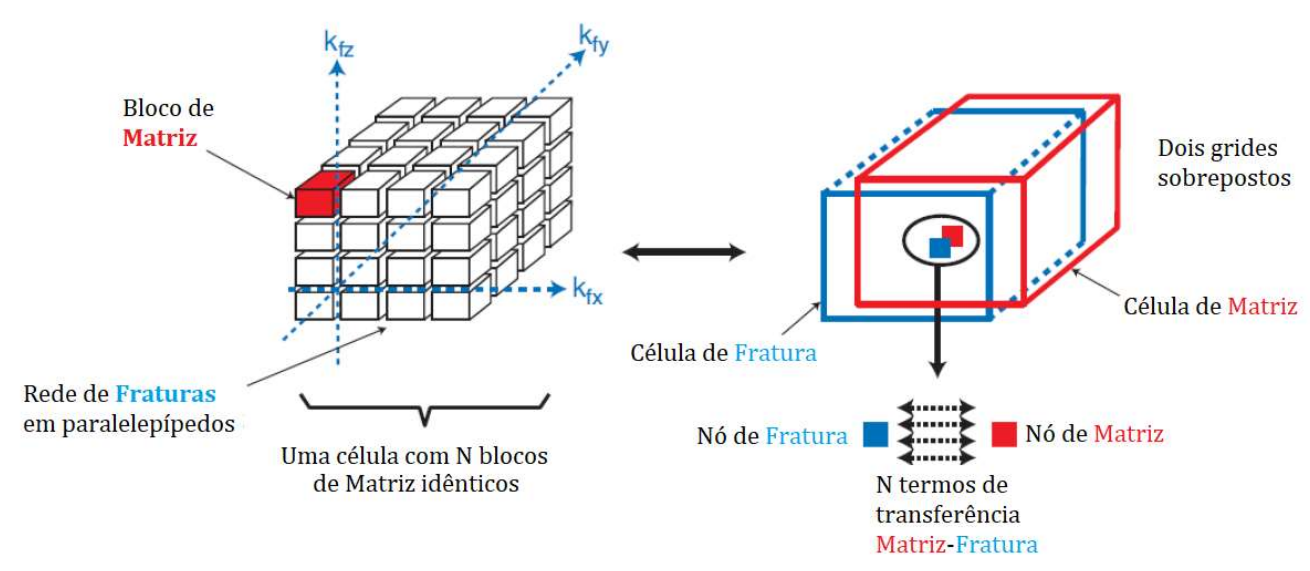

Figura 3.5: Esquema da sobreposição de malhas na simulação de dupla porosidade e dupla permeabilidade.

Fonte: Modificado de LEMONNIER e BOURBIAUX (2010).

O acoplamento entre as duas malhas é feito através do termo de transferência matrizfratura $\tau_{\mathrm{mf}}$. Inserindo esse fator na equação de balanço de massa apresentada anteriormente, temos as Equações 3-43 e 3-44 relativas às células de matriz (NGHIEM e LI, 1988 apud CMG, 2019). 


$$
\begin{aligned}
& \frac{\partial}{\partial x}\left(T_{o x} \cdot \Delta x \rho_{o} x_{m} \cdot\left(\frac{\partial p_{o}}{\partial x}-\gamma_{o} \frac{\partial Z}{\partial x}\right)\right. \\
& \left.+T_{g x} \cdot \Delta x \rho_{g} \boldsymbol{y}_{m \cdot}\left(\frac{\partial p_{o}}{\partial x}-\frac{\partial p_{\operatorname{cog}}}{\partial x}-\gamma_{g} \frac{\partial Z}{\partial x}\right)\right) \Delta x \\
& +\frac{\partial}{\partial y}\left(T_{o y} \cdot \Delta y \rho_{o} x_{m} \cdot\left(\frac{\partial p_{o}}{\partial y}-\gamma_{o} \frac{\partial Z}{\partial y}\right)\right. \\
& \left.+T_{g y} \Delta y \rho_{g} \boldsymbol{y}_{m \cdot}\left(\frac{\partial p_{o}}{\partial y}-\frac{\partial p_{\operatorname{cog}}}{\partial y}-\gamma_{g} \frac{\partial Z}{\partial y}\right)\right) \Delta y \\
& +\frac{\partial}{\partial z}\left(T_{o z} \cdot \Delta z \rho_{o} x_{m} \cdot\left(\frac{\partial p_{o}}{\partial z}-\gamma_{o} \frac{\partial Z}{\partial z}\right)\right. \\
& \left.+T_{g z \cdot} \Delta z \rho_{g} \boldsymbol{y}_{m} \cdot\left(\frac{\partial p_{o}}{\partial z}-\frac{\partial p_{\operatorname{cog}}}{\partial z}-\gamma_{g} \frac{\partial Z}{\partial z}\right)\right) \Delta z+q_{m} \\
& -\tau_{m f_{o}}-\tau_{m f_{g}}=V_{b} \frac{\partial N_{m}}{\partial t} \\
& \frac{\partial}{\partial x}\left[T_{w x} . \Delta x \rho_{w}\left(\frac{\partial p_{o}}{\partial x}-\frac{\partial p_{c o w}}{\partial x}-\gamma_{w} \frac{\partial Z}{\partial x}\right)\right] \Delta x \\
& +\frac{\partial}{\partial y}\left[T_{w y} \cdot \Delta y \rho_{w}\left(\frac{\partial p_{o}}{\partial y}-\frac{\partial p_{c o w}}{\partial y}-\gamma_{w} \frac{\partial Z}{\partial y}\right)\right] \Delta y \\
& +\frac{\partial}{\partial z}\left[T_{w z} \cdot \Delta z \rho_{w}\left(\frac{\partial p_{o}}{\partial z}-\frac{\partial p_{c o w}}{\partial z}-\gamma_{w} \frac{\partial Z}{\partial z}\right)\right] \Delta z+q_{w} \\
& -\tau_{m f_{w}}=V_{b} \frac{\partial N_{w}}{\partial t} \text {. }
\end{aligned}
$$

Nota-se que caso os coeficientes $\tau_{m f}$ sejam nulos, as equações são iguais às Equações 3-10 e 3-11.

A formulação das células de fratura é feita de forma semelhante, substituindo-se o sinal do termo de transferência matriz-fratura, conforme as Equações 3-45 e 3-46. 


$$
\begin{aligned}
& \frac{\partial}{\partial x}\left(T_{o x} \cdot \Delta x \rho_{o} \boldsymbol{x}_{m} \cdot\left(\frac{\partial p_{o}}{\partial x}-\gamma_{o} \frac{\partial Z}{\partial x}\right)\right. \\
& \left.+T_{g x} \cdot \Delta x \rho_{g} \boldsymbol{y}_{m \cdot}\left(\frac{\partial p_{o}}{\partial x}-\frac{\partial p_{\operatorname{cog}}}{\partial x}-\gamma_{g} \frac{\partial Z}{\partial x}\right)\right) \Delta x \\
& +\frac{\partial}{\partial y}\left(T_{o y} \cdot \Delta y \rho_{o} x_{m} \cdot\left(\frac{\partial p_{o}}{\partial y}-\gamma_{o} \frac{\partial Z}{\partial y}\right)\right. \\
& \left.+T_{g y} \cdot \Delta y \rho_{g} \boldsymbol{y}_{m} \cdot\left(\frac{\partial p_{o}}{\partial y}-\frac{\partial p_{\operatorname{cog}}}{\partial y}-\gamma_{g} \frac{\partial Z}{\partial y}\right)\right) \Delta y \\
& +\frac{\partial}{\partial z}\left(T_{o z} \cdot \Delta z \rho_{o} x_{m} \cdot\left(\frac{\partial p_{o}}{\partial z}-\gamma_{o} \frac{\partial Z}{\partial z}\right)\right. \\
& \left.+T_{g z} \cdot \Delta z \rho_{g} \boldsymbol{y}_{m} \cdot\left(\frac{\partial p_{o}}{\partial z}-\frac{\partial p_{\operatorname{cog}}}{\partial z}-\gamma_{g} \frac{\partial Z}{\partial z}\right)\right) \Delta z+q_{m} \\
& +\tau_{m f_{o}}+\tau_{m f_{g}}=V_{b} \frac{\partial N_{m}}{\partial t} \\
& \frac{\partial}{\partial x}\left[T_{w x} . \Delta x \rho_{w}\left(\frac{\partial p_{o}}{\partial x}-\frac{\partial p_{c o w}}{\partial x}-\gamma_{w} \frac{\partial Z}{\partial x}\right)\right] \Delta x \\
& +\frac{\partial}{\partial y}\left[T_{w y} \cdot \Delta y \rho_{w}\left(\frac{\partial p_{o}}{\partial y}-\frac{\partial p_{c o w}}{\partial y}-\gamma_{w} \frac{\partial Z}{\partial y}\right)\right] \Delta y \\
& +\frac{\partial}{\partial z}\left[T_{w z} \cdot \Delta z \rho_{w}\left(\frac{\partial p_{o}}{\partial z}-\frac{\partial p_{c o w}}{\partial z}-\gamma_{w} \frac{\partial Z}{\partial z}\right)\right] \Delta z+q_{w} \\
& +\tau_{m f_{w}}=V_{b} \frac{\partial N_{w}}{\partial t} \text {. }
\end{aligned}
$$

O termo de transferência matriz-fratura pode ser calculado através da Equação 3-47 (KAZEMI,1976).

$$
\tau_{m f_{j}}=\sigma \cdot V_{b} \cdot \frac{k_{r_{j}} \rho_{j}}{\mu_{j}} \cdot\left(p_{m_{j}}-p_{f_{j}}\right)
$$

onde j representa a fase óleo, gás ou água. 
Conforme explicado no Capítulo 2, há diversas formas de calcular o fator de forma. Nesse trabalho foi utilizada a formulação de GILMAN e KAZEMI (1983), apresentada na Equação 3-48.

$$
\sigma=4 .\left(\frac{k_{m x}}{l_{x}^{2}}+\frac{k_{m y}}{l_{y}^{2}}+\frac{k_{m z}}{l_{z}^{2}}\right)
$$




\section{Metodologia}

A descrição da metodologia consiste em duas partes. Inicialmente são descritos os experimentos realizados e os parâmetros considerados. Posteriormente, o modelo utilizado é detalhado.

\subsection{Organização do Trabalho}

O presente trabalho abrange uma análise do impacto de diversos parâmetros de simulação de reservatórios. As premissas adotadas para os casos simulados são descritas, juntamente com as características de reservatório a ser utilizado. Também são indicados os parâmetros avaliados, após uma análise de sensibilidade.

\subsubsection{Simulação}

A simulação foi realizada utilizando o software GEM, versão 2019.10, da empresa CMG (Computer Modelling Group). Trata-se de um simulador composicional de escoamento utilizado na modelagem de reservatórios de petróleo que permite avaliar os balanços de massa e energia baseados em cada pseudo-componente utilizado na caracterização dos fluidos. A escolha do simulador também levou em conta que o GEM é amplamente utilizado na indústria do petróleo especialmente para simulações de campos que possuam fluidos compressíveis como óleos voláteis e gases retrógrados. Sua robustez numérica e rigor das formulações tornam o GEM também vastamente utilizado em campos nos quais são aplicados métodos químicos de recuperação, com especial destaque para processos miscíveis.

O uso de simulação composicional não é mandatório para essa pesquisa, haja vista que não serão estudados cenários que alterem significativamente a composição dos hidrocarbonetos. Simulações com formulação black-oil chegariam a resultados similares. Não obstante, como os fluidos do pré-sal são tipicamente caracterizados através de modelos composicionais, esse trabalho foi realizado com esse tipo de simulador, realizando apenas balanços de massa.

Para simplificar a análise dos resultados, foram considerados casos apenas com um poço produtor e, nos casos com injeção, também foi acrescentado um poço injetor de água para fins de criação de cenários operando sob manutenção de pressão. Essa simplificação auxilia a análise, mas difere largamente da prática de campos reais em que são utilizados diversos poços para a otimização da produção, além da aplicação de injeção dos fluidos água e/ou gás 
(com distintas composições) para recuperação suplementar. Os poços possuem geometria vertical e são canhoneados em toda a extensão do modelo na direção $k$, incluindo células de fratura, caso possível (i.e., os poços são multicompletados em todas as células atravessadas, inclusive as de fraturas). Por 12 mil dias, cerca de 33 anos, os poços são abertos com vazões fixadas em $5 \mathrm{mil} \mathrm{m}^{3} / \mathrm{d}$, nas condições de fundo de poço. Como a pressão de fundo dos dois poços não são iguais, há uma pequena diferença entre o volume produzido e o injetado. Não obstante, a pressão média do reservatório se mantém praticamente constante durante todo o período dos experimentos. Nenhum dano à produtividade ou injetividade dos poços foi considerada, sendo estabelecido um fator de película (skin) nulo.

Não foi considerada a presença nem de aquífero, nem de capa de gás. No instante inicial da simulação, a água presente no modelo é apenas a correspondente à saturação irredutível. Portanto, a água eventualmente produzida corresponde essencialmente à água injetada. Da mesma forma, não há gás livre inicialmente no campo. $O$ gás produzido advém da porção solubilizada no óleo produzido ou do declínio da pressão no reservatório abaixo do ponto de bolha do fluido $\left(\mathrm{P}_{\text {sat }}\right)$. Esse segundo caso só ocorre quando não há injeção para manter a pressão do reservatório acima da pressão de saturação.

\subsubsection{Variáveis Estudadas}

Foram escolhidos cinco parâmetros independentes para a análise de sensibilidade realizada:

1. Homogeneidade/heterogeneidade da matriz;

2. Posição dos poços em relação à malha do modelo;

3. Posição do corredor de fraturas em relação aos poços;

4. Largura do corredor de fraturas;

5. Permeabilidade absoluta das células de fratura.

Para todos os casos submetidos à simulação nesse estudo, os demais parâmetros de entrada do simulador são constantes, tanto na parte da caracterização do reservatório, como nos controles numéricos. Assim, as comparações dos resultados podem ser realizadas.

A análise de sensibilidade utiliza valores discretos de forma combinatória. Foram selecionados (i) dois para a homogeneidade/heterogeneidade da matriz; (ii) três posições de poços; (iii) três posições de corredor de fratura; (iv) três larguras para o corredor de fraturas; e (v) oito valores de permeabilidade de fraturas. Portanto, foram submetidos 432 ( $2 \times 3 \times 3 \times$ $3 \times 8$ ) casos ao simulador.

Na próxima seção serão apresentadas as variáveis selecionadas e os respectivos valores adotados. 


\subsubsection{Homogeneidade/Heterogeneidade da Matriz da Rocha}

A distribuição das características permoporosas nas células da matriz do modelo reflete as heterogeneidades características de rochas carbonáticas. Essa heterogeneidade ocasiona um escoamento não uniforme pelo reservatório, que afeta a produção do campo, com reflexo no desempenho numérico das simulações. Inicialmente foram construídos modelos com porosidade e permeabilidade horizontal médias da rocha de 17,3\% e $680 \mathrm{mD}$, respectivamente. Apenas as células da matriz são heterogêneas. As fraturas sempre possuem valores constantes de porosidade e de permeabilidade. A heterogeneidade presente na matriz do modelo pode ser observada na seção transversal (Figura 4.1) que corta o modelo ao meio na direção Leste-Oeste.

(a)

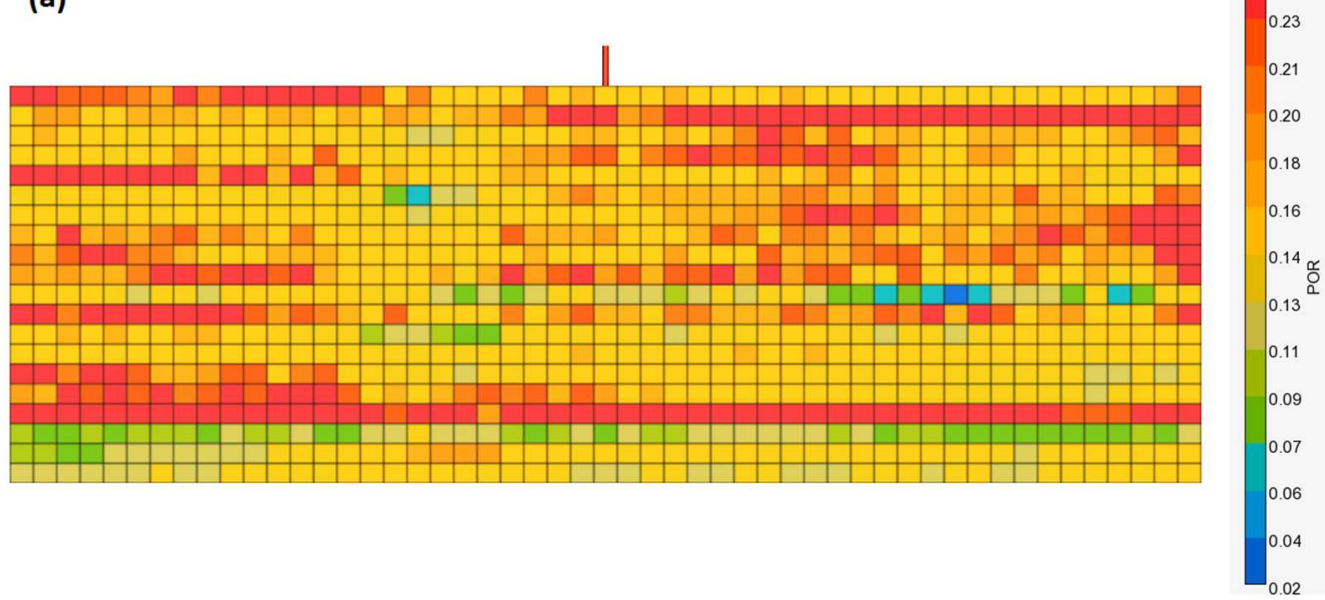

(b)

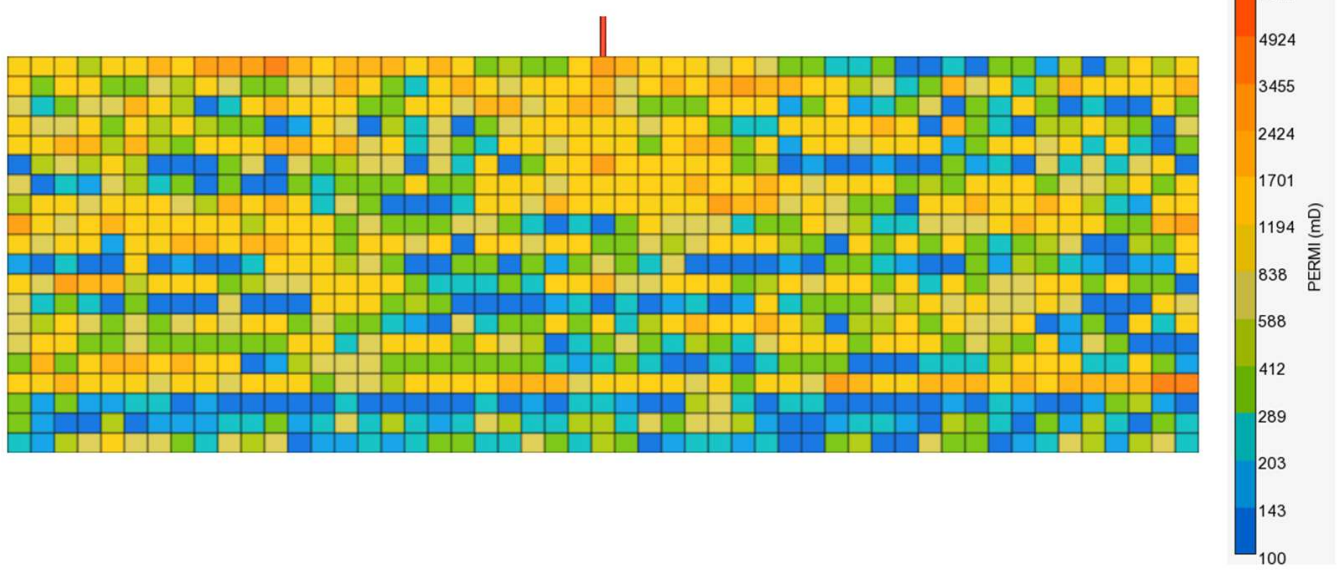

Figura 4.1: (a) Porosidade do modelo e (b) permeabilidade horizontal do modelo.

O grau de heterogeneidade da permeabilidade é representado pelo coeficiente de Dykstra-Parsons $(v)$ (LAKE e JENSEN, 1991). O valor desse parâmetro tende a zero para 
permeabilidades homogêneas e aumenta com o crescimento da heterogeneidade. Seu valor pode ser expresso da seguinte forma:

$$
v=\frac{k_{84}-k_{50}}{k_{50}}
$$

onde $\mathrm{k}$ é a permeabilidade e o subscrito representa o percentil do valor da permeabilidade.

Com o objetivo de analisar a heterogeneidade vertical, as células do modelo foram agrupadas nessa direção e, para cada grupo, foi calculado esse coeficiente. Para fins de comparação, foi realizado um ajuste considerando uma distribuição log-normal e calculado o coeficiente de correlação. Os mapas obtidos são apresentados na Figura 4.2.
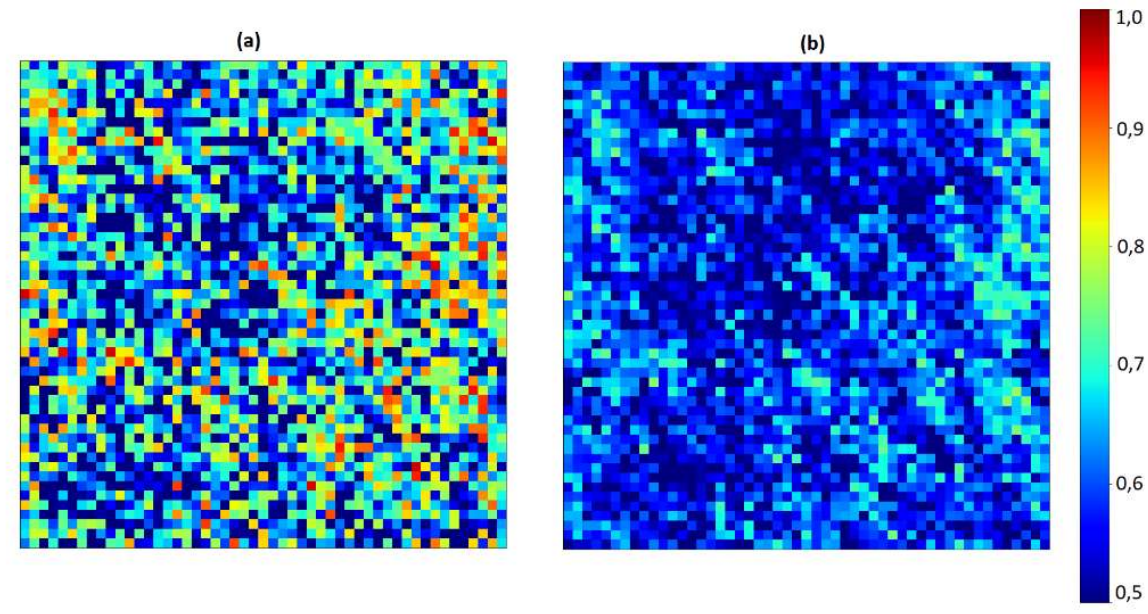

Figura 4.2: Mapas com o coeficiente de Dykstra-Parsons: (a) modelo utilizado e (b) ajuste à curva log-normal.

\subsubsection{Posicionamento dos Poços}

Nesse estudo são propostas três configurações de posicionamento de poços. A primeira, mais simples, utiliza apenas um poço produtor. Essa configuração reflete o comportamento de produção por depleção, quando não há suporte de pressão. As outras duas configurações são compostas de um par de poços produtor-injetor. Eles estão dispostos a $1.700 \mathrm{~m}$ de distância em ambos os casos. Essas duas configurações diferem quanto à orientação da malha com relação ao posicionamento dos poços. Em um caso, o par de poços forma um ângulo de $45^{\circ}$ em relação à grade do modelo enquanto, no outro, eles estão alinhados na mesma direção. O efeito de orientação de malha pode vir a ser relevante em alguns modelos. Em ambos os casos, apenas a injeção de água foi avaliada. A Figura 4.3 apresenta as posições das três malhas. 


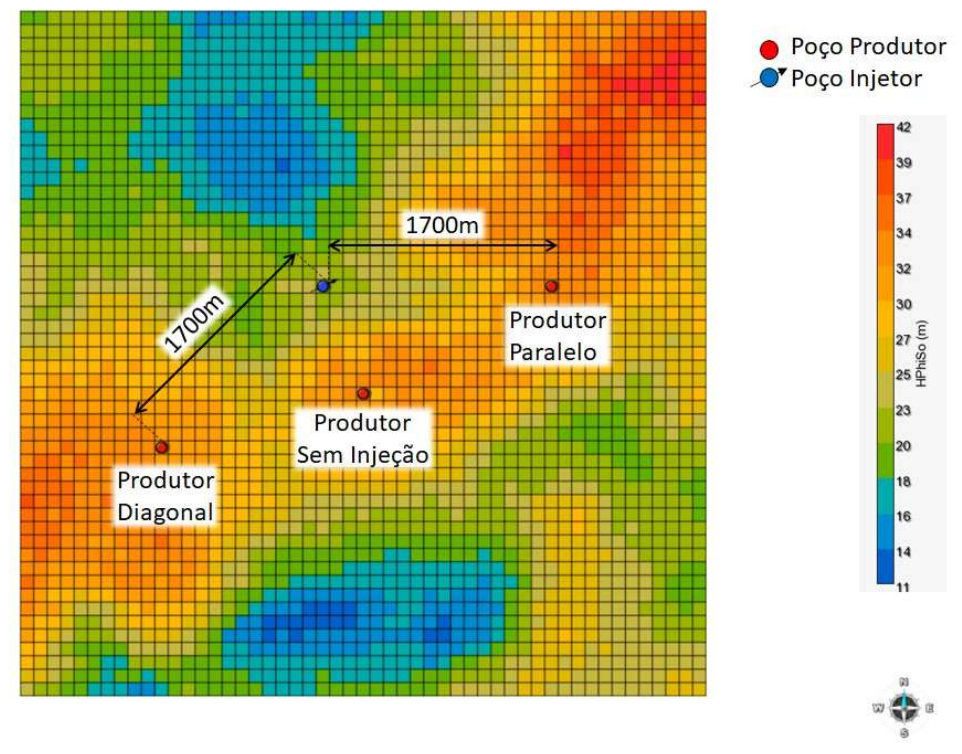

Figura 4.3: Localização dos poços.

Ressalta-se que, para o cenário com apenas um poço produtor, foi adicionada a restrição de pressão de fundo mínima de $40.000 \mathrm{kPa}$. Isso é necessário para evitar operar o modelo muito abaixo da pressão de bolha, resultando em elevada saturação de gás com aumento do esforço computacional. Contudo, a pressão ligeiramente abaixo da pressão de saturação permite que ocorra o aumento da RGO o que indica o atingimento da pressão mínima definida.

Por fim, destaca-se que os poços são todos sempre canhoneados tanto nas células da grade de matriz como nas células da grade de fraturas e em toda a extensão vertical do reservatório.

\subsubsection{Corredor de Fraturas}

As fraturas foram representadas por meio de corredores no modelo. Essa metodologia está baseada no conceito de zona de dano, apresentado no Capítulo 3. Portanto, considerouse uma falha de rejeito desprezível, atravessando o modelo na mesma direção do par produtor-injetor, ou, no caso sem injeção, na direção leste-oeste. Essa falha cria uma zona de dano cujas fraturas são as únicas presentes no modelo.

Há duas variáveis geométricas desses corredores a serem avaliadas na análise de sensibilidade: (i) a largura (L) do corredor; e (ii) a distância (D) entre o corredor e os poços.

Foram adotados três valores para cada um desses atributos. A largura foi considerada de uma, duas ou três células. Para a distância da fratura aos poços, foram definidos os 
seguintes casos: (i) zero, que significa que o corredor passa nas células canhoneadas pelos poços; (ii) um, no qual a primeira célula do corredor de fratura é adjacente aos poços; e (iii) cinco, em que a primeira célula do corredor de fratura dista cinco células dos poços.

A Figura 4.4 exemplifica alguns casos considerados. É interessante observar o caso particular no qual a direção do par produtor-injetor não é paralela à grade e o corredor de fraturas possui a largura de apenas uma célula. Nesse cenário, os blocos fraturados não estão conectados entre si. $O$ efeito dessa falta de continuidade será tema de análise no Capítulo 5.

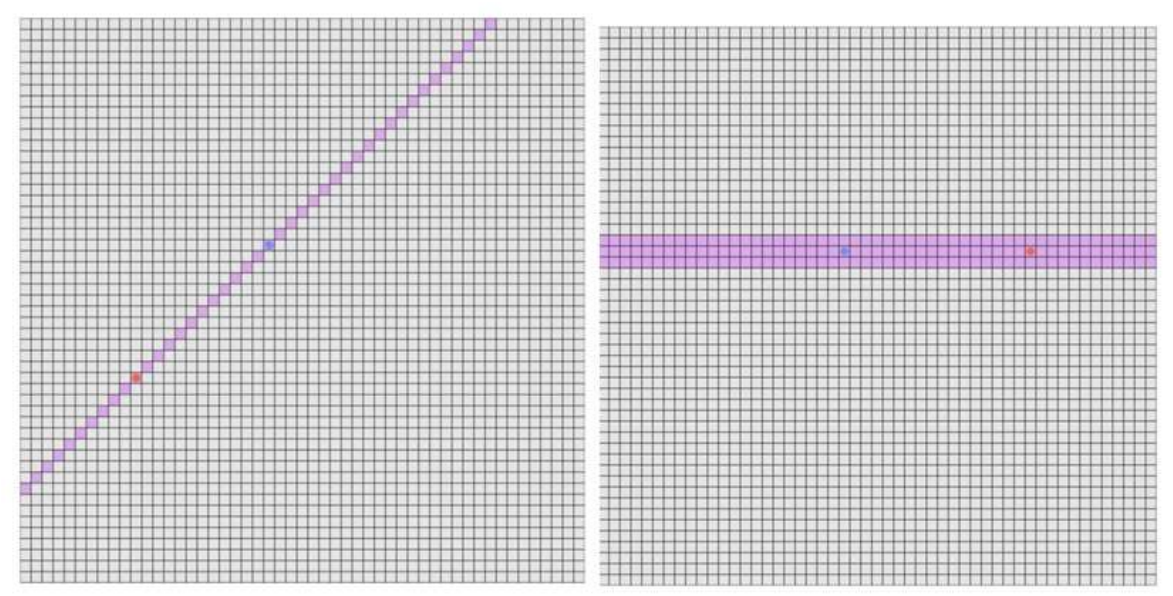

Figura 4.4: Exemplos de corredores de fraturas com diferentes geometrias.

\subsubsection{Permeabilidade Efetiva das Fraturas}

A influência da permeabilidade efetiva das fraturas $\left(K_{\text {frat }}\right)$ nos resultados de produção do campo requer avaliação. Esse parâmetro será variado de forma que a classificação do reservatório varie desde o tipo 3 (qualidade permoporosa da matriz comparável à das fraturas) até o tipo 4 (qualidade permoporosa da matriz superior à das fraturas). Ou seja, com permeabilidades baixas, as fraturas não devem ter impacto relevante na produção. Conforme o valor da variável aumenta, o corredor passa a dominar o escoamento com relação à matriz.

Os resultados de diversos experimentos numéricos (KAZEMI et al., 1976; SONLER et al., 1988; BAKER e KUPPE, 2000; WU et al., 2011) mostram que o aumento da permeabilidade das fraturas gera uma aceleração na frente de água e, consequentemente, uma antecipação na chegada dos fluidos injetados aos poços produtores, além de uma piora na eficiência de varrido. Esse trabalho visa confirmar esse comportamento no modelo utilizado.

Para essa análise, as permeabilidades efetivas das fraturas são constantes e iguais nas três direções. Serão gerados casos em que os valores das permeabilidades variam de $10^{1,5} \mathrm{a}$ $10^{5,0} \mathrm{mD}$. A variação ocorreu em escala logarítmica, com passos de $10^{0,5} \mathrm{mD}$. Consequentemente, oito valores de permeabilidade efetiva de fratura foram analisados. 
Os valores de permeabilidade horizontal da matriz ( $\left.K_{\text {matriz }}\right)$ variam de aproximadamente $1 \mathrm{mD}$ a $4000 \mathrm{mD}$, e a média é de $680 \mathrm{mD}$. Logo, a relação $K_{\text {frat }} / K_{\text {matriz }}$ varia de 20 até cerca de 0,01 .

\subsubsection{Resultados Avaliados}

As análises são feitas em duas etapas. A primeira foca na malha com apenas um poço produtor. A segunda considera os casos com injeção de água. Essa divisão é necessária pois, no primeiro caso, a variável que controla a produção de petróleo é o aumento da razão gásóleo (RGO), enquanto o corte de água se mantém nulo. Em contrapartida, no segundo cenário, a RGO se mantém constante, já que a pressão do reservatório é constante e a evolução do corte de água (wcut) controla a produção de petróleo.

Para cada um desses casos, as variáveis que são analisadas também são divididas em duas categorias: parâmetros de produção e de controle numérico da simulação.

\subsubsection{Previsão de Produção}

Os dados de produção a serem avaliados consistem na produção acumulada de óleo ao longo do tempo e o tempo de chegada da frente de água (breakthrough).

O volume de óleo produzido decorre de duas variáveis calculadas do simulador a cada timestep: vazão de óleo $\left(q_{o}\right)$ e tamanho do timestep. Ao se multiplicar essas duas variáveis, obtém-se o volume de óleo produzido durante aquele timestep. Somando-se os volumes de todos os timesteps, chega-se ao volume de óleo total produzido $\left(N_{p}\right)$, conforme apresentado na Equação 4-2.

$$
N_{p}=\sum_{n=0}^{n_{t}} q_{o} * \Delta t_{n}
$$

onde $n_{t}$ representa o último timestep da simulação.

Para determinar o tempo de chegada da frente de água, foi necessário, primeiramente, arbitrar um valor de referência. O corte de água superior ao valor referenciado é considerado o início do breakthrough. Não é recomendável utilizar o valor intuitivo de zero. Caso isso seja feito, possivelmente haverá casos nos quais um aumento marginal no percentual de água produzido (i.e., água cognata que se tornou móvel pela compressibilidade do meio poroso) mascare o momento correto da chegada da frente de água injetada. Portanto, nesse estudo foi adotado o valor de corte de água superior a $1 \%$.

De forma semelhante, o tempo até o atingimento da pressão de bolha do fluido foi medido utilizando-se também um valor de referência. No entanto, essa medição foi feita indiretamente, por meio do aumento da razão gás óleo (RGO) do campo. Foi escolhido um 
valor referente ao aumento aproximado de 1\% da RGO. Como o valor original é de 206,8 $\mathrm{m}^{3}$ $s t d / m^{3} s t d$, o limite de RGO, acima do qual foi considerado que se atingiu a pressão de bolha foi $208,8 \mathrm{~m}^{3} \mathrm{std} / \mathrm{m}^{3} \mathrm{std}$.

Com a finalidade de tornar o estudo mais genérico, são utilizadas três variáveis adimensionais: (1) Fator de Recuperação $(F R)$; (2) Tempo Adimensional até a Chegada da Frente de Água $\left(t_{D w}\right)$; (3) Tempo Adimensional até a Pressão do Reservatório Chegar ao Ponto de Bolha $\left(t_{D p b}\right)$.

$$
\begin{gathered}
F R=\frac{N_{p}}{V O I P} ; \\
t_{D w}=\frac{q_{w i}(R C)}{V_{p}} \cdot t_{b t} ; \\
t_{D p b}=\frac{q_{o i}(R C)}{V_{p}} \cdot t_{p b}
\end{gathered}
$$

onde $N_{p}$ é a produção de óleo acumulada, VOIP é o volume de óleo inicial no modelo em condições de superfície, $q_{w i}(R C)$ é a vazão de água injetada em condições de reservatório, $q_{o i}(R C)$ é a vazão de óleo produzido em condições de reservatório, $t_{b t}$ é o tempo decorrido até o breakthrough de água, $t_{p b}$ é o tempo decorrido até atingir a pressão de bolha e $V_{p}$ é o volume poroso do reservatório. Ressalta-se que, para esse estudo, as vazões de produção de óleo e de injeção de água em condições de reservatório são constantes e iguais a $5 \mathrm{mil} \mathrm{m} / \mathrm{d}$ em condições de reservatório.

O FR (fator de recuperação) representa a fração de óleo recuperada do reservatório até a data final da simulação. O tempo adimensional de água é a razão entre vazão de injeção e volume poroso do reservatório, multiplicada pelo tempo decorrido até o breakthrough e equivale ao volume de água injetada em relação ao volume poroso da rocha até a data da chegada de água no poço produtor. Por sua vez, o tempo adimensional de gás é a relação entre vazão de produção e o volume poroso do reservatório, multiplicada pelo tempo até se chegar à pressão de saturação do fluido do reservatório e representa a fração de óleo extraído do campo até o atingimento da pressão de saturação do fluido.

Para esse modelo, foram utilizados os seguintes valores:

- $V O I P=302,166 \times 106 \mathrm{~m}^{3}$;

- $V_{p}=453,892 \times 106 \mathrm{~m}^{3}$;

- $q_{w i}(R C)=q_{o i}(R C)=5000 m^{3} / \mathrm{d}$. 
Portanto, as equações, para esse trabalho, são:

$$
\begin{gathered}
F R=\frac{N_{p}}{302,166} * 10^{-6} \\
t_{D w}=\frac{5000 * t_{b t}}{453,892} * 10^{-6} \\
t_{D p b}=\frac{5000 * t_{p b}}{453,892} * 10^{-6}
\end{gathered}
$$

\subsubsection{Resultados Numéricos}

As vazões de fluidos produzidos e injetados, juntamente com as taxas de produção (wcut e RGO) são importantes informações para a análise do desempenho dinâmico dos reservatórios. Todavia, a avaliação numérica nos permite averiguar se os resultados são confiáveis e, também, se é possível otimizar o tempo necessário para a simulação dos casos considerados. Portanto, esse aspecto deve ser avaliado de forma criteriosa com os demais resultados. O controle de qualidade serviu de base para a definição dos controles numéricos utilizados nas simulações desse trabalho.

Não existe uma parametrização numérica única que otimize individualmente todos os modelos que sejam submetidos ao simulador. Cada caso apresenta diferentes complexidades a serem solucionadas e descobrir cada especificação que dê bons resultados é um trabalho oneroso. Não obstante, buscou-se uma configuração numérica que apresente resultados aceitáveis de forma a viabilizar a análise dos resultados.

Nesse trabalho, foi usada uma parametrização única para facilitar a comparação na análise de sensibilidade nos resultados numéricos. Contudo, seria possível selecionar apenas as simulações com respostas não-satisfatórias e ajustá-las individualmente, de forma que todos os casos fossem confiáveis.

A definição de controles numéricos padrão (default) em um simulador que lida com uma variada gama de não-linearidades, exige um foco em determinadas classes de problemas mais usuais. Mesmo assim, optou-se por testar as simulações desse trabalho de pesquisa com o controle numérico padrão do simulador. Esse primeiro grupo de resultados deixou claro que parte dos casos sem injeção requer tratamento numérico melhorado. Entre as simulações com injeção de água para manutenção de pressão, 14\% não chegaram até o final pois, devido à parametrização numérica inadequada para o caso, não foi possível convergir para a solução. Para os casos com produção por depleção, que apresentam maiores complexidades devido 
ao aparecimento da fase gás, $61 \%$ das simulações não chegaram ao final. A Figura 4.5 apresenta o histograma do erro de balanço de massa acumulado dos casos submetidos
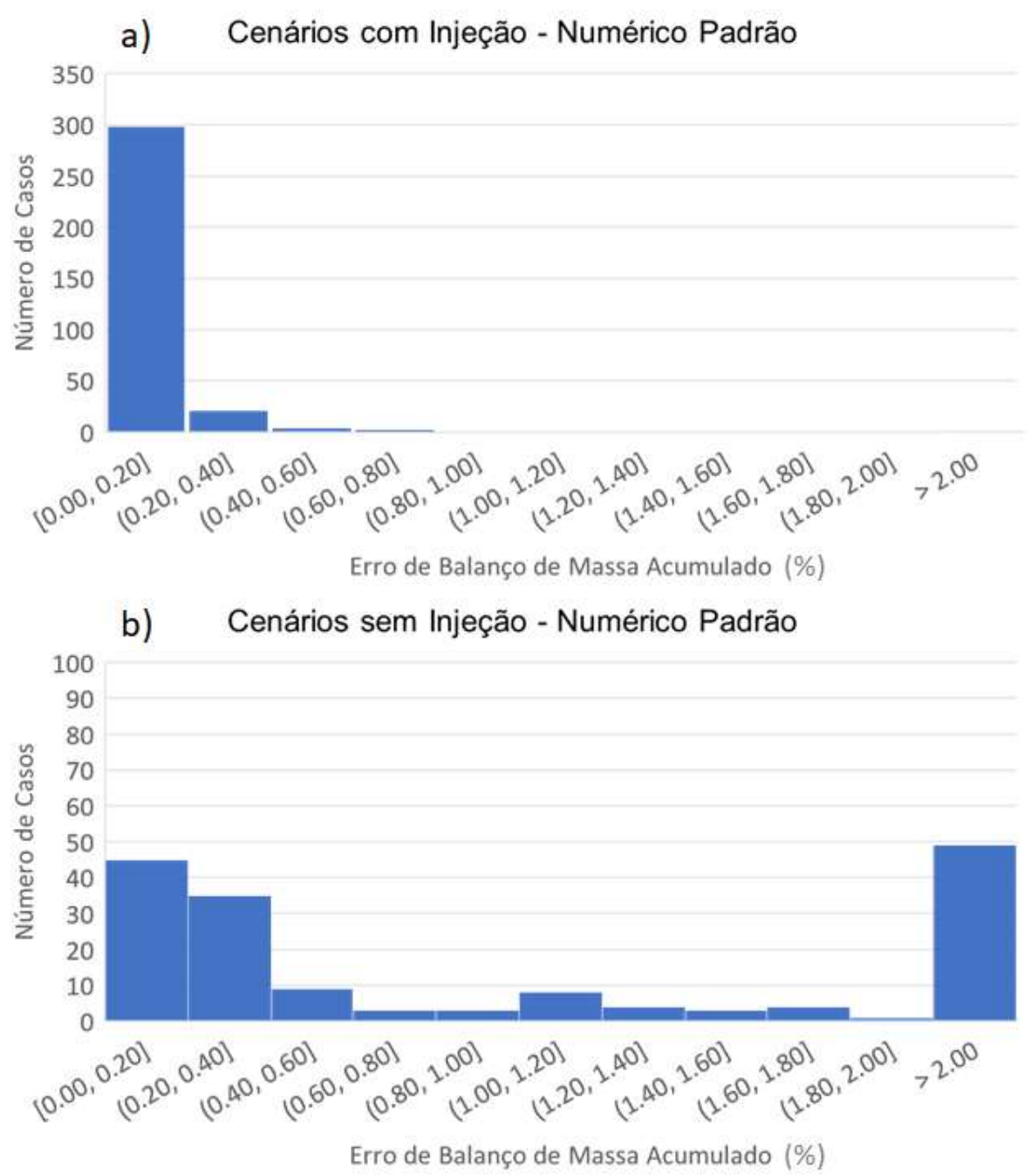

Figura 4.5: Histogramas do erro de balanço de massa acumulado dos cenários com controle numérico default a) com injeção e b) sem injeção.

O erro de balanço de materiais acumulado nas simulações permite avaliar o quanto de massa não foi preservada no final de todo o tempo de simulação coberto pelo somatório dos passos de tempo. As dificuldades numéricas para os casos sem injeção de água decorrem da depleção do reservatório abaixo da pressão de bolha. Nesse contexto, ocorre o aparecimento da fase gasosa que impõe dificuldades de convergência para o tipo de fluido utilizado nos modelos. Nos casos com injeção de água, ocorre a manutenção da pressão do reservatório acima da pressão de saturação que permite o escoamento ocorrer sem a presença de uma fase gasosa. Na medida que as dificuldades numéricas específicas do problema investigado ocorrem, aumenta o número de vezes que o solver linear não consegue alcançar a convergência. Esse resultado tem impacto no controle do método adaptativo implícito, que 
aloca um maior número de células para solução totalmente implícita, por ser mais estável numericamente. Também o número elevado de falhas de convergência do solver linear faz com que a simulação avance acumulando a cada passo de tempo um erro de balanço de massa mais elevado que resulta num valor de erro final mais elevado para o caso de aparecimento da fase gasosa.

Foi realizada uma análise de sensibilidade de diversos parâmetros numéricos do simulador. Entre eles estão os seguintes: os critérios de convergência do solver linear e nãolinear, o critério de alocação das equações mais não-lineares para tratamento totalmente implícito do método adaptativo implícito e a otimização através do ADTSC. Ao final, o conjunto de controles numéricos adotados para as simulações está apresentado na Tabela 4.1 e o respectivo histograma de erro de balanço de materiais está na Figura 4.6.

Tabela 4.1: Parâmetros Numéricos Finais

\begin{tabular}{llll}
\hline & Parâmetro & Palavra-chave & \multicolumn{1}{l}{ Valor } \\
\cline { 2 - 4 } & Tolerância para convergência do solver linear & PRECC & $10^{-5}$ \\
\cline { 2 - 4 } & Tolerância do AIM & AIM STAB AND-THRESH & $10^{-2}$ \\
\cline { 2 - 4 } & Tolerância para convergência do solver não linear & CONVERGE MAXRES & $10^{-4}$ \\
\cline { 2 - 4 } & Parâmetro de auxílio de convergência do solver não-linear & UNDERRELAX & \multirow{2}{*}{0,2} \\
\cline { 2 - 4 } & Adaptative Time Step Control & ADTSC & OFF \\
\cline { 2 - 4 } & & &
\end{tabular}




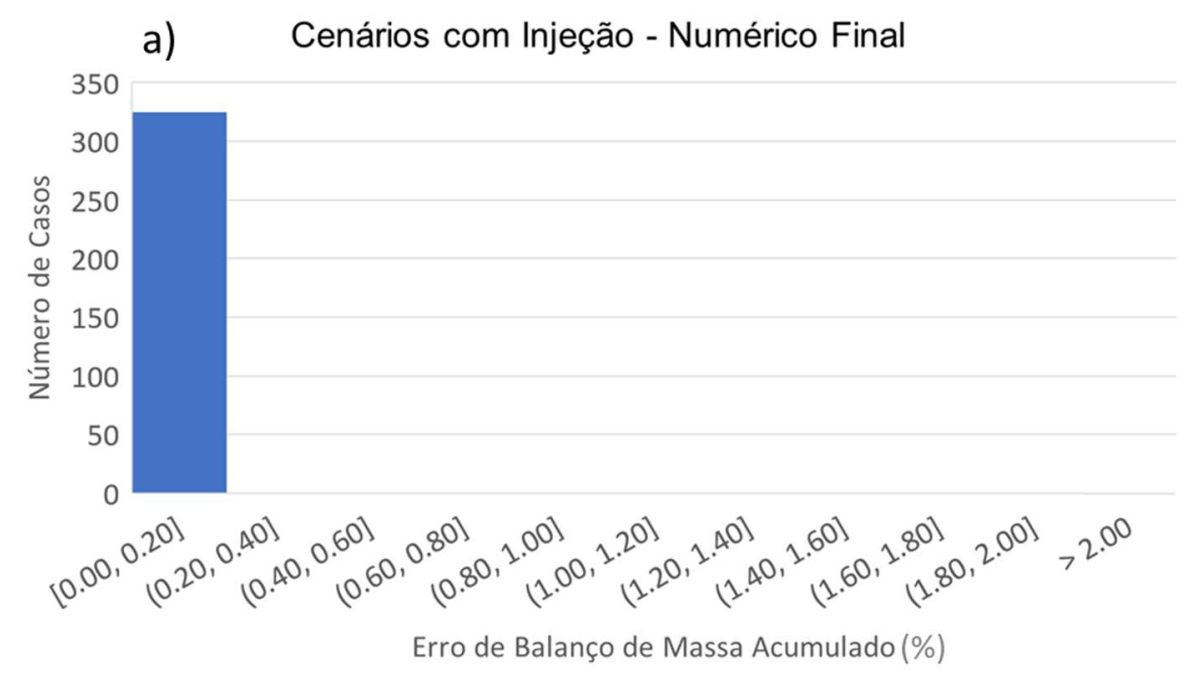

b) Cenários sem Injeção - Numérico Final

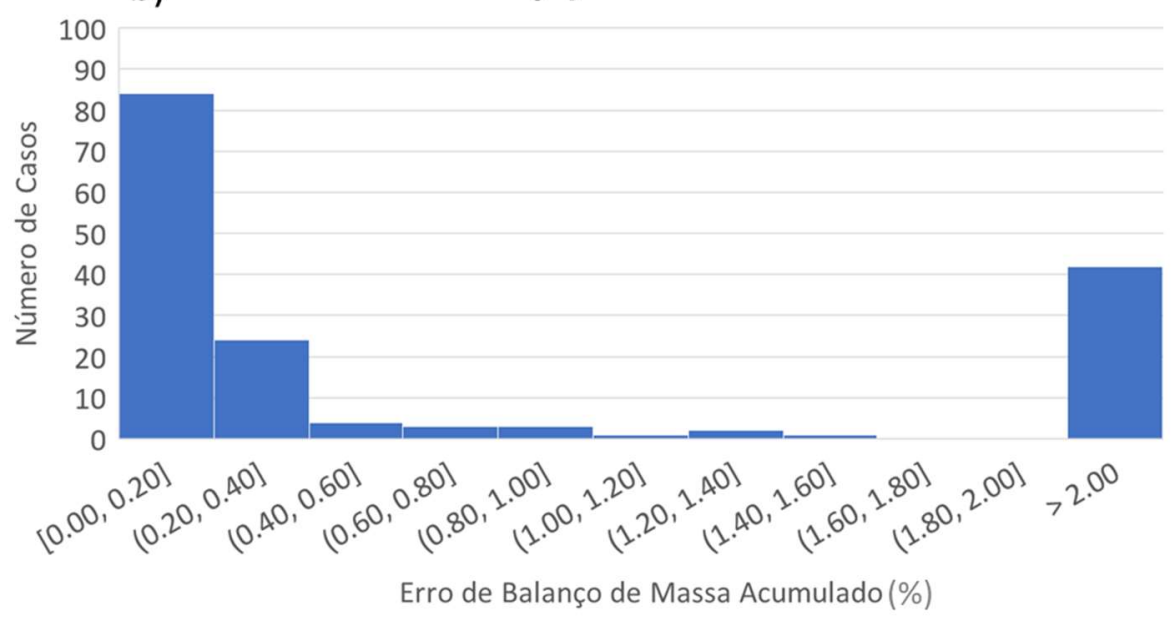

Figura 4.6: Histogramas do erro de balanço de massa acumulado dos cenários com controle numérico final a) com injeção e b) sem injeção

Com essa nova configuração dos controles numéricos, o número de casos que não chegaram ao final da simulação foi drasticamente reduzido. Nos cenários com injeção de água foi de $14 \%$ para $0 \%$ e nos sem injeção foi de $61 \%$ para $10 \%$. Além dessa melhora, também houve diminuição no erro de balanço de massa. Nota-se que os casos com injeção não possuem mais nenhuma simulação com erro superior a $0,2 \%$. As simulações por depleção, conforme explicitado anteriormente, são de solução mais complexas e, apesar de apresentarem uma redução do EBM, particularmente dos casos acima de $2 \%$, ainda não apresentam bons resultados. Nada obstante, seria necessária uma análise mais aprofundada sobre as simulações com problemas para se buscar a parametrização numérica correta de cada caso específico. Essa necessidade decorre da imposição de não-linearidades elevadas que exigem ajustes nos controles numéricos os quais permitam alcançar a convergência sem perda da precisão dos resultados. Como esse trabalho utilizará os mesmos parâmetros numéricos em todos os casos, a configuração adotada foi considerada satisfatória. 
Serão analisados oito parâmetros relacionados com o desempenho numérico, conforme indicado a seguir. O primeiro é o (1) erro de balanço de materiais (EBM) total ao final da simulação. O crescimento dessa variável indica uma menor confiabilidade nos resultados de previsão do comportamento do reservatório. Também será avaliada a (2) implicitude média. Através dela será possível observar a forma como o simulador altera a metodologia de cálculo em cenários com maior complexidade.

Há casos em que ocorrem grandes alterações nas variáveis analisadas pelo simulador, o que gera falhas no solver linear e a necessidade de cortes no tamanho do timestep. Portanto, outros dois fatores analisados são o (3) número de falhas do solver e o (4) número de cortes de timesteps. Naturalmente, simulações mais complexas exigirão timesteps de dimensão reduzidas. Como o período simulado é constante, serão necessários mais timesteps, mais iterações do solver e mais ciclos newtonianos para se chegar ao final. Consequentemente, também serão avaliados o (5) número de timesteps, o (6) número de ciclos newtonianos e o (7) número de iterações do solver. Por fim, sabe-se que é possível obter resultados extremamente confiáveis, ajustando alguns parâmetros numéricos. Todavia, muitas vezes o profissional de simulação se vê obrigado a abrir mão dessa confiabilidade para que o tempo da rodada não inviabilize a utilização do modelo. Portanto, foi incluída como parâmetro a ser analisado o (8) tempo de simulação.

\subsection{Modelo de Reservatório}

O modelo de reservatório adotado para as análises dessa pesquisa é representativo de alguns reservatórios carbonáticos do pré-sal brasileiro. Esses campos possuem dimensões quilométricas, resultando em malhas de simulação com milhões de células ativas e, por conseguinte, podem demandar horas para serem simulados. Portanto, foi necessário utilizar um modelo que tivesse dimensões significativamente menores, mas cujas características fossem representativas das rochas carbonáticas de campos do pré-sal. Partindo de um modelo proxy desses campos, foi construído o modelo a ser utilizado nos exercícios numéricos desse trabalho de pesquisa.

\subsubsection{Condições Iniciais do Modelo}

Estimou-se uma profundidade de $5380 \mathrm{~m}$ para a localização do topo do modelo estudado. Dessa forma, foi calculada uma pressão inicial de $52.760 \mathrm{kPa}$ a essa profundidade, utilizando um gradiente de pressão igual ao da água $(9,8 \mathrm{kPa} / \mathrm{m})$. 0 valor de $5 \times 10^{-7}(1 / \mathrm{kPa})$ foi aplicado para a compressibilidade da rocha, a uma pressão de $50.000 \mathrm{kPa}$. 0 modelo não possui capa de gás, nem aquífero presentes. O reservatório encontra-se inicialmente em equilíbrio, pois os contatos entre fluidos estão fora da área de interesse. Não ocorre gradação 
composicional, sendo a composição do óleo subsaturado constante em todo o reservatório. Por simplicidade, o modelo considerado para os exercícios numéricos dessa pesquisa possui fronteiras fechadas. A temperatura inicial do reservatório é de $80{ }^{\circ} \mathrm{C}$ e a água injetada possui a mesma temperatura, permitindo uma modelagem isotérmica.

\subsubsection{Estrutural}

O arcabouço estrutural e estratigráfico do reservatório está capturado no modelo geocelular apresentado na Figura 4.7.

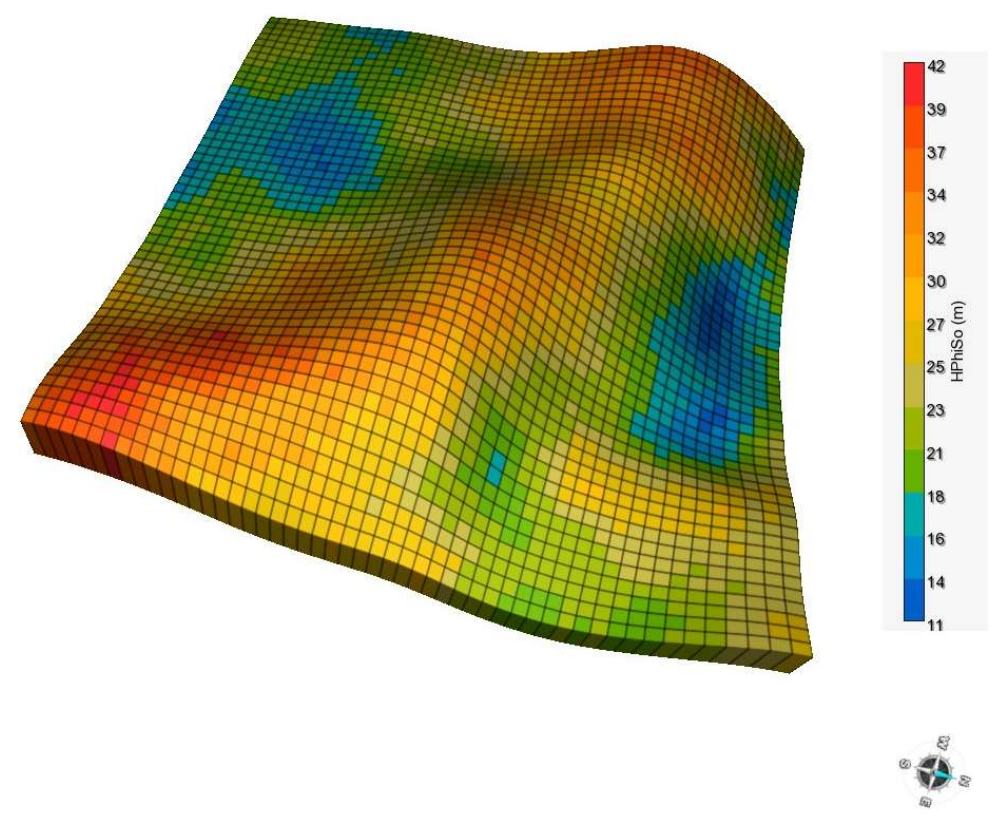

Figura 4.7: Modelo proxy original $-H \times \varphi \times S_{o}(m)$.

Todavia, a variação estrutural do reservatório acrescenta características que não estão sendo analisados nesse trabalho. Caso esse modelo original fosse adotado, seria necessário avaliar a posição relativa dos poços, além de espessura de células que fogem do foco dessa dissertação. Algumas análises poderiam ser influenciadas por esses fatores e, possivelmente, gerar resultados inconclusivos. Para evitar a influência do efeito da topografia do modelo, adotou-se uma malha regular de $51 \times 51 \times 20$ células. Cada célula da malha possui dimensões de $100 m \times 100 m \times 9 m$, totalizando um meio poroso total com dimensões de $5100 m \times 5100$ $m \times 180 \mathrm{~m}$. A Figura 4.8 mostra a geometria final do modelo tridimensional.

A alteração da espessura do bloco, com a manutenção dos valores de porosidade e permeabilidade, modifica a capacidade ao fluxo e seu volume poroso. Para compatibilizar os modelos original e final, aplicou-se um fator multiplicador na porosidade e na permeabilidade, 
igual à relação da espessura da célula no modelo original e a espessura da célula no modelo regular. Os multiplicadores refletem a relação net-to-gross, como mostrados no mapa da Figura 4.9.

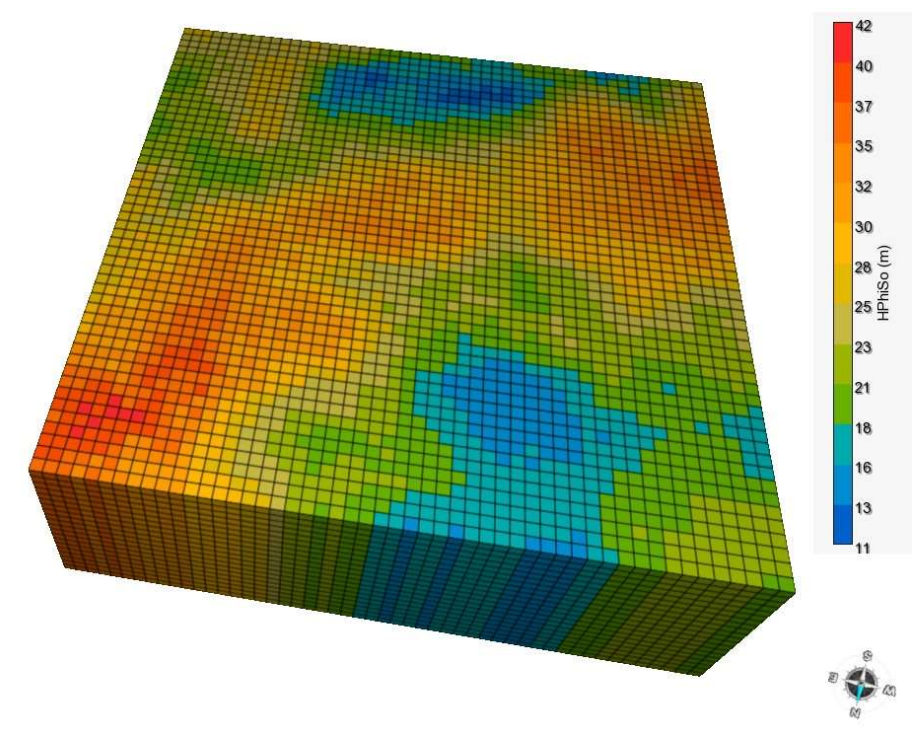

U్ర

Figura 4.8: Modelo final $-H \times \varphi \times S_{o}(m)$ após multiplicação por NTG.

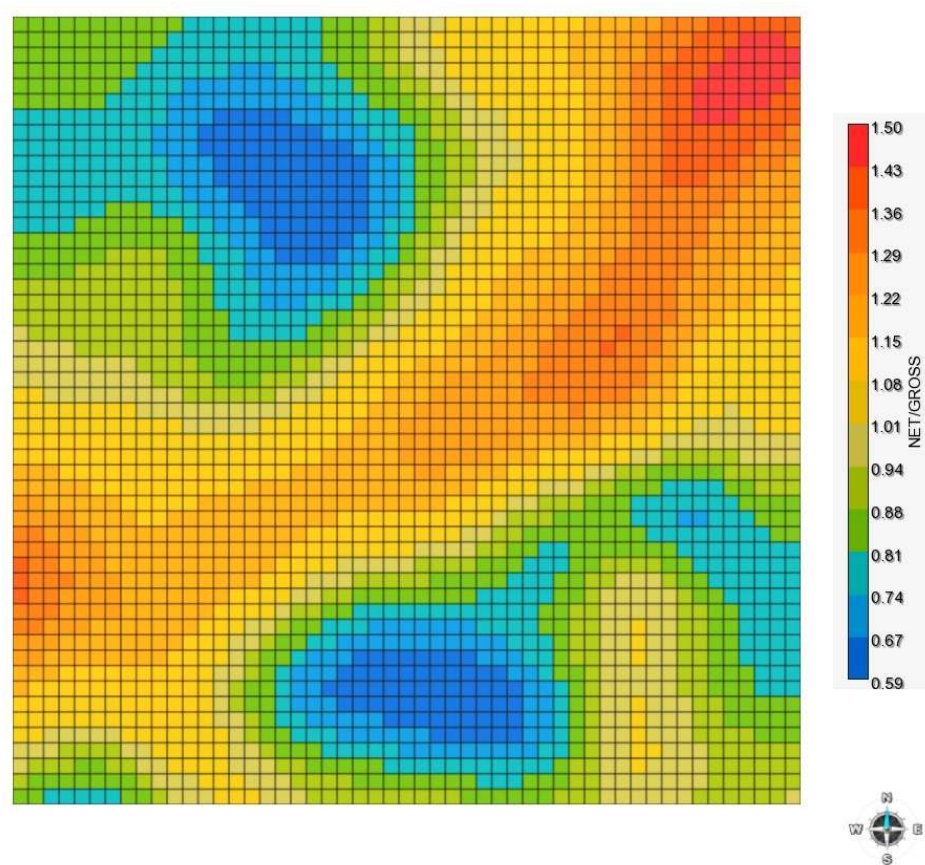

Figura 4.9: Modelo final - NTG 


\subsubsection{Fluido}

A caracterização da mistura de hidrocarbonetos no modelo de escoamento utiliza a equação de Peng-Robinson ajustada a fluidos representativos de campos do pré-sal brasileiro. A composição do fluido utilizada foi agrupada em oito pseudo-componentes preservando a representatividade do fluido original. Sem gradação composicional, o estado dessa mistura fica determinado pela pressão de cada célula do modelo e a temperatura constante estabelecida para o meio poroso. As características mais relevantes dos fluidos são descritas na Tabela 4.2. Os pseudo-componentes da mistura com os respectivos percentuais molares constam na Tabela 4.3. Por fim, a Figura 4.10 apresenta o envelope de fases indicando a pressão inicial $\left(P_{0}\right)$ subsaturada acima da pressão de saturação $\left(P_{\text {sat }}\right)$.

Tabela 4.2: Características dos fluidos utilizados.

\begin{tabular}{lll}
\hline Característica & Unidade & Valor \\
\hline Viscosidade do Óleo na $\mathrm{P}_{0}$ & $c P$ & 1,039 \\
\hline $\mathrm{R}_{\mathrm{s}}$ & $m^{3} s t d / \mathrm{m}^{3} s t d$ & 207 \\
\hline $\mathrm{B}_{\mathrm{oi}}$ & $m^{3} R C / \mathrm{m}^{3} s t d$ & 1,503 \\
\hline Densidade do Óleo na $\mathrm{P}_{0}$ & - & 0,734 \\
\hline Teor original de CO & $\%$ & 10 \\
\hline Pressão de Bolha & $k P a$ & 40011 \\
\hline Viscosidade da Água na $\mathrm{P}_{0}$ & $c P$ & 0,500 \\
\hline Bwi & - & 0,998 \\
\hline
\end{tabular}

Tabela 4.3: Percentuais molares dos pseudo-componentes.

\begin{tabular}{ccc}
\hline Pseudo-Componente & Percentual Molar (\%) & Peso Molecular(g/gmol) \\
\hline PC1 & 10 & 44 \\
\hline PC2 & 50 & 16.5 \\
\hline PC3 & 12 & 35.9 \\
\hline PC4 & 6 & 61.7 \\
\hline PC5 & 7 & 153 \\
\hline PC6 & 6 & 233 \\
\hline PC7 & 6 & 362 \\
\hline PC8 & 3 & 818 \\
\hline
\end{tabular}




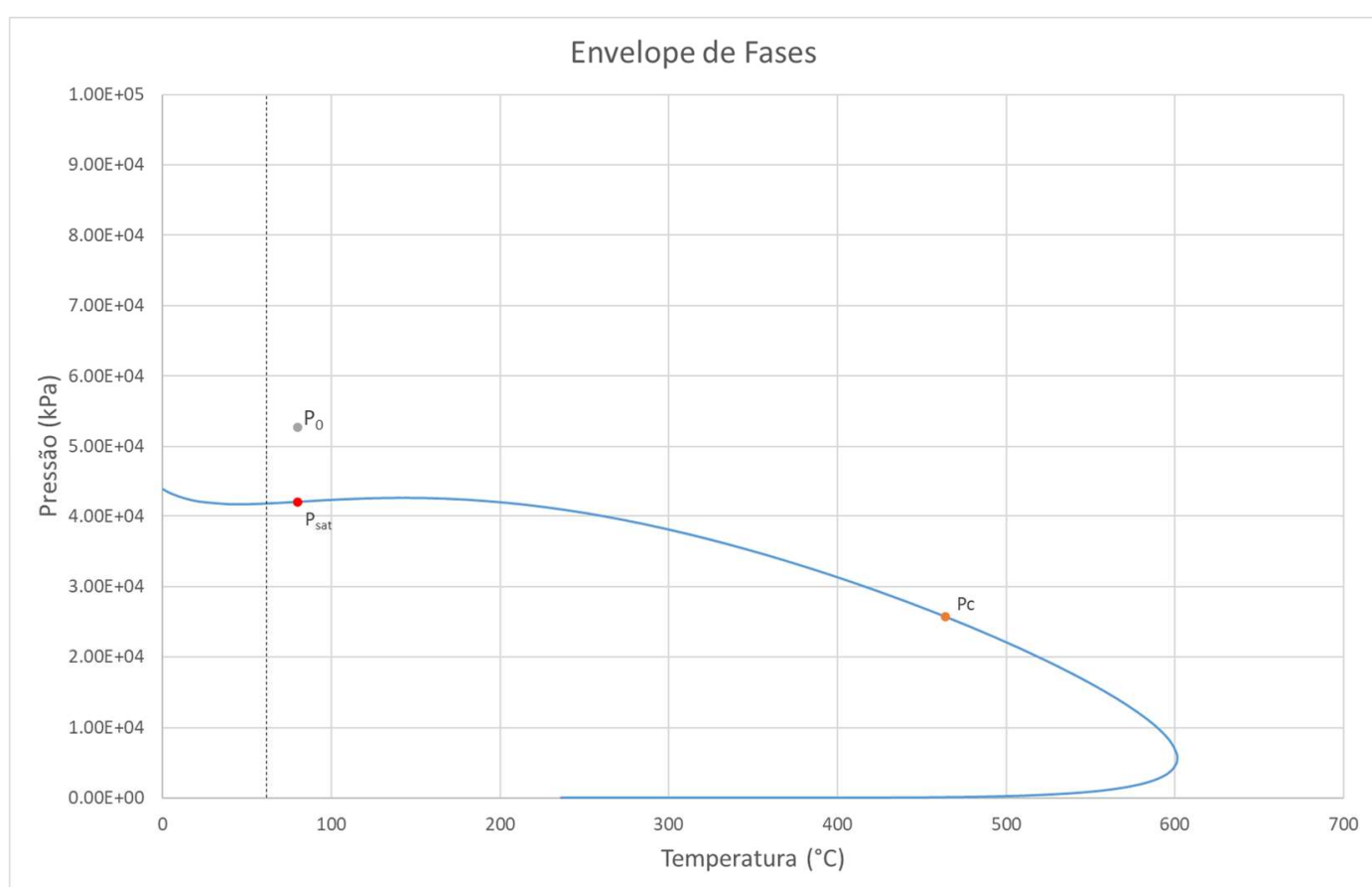

Figura 4.10: Envelope de Fases do Fluido Utilizado com Pressão Original do Reservatório (P0); Pressão de Saturação do Reservatório (Psat) e Ponto Crítico do Fluido (Pc).

\subsubsection{Distribuição das Propriedades}

As propriedades das células foram distribuídas segundo a estrutura deposicional original do reservatório, de forma que as regiões mais altas possuem melhor qualidade permoporosa. Não foi determinada anisotropia areal, de forma que a permeabilidade absoluta horizontal de cada célula é especificada e a permeabilidade vertical é estimada como sendo $1 / 10$ da permeabilidade horizontal. Na Tabela 4.4 são apresentadas as características das distribuições da porosidade e da permeabilidade horizontal finais e na Figura 4.11, os seus histogramas.

Tabela 4.4: Características das distribuições de $\varphi$ e de $K_{\text {matriz }}$ do modelo.

\begin{tabular}{ccc}
\hline Característica & $\boldsymbol{\varphi ( \% )}$ & $\boldsymbol{K}_{\text {matriz }}(\boldsymbol{m D})$ \\
\hline Média & 17,3 & 683,5 \\
\hline Máximo & 25,0 & 3995,0 \\
\hline Mínimo & 2,0 & 1,0 \\
\hline Desvio Padrão & 4,4 & 604,3 \\
\hline Mediana & 17,0 & 492,5 \\
\hline
\end{tabular}



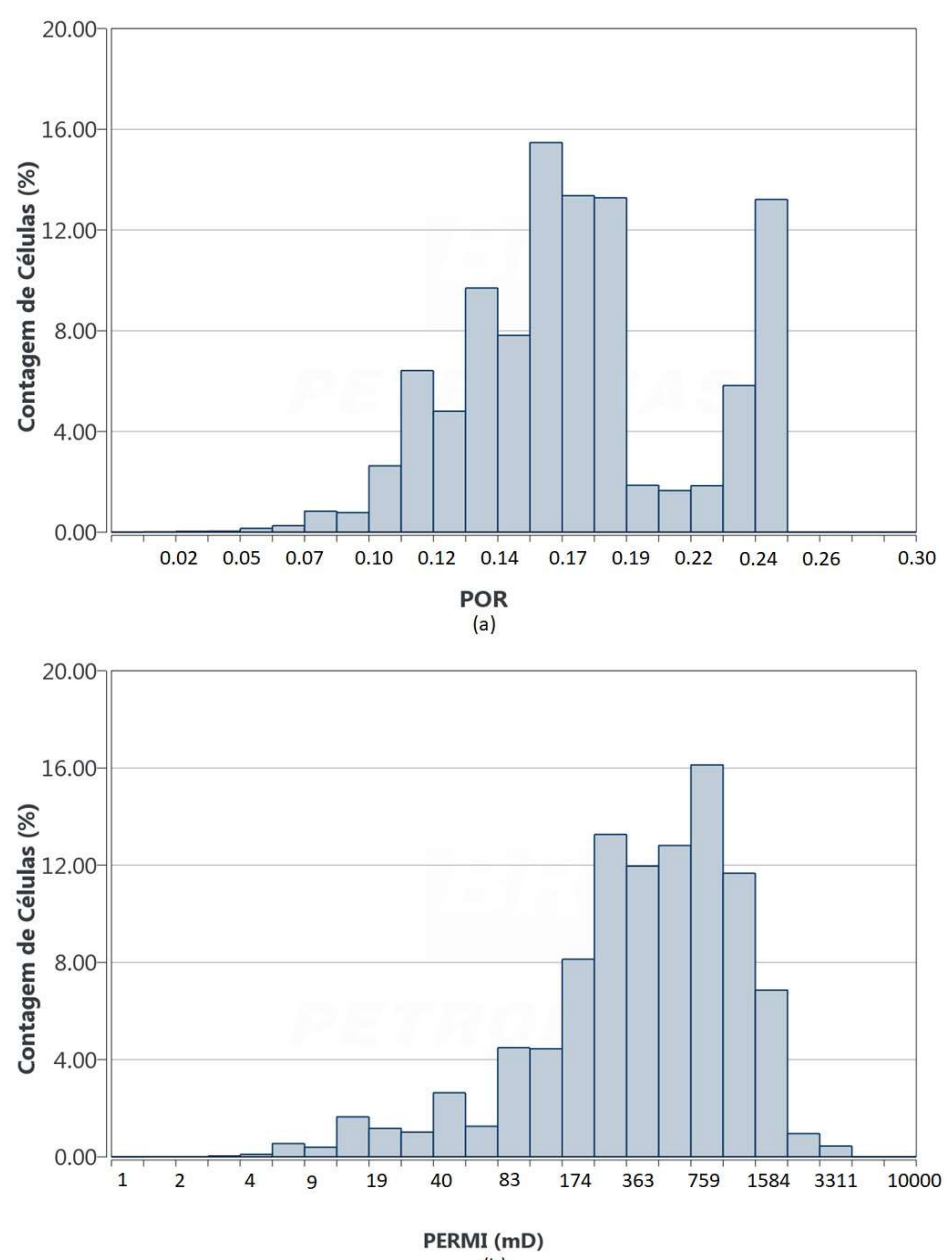

(b)

Figura 4.11: Histogramas de propriedades da rocha: (a) porosidade efetiva e (b) permeabilidade absoluta horizontal.

\subsubsection{Fraturas}

Para se modelar as fraturas, foram utilizados corredores retos, atravessando todo o reservatório. Assim, foi possível emular casos práticos com corredores acompanhando falhas geológicas. Deste modo, as células com fraturas são determinadas com base na especificação da direção, distância dos poços e largura do corredor. Para o cálculo do fator de forma, foi escolhida a formulação de GILMAN e KAZEMI (1988), conforme especificada na Equação 348. Esse cálculo está disponível na maioria dos simuladores comerciais.

$O$ volume de fluido inicial do modelo é constante em todos os casos simulados. Desse modo, a energia interna associada ao volume de óleo inicial que satura o meio poroso é mantida constante de modo a permitir uma comparação adequada dos modelos simulados. Para isso, as células do corredor de fraturas tiveram a porosidade da matriz reduzida para compensar os volumes atribuídos às fraturas. 
Para a porosidade das fraturas, foi especificado o valor de $1 \%$. Porosidades muito menores, apesar de representarem mais corretamente o volume presente nessas estruturas, podem inviabilizar a simulação. As grandes variações de saturação de fluidos geradas nessas células podem levar a tempos de simulação impeditivos ou a falhas, uma vez que a velocidade do escoamento pode atingir valores muito altos, causando variações demasiado abruptas nas variáveis primárias. Esse aumento de volume de óleo nas fraturas é compensado por um alto Sor, buscando limitar o óleo móvel, conforme será mostrado.

As permeabilidades das fraturas com variação de 32 a $100000 \mathrm{mD}$ permitem avaliar o contraste com a permeabilidade absoluta do meio poroso, cuja média é de cerca de $680 \mathrm{mD}$. Assim, pode-se investigar o impacto da preponderância do escoamento pelo meio poroso versus sistema de fraturas.

O espaçamento entre as fraturas utilizado na modelagem de dupla porosidade e dupla permeabilidade foi de $5 \mathrm{~m}$. Como as células possuem dimensão areal de $100 \mathrm{~m} \times 100 \mathrm{~m}$, foi considerada a presença de 20 fraturas nas direções i e j. Na direção k, considerou-se o mesmo espaçamento e a mesma permeabilidade das direções horizontais.

\subsubsection{Permeabilidade Relativa}

Os carbonatos do pré-sal brasileiro possuem uma vasta gama de possíveis curvas de permeabilidade relativa. Contudo, nesse trabalho foi utilizada somente um conjunto de curvas de permeabilidade relativa água-óleo e gás-líquido para o meio poroso e outro para o sistema de fraturas. Essas curvas são consideradas representativas para os reservatórios estudados.

As curvas de permeabilidade relativa para o meio poroso foram geradas pela correlação de COREY (1954). Na Tabela 4.5 encontram-se os parâmetros para a geração das curvas e a Figura 4.12 mostra os resultados.

Tabela 4.5: Parâmetros das curvas de permeabilidade relativa da matriz.

\begin{tabular}{lll}
\hline Parâmetro & Matriz & Fratura \\
\hline$n_{\circ}$ & 2,0 & 1,0 \\
\hline$n_{w}$ & 4,0 & 1,0 \\
\hline$S_{\text {wi }}$ & 0,2 & 0,2 \\
\hline$S_{\text {or }}$ & 0,3 & 0,5 \\
\hline$K_{\text {ro } @ S_{w i}}$ & 1,0 & 1,0 \\
\hline$K_{\text {rw }} @ 1-S_{o r}$ & 0,5 & 1,0 \\
\hline
\end{tabular}




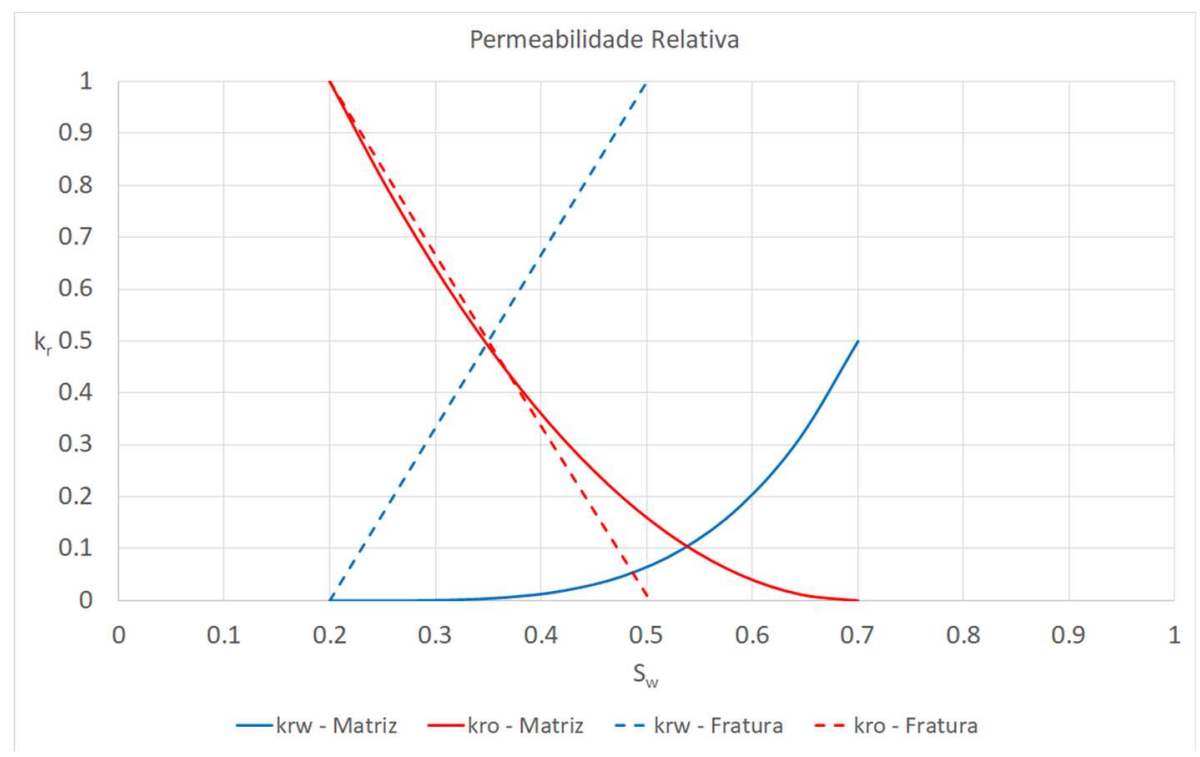

Figura 4.12: Curvas de permeabilidade relativa da matriz e da fratura.

Para o sistema de fraturas, foram adotadas curvas com o formato de $X$, tipicamente utilizadas em simulações comerciais (ROSSEN e KUMAR, 1994) e podem ser observadas no mesmo gráfico da Figura 4.12. O óleo residual das fraturas, normalmente é estimado como nulo. Todavia, para compensar a maior porosidade de fraturas, necessária para garantir a estabilidade das simulações, aumenta-se o $S_{\text {or, }}$ uma vez que as fraturas causam uma menor recuperação de óleo da matriz adjacente (LIAN et al., 2012). 


\section{Resultados e Análises}

Nesse trabalho de pesquisa foi necessário realizar 432 simulações decorrentes da combinação das variáveis apresentadas no Capítulo 4 e cujo resumo encontra-se na Tabela 5.1.

Tabela 5.1: Resumo das características dos modelos de reservatório a serem combinadas

\begin{tabular}{lllll}
\hline Malha & $\boldsymbol{\varphi}$ e $\boldsymbol{k}$ da Matriz & Distância (D) & Largura (L) & $K_{\text {frat }}(\boldsymbol{m D})$ \\
\hline 1 Produtor & Homogêneo & 0 células & 1 célula & 32 \\
\hline $\begin{array}{l}\text { Prod-Inj } \\
\text { Paralelo }\end{array}$ & Heterogêneo & 1 célula & 2 células & 100 \\
\hline $\begin{array}{l}\text { Prod-Inj } \\
45^{\circ}\end{array}$ & - & & & 320 \\
\hline- & - & 5 células & 3 células & \\
\hline- & - & - & - & 1.000 \\
\hline- & - & - & - & 3.200 \\
\hline- & - & - & - & 10.000 \\
\hline- & - & - & - & 32.000 \\
\hline
\end{tabular}

A apresentação dos resultados obtidos com as simulações será realizada em duas etapas. Na primeira, são mostrados os casos sem injeção de água, investigando as peculiaridades de reservatórios submetidos a depleção. A segunda etapa envolve os casos com injeção de água com o objetivo de manutenção da pressão e deslocamento do óleo pela água.

Um resumo dos parâmetros analisados é apresentado a seguir:

\section{Parâmetros de Produção:}

1. FR: Fator de recuperação;

2. $t_{D w}$ : Tempo adimensional até o breakthrough de água;

3. $t_{D p b}$ : Tempo adimensional até se atingir a pressão de bolha no reservatório.

Parâmetros Numéricos:

1. Erro de balanço de materiais;

2. Implicitude média; 

3. Número de falhas do solver;
4. Número de cortes de timesteps;
5. Número de timesteps;
6. Número de ciclos newtonianos;
7. Número de iterações do solver;
8. Tempo de simulação.

\subsection{Simulações sem Injeção}

A Figura 5.1 exemplifica os parâmetros de produção obtidos das simulações de escoamento para os casos sem injeção. Nela podemos observar a vazão de óleo, a razão gásóleo (RGO) e a pressão média do reservatório. Nesse caso, pode-se ressaltar alguns fatores relevantes. Primeiramente, nota-se que ocorre uma leve diminuição na RGO, precedendo o aumento brusco dessa taxa de produção. Isso se deve à necessidade do estabelecimento de uma saturação mínima do gás para que haja mobilidade. Portanto, as primeiras bolhas de gás decorrentes da mudança de fases ainda não formam uma fase contínua no meio poroso, permanecendo imóveis. Assim, o óleo produzido nesse primeiro momento abaixo da pressão de bolha tem menos gás em solução do que havia originalmente. Outro fator relevante é a ligeira queda na produção de óleo com o decorrer do tempo. Isso ocorre devido à alteração do fator volume de formação do óleo $\left(B_{o}\right)$ com a diminuição da pressão média do campo submetido a depleção. A vazão de produção do óleo no fundo do poço se mantém constante, enquanto for possível reduzir a pressão no fundo do poço de forma continuada. 


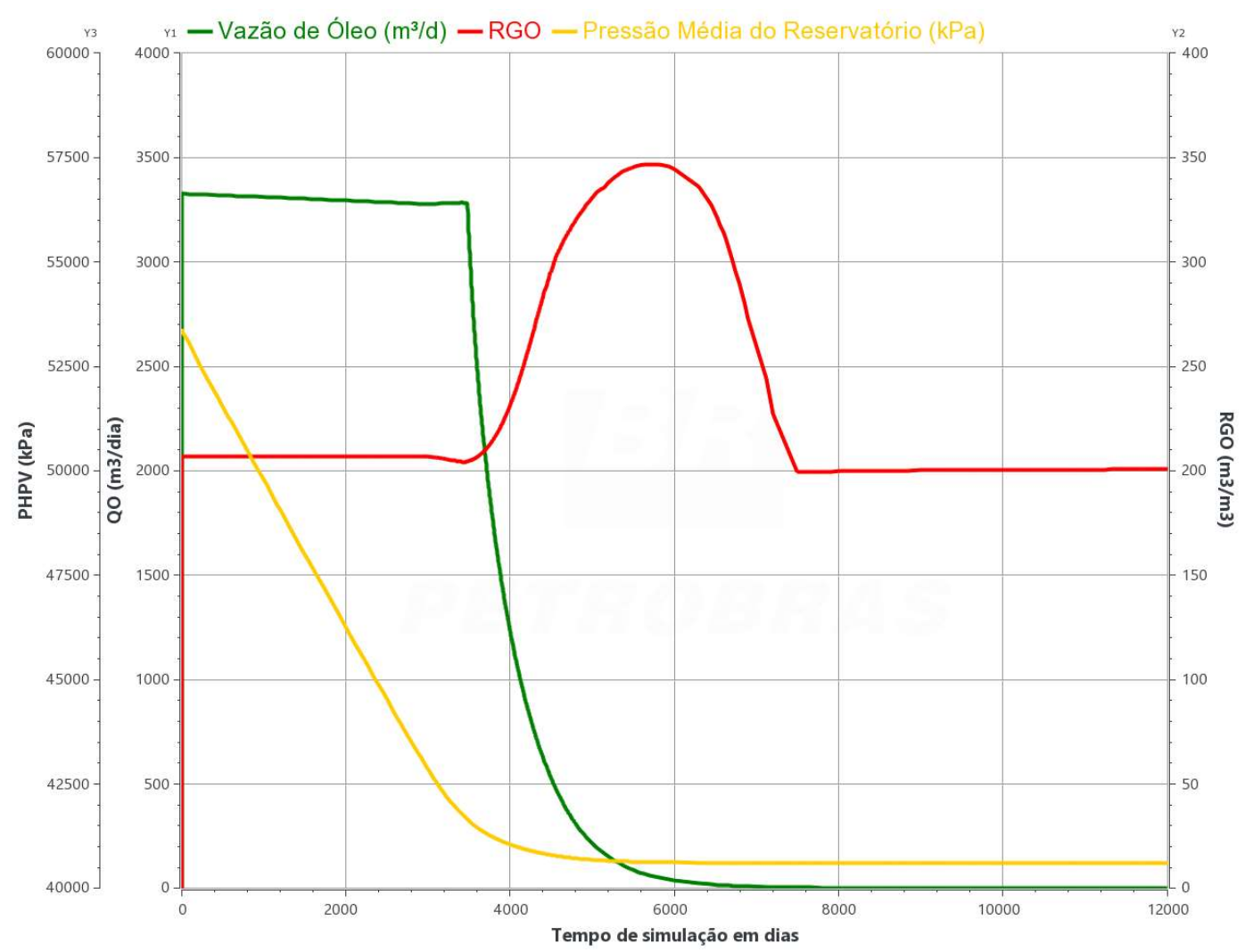

Figura 5.1: Exemplo de curva de produção de óleo e gás sem manutenção da pressão por injeção de água.

\subsubsection{Controle de Qualidade da Solução Numérica}

O controle de qualidade de um modelo de simulação considera a escolha de um conjunto de parâmetros de controle numérico que permita alcançar a precisão necessária dos resultados da simulação no menor tempo de execução possível. Conforme detalhado na Seção 4.1.3.2, para essa pesquisa foi adotado um conjunto de controles numéricos a ser utilizado para todas as análises. Isso permite uma análise crítica dos resultados filtrando-se as simulações que requerem outro conjunto de parâmetros numéricos, conforme exemplificado a seguir.

A necessidade de um tratamento dos resultados antes da avaliação pode ser demonstrada ao se avaliar um caso como o da Figura 5.2, que apresenta o $F R$ e o $t_{D p b}$ do cenário heterogêneo com $\mathrm{D}=0$ e $\mathrm{L}=2$. Nela, nota-se uma mudança abrupta no comportamento de ambos os parâmetros analisados entre as permeabilidades de fratura de $10^{4,0}$ e $10^{4,5} \mathrm{mD}$. Também cabe avaliar as variáveis apresentadas na Figura 5.3. O tempo de simulação, número de timesteps, iterações do solver e ciclos newtonianos apresentam a tendência esperada de crescimento até se atingir $K_{\text {frat }}=10^{4,5} \mathrm{mD}$, valor no qual todas essas variáveis decrescem bruscamente. Não obstante, a explicação encontra-se na Figura 5.4. O erro de balanço de materiais que cresce paulatinamente com o aumento da permeabilidade das fraturas, quando 
chega a $K_{\text {frat }}=10^{4,5} \mathrm{mD}$, irrompe para cerca de $8 \%$, que é um valor muito acima do aceitável em termos de qualidade de simulação, ressaltando a baixa credibilidade dos valores de $F R$ e $t_{D p b}$ obtidos.
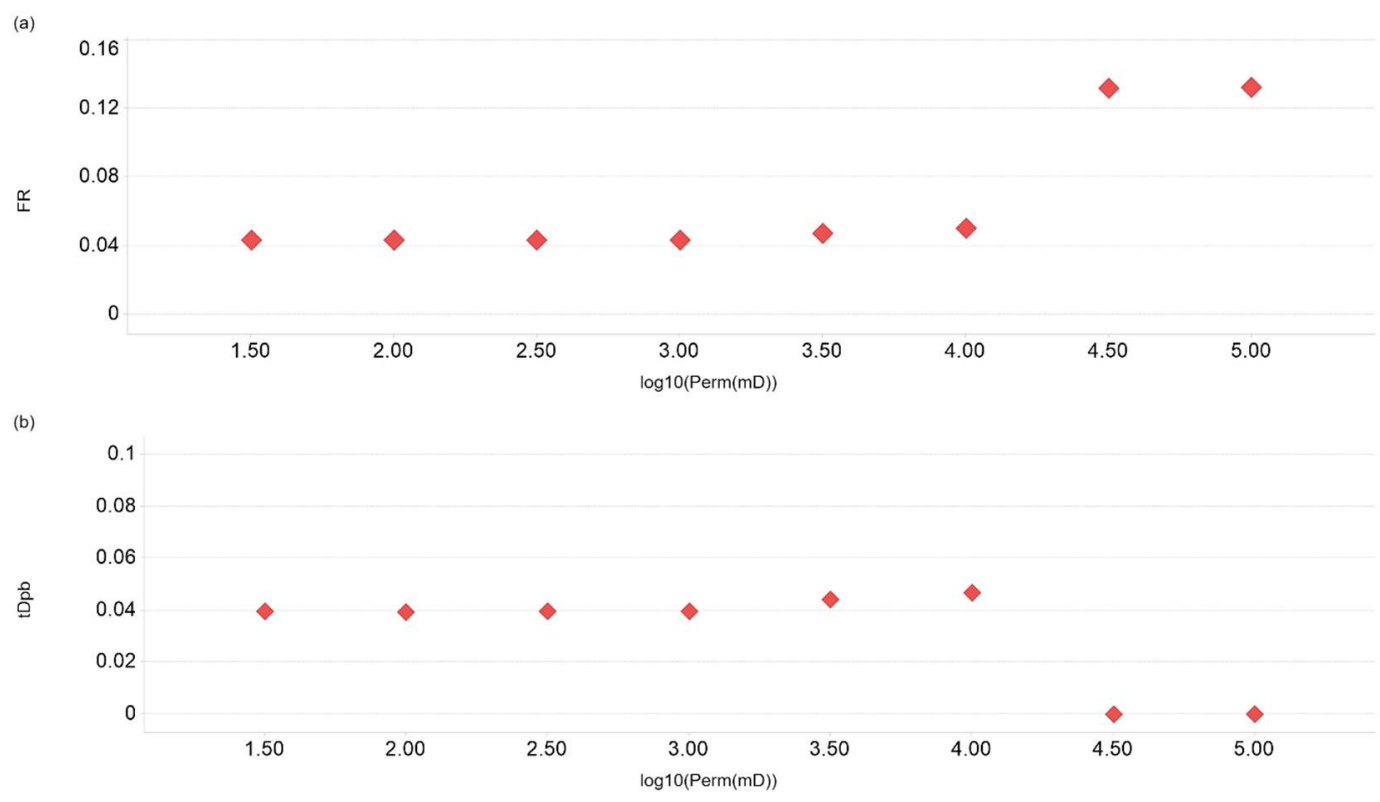

Figura 5.2: (a) Fator de recuperação e (b) $t_{D p b}$ das simulações sem injeção, com matriz heterogênea e corredor de fraturas com largura=2 e distância $=0$.
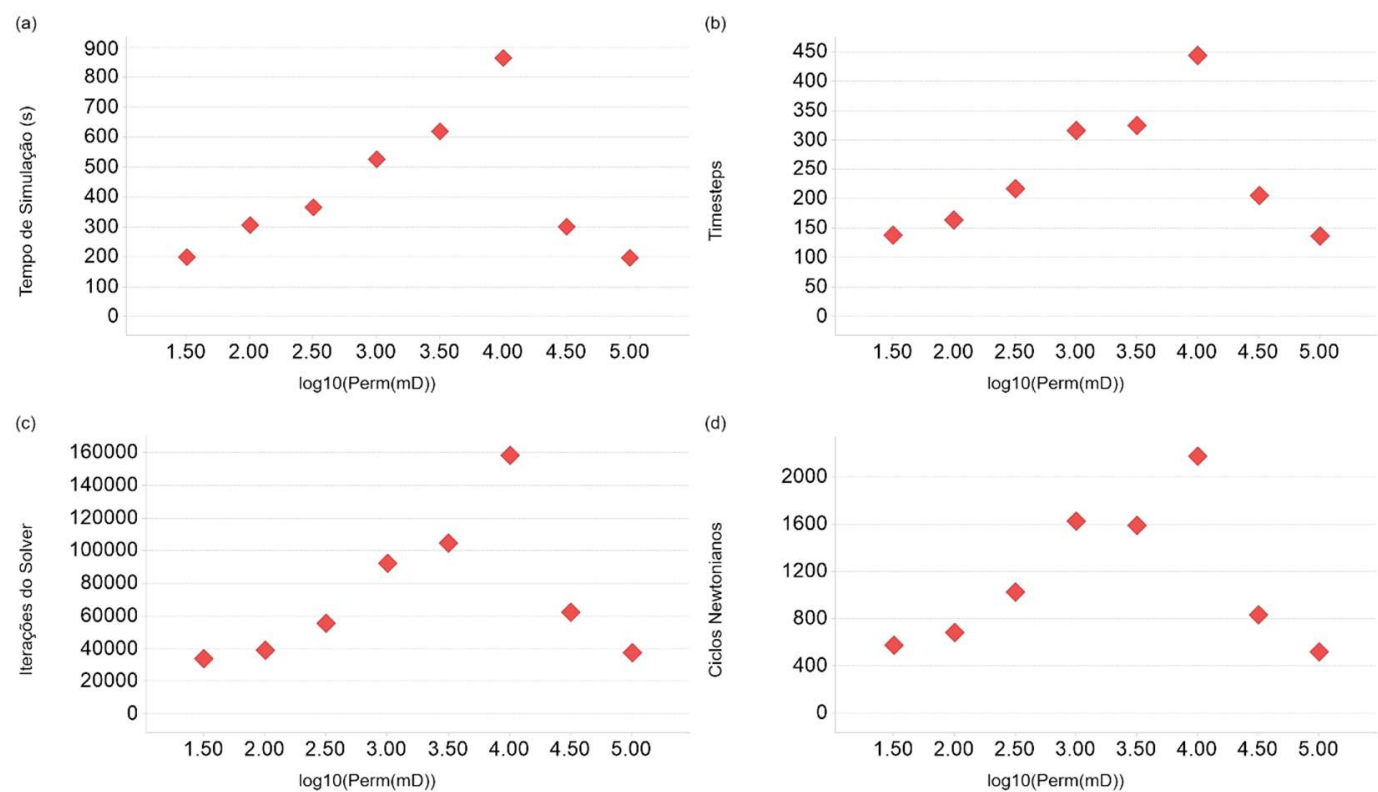

Figura 5.3: (a) Tempo de simulação, (b) número de timesteps, de (c) iterações do solver e de (d) ciclos newtonianos das simulações sem injeção, com matriz heterogênea e corredor de fraturas com largura $=2$ e distância $=0$. 

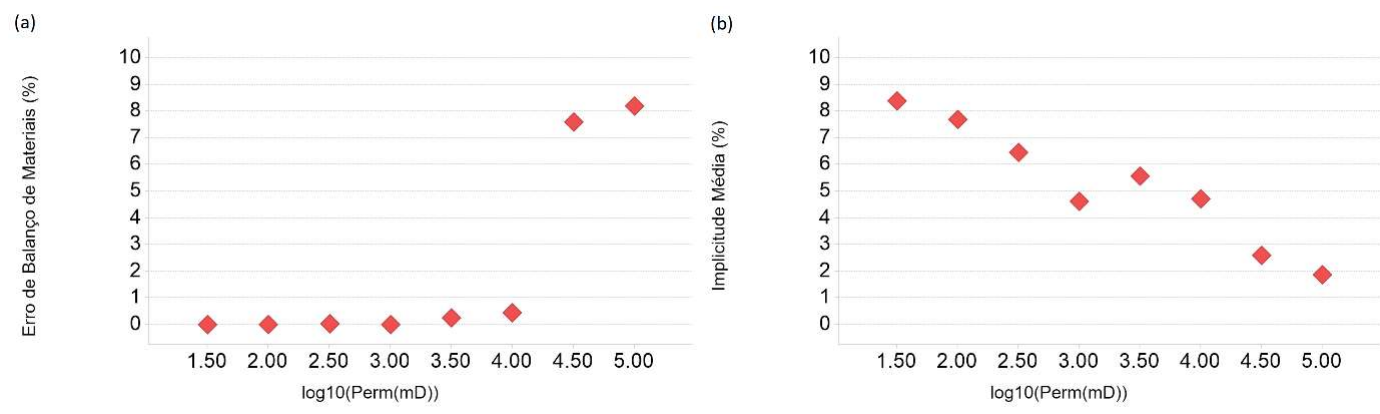

Figura 5.4: (a) Erro de balanço de materiais e (b) implicitude média das simulações sem injeção, com matriz heterogênea e corredor de fraturas com largura=2 e distância=0.

Percebe-se que a implicitude continuou decrescendo com o aumento da permeabilidade de fraturas. Portanto, o simulador detectou menos células que atendem aos critérios de estabilidade numérica, permitindo seu cálculo como IMPECS. Isso é esperado, uma vez que o escoamento passa a se concentrar nas células de fratura, fazendo com que os blocos de matriz contribuam com uma variação de pressão e de concentrações molares menores, tornando-se mais estáveis. Todavia, os resultados atingidos pelos solvers provocaram erros que se acumularam e geraram distorções nos resultados.

Para se mitigar esse problema, fez-se um filtro para excluir as simulações cujos resultados de EBM excedam $1 \%$. Portanto, eventualmente, não constarão todos os pontos em alguns dos gráficos apresentados sem, contudo, comprometer as análises realizadas.

\subsubsection{Homogeneidade da Matriz}

Inicialmente, será feita a análise do impacto das características de homogeneidade da matriz. Ou seja, serão comparadas simulações com as mesmas características, exceto que, em um caso, as porosidades $(\varphi)$ e permeabilidades $(K)$ de cada célula são iguais, enquanto no outro, essas propriedades são distribuídas heterogeneamente. Não obstante, a média de $\varphi \mathrm{e}$ de $K$ em todo o modelo são as mesmas em ambos os cenários.

Casos de depleção, sem aquífero ou capa de gás, não demostram serem afetados pelos caminhos mais permeáveis criados por meios heterogêneos. A produção é resultante do efeito das compressibilidades de fluido e rocha que compõem o sistema em depleção e menos sujeita a efeitos hidrodinâmicos. Em todos os cenários simulados, a diferença entre a matriz homogênea ou heterogênea é pouco significativa, conforme é exemplificado na Figura 5.5. 


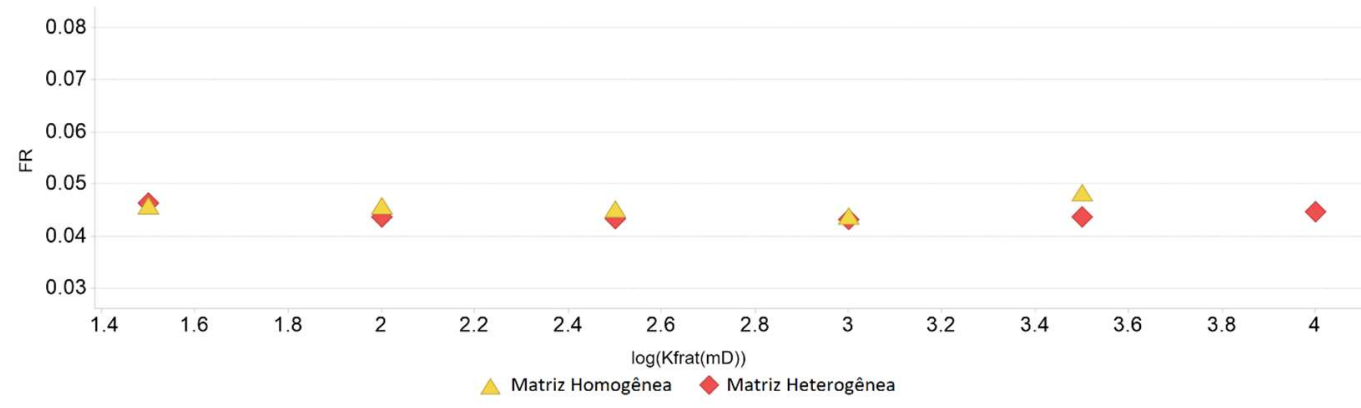

Figura 5.5: Fator de recuperação das simulações sem injeção e corredor de fraturas com largura=1 e distância=1.

Em geral, os aspectos numéricos também se comportam de forma similar entre os casos. O único ponto digno de nota é a implicitude média que consistentemente apresenta valores menores para os cenários de matriz homogênea (Figura 5.6). Portanto, nesse caso, o algoritmo AIM categoriza um número maior de equações de células do caso heterogêneo como pouco estáveis, dando-lhes um tratamento totalmente implícito. A dispersão dos valores de permeabilidade e porosidade em torno das médias do caso homogêneo tornam a simulação desse caso computacionalmente mais onerosa.

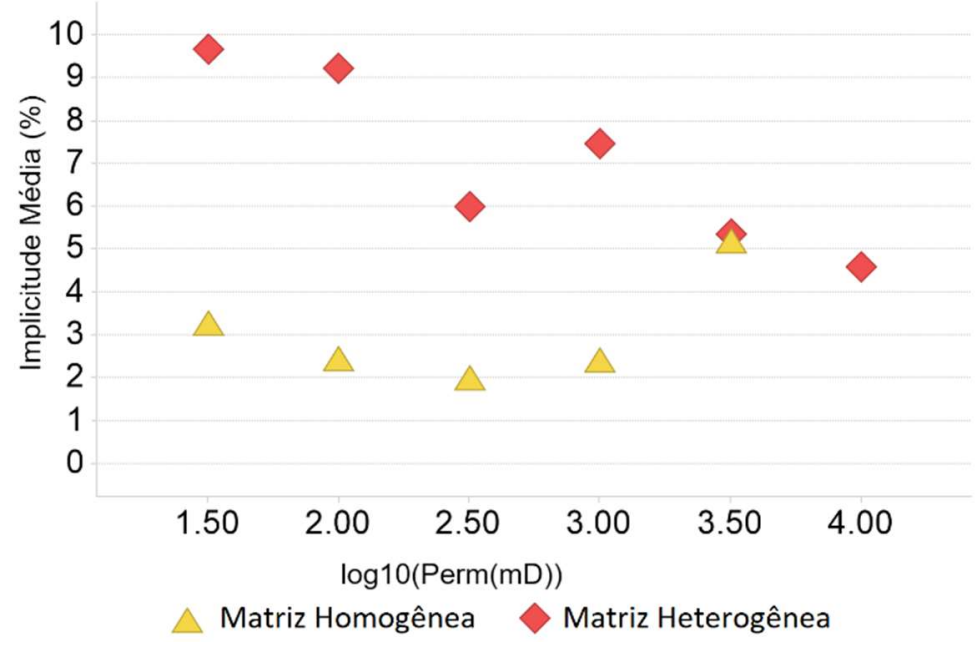

Figura 5.6: Implicitude média das simulações sem injeção e corredor de fraturas com largura $=3$ e distância $=0$.

\subsubsection{Aspectos Geométricos do Corredor de Fraturas}

Após a análise da homogeneidade da matriz, procurou-se investigar a influência da geometria do corredor de fraturas nas saídas da simulação. Ou seja, a sua largura e a distância dos corredores até os poços. 
A expectativa é de um aumento de tempo de simulação para células fraturadas mais próximas ao poço. Afinal, os maiores diferenciais de pressão e velocidade de escoamento ocorrem na vizinhança dos poços. Por conseguinte, caso as maiores permeabilidades também se encontrem nessa região, as variações de pressão e de percentual molar dos componentes também aumentará. Como consequência, haverá um maior número falhas do solver, de cortes de timestep, de número de timesteps e, por fim, um maior tempo de simulação. Já a largura do corredor é um ponto mais complexo de se avaliar. Ao aumentá-la, tem-se mais células com dupla permeabilidade. Por conseguinte, aumenta-se a capacidade ao fluxo, melhorando a comunicação entre as células. No entanto, um corredor mais largo pode causar um escoamento menos veloz através das fraturas, uma vez que o diferencial de pressão é o mesmo, mas a área aberta ao fluxo no meio fraturado é maior. Menores velocidades geram simulações mais rápidas, pois a definição do tamanho do passo de tempo é controlada pelas alterações nas variáveis primárias. Todavia, isso se obtém devido a um maior número de células fraturadas, o que dificulta as soluções computacionais. Logo, há um efeito ambíguo que pode levar os resultados numéricos para lados opostos, dependendo do contraste de propriedades do meio poroso versus sistema de fraturas.

Os resultados das simulações, entretanto, mostrou que a distância (D) entre fraturas e poços tem pouca influência nos parâmetros monitorados nos casos analisados, como é exemplificado na Figura 5.7. O tempo de simulação não decresce com o aumento de D. Isso é um indício de que as velocidades de escoamento dos fluidos, impostas pelo poço nas células fraturadas, não foram suficientemente altas para provocar uma diminuição significativa dos timesteps, nem para gerar dificuldades para a convergência do simulador. Consequentemente, o tempo de simulação sofre pouca influência da distância entre poços e corredor de fraturas, para essas simulações avaliadas. 


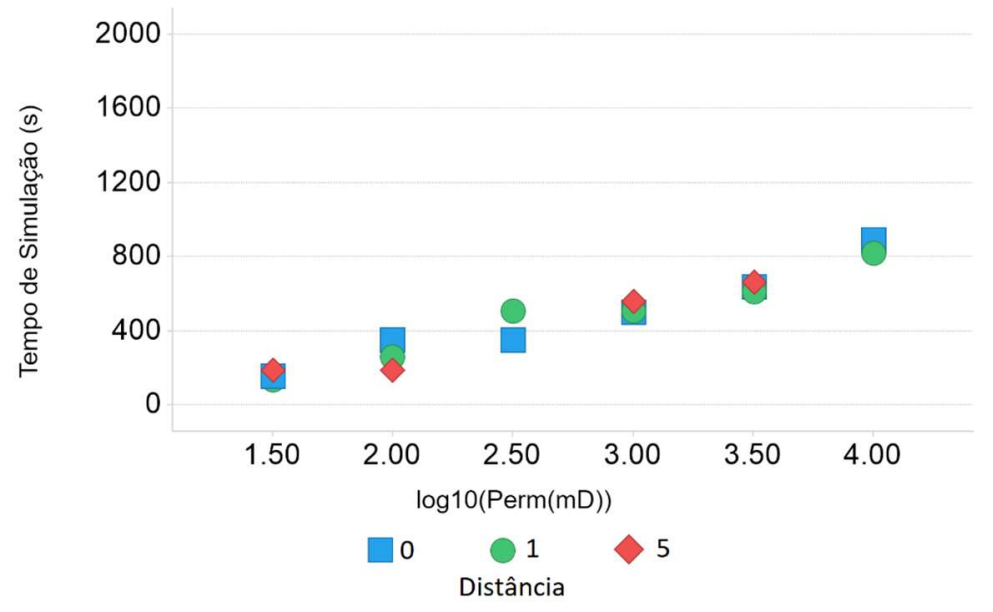

Figura 5.7: Tempo de simulação dos cenários sem injeção, matriz heterogênea e com largura $=2$.

Os casos com maiores valores de $K_{\text {frat }}$ apresentaram erros de balanço de materiais acima do limite estabelecido de 1\%. Para que a análise pudesse incluir esses casos, seria necessário encontrar uma parametrização numérica mais adequada à simulação de escoamento de gás em meios de dupla permeabilidade.

A largura, em contrapartida, mostrou influência quando seu valor era unitário. Nesses cenários, foi possível notar menores tempos de simulação e melhores resultados numéricos, para variadas permeabilidades. Na Figura 5.8 é mostrado o comportamento do tempo de simulação para o caso de $\mathrm{D}=0$.

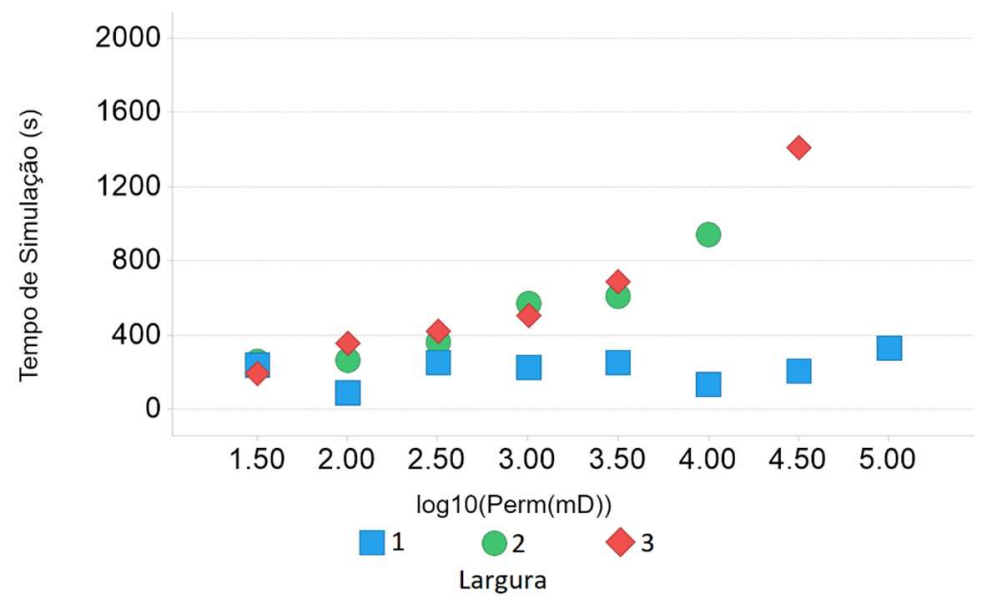

Figura 5.8: Tempo de simulação dos cenários sem injeção, matriz heterogênea e com distância $=0$. 
Esses resultados apontam a uma maior dificuldade de convergência com o maior número de células fraturadas. Ou seja, o efeito esperado de diminuição da velocidade do fluxo com o aumento da largura do corredor de fraturas não teve impacto significativo na parte computacional da simulação nos casos testados. As menores variações de pressão e de composição não compensaram o maior número de cálculos necessários para se resolver o escoamento nas fraturas. Portanto, nesse cenário estudado de depleção, corredores mais largos têm desempenho numérico inferior.

Conforme esperado, o aumento de $K_{\text {frat }}$ causa um maior tempo de simulação, pois aumenta o contraste de permeabilidade entre o sistema de fraturas e o meio poroso. Os demais resultados numéricos também acompanham esse padrão. Entretanto, esse aumento não é consistente para todos os valores de permeabilidade.

Quanto ao fator de recuperação e tempo de atingimento da $\mathrm{P}_{\mathrm{sat}}$, ao contrário do esperado, os gráficos apresentados mostram pequena influência da geometria das fraturas (Figura 5.9). Mesmo as pequenas diferenças obtidas não podem ser avaliadas com precisão, pois alguns desses cenários com resultados mais elevados, também apresentaram EBM um pouco mais alto, apesar de ser abaixo do limite de 1\%. Logo, essas variações não chegam a ser conclusivas.

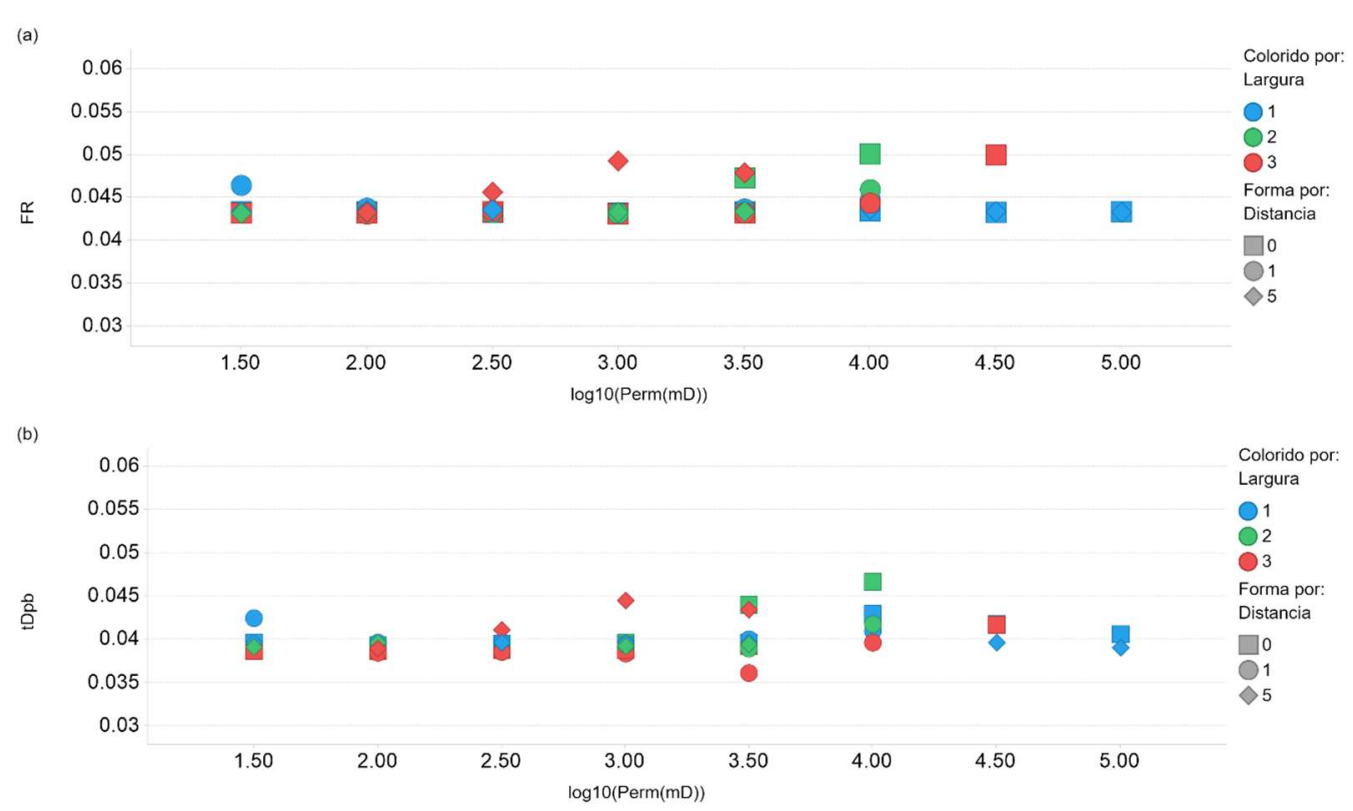

Figura 5.9: (a) Fator de recuperação e (b) $t_{D p b}$ nos cenários sem injeção e com matriz heterogênea.

Note-se que a produção do caso com depleção, assim como na análise sobre a homogeneidade da matriz, não sofre influência significativa de heterogeneidades, mesmo que de altas permeabilidades, o que pode estar também relacionado ao efeito da 
descompressão do sistema como mecanismo principal de produção. Também é importante ressaltar, contudo, que esse resultado foi observado apenas nesses casos muito específicos que estão sendo simulados nesse trabalho. Cenários diversos dos considerados nessa pesquisa requerem a análise de outras variáveis que podem influenciar os resultados, tais como presença de aquífero ou de capa de gás, presença de outros poços, dimensão do modelo, entre outras.

\subsection{Simulações com Injeção}

A Figura 5.10 exemplifica o comportamento de produção de simulação de escoamento para os casos de manutenção de pressão com injeção de água. Nela podemos observar a vazão de óleo, o corte de água (wcut) e a pressão média do reservatório. Nota-se que a pressão no reservatório se mantém constante devido à reposição de fluido produzido por fluido injetado no meio poroso. Também se observa a influência direta entre o corte de água e a produção de óleo. A produção de líquido se mantém constante. Logo, quanto mais cedo a água injetada chega no poço produtor, menor será a produção acumulada de óleo $\left(\mathrm{N}_{\mathrm{p}}\right)$.

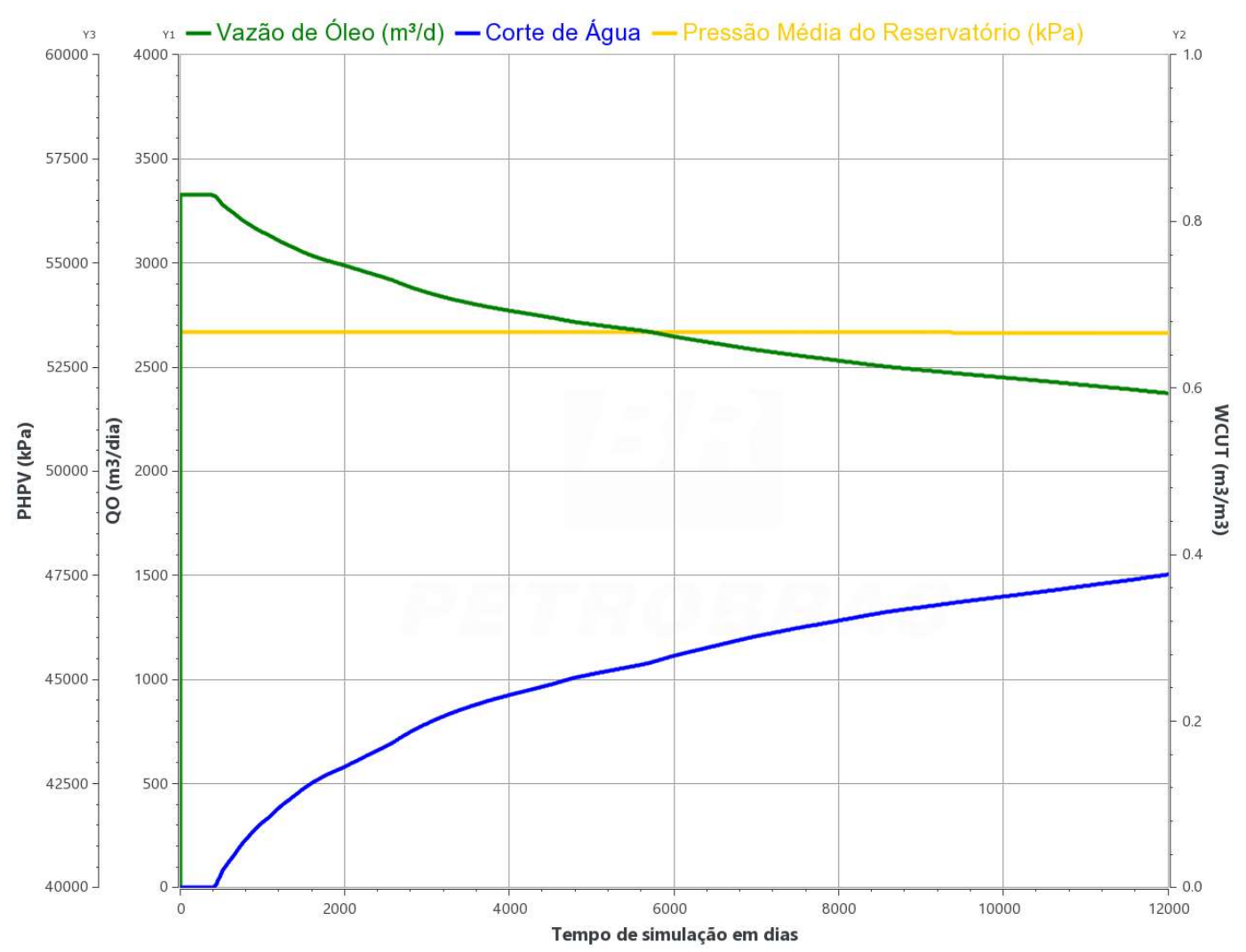

Figura 5.10: Exemplo de curva de produção com injeção. 


\subsubsection{Controle de Qualidade da Solução Numérica}

Da mesma forma que para as simulações por depleção do reservatório, o primeiro passo da análise é realizar um controle de qualidade da solução numérica decorrente do grau de dificuldade para a solução do sistema de equações imposta ao simulador pelo profissional de simulação. Caso o erro de balanço de massa não seja aceitável para a precisão desejada ou houver desperdício de esforço computacional, seja por número de cortes de timestep elevados, descompasso nos critérios de convergência dos solvers linear e não-linear ou número excessivo de falhas de convergência, há a necessidade de rever os parâmetros de controle numérico para a busca do melhor tempo de simulação que permita alcançar a precisão desejada. Em situações mais extremas, especialmente quando há grande contraste de mobilidade $(K / \mu)$ de fluidos, há necessidade de busca de equilíbrio entre o tempo computacional e erro de balanço de massa toleráveis.

Para os cenários com injeção de água, nos quais não há a presença de gás no meio poroso, as simulações se mostraram muito mais estáveis. Nesses casos, devido à manutenção da pressão, as alterações das variáveis primárias são mais modestas e, sempre que a produção ocorre acima da pressão de saturação, não há o aparecimento de uma fase gasosa no meio poroso, diminuindo a necessidade de um esforço computacional mais intenso. 0 maior erro de balanço de materiais foi de $0,19 \%$ e a média de todos os casos foi de $0,005 \%$. Esses valores estão dentro do aceitável para se considerar todas as estimativas de produção resultantes como válidas.

Ao contrário do que acontece nos cenários sem injeção, nenhum dos casos com injeção foi interrompido por causa de não-convergência do solver. Portanto, todos os casos submetidos a simulação foram avaliados nos itens subsequentes.

\subsubsection{Homogeneidade da Matriz}

Nessa seção, volta-se a investigar a influência da heterogeneidade das propriedades da matriz nos resultados da simulação. Avaliando-se o aspecto computacional, a heterogeneidade aumenta a complexidade da simulação. Assim, espera-se um aumento do tempo de simulação e das variáveis correlatas em sistemas heterogêneos. De fato, é o que foi observado: um maior número de ciclos newtonianos e de iterações do solver além de uma maior quantidade de timesteps são necessários para resolver o equacionamento dos cenários heterogêneos devido às maiores variações das pressões e composições molares nas células decorrentes das maiores permeabilidades encontradas nos modelos heterogêneos. A soma desses fatores implica em um maior tempo de simulação nesses casos (Figura 5.11). 
(a)

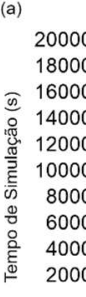

20000
180000
160000
140000
12000
10000
8000
60000
40000
2000

$\begin{array}{llllllll}1.50 & 2.00 & 2.50 & 3.00 & 3.50 & 4.00 & 4.50 & 5.00\end{array}$ $\log 10(\operatorname{Perm}(\mathrm{mD}))$

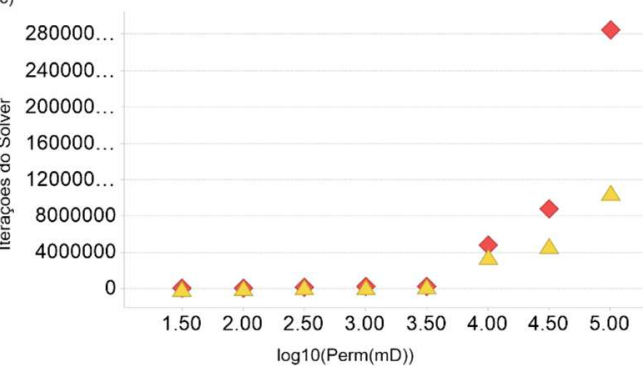

(b)

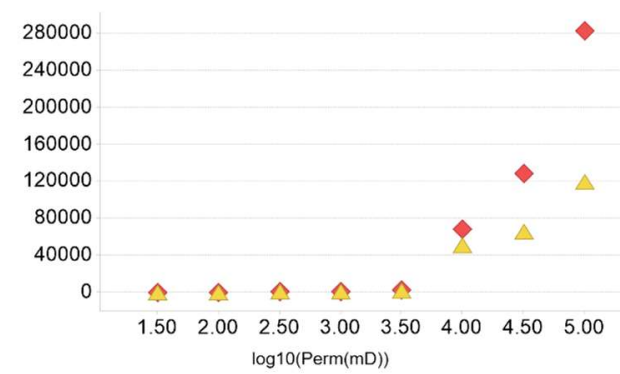

(d)

1600000

1200000
800000
400000

$0 \wedge \hat{\imath} \leqslant 1$

$\begin{array}{llllllll}1.50 & 2.00 & 2.50 & 3.00 & 3.50 & 4.00 & 4.50 & 5.00\end{array}$ $\log 10(\operatorname{Perm}(\mathrm{mD}))$

Figura 5.11: (a) Tempo de simulação, (b) número de timesteps, (c) número de iterações do solver e (d) número de ciclos newtonianos das simulações com malha paralela à grade, com injeção e corredor de fraturas com largura=1 e distância $=0$.

É possível notar, também, que as diferenças entre os casos de matriz homogênea e heterogênea não são constantes. Para permeabilidades de fratura até $10^{3,5} \mathrm{mD}$, as variáveis se apresentam muito semelhantes. Conforme se aumenta $K_{\text {frat }}$ acima desse valor, a diferença entre os casos também aumenta. Isso decorre em função da preponderância do transporte de massa pelas fraturas causando maior dificuldade de convergência das equações relativas ao meio poroso.

Isso mostra que nos cenários em que para esse modelo simplificado de um reservatório e para os valores de porosidade e permeabilidades usados nesse trabalho, apenas a diferença de heterogeneidade não é suficiente para impor dificuldades de convergência ao simulador ou a necessidade de diminuição do valor dos timesteps. Contudo, quando se adiciona ao equacionamento permeabilidades significativas no meio fraturado, as variações de pressão e concentração molar nesse meio, aliado com as maiores variações do meio da matriz heterogênea, geram a necessidade de menores timesteps e uma maior dificuldade de se encontrar as soluções das equações.

Outra análise digna de nota é a da implicitude média, apresentada na Figura 5.12. Observa-se que para menores valores de $K_{\text {frat, }}$ os cenários homogêneos apresentam implicitude média menores do que os heterogêneos. Conforme a permeabilidade do meio fraturado aumenta, a implicitude média das simulações diminui, assim como a diferença entre os casos comparados. O primeiro efeito é indício de que a matriz heterogênea gera frentes de escoamento mais instáveis, obrigando à resolução de um maior número de células através do 
método totalmente implícito. Como visto anteriormente, essa diferença não é suficiente para gerar um aumento no tempo de simulação nos casos estudados. Contudo, em modelos maiores, com um maior número de poços, grande contraste de permeabilidade do meio poroso ou estratificações severas, pode ocorrer um aumento do esforço computacional para a solução numérica. O segundo fenômeno reforça que quando o escoamento passa a ser majoritariamente através das fraturas, há um maior número de células na matriz cuja equações alcançam os critérios de convergência com baixo esforço computacional, de forma a permitir uma diminuição da implicitude.

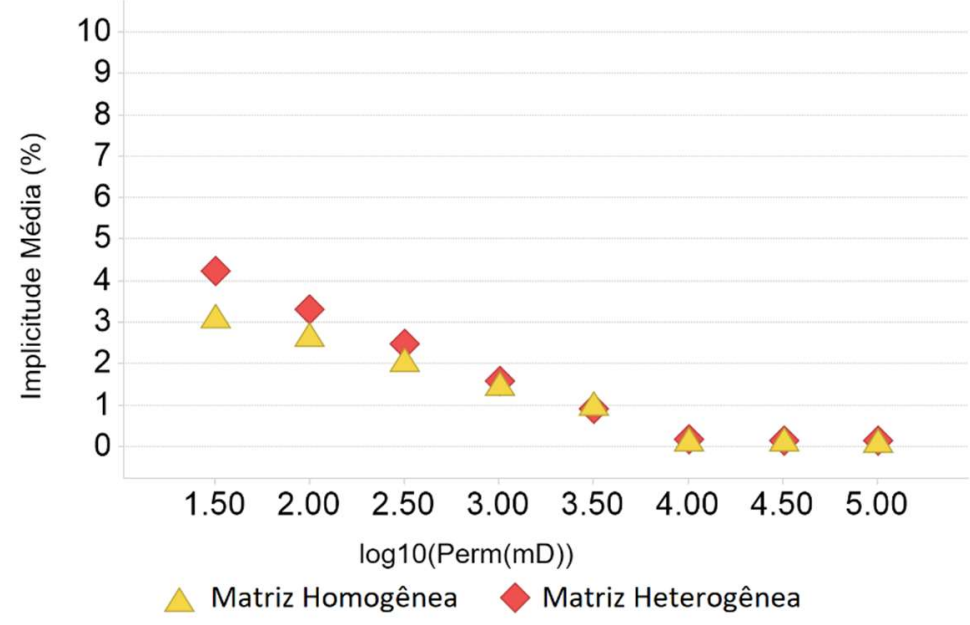

Figura 5.12: Implicitude média das simulações com malha paralela à grade, com injeção e corredor de fraturas com largura $=1$ e distância $=0$.

Em relação aos resultados de produção, em cenários com injeção, a heterogeneidade da matriz deveria se mostrar um fator determinante para a chegada de água. Cenários heterogêneos geram canais preferenciais por onde o fluido injetado percola até o poço produtor. Entretanto, a dupla permeabilidade também funciona como um caminho preferencial para o escoamento. Por conseguinte, é importante investigar a partir de qual valor de $K_{\text {frat }}$ as fraturas passam a dominar o escoamento, de forma que a heterogeneidade da matriz passa a ter pouco impacto na produção.

Conforme esperado, ao contrário do que foi constatado no caso sem injeção, a homogeneidade da matriz da rocha impacta os resultados de produção. Pode-se observar na Figura 5.13 que, para permeabilidades de fratura menores, apesar de fatores de recuperação semelhantes, os tempos para a chegada de água nos modelos homogêneos é menor. Não obstante, com o aumento da permeabilidade do corredor de fraturas, os tempos de chegada de água se equiparam, enquanto os fatores de recuperação dos casos heterogêneos se tornam relativamente menores. 

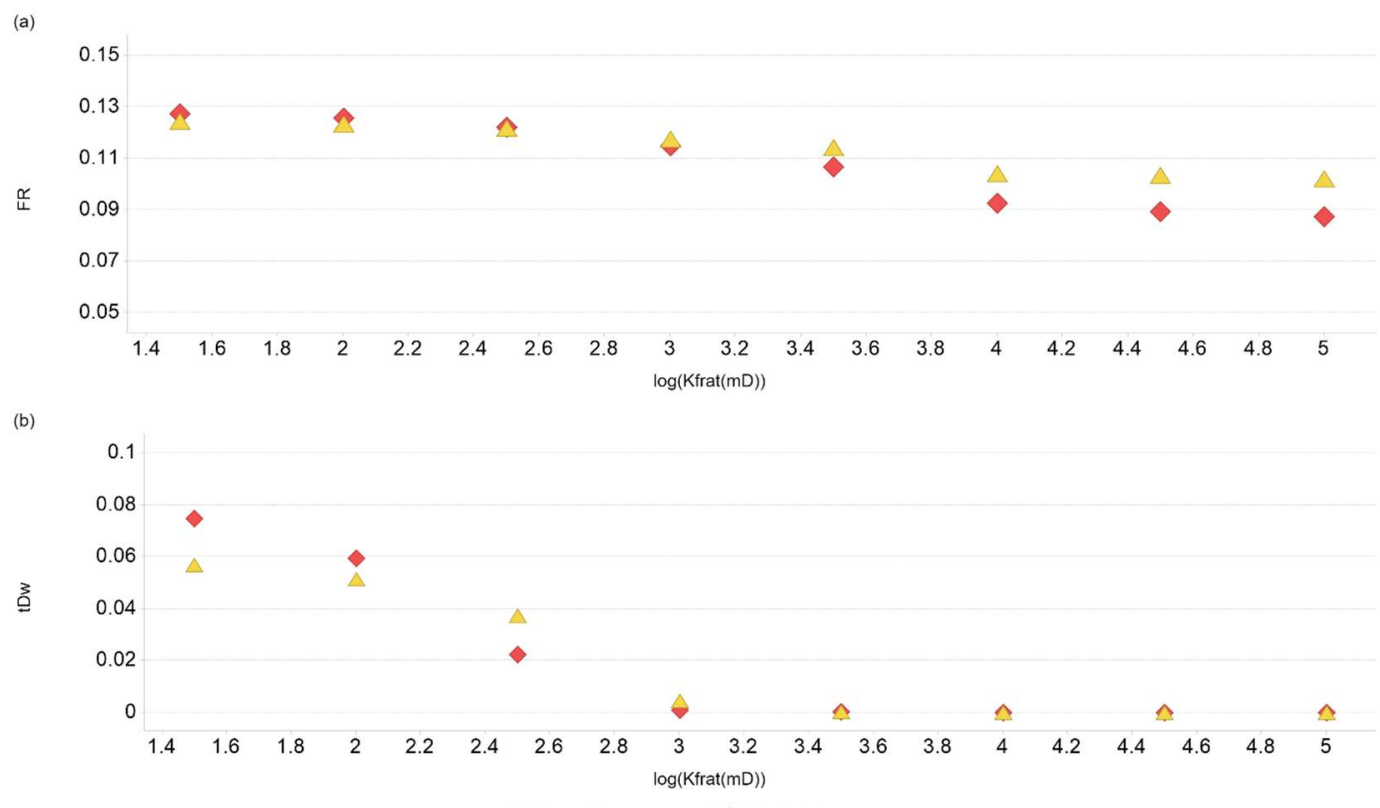

$\triangle$ Matriz Homogênea Matriz Heterogênea

Figura 5.13: (a) Fator de recuperação e (b) $t_{D w}$ das simulações com injeção em malha paralela à grade, distância $=0$ e com largura $=1$.

Também é possível observar padrões relevantes em gráficos de $t_{D w}$ versus $F R$ como o da Figura 5.14. Nele, os pontos são coloridos segundo a característica da matriz e o tamanho de cada um é proporcional ao valor de $K_{\text {frat }}$. Nos cenários de matriz homogênea, ocorre uma maior concentração dos casos em valores intermediários de recuperação. Apesar do tempo até o breakthrough chegar a ser nulo para valores maiores de $K_{\text {frat, }}$ não são atingidas produções tão baixas. Ou seja, as fraturas reduzem $t_{D w}$ ao menor nível possível, porém os fatores de recuperação continuam maiores do que no caso heterogêneo. Todavia, no lado direito do gráfico, os cenários homogêneos não prevalecem. Os casos em que a água leva mais dias para chegar ao produtor, gerando maiores fatores de recuperação, são, igualmente, os de matriz heterogênea. 


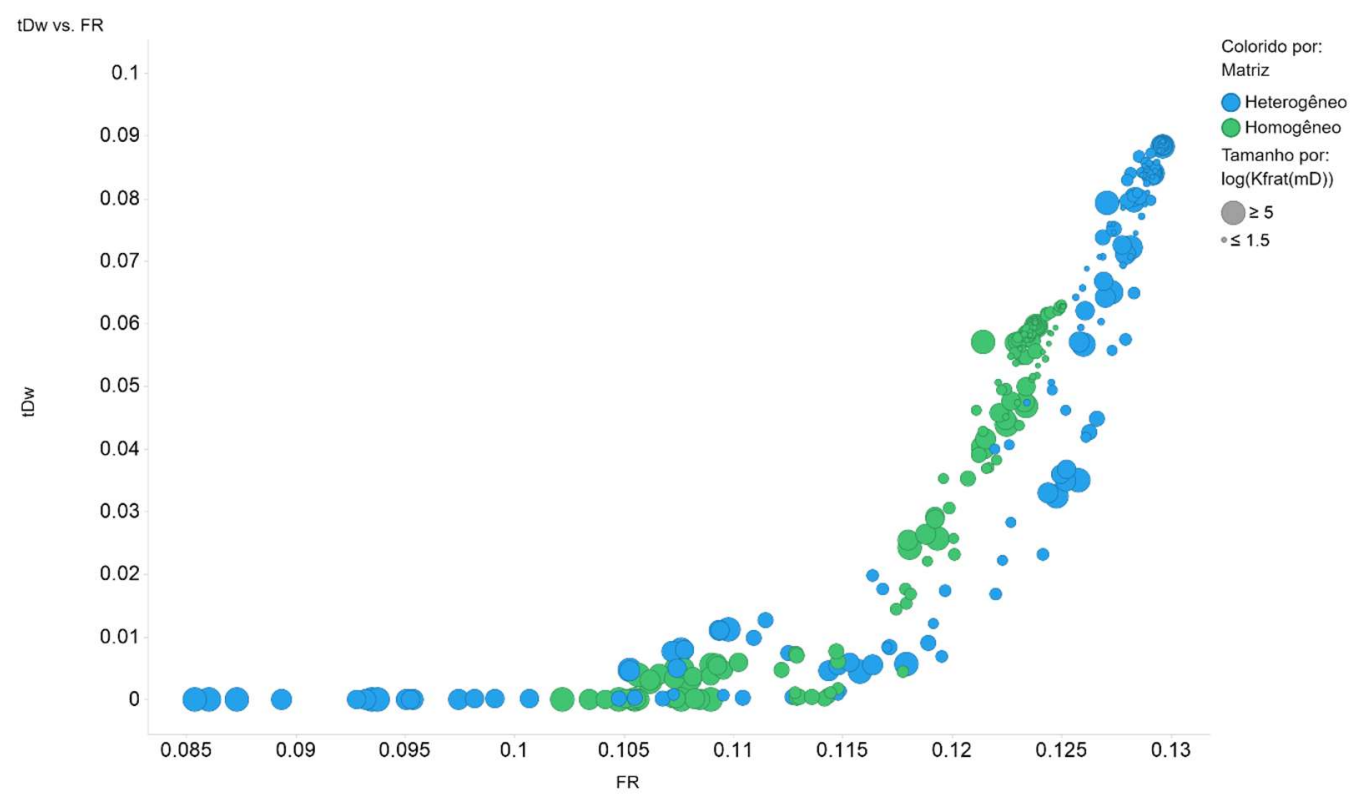

Figura 5.14: $t_{D w}$ versus FR, colorido pela homogeneidade da matriz e com pontos de tamanho proporcional a $K_{\text {frat }}$.

Ora, se foi estabelecido que a produção acumulada depende de dois fatores, sendo um deles o $t_{D w}$, o que explica esse FR menor para $t_{D w}$ semelhantes só pode ser um crescimento mais rápido do corte de água nos cenários heterogêneos. De fato, vemos um exemplo na Figura 5.15 de como o seu avanço é mais agressivo, resultando em um menor valor de produção acumulada de óleo $\left(\mathrm{N}_{\mathrm{p}}\right)$.

O modelo homogêneo possui apenas dois caminhos entre os poços. Um de alta permeabilidade e outro de baixa. Assim, a injeção é concentrada no meio mais permeável, e pouco volume de água vai para a matriz. O resultado é uma chegada mais rápida da água, mas com vazão relativamente controlada pela capacidade de escoamento no corredor de fratura.

Por outro lado, o modelo heterogêneo dispõe de diversos canais comunicando os poços. Consequentemente, o volume injetado é distribuído por esses caminhos, retardando a chegada de água. Não obstante, quando ela atinge o poço produtor, ela não advém exclusivamente do meio fraturado. Assim, a vazão de água cresce de forma mais acentuada. 


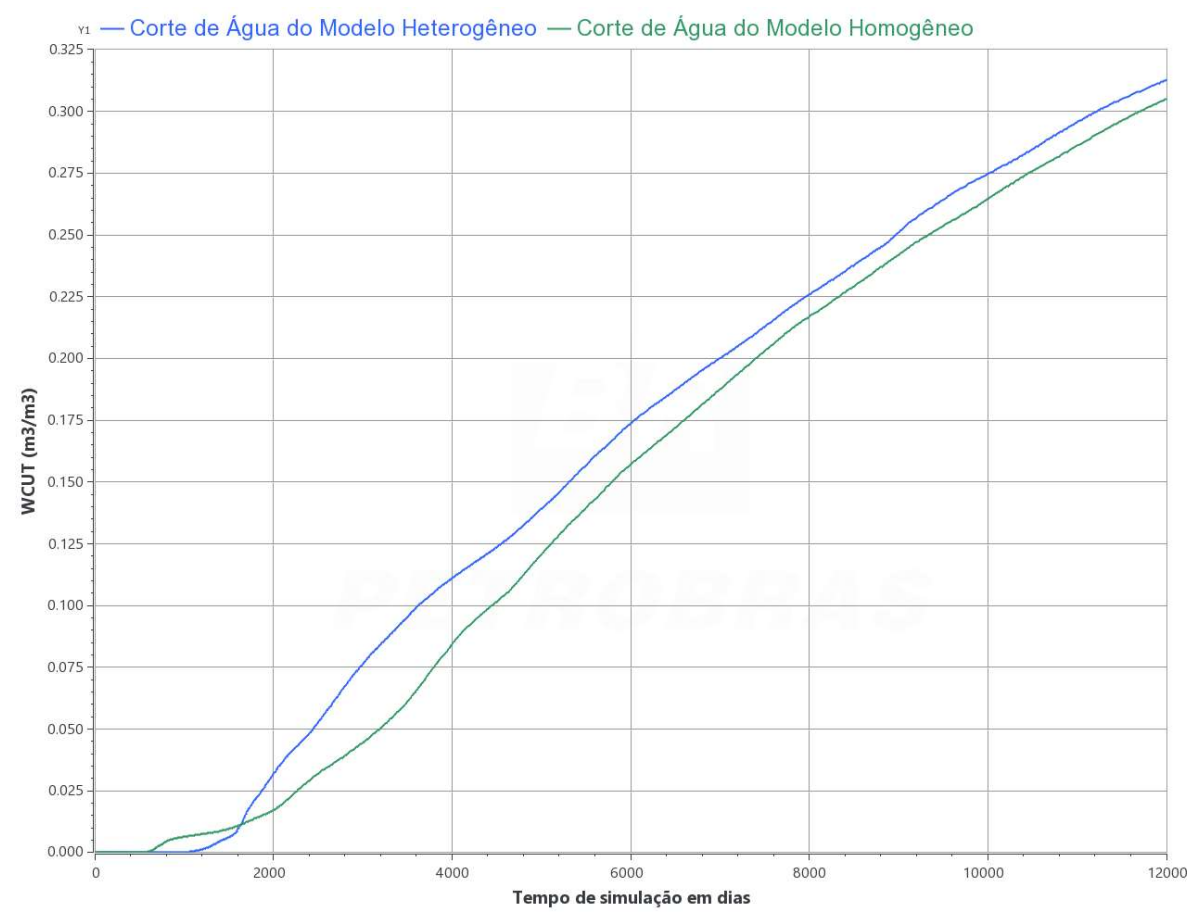

Figura 5.15: Corte de água para os cenários com distância $=1$, largura $=2$ e $K_{\text {frat }}=1.000 \mathrm{mD}$.

Esse efeito, entretanto, não se deve exclusivamente às fraturas. Na Figura 5.16 constam os resultados de produção dos casos em que o corredor é afastado. Nota-se, primeiramente, que a dupla permeabilidade não tem grande impacto. $O$ aumento de várias ordens de grandeza em $K_{\text {frat }}$ causa apenas uma diminuição discreta no tempo até o breakthrough de água. Não obstante, os casos homogêneos apresentam resultados piores na comparação. 


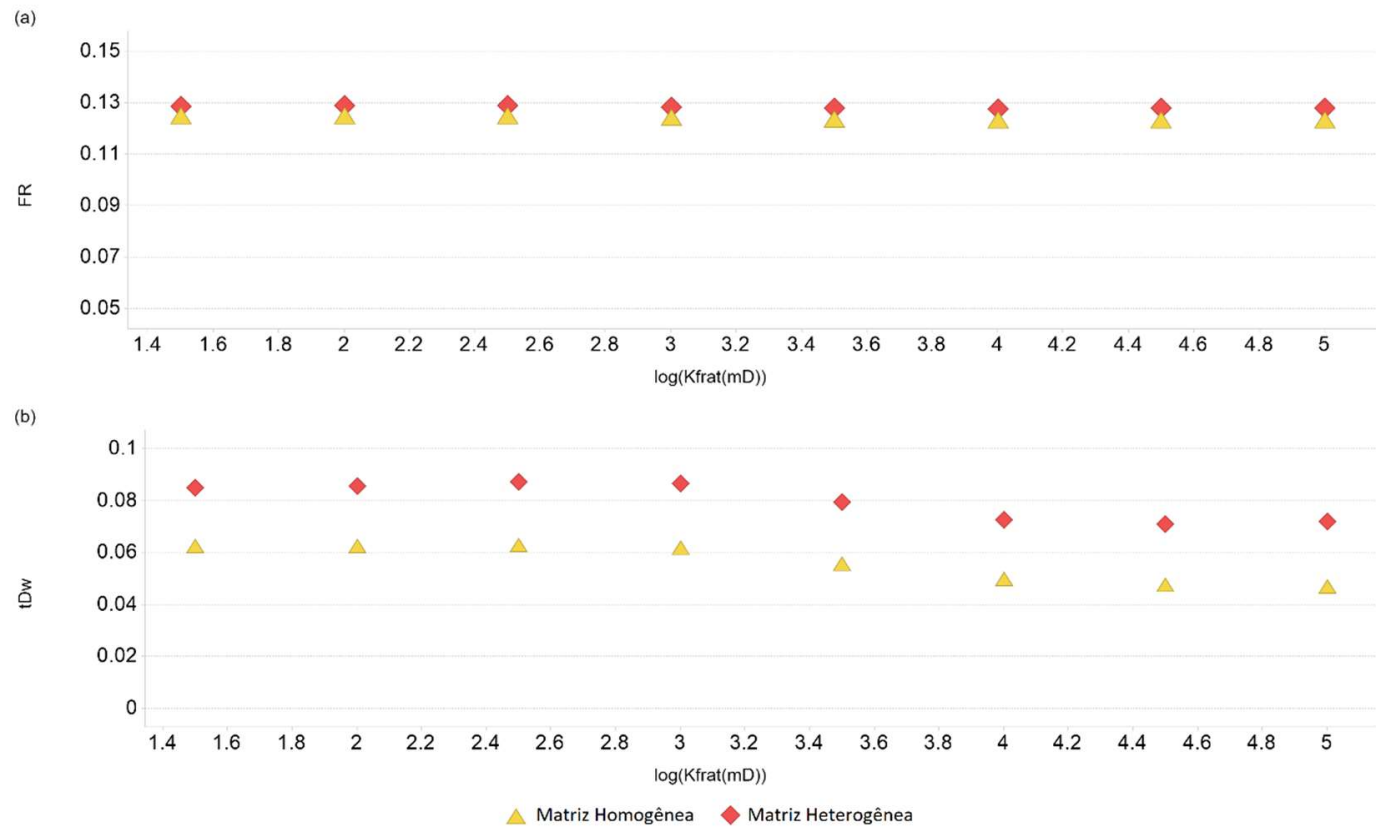

Figura 5.16: Resultados de produção das simulações com injeção em malha paralela à grade, distância=5 e com largura=3: (a) FR; (b) $t_{D w}$.

Há, portanto, outro fator influenciando as variáveis de produção. Na Figura 5.17 é possível observar um padrão que explica o fenômeno. Aqui, são apresentadas seções comparativas de saturação de água $\left(S_{w}\right)$. Vê-se como o efeito gravitacional se torna dominante no caso homogêneo. O escoamento do injetor para o produtor se dá pela base do reservatório. Em contrapartida, no outro cenário, há permeabilidades maiores em células mais próximas ao topo do reservatório. Por conseguinte, a frente de água fica mais distribuída, verticalmente. A consequência é um $t_{D w}$ menor no caso homogêneo, mas um crescimento mais abrupto no caso heterogêneo devido à homogeneização da frente de água injetada causada pela heterogeneidade da rocha.

Outra justificativa é a posição dos poços e a distribuição de volume de óleo causada pelo modelo homogêneo. A referência para o presente trabalho foi um modelo aproximado de um reservatório real, no qual as regiões de topo estrutural mais alto concentram melhores qualidades permoporosas e, portanto, maior volume de óleo. É nesses locais que estão posicionados os poços. Quando o modelo é homogeneizado, esse volume de hidrocarbonetos que está originalmente concentrado próximo aos poços é distribuído por todas as células do modelo de forma uniforme. Como resultado, as áreas próximas aos poços ficam com menor volume de óleo a ser drenado. Por conseguinte, os fatores de recuperação no caso heterogêneo ficam melhores, caso não haja impacto da dupla permeabilidade. 


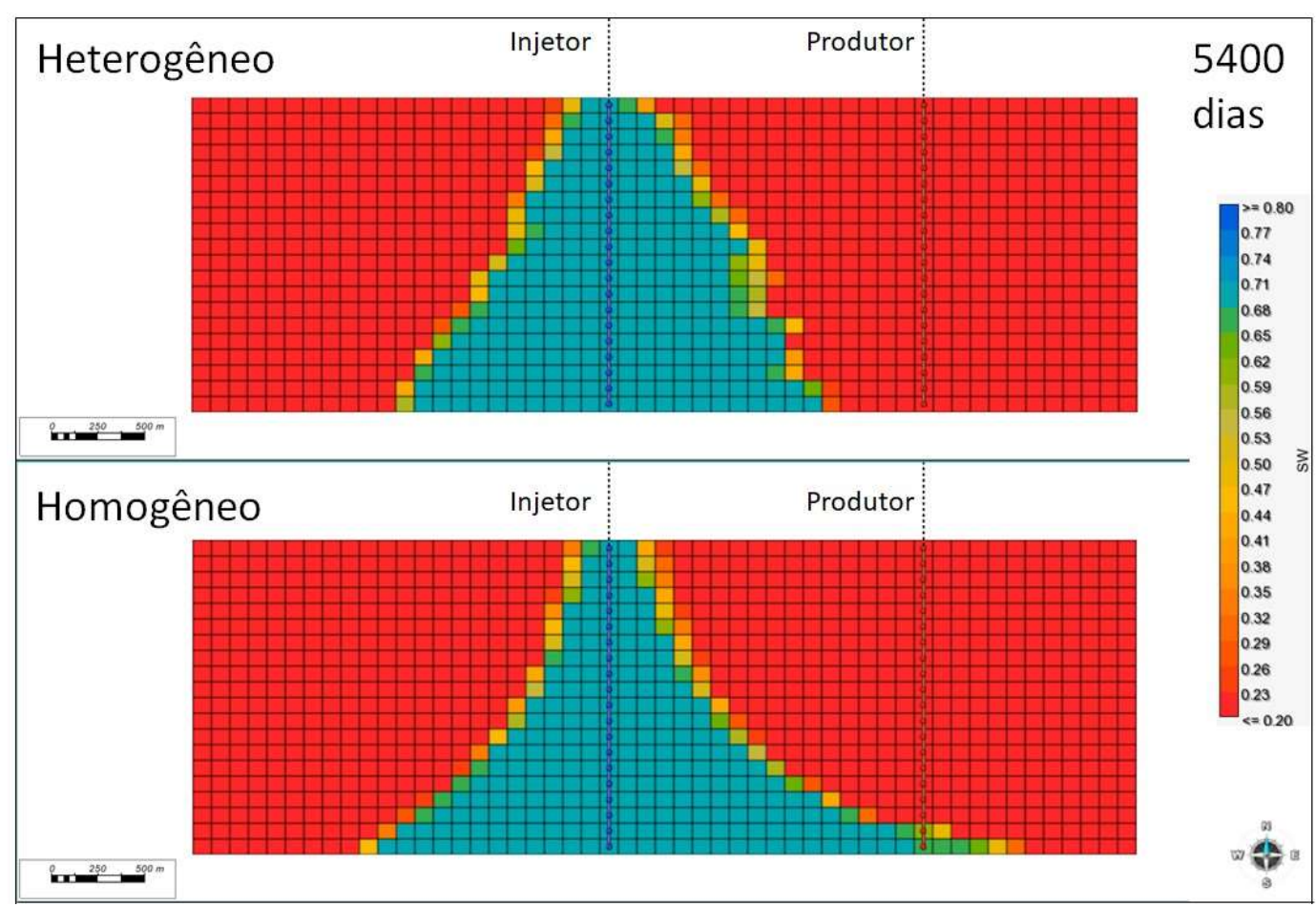

Figura 5.17: Seção na direção dos poços comparando a saturação de água nos casos de matriz heterogênea e homogênea.

\subsubsection{Direção da Malha de Poços em Relação à Malha do Modelo}

O objeto da análise dessa seção será a influência da direção do escoamento em relação à malha de simulação. Assim sendo, serão apresentados resultados de simulações com os mesmos parâmetros e matriz homogênea, nas quais é alterada a malha de poços. Em um caso, o par produtor-injetor está alinhado com um dos eixos cartesianos do modelo. Para representar um caso extremo, no outro caso, foi especificado um ângulo de $45^{\circ}$ com relação aos eixos $x$ e y. A distância entre os dois poços, contudo, se mantém constante em ambos os casos.

A análise em questão não apresentou impactos numéricos relevantes. No entanto, é esperado que o caso com malha não alinhada com um dos eixos horizontais retarde a chegada de água, haja vista a discretização espacial das equações de transporte de massa de 5 pontos em 2D e 7 pontos em 3D. O efeito de orientação de malha, como é denominado, resulta em um deslocamento afetado pela discretização, já que os termos cruzados da discretização espacial foram desconsiderados. Um exemplo de escoamento com $45^{\circ}$ em relação aos eixos coordenados horizontais é apresentado na Figura 5.18. Ou seja, embora a solução das equações de todas as células seja simultânea, pode haver uma discrepância de resultados com respeito à conformidade, ou não, do escoamento com relação um dos eixos horizontais do sistema coordenado. Há propostas para se realizar ajustes na permeabilidade que 
compensem esse efeito (CAVALCANTE FILHO, 2016), mas nenhum tratamento foi realizado no presente trabalho.

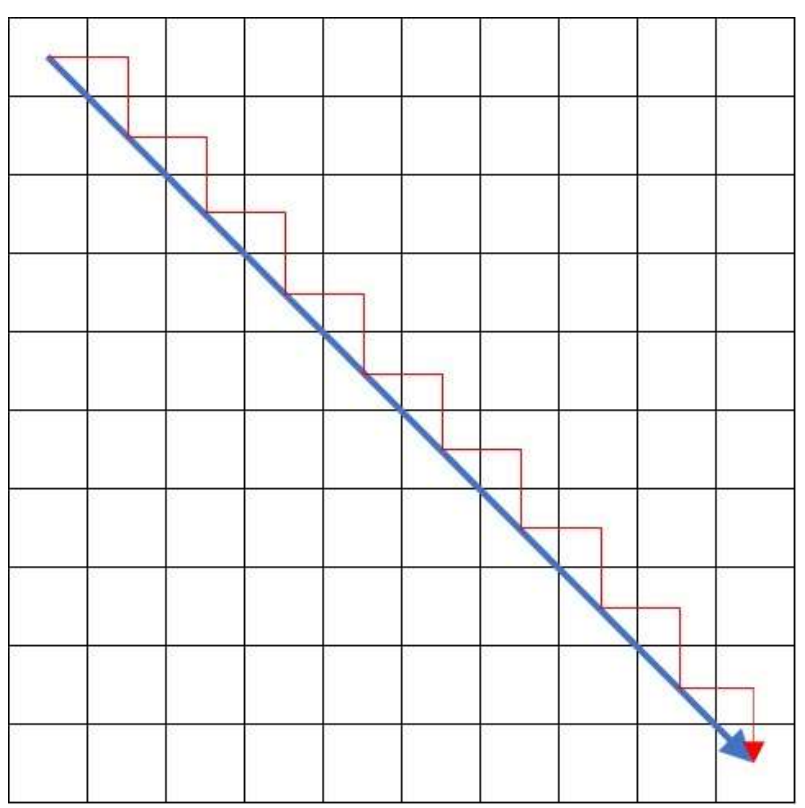

Figura 5.18: Representação esquemática de escoamento não alinhado com um dos eixos coordenados da malha de simulação.

As previsões de produção têm um comportamento dentro da expectativa para valores pequenos de $K_{\text {frat }}$. Contudo, com maiores permeabilidades de fratura, a transferência de massa passa a ser dominada pelas fraturas, fazendo com que o efeito de orientação de malha passe a ter menor influência. A Figura 5.19 apresenta os fatores de recuperação dos cenários com distância zero e larguras três e um. Com L=3, ambos os casos apresentam uma redução de $t_{D w}$ com o aumento de $K_{\text {frat }}$. Todavia, para L=1, os cenários de orientação de malha diagonal são pouco impactados pela permeabilidade das fraturas enquanto os com malha paralela apresentam o comportamento dentro do esperado.

A falta de continuidade direta das células que compõem o corredor de fraturas prejudica a representação das zonas fraturadas. Na Figura 5.20, o mapa mostra um exemplo de como as células de um corredor de fraturas não se conectam diretamente. Ou seja, o termo da equação que modela o escoamento de uma célula de fratura para a adjacente se torna nulo, havendo somente a transferência indireta pelo meio poroso. Assim, a água injetada entra no meio fraturado, uma vez que o termo de transferência matriz-fratura continua existindo. Contudo, os fluidos contidos nas fraturas não escoam para as células adjacentes, fazendo com que não haja o efeito esperado de um corredor de fraturas. 

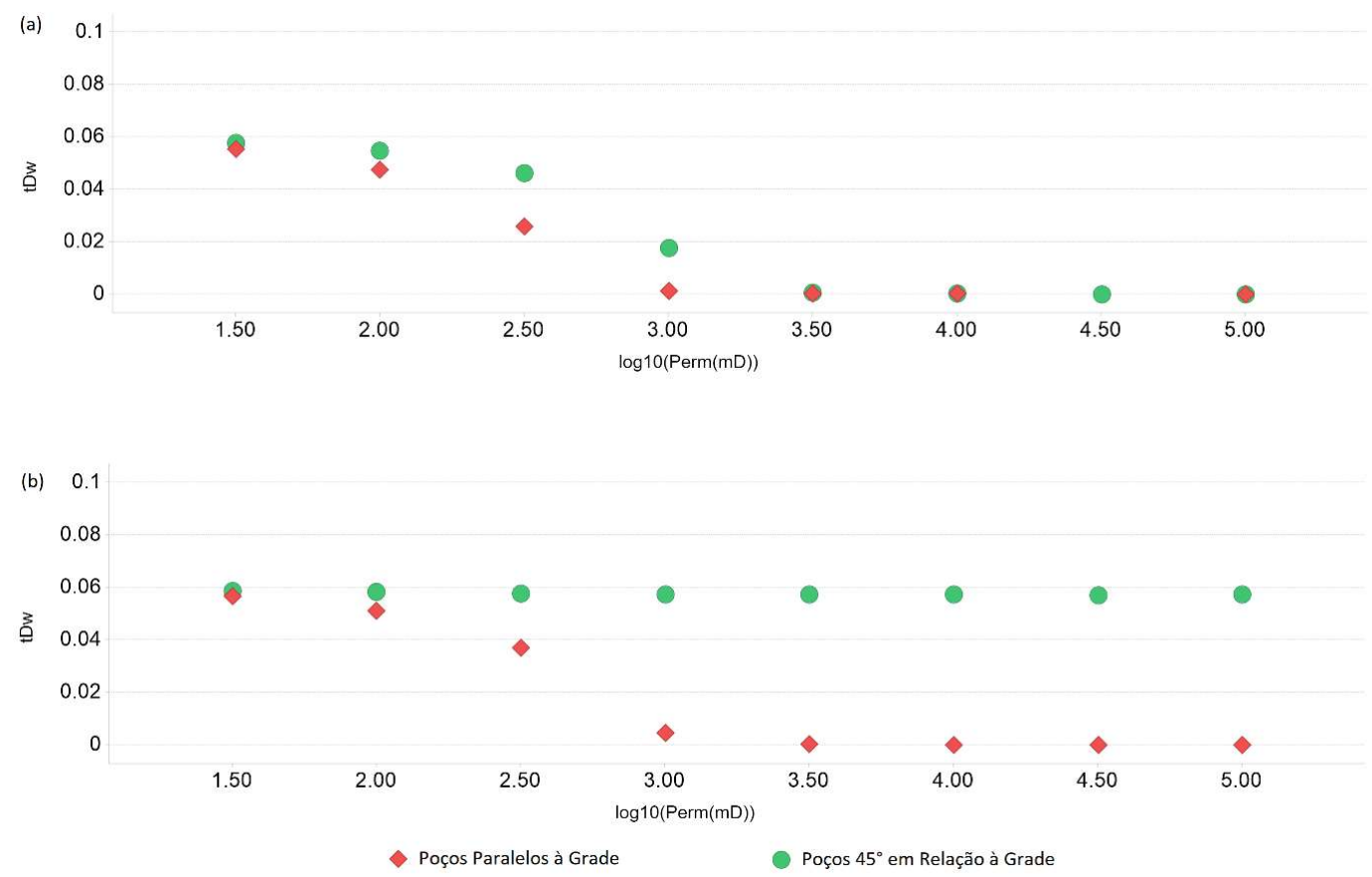

Figura 5.19: $t_{D w}$ das simulações com injeção em matriz homogênea, distância=0 e com: (a) largura=2; (b) largura=1.

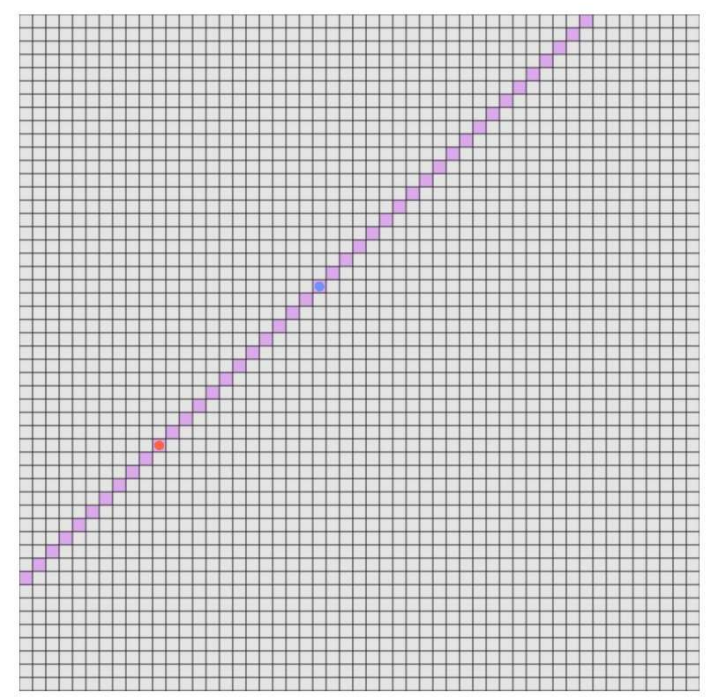

Figura 5.20: Mapa das células fraturadas no caso poços diagonais à grade, distância=0 e largura=1.

\subsubsection{Aspectos Geométricos do Corredor de Fraturas}

Nesta seção, o impacto dos aspectos geométricos referentes ao corredor de fraturas será analisado: (i) distância entre os poços e o corredor (D); e (ii) largura do corredor (L). 
O aumento da distância entre as células de dupla permeabilidade e os poços têm, normalmente, impacto positivo nos aspectos computacionais, reduzindo o tempo de simulação pois facilita a convergência. Os maiores diferenciais de pressão e, consequentemente, as maiores velocidades de escoamento ocorrem próximo aos poços. Portanto, ao se distanciar as células fraturadas dessas posições, as não-linearidades tendem a diminuir. Entretanto, os poços que atravessam células fraturadas são canhoneados tanto no meio poroso como no sistema de fraturas. Ou seja, no equacionamento, os blocos fraturados recebem um aporte ou retirada adicional de massa caso o poço seja produtor ou injetor, respectivamente. Portanto, esse termo gera maiores variações de pressão e de concentração molar dos componentes, o que causa a necessidade de menores timesteps e maiores dificuldades de convergência durante a simulação.

Para os valores de $K_{\text {frat }}$ iguais e superiores a $10.000 \mathrm{mD}$, é possível observar como os cenários em que as fraturas cruzam os poços $(D=0)$ aumentam em algumas ordens de grandeza o tempo de simulação, número de timesteps, número de iterações do solver e quantidade de ciclos newtonianos. Isso é decorrente das altas velocidades impostas por uma permeabilidade muito elevada nas células canhoneadas. Esse excessivo contraste de permeabilidade nas células completadas em relação às células da matriz adjacentes à falha causa dificuldades de convergência que oneram excessivamente o tempo de simulação. Se as fraturas são deslocadas, seja para células adjacentes $(D=1)$ ou para mais distante $(D=5)$, o efeito da distância, atenua significativamente as dificuldades de convergência nos casos testados.

A Figura 5.21 expõe esse fenômeno de forma clara. Nesse gráfico, foram considerados todos os casos com injeção simulados. Para cada combinação de valores de D e $K_{\text {frat }}$, foi feita a média do tempo de simulação em segundos, resultando nesse gráfico de barras. Essa imagem ressalta o aumento de tempo de simulação causado pela distância nula até as células fraturadas. Ao se canhonear células fraturadas, a simulação é altamente onerada computacionalmente. Para o cenário de $K_{\text {frat }}=100.000 \mathrm{mD}$, as simulações demoraram cerca de 40 vezes mais do que os casos com $D$ maior do que zero. Porém, embora haja um aumento do tempo de simulação sistemático com o aumento da permeabilidade da fratura, observase que somente no caso de $D=0$, o efeito combinado da alta produtividade/injetividade dos poços completados na fratura e comunicação direta com todas as células da região fraturada causa um esforço numérico elevado para a alimentação ou dissipação do produtor ou injetor, respectivamente. Portanto, somente nos casos de $K_{\text {frat }}$ maior ou igual a $10.000 \mathrm{mD}$ haveria necessidade de revisão dos controles numéricos para conciliar o equilíbrio entre o tamanho dos timesteps e os critérios de convergência em cenários de elevado contraste.

Observa-se que o tempo de simulação também diminui com a diminuição da distância dos poços às células de dupla permeabilidade, mesmo excluindo da análise apenas os casos 
com $\mathrm{D}=0$ e $\mathrm{K}_{\text {frat }}$ maior ou igual a $10.000 \mathrm{mD}$. Portanto, há um efeito provocado exclusivamente pela distância.

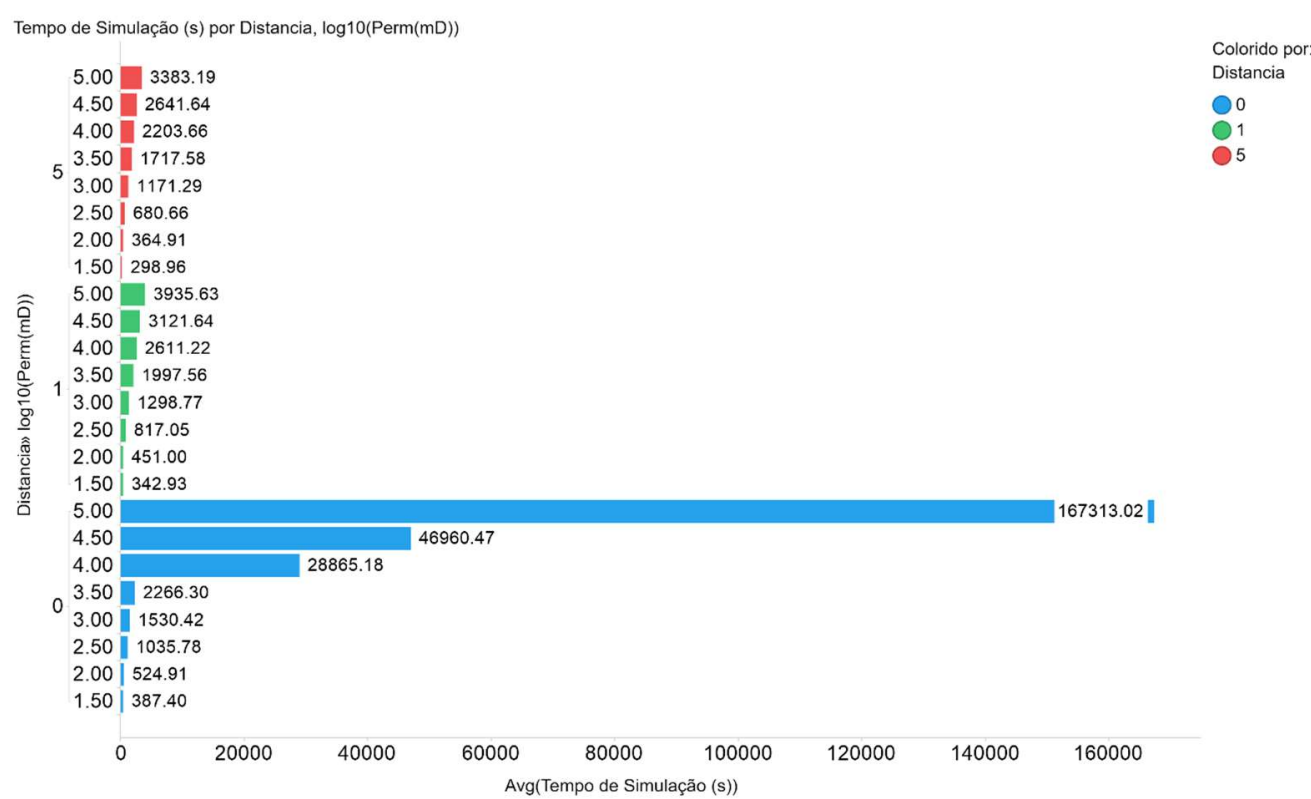

Figura 5.21: Média do tempo de simulação por $\log _{10}\left(K_{\text {frat }}\right)$ e distância do corredor de fraturas.

Ao contrário dos demais parâmetros numéricos, a implicitude média não apresenta nenhuma alteração decorrente da mudança de D (Figura 5.22). Da mesma forma que nos casos apresentados anteriormente, ela apenas decresce com o aumento da permeabilidade efetiva das fraturas. Isso indica que, mesmo afastadas dos poços, as células de fraturas mostram-se as mais instáveis computacionalmente enquanto os blocos da matriz se tornam mais estáveis devido à consequente diminuição do tamanho dos timesteps. Assim, o número de células cuja formulação é resolvida explicitamente aumenta. 


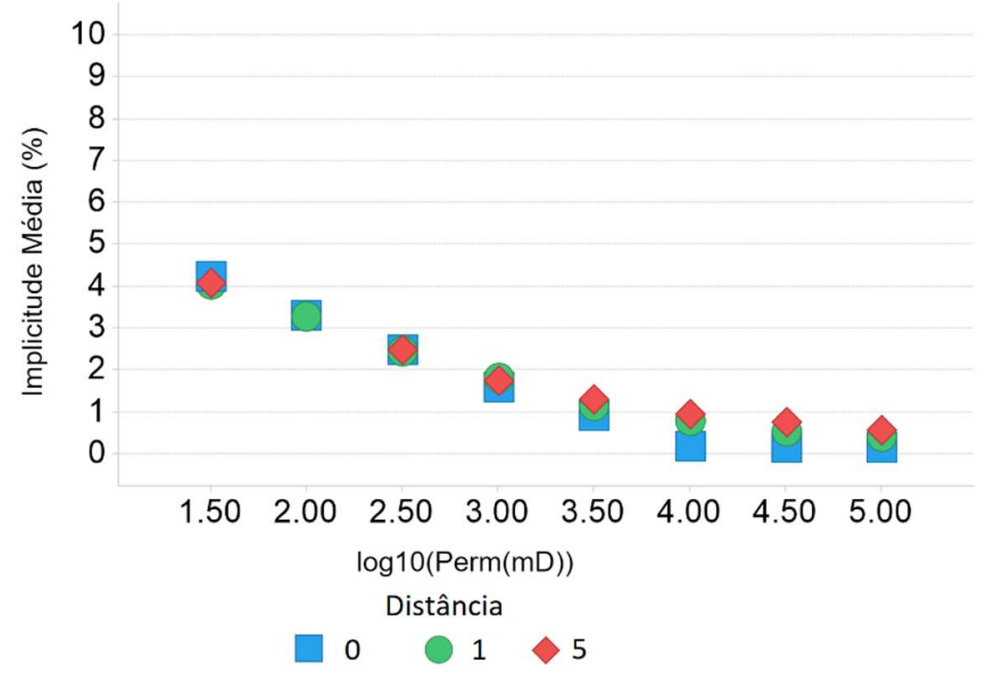

Figura 5.22: Implicitude média das simulações com injeção em matriz heterogênea, malha paralela à grade e com largura $=1$.

O fator de recuperação e o tempo para o breakthrough de água apresentam padrões similares entre si. Conforme esperado, o distanciamento do corredor de fraturas causa um aumento do $F R$ e uma irrupção de água mais tardia. Afinal, com o afastamento entre fraturas e poços, há uma piora na comunicação direta entre injetor e produtor. Não obstante, a diferença entre $D=0$ e $D=1$ não é tão destacada como nos aspectos numéricos (Figura 5.23). Em outras palavras, ao se deslocar a célula fraturada do poço para a célula adjacente, temos uma diferença pequena nas previsões de produção e um custo computacional severamente reduzido. Ressalta-se, entretanto, que as diferenças em $F R$ e $t_{D w}$ desses casos são pequenas, mas não desprezíveis, sobretudo para maiores valores de $K_{\text {frat }}$. Outro detalhe importante que causa essa diferença entre $D=0$ e $D=1$ é o canhoneio nas células fraturadas. Com isso, a água de injeção não passa pelo termo de transferência entre matriz e fratura. Ela entra no sistema diretamente nos blocos fraturados, escoa até o poço produtor e é produzida também diretamente, sem a necessidade de se passar para a matriz o que retardaria um pouco o breakthrough. Esse efeito pode ser observado na comparação dos mapas apresentada na Figura 5.24. $O$ caso com poços canhoneados em células de fratura apresentam $S_{\text {wi }}$ nas células de matriz, o que significa que a água injetada escoou preferencialmente pelas fraturas, muito mais permeáveis, chegando rapidamente ao poço produtor. Em contrapartida, no cenário em que as fraturas se encontram na célula adjacente ao poço, observa-se uma área com saturação de água aumentada pois não houve comunicação direta entre o poço e as fraturas. Portanto, parte do volume de água injetado foi disperso, retardando o breakthrough de água no poço produtor. 


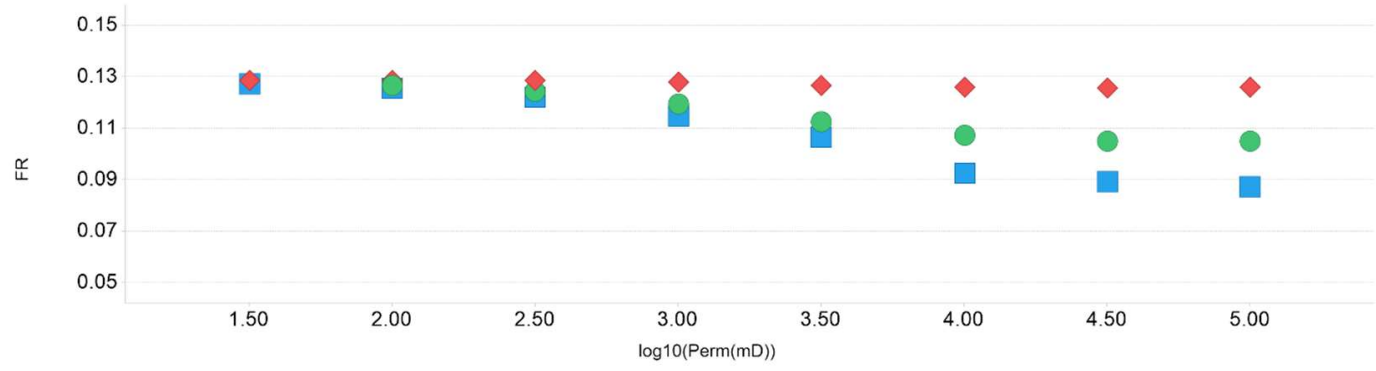

(b)

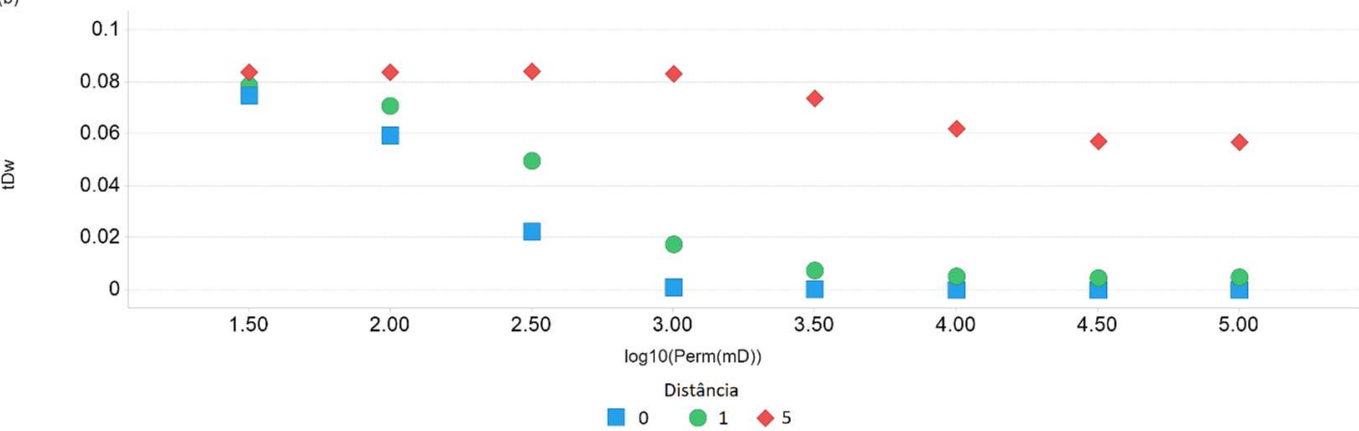

Figura 5.23: Resultados de produção das simulações com injeção em matriz heterogênea, malha paralela à grade e com largura=1: (a) FR; (b) $t_{D w}$.

Mapa da Saturação de Água na Camada $k=10$ no instante $t=3000$ dias

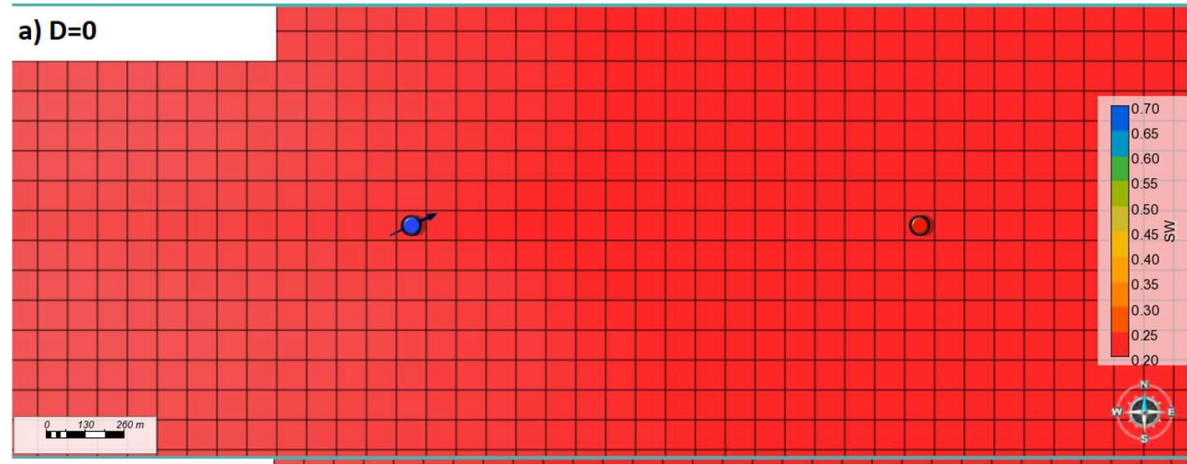

b) $D=1$

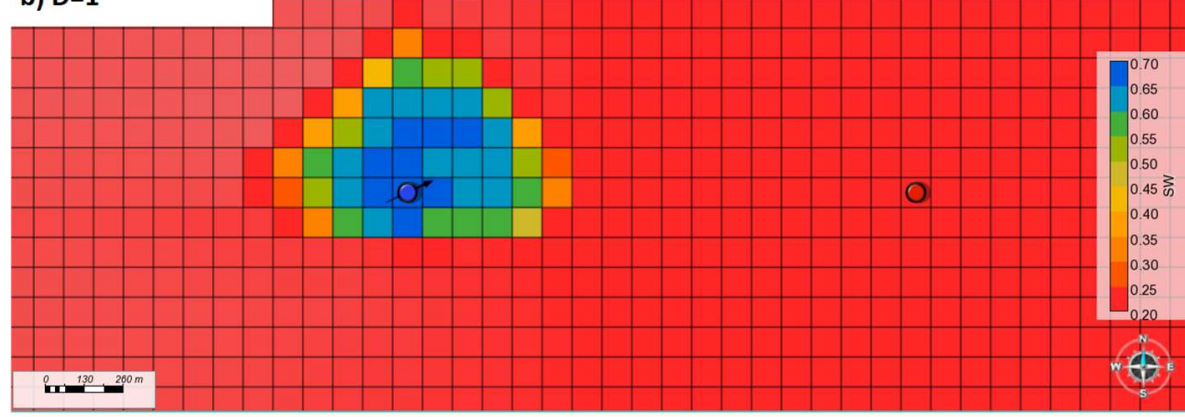

O Poço Produtor

or Poço Injetor de Água

Figura 5.24: Mapas de $S_{w}$ na matriz da camada $k=10$ no instante $t=3.000$ dias, do cenário de malha paralela, matriz heterogênea, L=1 e $K_{\text {frat }}=32.000 \mathrm{mD}$, comparando os cenários com a) $D=0$ e b) $D=1$. 
Ao se analisar a largura do corredor de fraturas, espera-se que seu aumento gere dois efeitos opostos na simulação. Por um lado, aumenta-se o número de blocos fraturados. Em compensação, como há uma maior área sendo varrida por essas células e a vazão de injeção e de produção são constantes, a velocidade do escoamento é menor. Investiga-se, pois, se a complexidade inserida pelo maior número de células é compensada pela diminuição das variações de pressão e de composição molar dos componentes nos blocos.

Ao se avaliar o comportamento das variáveis numéricas, com $D=5$ ou $D=1$, não se observam alterações relevantes entre os diversos valores de largura do corredor de fraturas. Apenas no número de cortes de timesteps se observa alguma alteração (Figura 5.25). Para permeabilidades de fratura acima de $10^{3,5} \mathrm{mD}$, as menores larguras apresentam um aumento de cortes de timestep. Isso é um indício de que em algum momento da simulação, as variações de pressão e de concentração molar dos componentes do fluido se tornaram muito altas, gerando a necessidade de menores timesteps para se chegar à convergência do simulador. Essas variações se mostram mais abruptas nos casos de menor largura (L). Esse resultado confirma o efeito esperado de maiores velocidades em corredores menos largos.

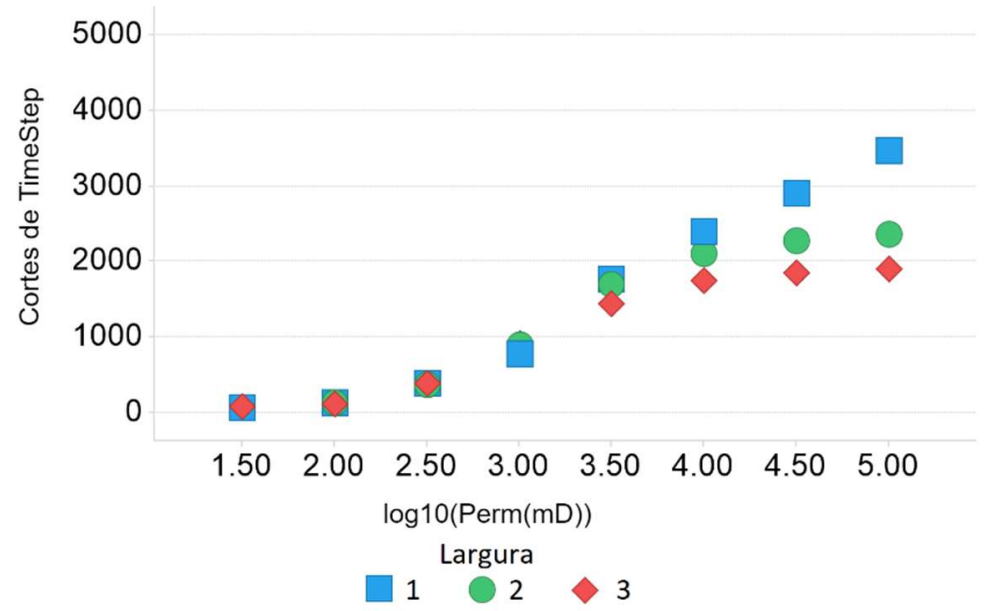

Figura 5.25: Número de cortes de timestep das simulações com injeção em matriz heterogênea, malha paralela à grade e com $\mathrm{D}=1$.

O cenário de $D=0$ apresentou outros resultados pertinentes. Algumas variáveis numéricas passam a ser afetadas pela largura do corredor de fraturas nessa condição. É o caso do número de ciclos newtonianos, de iterações do solver, de timesteps e do tempo de simulação. Não obstante, esses itens não são alterados da mesma maneira. Eles estão apresentados na Figura 5.26. Nota-se que o número de timesteps se comporta conforme o esperado, uma vez que são necessários passos de tempo menores para se convergir no caso em que os fluidos escoam mais rapidamente. Da mesma forma, são necessários mais ciclos 
newtonianos para se linearizar as equações decorrentes desses cenários. No entanto, ao se observar a quantidade de iterações do solver linear, nota-se que elas diminuem para o caso de $L=1$. $O$ cenário que apresenta maior número de iterações é o de $L=2$, seguido por $L=3$. Isso se deve ao maior número de células fraturadas nesses dois cenários, que tornam as equações desses casos mais complexas. Assim, a consequência final é um tempo maior de simulação para os cenários de largura maior do corredor de fraturas, a despeito do maior número de timesteps do caso com L=1.
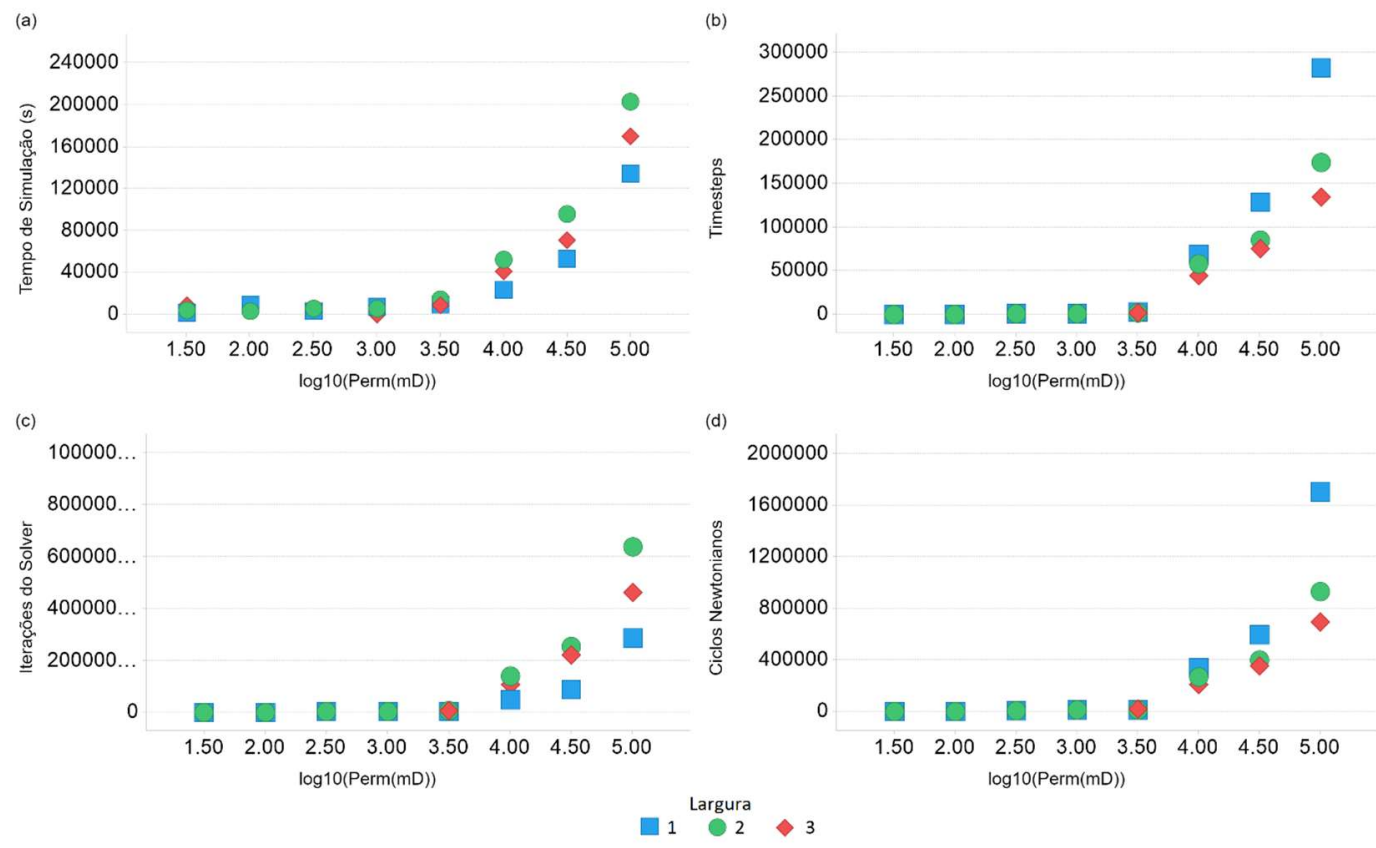

$\square=\frac{\text { Largura }}{2} \underset{2}{2}$

Figura 5.26: (a)Tempo de simulação, (b) número de timesteps, (c) de iterações do solver e (d) de ciclos newtonianos das simulações com injeção em matriz heterogênea, malha paralela à grade e com $\mathrm{D}=0$.

Por fim, foi observado um impacto modesto na produção (Figura 5.27). Esperava-se que a menor velocidade do escoamento decorrente do aumento de $\mathrm{L}$ trouxesse maiores recuperações e maior tempo até a chegada de água no produtor. Isso ocorre, porém de forma pouco relevante. Sobretudo porque para valores muito altos de $K_{\text {frat }}$ o breakthrough passa a ocorrer com tempos próximos de zero. Logo, apesar de se observar uma velocidade menor dos fluidos, isso não é refletido em termos de produção, para esse caso simplificado que foi estudado. Cenários com mais poços e diferentes associações (malhas de drenagem) poderiam gerar resultados diferentes. 


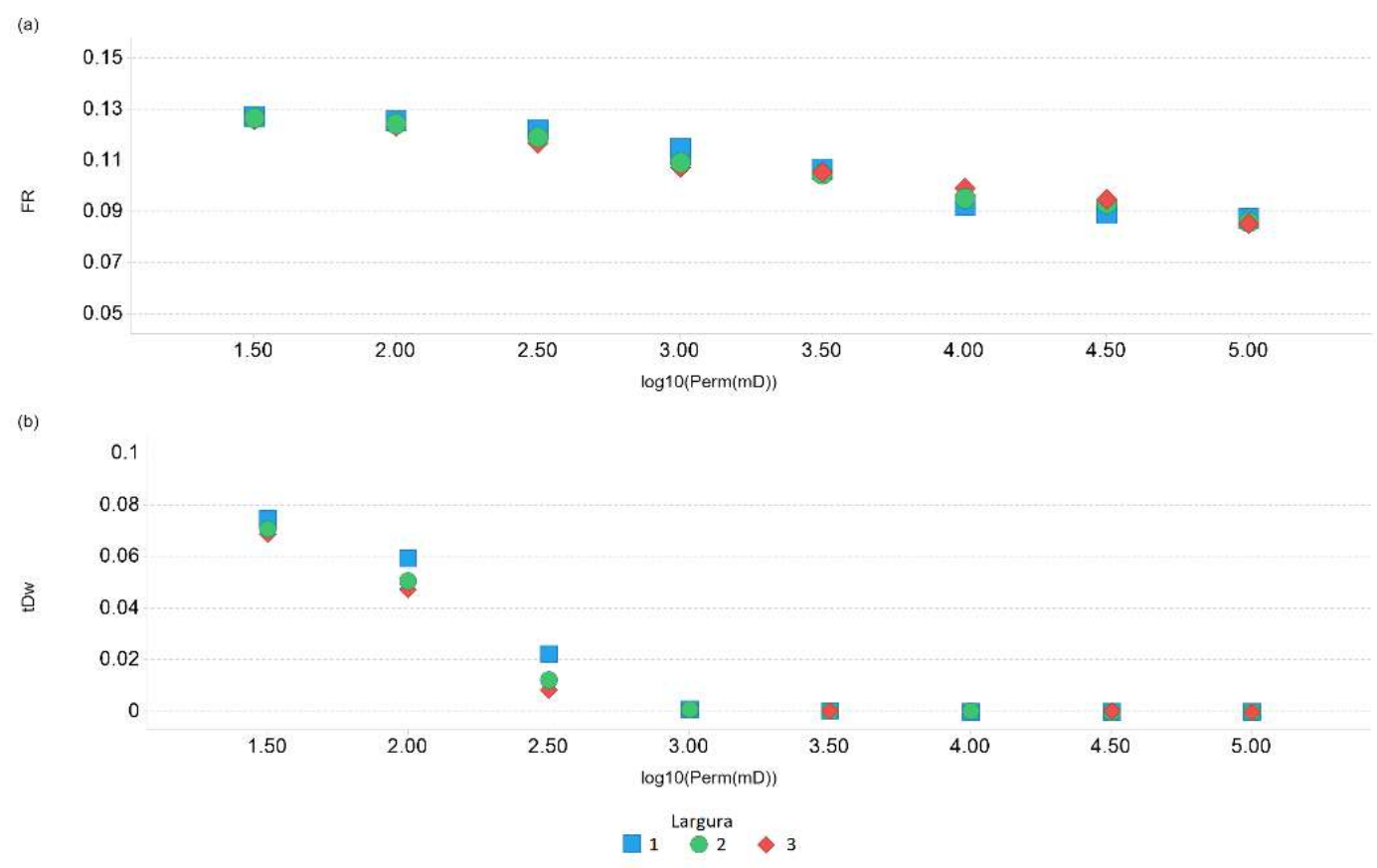

Figura 5.27: (a)FR e (b) $t_{D w}$ das simulações com injeção em matriz heterogênea, malha paralela à grade e com $\mathrm{D}=0$.

\subsubsection{Comportamento das Previsões de Produção em Relação à Permeabilidade Efetiva de Fraturas}

O objetivo dessa seção é estabelecer um padrão para o comportamento do fator de recuperação e do tempo até o breakthrough em relação à permeabilidade do corredor de fraturas.

As Figuras 5.28 e 5.29 mostram a média dos valores de fator de recuperação e de tempo adimensional até o breakthrough, de água, respectivamente, para cada valor de permeabilidade do corredor de fraturas. Observa-se a tendência sigmoidal de resposta das variáveis. Ou seja, para permeabilidades de fratura pequenas, os resultados pouco se alteram e o mesmo ocorre para $K_{\text {frat }}$ muito altos. Todavia, esses dois patamares são diferentes, de forma que em valores intermediários, ocorre uma transição entre eles. 


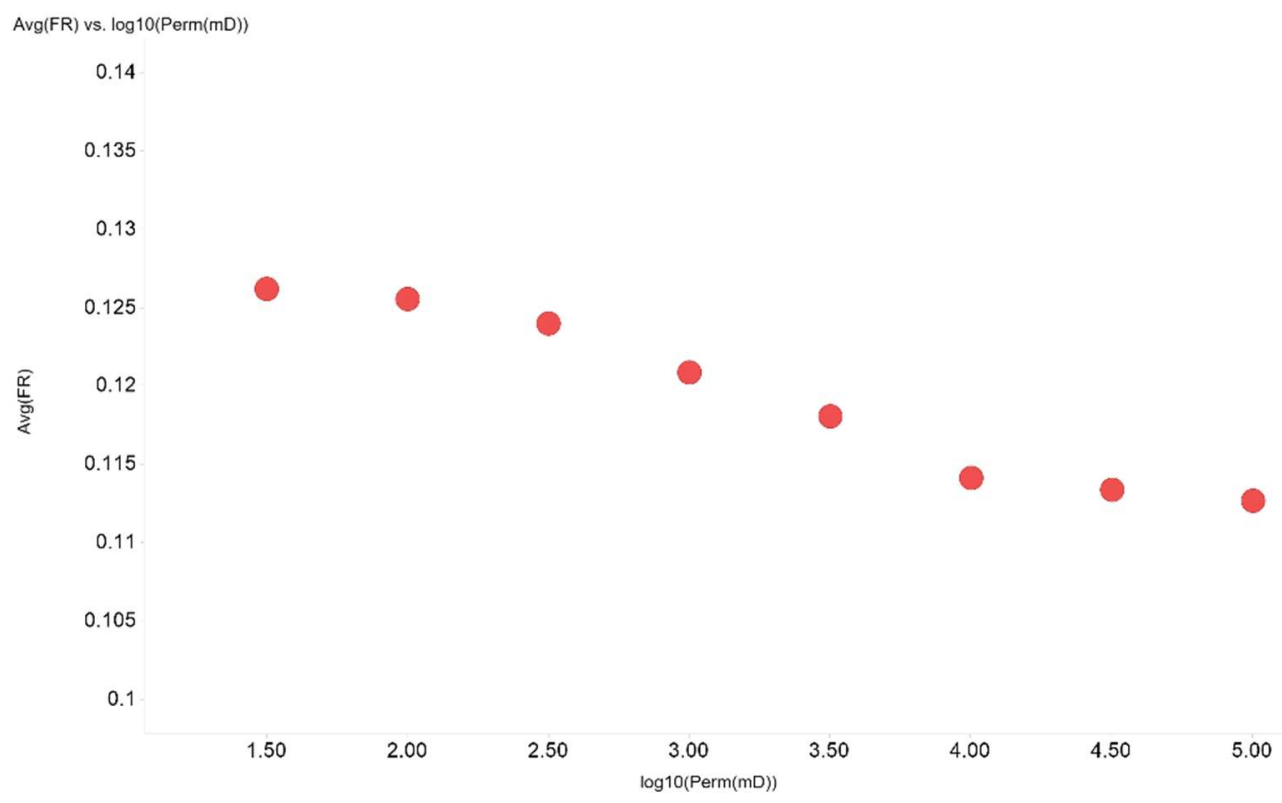

Figura 5.28: $F R$ médio $\times \log _{10}\left(K_{\text {frat }}\right)$.

$\operatorname{Avg}(\mathrm{tD} w)$ vs. $\log 10($ Perm(mD))

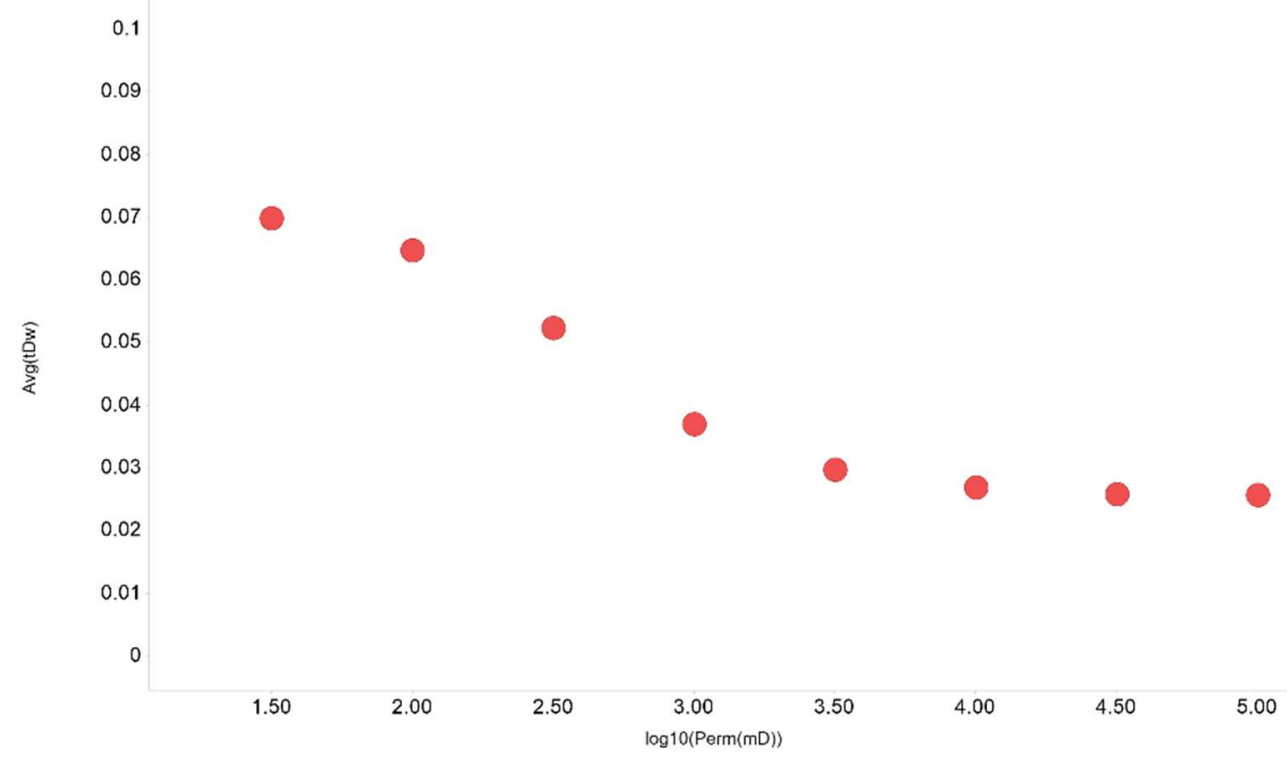

Figura 5.29: $t_{D w}$ médio $x \log _{10}\left(K_{f r a t}\right)$.

Modelar esse comportamento assintótico é pertinente para o trabalho de simulação de escoamento em reservatórios pois o seu objetivo é representar o comportamento do campo de forma fidedigna com o menor custo computacional possível. Portanto, se for possível estimar um valor de permeabilidade de fraturas a partir do qual incrementá-lo não cause impacto na estimativa de produção, será possível realizar simulações mais simples e rápidas com produtos confiáveis. Consequentemente, optou-se por fazer um ajuste utilizando uma 
equação conhecida como função logística (PENG et al., 2002), cuja fórmula foi apresentada na Equação 3-2.

Qualitativamente, pode-se afirmar que os fatores relevantes para essa avaliação são o ponto de inflexão $\left(p_{i}\right)$ e a inclinação da curva no ponto de inflexão $(h)$. Entretanto, é pertinente experimentar buscar uma quantificação para a assintocidade da curva modelada. O ponto de partida, naturalmente, é a derivação da Equação 3-2:

$$
\begin{gathered}
\frac{d y}{d x}=\frac{d}{d x}\left(y_{\text {mín }}+\frac{\left(y_{\text {máx }}-y_{\text {min }}\right)}{1+\left(10^{h\left(p_{i}-x\right)}\right)}\right) \\
\frac{d y}{d x}=\left(y_{\text {máx }}-y_{\text {mín }}\right) \frac{d}{d x}\left(\frac{1}{1+\left(10^{h\left(p_{i}-x\right)}\right)}\right) \\
\frac{d y}{d x}=-\left(y_{\text {máx }}-y_{\text {mín }}\right)\left(\frac{\frac{d}{d x}\left(1+\left(10^{h\left(p_{i}-x\right)}\right)\right)}{\left(1+\left(10^{h\left(p_{i}-x\right)}\right)\right)^{2}}\right) \\
\frac{d y}{d x}=-\left(y_{\text {máx }}-y_{\text {mín }}\right) \ln (10)\left(\frac{10^{h\left(p_{i}-x\right)}\left(\frac{d\left(h\left(p_{i}-x\right)\right)}{d x}\right)}{\left(1+\left(10^{h\left(p_{i}-x\right)}\right)\right)^{2}}\right) \\
\frac{d y}{d x}=h\left(y_{\text {máx }}-y_{\text {mín }}\right) \ln (10)\left(\frac{10^{h\left(p_{i}-x\right)}}{\left(1+\left(10^{h\left(p_{i}-x\right)}\right)\right)^{2}}\right) .
\end{gathered}
$$

Em seguida, é necessário rearranjar a equação para melhor avaliar a assintocidade:

$$
\begin{gathered}
\frac{d y}{d x}=h\left(y_{\text {máx }}-y_{\text {mín }}\right) \ln (10)\left(\frac{10^{h\left(p_{i}-x\right)}+(1-1)}{\left(1+\left(10^{h\left(p_{i}-x\right)}\right)\right)^{2}}\right) \\
\frac{d y}{d x}=h\left(y_{\text {máx }}-y_{\text {mín }}\right) \ln (10)\left(\frac{10^{h\left(p_{i}-x\right)}+1}{\left(1+\left(10^{h\left(p_{i}-x\right)}\right)\right)^{2}}-\frac{1}{\left(1+\left(10^{h\left(p_{i}-x\right)}\right)\right)^{2}}\right) \\
\frac{d y}{d x}=h\left(y_{\text {máx }}-y_{\text {mín }}\right) \ln (10)\left(\frac{1}{\left(1+\left(10^{h\left(p_{i}-x\right)}\right)\right)}-\frac{1}{\left(1+\left(10^{h\left(p_{i}-x\right)}\right)\right)^{2}}\right) .
\end{gathered}
$$

Por fim, para a função se tornar assintótica, sua derivada deve tender a zero. Consequentemente, tem-se que:

$$
\frac{1}{\left(1+\left(10^{h\left(p_{i}-x\right)}\right)\right)}-\frac{1}{\left(1+\left(10^{h\left(p_{i}-x\right)}\right)\right)^{2}} \rightarrow 0
$$

Agora, para facilitar a análise da convergência dessa função, são feitas as seguintes substituições: 


$$
\begin{gathered}
\alpha=h\left(p_{i}-x\right) \\
\beta=\frac{1}{\left(1+\left(10^{\alpha}\right)\right)}-\frac{1}{\left(1+\left(10^{\alpha}\right)\right)^{2}} \rightarrow 0 .
\end{gathered}
$$

E, por fim, apresenta-se a Tabela 5.2 com alguns resultados dessa função.

Tabela 5.2: Convergência da equação logística $(\alpha \times \beta)$

\begin{tabular}{cccc}
\hline$\alpha$ & $\frac{1}{2}$ & 1 & \\
\cline { 2 - 4 } & $\left(1+\left(10^{\alpha}\right)\right)$ & $\left(1+\left(10^{\alpha}\right)\right)^{2}$ & $\beta$ \\
\hline 0 & 0.50000 & 0.25000 & 0.25000 \\
\hline 1 & 0.90909 & 0.82645 & 0.08264 \\
\hline 2 & 0.99010 & 0.98030 & 0.00980 \\
\hline 3 & 0.99900 & 0.99800 & 0.00100 \\
\hline 4 & 0.99990 & 0.99980 & 0.00010 \\
\hline 5 & 0.99999 & 0.99998 & 0.00001 \\
\hline
\end{tabular}

Percebe-se que $\beta$ converge rapidamente, permitindo definir quando a curva pode ser considerada assintótica. A partir desse valor definido, tem-se um alvo para $\alpha$, denominado $\alpha_{a}$. Portanto, tem-se que:

$$
\begin{gathered}
\alpha_{a}=h\left(p_{i}-x_{a}\right) ; \\
x_{a}=\frac{\alpha_{a}}{h}+p_{i}
\end{gathered}
$$

onde $x_{a}$ é a permeabilidade de fratura a partir da qual o comportamento da saída é assintótico.

Em seguida, fez-se o exercício de realizar um ajuste automático para cada cenário estudado. Para fins de exemplificação, alguns dos ajustes são apresentados na Figura 5.30. 

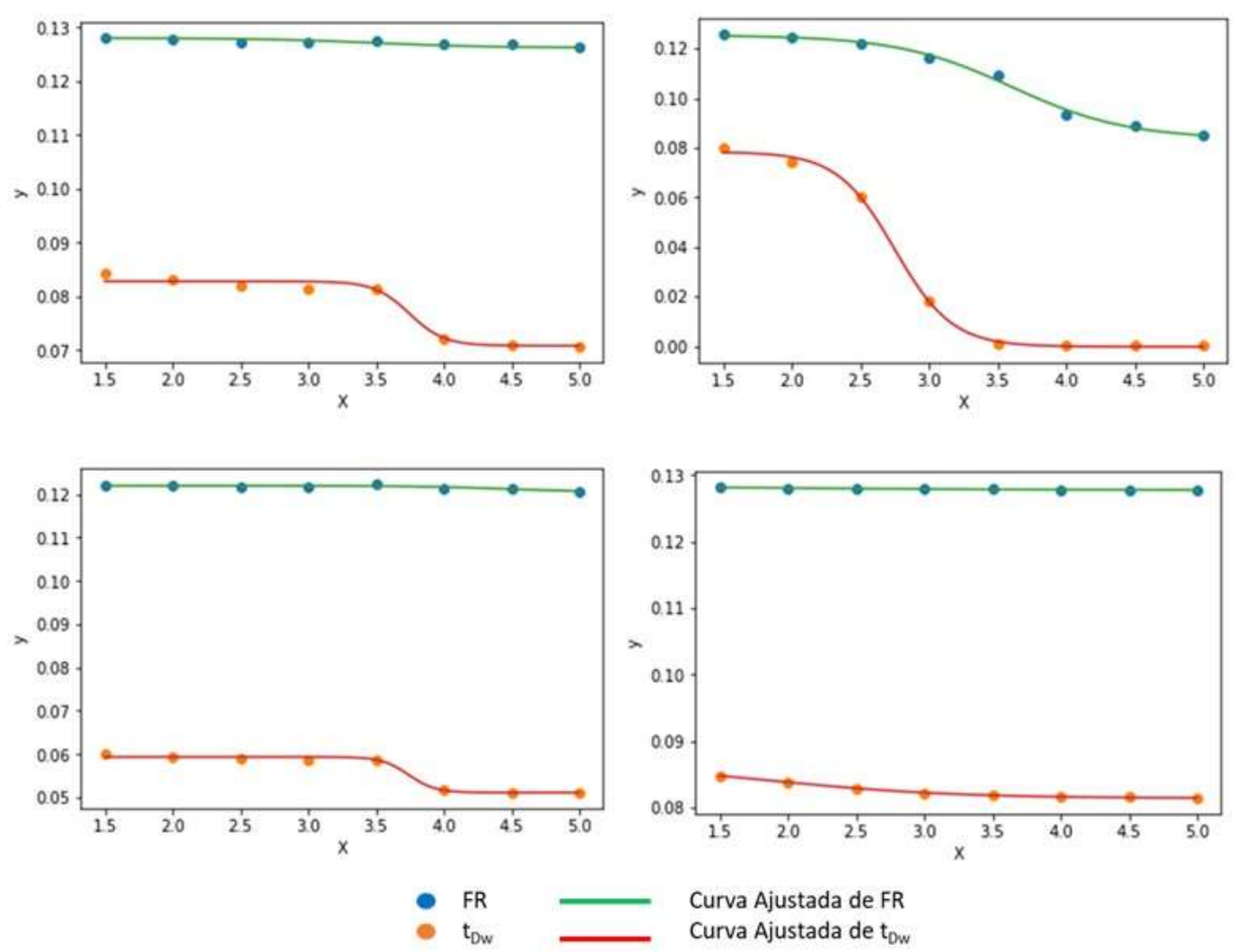

Figura 5.30: Exemplos de ajustes de $t_{D w}$ e de $F R$ por $K_{\text {frat }}$.

Os resultados obtidos podem ser encontrados no Apêndice B. Nas tabelas, há uma coluna determinada $x_{a}$ cujos valores foram calculados com $\alpha=1$. Com esse valor, as derivadas resultantes desses pontos são inferiores a 0.01 para $F R$ e 0.1 para $t_{D w}$. Para as análises foram excluídos os dados com malha diagonal à grade e $L=1$, considerando as distorções que esses casos geram.

O foco desse trabalho está na determinação de $x_{a}$. O interesse de se modelar o comportamento das saídas de produção pela permeabilidade efetiva das fraturas é investigar a possibilidade de haver um valor que permita a simplificação das simulações de dupla permeabilidade sem alterar os resultados significativamente.

Na Figura 5.31, observa-se um gráfico que compara os valores de $x_{a}$ obtidos para as duas saídas de produção ( $t_{D w}$ e $F R$ ), ao mesmo tempo que destaca através da cor os casos com valores de $D$ iguais. Nele se observa que as duas variáveis não são facilmente correlacionáveis. Isso é decorrente do tempo até o breakthrough possuir um valor mínimo que faz com que esse parâmetro atinja a assintocidade com mais facilidade. Nota-se, portanto, pouca variação do valor de $x_{a}$ de $t_{D w}$ quando se faz o agrupamento por D. Para os outros parâmetros, L, posição dos poços e heterogeneidade da matriz, não foi observado nenhum padrão claro de agrupamento. 


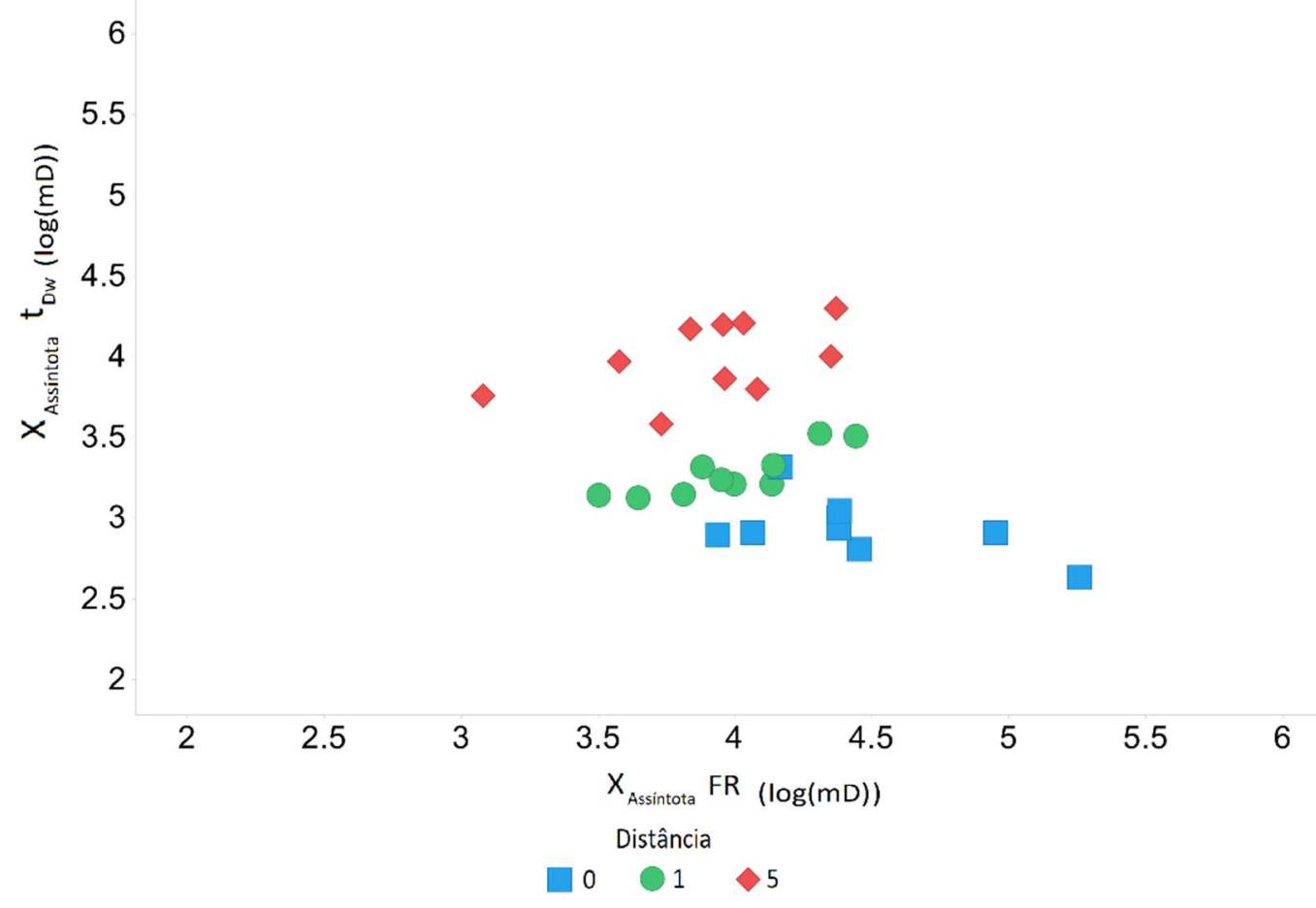

Figura 5.31: $x_{a}$ de $t_{D w}$ por $x_{a}$ de $F R$ colorido pela distância entre poços e fraturas.

Através desse mesmo gráfico, é possível perceber que para os dois parâmetros mostrados, os valores obtidos variam de cerca de $10^{3} \mathrm{mD}$ a $10^{5,5} \mathrm{mD}$. Logo, pode-se afirmar que para alguns dos cenários simulados, seria possível utilizar valores de $K_{\text {frat }}$ mais baixos e obter resultados de produção semelhantes.

Outro ponto relevante são os valores mínimos de ambos os $x_{a}$. Nota-se que para permeabilidades de fratura abaixo de $10^{3} \mathrm{mD}$, nenhum caso atinge a assintocidade. Ou seja, para variações abaixo desse valor, espera-se que haja impacto nas saídas de produção em todos os casos estudados.

Como comentário final desse capítulo, relembra-se que as simulações utilizadas nesse trabalho são baseadas em um modelo simplificado. Não há capa de gás, nem aquífero. Outras simplificações estão associadas à utilização de apenas um par de poços produtor-injetor, a estrutura do modelo não possuir variação estrutural e a vazão dos poços ser constante. Por conseguinte, os resultados apresentados nesse capítulo não devem ser extrapolados diretamente para casos reais com todas as complexidades supracitadas. Todavia, os casos apresentados servem de ponto de partida para análises mais aprofundadas dos temas abordados. 


\section{Conclusões}

As conclusões são apresentadas em três partes: a primeira referente ao ajuste dos parâmetros numéricos dos modelos de simulação, seguida dos cenários de depleção com apenas um poço produtor e, finalmente, dos cenários com manutenção de pressão com um par de poços produtor-injetor. Para finalizar, são sugeridos temas de pesquisa para trabalhos futuros.

\subsection{Ajuste dos Parâmetros Numéricos}

O simulador de reservatórios composicional GEM mostrou-se bastante robusto e eficiente para a análise de reservatórios de dupla porosidade e permeabilidade. A existência de extenso conjunto de parâmetros de controle numérico e a disponibilidade detalhada dos resultados numéricos obtidos permitiu uma análise rigorosa dos problemas investigados. Portanto, fica confirmada a adequação da escolha do simulador ao qual foram submetidos com êxito vários problemas numericamente desafiadores.

A especificação dos controles numéricos do simulador de reservatórios define o tempo que será gasto na execução e análise, assim como a qualidade dos resultados que serão obtidos das simulações. Logo, é importante que esses parâmetros sejam definidos de forma a minimizar o tempo de simulação, mantendo a precisão dos resultados encontrados.

Devido à maior simplicidade dos casos com injeção de água, em que não há gás livre no reservatório, os parâmetros utilizados foram satisfatórios. Não era de interesse durante esse trabalho, todavia, realizar ajustes específicos para que as simulações obtivessem resultados numéricos melhores também nos casos de depleção, uma vez que isso seria demasiado oneroso e poderia gerar comparações inconclusivas para as análises numéricas.

Não há uma parametrização numérica única que seja adequada para todo e qualquer reservatório que venha a ser simulado com formulação composicional. Nos casos de dupla porosidade e dupla permeabilidade, o problema se agrava. Quando há contrastes significativos nas propriedades permoporosas da matriz e da fratura, a mesma especificação não é capaz de lidar de forma ótima em ambos os contextos. Assim, buscar esses parâmetros pode ser um trabalho árduo. Para trabalhos que envolvam a comparação de muitas simulações, sugere-se rodar todos os casos com uma parametrização que gere resultados minimamente confiáveis. Em seguida, selecionar os cenários mais promissores e realizar um ajuste da especificação numérica apenas para essa menor quantidade de simulações. 


\subsection{Cenários sem Injeção}

Para se realizar as análises dos cenários nos quais se produziu apenas por depleção do reservatório foi necessário utilizar um filtro expurgando os casos de EBM excessivo. Ainda assim, os casos com erro abaixo de $1 \%$ foram avaliados, chegando-se a algumas conclusões.

A heterogeneidade da matriz nos casos testados não produz impacto relevante nas simulações, tanto numericamente como nas saídas de produção. Ou seja, mesmo em rochas heterogêneas, as propriedades médias da rocha são os fatores mais determinantes para a produção, no caso de depleção, pois o impacto da compressibilidade da rocha e dos fluidos do reservatório se sobrepõe aos efeitos hidrodinâmicos.

Os aspectos geométricos do corredor de fraturas também não mostram impactos significativos em relação à previsão de produção. Não obstante, apesar dos resultados observados nesse estudo, há casos em que isso pode não ocorrer. Para reservatórios com aquífero ou capa de gás, as fraturas podem comunicá-los com os poços produtores. Consequentemente, haveria uma produção de fluidos indesejada, diminuindo a recuperação de óleo. Portanto, é recomendável ter cautela ao lidar com produção de reservatórios fraturados, mesmo sem injeção de fluidos.

A largura do corredor de fraturas apresentou um efeito no tempo de simulação. Os casos com mais células fraturadas ( $L$ maior) acarretou maiores tempos de simulação. Este é um indício de que, dentro dos cenários propostos, um número maior de blocos de fratura torna a solução das equações de escoamento mais demorada e esse efeito não é compensado pelas menores velocidades dos fluidos nas fraturas.

\subsection{Cenários com Injeção}

Os casos com injeção não apresentaram dificuldades da solução numérica e permitem avaliar de forma clara como as fraturas impactam a produção. Porém, para que isso ocorra, é necessário que haja continuidade no sistema de dupla permeabilidade, ou seja, que as células fraturadas sejam adjacentes.

Casos homogêneos apresentaram tempos menores até o breakthrough. Não obstante, o aumento do corte de água se mostra mais suave, quando comparado com os casos heterogêneos. Esse efeito se deve, principalmente, à homogeneização da frente de água injetada causada pela permeabilidade heterogênea da matriz, mitigando a segregação gravitacional que causa o breakthrough verificado para os casos homogêneos.

A comparação das duas orientações de malha revelou os efeitos numéricos da discretização espacial. O par produtor-injetor direcionado a $45^{\circ}$ em relação à grade de simulação obteve maiores tempos para a irrupção de água e fatores de recuperação mais 
elevados, em geral. As exceções ocorrem quando as permeabilidades do corredor de fraturas são demasiadamente altas.

O cenário com a direção dos poços a $45^{\circ}$ da orientação da malha do modelo mostrou a importância da continuidade do sistema de fraturas para que ele seja efetivo. No cenário em que a largura do corredor é igual a uma célula, os blocos de fratura não se conectam, e, assim, o aumento de $K_{\text {frat }}$ não causa efeitos na produção.

A largura do corredor de fraturas apresenta impacto restrito. Seu efeito mais intenso é na qualidade dos resultados da simulação, devido ao maior número de células de dupla permeabilidade. No entanto, a distância aos poços influencia tanto nos aspectos numéricos como nos resultados de produção. O tempo de simulação aumenta em quase duas ordens de grandeza quando as células canhoneadas possuem dupla permeabilidade. Outrossim, precisão das variáveis de produção apresentam uma piora com a diminuição da distância.

O comportamento do fator de recuperação e do tempo até o breakthrough de água se mostrou assintótico, com o aumento da permeabilidade das fraturas. Foi possível modelar esse comportamento como uma sigmoide por meio de uma equação logística. Através dessa função, buscou-se estimar um valor denominado $x_{a}$ que representa a permeabilidade efetiva de fratura a partir da qual não há mais impacto significativo na produção de óleo nem no tempo até o breakthrough de água.

Funções logísticas foram definidas com capacidade de modelar os casos estudados. A partir desses resultados, foram calculados os valores de $x_{a}$ para o $F R$ e o $t_{D w}$ de cada cenário. Esses valores não são diretamente correlacionáveis, sendo que $t_{D w}$ atinge o padrão assintótico com menores valores de $K_{\text {frat }}$. Por fim, foram apresentados valores que apresentam comportamentos assintóticos em todos os cenários estudados. Entretanto, esse resultado não pode ser extrapolado para outros cenários mais complexos. Para tanto, seriam necessários estudos adicionais levando em consideração diversos parâmetros que foram simplificados nesse trabalho. Todavia, é um indício de que há casos em que é possível utilizar valores menores de permeabilidade de fratura, de forma a acelerar a simulação, sem que haja alteração significativa nos resultados de previsão de produção.

\subsection{Sugestões para Trabalhos Futuros}

Nesse trabalho foi possível modelar o comportamento sigmoidal das variáveis de produção de um par de poços em meio poroso com equações empíricas. Entretanto, é importante aprofundar a investigação sobre as variáveis que controlam essa modelagem. Dessa forma, seria viável estimar um valor de $K_{\text {frat }}$, a partir do qual, não há impacto nas previsões de produção, sem a necessidade de realizar previamente as simulações. 
O canhoneio das células de dupla permeabilidade requer pesquisa adicional. Os poços que atravessam fraturas são canhoneados tanto no meio poroso como no sistema de fraturas em todas as simulações aqui apresentadas. A análise dos casos nos quais os poços não se comunicam diretamente com as fraturas pode ampliar o conhecimento sobre os sistemas de dupla permeabilidade.

Existem outros modelos para simular as múltiplas porosidades e permeabilidades, tais como MINC; Brinkman; tripla porosidade e múltiplas porosidades. O estudo apresentado nessa pesquisa pode ser replicado com outras metodologias, utilizando outros simuladores e até mesmo empregando modelos de porosidade simples equivalente, tornando a análise comparativa ainda mais robusta. Como motivação, seguem algumas referências:

- Porosidade Simples Equivalente (SAALFELD, 2016);

- MINC (PRUESS e NARASIMHAN, 1985);

- Brinkman (BRINKMANN, 1942) (HALLACK e CAVALCANTE FILHO, 2019);

- Tripla porosidade (WU et al, 2011) (AL-GHAMDI et al. 2011);

- Múltiplas porosidades (YAN et al., 2016).

Finalmente, há vários aspectos de simulação que não foram abordados nesse trabalho, mas merecem ser analisados em estudos futuros. Dentre as questões de maior impacto na simulação, algumas merecem destaque:

- Dimensão das células;

- Relação $\mathrm{K}_{\mathrm{v}} / \mathrm{K}_{\mathrm{h}}$;

- Presença de aquífero;

- Permeabilidade relativa;

- Características do fluido;

- Distribuições das fraturas;

- Porosidade das fraturas;

- Espaçamento das fraturas;

- Injeção de gás;

- Presença de capa de gás. 


\section{Referências Bibliográficas}

[AL-GHAMDI et al., 2011] AL-GHAMDI,A., CHEN,B., BEHMANESH,H., QANBARI,F., AGUILERA,R. An improved triple-porosity model for evaluation of naturally fractured reservoirs. Society of Petroleum Engineers, 14:397-404, 2011.

[ALMEIDA et al., 2010] ALMEIDA,A.S., LIMA,S.T.C., ROCHA,P.S., ANDRADE, A.M.T., BRANCO, C.C.M., CAPELEIRO PINTO, A.C. CCGS opportunities in the Santos Basin pre-salt development. In: SPE INTERNATIONAL CONFERENCE ON HEALTH, SAFETY AND ENVIRONEMENT IN OIL AND GAS EXPLORATION AND PRODUCTION, Rio de Janeiro (Brasil), 2010.

[BAKER e KUPPE, 2000] BAKER,R.O., KUPPE, F. Reservoir characterization for naturally fractured reservoirs. In: SPE ANNUAL TECHNICAL CONFERENCE AND EXHIBITION, Dallas (Texas, EUA), 2000.

[BARENBLATT et al., 1960] BARENBLATT,G.I., ZHELTOV,YU.P. , KOCHINA, I.N. Basic concepts in the theory of seepage of homogeneous liquids in fissured rocks [strata]. Journal of Applied Mathematics and Mechanics, 24:1286-1303, 1960.

[BARRETO e SCHIOZER, 2012] BARRETO,C.E., SCHIOZER,D.J. Inclusion of environment assessment in the decision-making process of petroleum fields projects. In: SPE LATIN AMERICA AND CARIBBEAN PETROLEUM ENGINEERING CONFERENCE, Cidade do México (México), 2012.

[BOURBIAUX, 2010] BOURBIAUX, B. Fractured reservoir simulation: a challenging and rewarding issue. Oil \& Gas Science and Technology Revue d'IFP Energies nouvelles, 65:227-238, 2010.

[BRATTON et al., 2006] BRATTON,T. ,CANH,D., QUE,N., DUC,N.V., GILLES-

PIE,P., HUNT,D., LI,B., MARCINEW,R., RAY,S., MONTARON,B., NELSON,R., SCHODERBECK,D., SONNERLAND,L. The nature of naturally fractured reservoirs. Oilfield Review, 18:4-23, 2006.

[BREASTER, 1972] BREASTER,C. Simultaneous flow of immiscible liquids through porous fissured media. Society of Petroleum Engineers, 12:297-305, 1972. 
[BRINKMAN, 1942] BRINKMAN,H.C. A calculation of the viscous force exerted by a flowing fluid on a dense swarm of particles. Applied

Scientific Research, 1:27-34, 1942.

[CMG, 2019] COMPUTER MODELLING GROUP (CMG). Manual do usuário GEM v2019.10, 2019.

[CAVALCANTE FILHO, 2016] CAVALCANTE FILHO,J.S.A. Mobility control of gas injection in highly heterogeneous and naturally fractured reservoirs. Tese de doutorado, The University of Texas at Austin, Austin - Texas - EUA, 2016.

[CHABOUREAU, 2013] CHABOUREAU,A.C., GUILlOCHEAU,F., ROBIN,C., ROHAIS,S., MOULIN,M., ASLANIAN,D. Paleogeographic evolution of the central segment of the South Atlantic during early cretaceous times: Paleotopographic and geodynamic implications. Tectonophysics, 604:191-223, 2013.

[COATS et al., 1967] COATS,K.H., NIELSEN,R.L., TERHUNE,M.H., WEBER,A.G. Simulation of three-dimensional, two-phase flow in oil and gas reservoirs. Society of Petroleum Engineers Journal, 7:377388, 1967.

[COLLINS et al., 1992] COLLINS,D.A., LI,L.X., GRABONSTOTTER,J.E. An efficient approach to adaptive-implicit compositional simulation with an equation of state. SPE Reservoir Engineering, 7:259-264, 1967.

[COREY, 1954] COREY,A.T. The interrelation between gas and oil relative permeabilities. Producers Monthly, 19:38-41, 1954.

[CRAMER, 2002] CRAMER, J.S. The origins of logistic regression. Tinbergen Institute Working Paper, 119/4, 2002.

[DA COSTA FRAGA et al., 2015] DA COSTA FRAGA,C.T., CAPELEIRO PINTO,A.C., BRANCO,C.C.M., PIZARRO,J.O.S., DA SILVA PAULO,C.A. Brazilian pre-salt: An impressive journey from plans and challenges to concrete results. In: OFFSHORE TECHNOLOGY CONFERENCE, Houston (Texas, EUA), 2015.

[DEAN e LO, 1988] DEAN,R.H., LO,L.L. Simulations of naturally fractured reservoirs. SPE Reservoir Engineering, 3:638-648, 1988.

[FIROOZABADI, 2000] FIROOZABADI,A. Recovery mechanisms in fractured reservoirs and field performance. Petroleum Society of Canada, 39:13-17, 2000. 
[GILMAN e KAZEMI, 1983] GILMAN,J.R., E KAZEMI,H. Improvements in simulation of naturally fractured reservoirs. Society of Petroleum Engineers Journal, 23:695-707, 1983.

[GILMAN e KAZEMI, 1988] GILMAN,J.R., E KAZEMI,H. Improved calculations for viscous and gravity displacement in matrix blocks in dual-porosity simulators. Journal of Petroleum Technology, 40:1:60-70, 1988.

[GOMES et al., 2020] GOMES,J.P., BUNEVICH,R.B., TEDESCHI,L.R., TUCKER,M.E., WHITAKER,F.F. Facies classification and patterns of lacustrine carbonate deposition of the Barra Velha Formation, Santos Basin, Brazilian pre-salt. Marine and Petroleum Geology, 113, 2020.

[HALLACK e CAVALCANTE FILHO, 2019] HALLACK,D.M.C., CAVALCANTE FILHO,J.S.A., COUTO,P. Implementation of a two-phase simulator based on the Brinkman's equation for vuggy-karstified reservoirs. In: OFFSHORE TECHNOLOGY CONFERENCE BRASIL, p. 27-34, Rio de Janeiro, Brazil, 2019.

[KAZEMI et al, 1969] KAZEMI,H., SETH,M.S., THOMAS,G.W. The interpretation of interference tests in naturally fractured reservoirs with uniform fracture distribution. Society of Petroleum Engineers, 9:463-472, 1969.

[KAZEMI et al, 1976] KAZEMI,H., MERRILL,L.S., PORTERFIELD,K.L., ZEMAN,P.R. Numerical simulation of water-oil flow in naturally fractured reservoirs. Society of Petroleum Engineers, 5719:317-326, 1976.

[LAKE e JENSEN, 1991] LAKE,L., JENSEN,J. A review of heterogeneity measures used in reservoir characterization. In Situ, 15:409-439, 1991.

[LEMONIER e BOURBIAUX, 2010] LEMONNIER,P., BOURBIAUX,B. Simulation of naturally fractured reservoirs. state of the art - part 2 - matrix-fracture transfers and typical features of numerical studies. Oil Gas Science Technology - Rev. IFP, 65:263-286, 2010.

[LIAN et al., 2012] LIAN,P.Q., CHENG,L.S., MA,C.Y. The characteristics of relative permeability curves in naturally fractured carbonate reservoirs. Journal of Canadian Petroleum Technology, 51:137-142, 2012.

[LIMA E DE ROS, 2019] LIMA,B.E AND DE ROS,L.F. Deposition, diagenetic and hydrothermal processes in the Aptian pre-salt lacustrine carbonate reservoirs of the northern Campos Basin, offshore Brazil. Sedimentary Geology, 383:55-81, 2019. 
[MACHADO, 2018] MACHADO, M.V.B. Modelagem e simulação numérica de reservatórios de petróleo. Notas de Aula, 2018.

[MOCZYDLOWER et al., 2012] MOCZYDLOWER,B., SALOMAO,M.C., BRANCO,C.C.M., ROMEU,R.K., HOMEM,T.R., DE FREITAS,L.C., LIMA,H.A.T.S. Development of the Brazilian pre-salt fields when to pay for information and when to pay for flexibility. In: SPE LATIN AMERICA AND CARIBBEAN PETROLEUM ENGINEERING CONFERENCE, Cidade do México (México), 2012.

[MOREIRA et al., 2007] MOREIRA,J.L.P., MADEIRA,C.V., GIL,J.A., MACHADO,M.A.P. Bacia de Santos. Boletim de Geociências da Petrobras, 15:531-549, 2007.

[NELSON, 2001] NELSON,R. Geological Analysis of Naturally Fractured Reservoirs. Gulf Professional Publishing, Houston, Texas, EUA, $2^{\text {nd }}$ edition, 2001.

[NGHIEM e LI, 1988] NGHIEM,L.X., LI,Y.-K. Phase-equilibrium calculations for reservoir engineering and compositional simulation. In: FIRST INTERNATIONAL FORUM ON RESERVOIR SIMULATION, Alpbach (Austria), 1988.

[ODEH, 1965] ODEH,A.S. Unsteady-state behavior of naturally fractured reservoirs. Society of Petroleum Engineers, 5:60-66, 1965.

[ODEH, 1969] ODEH,A.S. Reservoir simulation ...what is it? Journal of Petroleum Technology, 21:1383-1388, 1969.

[PEACEMAN, 1977] PEACEMAN,D.W. Fundamentals of numerical reservoir simulation. Elsevier Scientific Publishing Company, Amsterdã, Holanda, $1^{\text {st }}$ edition, 1977.

[PENG et al., 2002] PENG,C.Y.J., LEE,K.L., INGERSOLL,G.M. An introduction to logistic regression analysis and reporting. Journal of Educational Research - J EDUC RES, 96:314, 2002.

[PIZARRO e BRANCO, 2012] PIZARRO,J.O.S., BRANCO,C.C.M. Challenges in implementing an EOR project in the pre-salt province in deep offshore Brazil. In: SPE EOR AT OIL AND GAS WEST ASIA, Muscat (Oman), 2012.

[PIZARRO et al., 2017] PIZARRO,J.O.S., POLI,R.E.B., ROSA,M.B., SILVA,V.C., BRANCO,C.C.M., CUNHA,B.M., DORIA,M.A.E, ALES,N., BATELLO,D., PINTO,A.C.C. Optimizing production of Santos Basin pre-salt fields through sound reservoir management practices. In: OFFSHORE TECHNOLOGY CONFERENCE BRASIL, Rio de Janeiro (Brasil), 2017. 
[PRUESS e NARASIMHAN, 1985] PRUESS,K., NARASIMHAN,T.N. A practical method for modeling fluid and heat flow in fractured porous media. Society of Petroleum Engineers, 25:14-26, 1985.

[ROSA et al., 2006] ROSA,A.J., CARVALHO,R., XAVIER,J.A. Engenharia de reservatórios de petróleo. Editora Interciência, Rio de Janeiro, Brasil, $2^{\mathrm{a}}$ edition, 2006.

[ROSA et al., 2018] ROSA,M.B., CAVALCANTE,J.S.A., MIYAKAWA,T.M., FREITAS,L.C.S. The giant Lula field: World's largest oil production in ultra-deep water under a fast-track development. In: OFFSHORE TECHNOLOGY CONFERENCE, Houston (Texas, EUA), 2018.

[ROSSEN e KUMAR, 1994] ROSSEN,W.R., KUMAR,A.T.A. Effect of fracture relative permeabilities on performance of naturally fractured reservoirs. In: INTERNATIONAL PETROLEUM CONFERENCE AND EXHIBITION OF MEXICO, Veracruz (México), 1994.

[SAALFELD, 2016] SAALFELD,R.Q. Simulação de reservatórios naturalmente fraturados utilizando modelos equivalentes de porosidade simples. Dissertação de mestrado, Universidade Estadual de Campinas - SP, Campinas - SP - Brasil, 2016.

[SALOMÃO et al., 2015] SALOMÃO,M.C., MARÇON,D.R., ROSA,M.B., PESSOA,T.C.S., CAPELEIRO PINTO, A.C. Broad strategy to face with complex reservoirs: Expressive results of production in pre-salt area, offshore Brazil. In: OFFSHORE TECHNOLOGY CONFERENCE, Houston (Texas, EUA), 2015.

[SANTOS, 2013] SANTOS, L.O.S. Development of a multi-formulation compositional simulator. Tese de doutorado, The University of Texas at Austin, Austin - Texas - EUA, 2013.

[SANTOS, 2015] SANTOS, L.O.S. Fundamentos de simulação de reservatório. Notas de Aula, 2015.

[SHELDON e CARDWELL, 1959] SHELDON, J.W., CARDWELL JR.,W.T. One-dimensional, incompressible, noncapillary, two-phase fluid flow in a porous medium. Transactions of the AIME, 216:290-296, 1959.

[SONIER et al., 1988] SONIER,F., SUILLARD,P., BLASKOVICH,F.T. Numerical simulation of naturally fractured reservoirs. SPE Reservoir Engineering, 3:1114-1122, 1988.

[STONE e GARDNER, 1961] STONE,H.L., GARDER JR.,A.O. Analysis of gas-cap or dissolved-gas drive reservoirs. Society of Petroleum Engineers Journal 1, 02:92-104, 1961. 
[THOMAS, 1981] THOMAS,G.W. Principles of hydrocarbon reservoir simulation. International Human Resources Development Corporation, Boston, EUA, $2^{\text {nd }}$ edition, 1981.

[TODD, 1972] TODD,M.R., O'DELL,P.M., HIRASKI,G.J. Methods for increased accuracy in numerical reservoir simulators. Society of Petroleum Engineers Journal, 12:515-530, 1972.

[TORABI et al., 2020] TORABI,A., ELLINGSEN,T.S.S., JOHANNESSEN,M.U., ALAEI,B., ROTEVATN,A., CHIARELLA,D. Fault zone architecture and its scaling laws: Where does the damage zone start and stop? Geological Society, London, Special Publications, 496:99-124, 2004.

[TRAN, 2004] TRAN,N.H. Characterization and modelling of naturally fractured reservoirs. University of New South Wales, Sidney, Australia, $1^{\text {st }}$ edition, 2004.

[WANG et al., 2015] WANG,F., LI,Y., TANG,X., CHEN,J., GAO,W. Petrophysical properties analysis of a carbonate reservoir with natural fractures and vugs using $\mathbf{x}$-ray computed tomography. Journal of Natural Gas Science and Engineering, 28:215-225, 2015.

[WARREN e ROOT, 1963] WARREN,J.E., ROOT,P.J. The behavior of naturally fractured reservoirs. Society of Petroleum Engineers, 426:245-255, 1963.

[WU et al, 2004] WU,Y., LIU,H.H., BODVARSSON, G.S. A triple-continuum approach for modeling flow and transport processes in fractured rock. Journal of Contaminant Hydrology, 73:145-179, 2004.

[WU et al, 2011] WU,Y., DI,Y., KANG,Z., FAKCHAROENPHOL,P. A multiple-continuum model for simulating single-phase and multiphase flow in naturally fractured vuggy reservoirs. Journal of Natural Gas Science and Engineering, 78:13-22, 2011.

[YAN et al., 2016] YAN,B., ALFI,M., AN,C., CAO,Y., WANG,Y., KILLOUGH,J. General multiporosity simulation for fractured reservoir modeling. Journal of Natural Gas Science and Engineering, 33:777-791, 201 


\section{Apêndice A. Tabelas com os Resultados das Simulações}

Tabela A.1: Resultados das simulações - numérico 1

\begin{tabular}{|c|c|c|c|c|c|c|c|c|}
\hline Matriz & Malha & D & $\mathbf{L}$ & $K_{\text {frat }}$ & Timesteps & $\begin{array}{c}\text { Ciclos } \\
\text { Newtonianos }\end{array}$ & $\begin{array}{l}\text { Iterações do } \\
\text { Solver }\end{array}$ & $\begin{array}{c}\text { Falhas do } \\
\text { Solver }\end{array}$ \\
\hline Heterogêneo & Depleção & 0 & 1 & 0 & 81 & 300 & 13279 & 68 \\
\hline Heterogêneo & Depleção & 0 & 1 & 32 & 116 & 465 & 23790 & 149 \\
\hline Heterogêneo & Depleção & 0 & 1 & 100 & 128 & 505 & 26516 & 176 \\
\hline Heterogêneo & Depleção & 0 & 1 & 320 & 173 & 754 & 39623 & 236 \\
\hline Heterogêneo & Depleção & 0 & 1 & 1000 & 150 & 688 & 35565 & 185 \\
\hline Heterogêneo & Depleção & 0 & 1 & 3200 & 139 & 588 & 31821 & 179 \\
\hline Heterogêneo & Depleção & 0 & 1 & 10000 & 117 & 459 & 25580 & 172 \\
\hline Heterogêneo & Depleção & 0 & 1 & 32000 & 146 & 583 & 29172 & 185 \\
\hline Heterogêneo & Depleção & 0 & 1 & 100000 & 255 & 1200 & 53803 & 372 \\
\hline Heterogêneo & Depleção & 0 & 2 & 0 & 76 & 292 & 13965 & 80 \\
\hline Heterogêneo & Depleção & 0 & 2 & 32 & 139 & 577 & 34047 & 291 \\
\hline Heterogêneo & Depleção & 0 & 2 & 100 & 164 & 683 & 39398 & 300 \\
\hline Heterogêneo & Depleção & 0 & 2 & 320 & 218 & 1032 & 55939 & 323 \\
\hline Heterogêneo & Depleção & 0 & 2 & 1000 & 316 & 1627 & 92669 & 601 \\
\hline Heterogêneo & Depleção & 0 & 2 & 3200 & 325 & 1591 & 104995 & 999 \\
\hline Heterogêneo & Depleção & 0 & 2 & 10000 & 444 & 2180 & 158621 & 1808 \\
\hline Heterogêneo & Depleção & 0 & 2 & 32000 & 206 & 839 & 62477 & 774 \\
\hline Heterogêneo & Depleção & 0 & 2 & 100000 & 137 & 524 & 37865 & 467 \\
\hline Heterogêneo & Depleção & 0 & 3 & 0 & 84 & 318 & 14490 & 80 \\
\hline Heterogêneo & Depleção & 0 & 3 & 32 & 178 & 768 & 46346 & 410 \\
\hline Heterogêneo & Depleção & 0 & 3 & 100 & 198 & 938 & 54331 & 441 \\
\hline Heterogêneo & Depleção & 0 & 3 & 320 & 407 & 1985 & 91607 & 453 \\
\hline Heterogêneo & Depleção & 0 & 3 & 1000 & 351 & 1759 & 97810 & 680 \\
\hline Heterogêneo & Depleção & 0 & 3 & 3200 & 348 & 1729 & 111264 & 1018 \\
\hline Heterogêneo & Depleção & 0 & 3 & 10000 & 317 & 1442 & 99913 & 1138 \\
\hline Heterogêneo & Depleção & 0 & 3 & 32000 & 814 & 4342 & 301349 & 3491 \\
\hline Heterogêneo & Depleção & 0 & 3 & 100000 & 138 & 516 & 38577 & 484 \\
\hline Heterogêneo & Depleção & 1 & 1 & 0 & 89 & 336 & 15812 & 76 \\
\hline Heterogêneo & Depleção & 1 & 1 & 32 & 117 & 466 & 23415 & 123 \\
\hline Heterogêneo & Depleção & 1 & 1 & 100 & 125 & 519 & 29072 & 179 \\
\hline Heterogêneo & Depleção & 1 & 1 & 320 & 190 & 873 & 54625 & 382 \\
\hline Heterogêneo & Depleção & 1 & 1 & 1000 & 196 & 896 & 61596 & 610 \\
\hline Heterogêneo & Depleção & 1 & 1 & 3200 & 247 & 1129 & 85044 & 968 \\
\hline Heterogêneo & Depleção & 1 & 1 & 10000 & 382 & 1847 & 142031 & 1708 \\
\hline
\end{tabular}




\begin{tabular}{|c|c|c|c|c|c|c|c|c|}
\hline Heterogêneo & Depleção & 1 & 1 & 32000 & 205 & 918 & 65578 & 799 \\
\hline Heterogêneo & Depleção & 1 & 1 & 100000 & 249 & 985 & 73953 & 918 \\
\hline Heterogêneo & Depleção & 1 & 2 & 0 & 79 & 284 & 14015 & 75 \\
\hline Heterogêneo & Depleção & 1 & 2 & 32 & 168 & 686 & 40993 & 350 \\
\hline Heterogêneo & Depleção & 1 & 2 & 100 & 183 & 798 & 46278 & 356 \\
\hline Heterogêneo & Depleção & 1 & 2 & 320 & 494 & 2299 & 100207 & 422 \\
\hline Heterogêneo & Depleção & 1 & 2 & 1000 & 375 & 1961 & 116141 & 842 \\
\hline Heterogêneo & Depleção & 1 & 2 & 3200 & 324 & 1557 & 108822 & 1147 \\
\hline Heterogêneo & Depleção & 1 & 2 & 10000 & 445 & 2148 & 158908 & 1843 \\
\hline Heterogêneo & Depleção & 1 & 2 & 32000 & 283 & 1219 & 86333 & 1045 \\
\hline Heterogêneo & Depleção & 1 & 2 & 100000 & 181 & 790 & 56334 & 692 \\
\hline Heterogêneo & Depleção & 1 & 3 & 0 & 80 & 329 & 16333 & 102 \\
\hline Heterogêneo & Depleção & 1 & 3 & 32 & 181 & 778 & 46074 & 384 \\
\hline Heterogêneo & Depleção & 1 & 3 & 100 & 196 & 817 & 49777 & 420 \\
\hline Heterogêneo & Depleção & 1 & 3 & 320 & 688 & 3173 & 121134 & 402 \\
\hline Heterogêneo & Depleção & 1 & 3 & 1000 & 531 & 2932 & 154565 & 947 \\
\hline Heterogêneo & Depleção & 1 & 3 & 3200 & 1436 & 8531 & 456264 & 2849 \\
\hline Heterogêneo & Depleção & 1 & 3 & 10000 & 582 & 2899 & 199197 & 2172 \\
\hline Heterogêneo & Depleção & 1 & 3 & 32000 & 130 & 475 & 36318 & 444 \\
\hline Heterogêneo & Depleção & 1 & 3 & 100000 & 136 & 477 & 35973 & 443 \\
\hline Heterogêneo & Depleção & 5 & 1 & 0 & 85 & 313 & 14932 & 87 \\
\hline Heterogêneo & Depleção & 5 & 1 & 32 & 118 & 447 & 23220 & 144 \\
\hline Heterogêneo & Depleção & 5 & 1 & 100 & 125 & 507 & 26249 & 160 \\
\hline Heterogêneo & Depleção & 5 & 1 & 320 & 150 & 705 & 39334 & 247 \\
\hline Heterogêneo & Depleção & 5 & 1 & 1000 & 237 & 1112 & 49002 & 226 \\
\hline Heterogêneo & Depleção & 5 & 1 & 3200 & 152 & 653 & 33862 & 217 \\
\hline Heterogêneo & Depleção & 5 & 1 & 10000 & 160 & 732 & 38437 & 253 \\
\hline Heterogêneo & Depleção & 5 & 1 & 32000 & 178 & 771 & 44024 & 337 \\
\hline Heterogêneo & Depleção & 5 & 1 & 100000 & 250 & 1203 & 71826 & 607 \\
\hline Heterogêneo & Depleção & 5 & 2 & 0 & 84 & 291 & 14071 & 82 \\
\hline Heterogêneo & Depleção & 5 & 2 & 32 & 161 & 648 & 37792 & 306 \\
\hline Heterogêneo & Depleção & 5 & 2 & 100 & 166 & 692 & 42938 & 384 \\
\hline Heterogêneo & Depleção & 5 & 2 & 320 & 480 & 2264 & 106650 & 510 \\
\hline Heterogêneo & Depleção & 5 & 2 & 1000 & 323 & 1592 & 97768 & 763 \\
\hline Heterogêneo & Depleção & 5 & 2 & 3200 & 359 & 1744 & 119053 & 1204 \\
\hline Heterogêneo & Depleção & 5 & 2 & 10000 & 130 & 510 & 36886 & 451 \\
\hline Heterogêneo & Depleção & 5 & 2 & 32000 & 112 & 370 & 27209 & 334 \\
\hline Heterogêneo & Depleção & 5 & 2 & 100000 & 178 & 750 & 53290 & 653 \\
\hline Heterogêneo & Depleção & 5 & 3 & 0 & 84 & 336 & 16367 & 107 \\
\hline Heterogêneo & Depleção & 5 & 3 & 32 & 177 & 791 & 49181 & 454 \\
\hline Heterogêneo & Depleção & 5 & 3 & 100 & 227 & 1021 & 57510 & 463 \\
\hline Heterogêneo & Depleção & 5 & 3 & 320 & 243 & 1179 & 67059 & 496 \\
\hline Heterogêneo & Depleção & 5 & 3 & 1000 & 1090 & 5409 & 219509 & 781 \\
\hline Heterogêneo & Depleção & 5 & 3 & 3200 & 483 & 2412 & 157189 & 1510 \\
\hline
\end{tabular}




\begin{tabular}{|c|c|c|c|c|c|c|c|c|}
\hline Heterogêneo & Depleção & 5 & 3 & 10000 & 104 & 430 & 32736 & 399 \\
\hline Heterogêneo & Depleção & 5 & 3 & 32000 & 141 & 563 & 38965 & 475 \\
\hline Heterogêneo & Depleção & 5 & 3 & 100000 & 141 & 548 & 38597 & 476 \\
\hline Heterogêneo & $\operatorname{Par} 45^{\circ}$ & 0 & 1 & 0 & 129 & 434 & 16313 & 61 \\
\hline Heterogêneo & $\operatorname{Par} 45^{\circ}$ & 0 & 1 & 32 & 293 & 1585 & 65946 & 168 \\
\hline Heterogêneo & $\operatorname{Par} 45^{\circ}$ & 0 & 1 & 100 & 430 & 2708 & 95354 & 53 \\
\hline Heterogêneo & $\operatorname{Par} 45^{\circ}$ & 0 & 1 & 320 & 862 & 7441 & 200192 & 37 \\
\hline Heterogêneo & $\operatorname{Par} 45^{\circ}$ & 0 & 1 & 1000 & 1623 & 13423 & 336877 & 53 \\
\hline Heterogêneo & $\operatorname{Par} 45^{\circ}$ & 0 & 1 & 3200 & 3059 & 20044 & 530357 & 144 \\
\hline Heterogêneo & $\operatorname{Par} 45^{\circ}$ & 0 & 1 & 10000 & 15548 & 84105 & 2315094 & 659 \\
\hline Heterogêneo & Par $45^{\circ}$ & 0 & 1 & 32000 & 25336 & 141993 & 3416776 & 1614 \\
\hline Heterogêneo & $\operatorname{Par} 45^{\circ}$ & 0 & 1 & 100000 & 223095 & 2508036 & 40268514 & 1569 \\
\hline Heterogêneo & $\operatorname{Par} 45^{\circ}$ & 0 & 2 & 0 & 172 & 604 & 22188 & 75 \\
\hline Heterogêneo & $\operatorname{Par} 45^{\circ}$ & 0 & 2 & 32 & 278 & 1498 & 73782 & 260 \\
\hline Heterogêneo & $\operatorname{Par} 45^{\circ}$ & 0 & 2 & 100 & 388 & 2490 & 102647 & 107 \\
\hline Heterogêneo & $\operatorname{Par} 45^{\circ}$ & 0 & 2 & 320 & 767 & 6680 & 210696 & 12 \\
\hline Heterogêneo & $\operatorname{Par} 45^{\circ}$ & 0 & 2 & 1000 & 1351 & 10979 & 285748 & 28 \\
\hline Heterogêneo & Par $45^{\circ}$ & 0 & 2 & 3200 & 2602 & 16892 & 499591 & 364 \\
\hline Heterogêneo & $\operatorname{Par} 45^{\circ}$ & 0 & 2 & 10000 & 60562 & 287424 & 9582315 & 49 \\
\hline Heterogêneo & Par $45^{\circ}$ & 0 & 2 & 32000 & 93727 & 441195 & 18644495 & 11389 \\
\hline Heterogêneo & Par $45^{\circ}$ & 0 & 2 & 100000 & 344601 & 2495099 & 142365656 & 425935 \\
\hline Heterogêneo & Par $45^{\circ}$ & 0 & 3 & 0 & 242 & 834 & 28533 & 84 \\
\hline Heterogêneo & Par $45^{\circ}$ & 0 & 3 & 32 & 310 & 1830 & 96817 & 422 \\
\hline Heterogêneo & Par $45^{\circ}$ & 0 & 3 & 100 & 441 & 2969 & 126027 & 284 \\
\hline Heterogêneo & Par $45^{\circ}$ & 0 & 3 & 320 & 761 & 6632 & 212662 & 131 \\
\hline Heterogêneo & Par $45^{\circ}$ & 0 & 3 & 1000 & 1460 & 12378 & 327454 & 104 \\
\hline Heterogêneo & $\operatorname{Par} 45^{\circ}$ & 0 & 3 & 3200 & 2146 & 15784 & 492774 & 612 \\
\hline Heterogêneo & Par $45^{\circ}$ & 0 & 3 & 10000 & 47048 & 218709 & 8146806 & 110 \\
\hline Heterogêneo & Par $45^{\circ}$ & 0 & 3 & 32000 & 68807 & 325495 & 14754163 & 18041 \\
\hline Heterogêneo & Par $45^{\circ}$ & 0 & 3 & 100000 & 173401 & 1179737 & 72542552 & 470922 \\
\hline Heterogêneo & $\operatorname{Par} 45^{\circ}$ & 1 & 1 & 0 & 119 & 424 & 16778 & 64 \\
\hline Heterogêneo & $\operatorname{Par} 45^{\circ}$ & 1 & 1 & 32 & 284 & 1591 & 63676 & 156 \\
\hline Heterogêneo & Par $45^{\circ}$ & 1 & 1 & 100 & 431 & 2891 & 102362 & 77 \\
\hline Heterogêneo & $\operatorname{Par} 45^{\circ}$ & 1 & 1 & 320 & 871 & 7189 & 194233 & 35 \\
\hline Heterogêneo & $\operatorname{Par} 45^{\circ}$ & 1 & 1 & 1000 & 1644 & 13641 & 341396 & 9 \\
\hline Heterogêneo & Par $45^{\circ}$ & 1 & 1 & 3200 & 2698 & 20411 & 566245 & 147 \\
\hline Heterogêneo & $\operatorname{Par} 45^{\circ}$ & 1 & 1 & 10000 & 3675 & 27850 & 860342 & 1295 \\
\hline Heterogêneo & Par $45^{\circ}$ & 1 & 1 & 32000 & 5050 & 42400 & 1248005 & 2343 \\
\hline Heterogêneo & $\operatorname{Par} 45^{\circ}$ & 1 & 1 & 100000 & 7394 & 69309 & 1939965 & 2767 \\
\hline Heterogêneo & $\operatorname{Par} 45^{\circ}$ & 1 & 2 & 0 & 159 & 545 & 20731 & 72 \\
\hline Heterogêneo & Par $45^{\circ}$ & 1 & 2 & 32 & 293 & 1682 & 80379 & 270 \\
\hline Heterogêneo & Par $45^{\circ}$ & 1 & 2 & 100 & 423 & 2760 & 105645 & 99 \\
\hline Heterogêneo & Par $45^{\circ}$ & 1 & 2 & 320 & 773 & 6579 & 202232 & 32 \\
\hline Heterogêneo & $\operatorname{Par} 45^{\circ}$ & 1 & 2 & 1000 & 1245 & 10890 & 336643 & 111 \\
\hline
\end{tabular}




\begin{tabular}{|c|c|c|c|c|c|c|c|c|}
\hline Heterogêneo & $\operatorname{Par} 45^{\circ}$ & 1 & 2 & 3200 & 2070 & 16639 & 661063 & 1068 \\
\hline Heterogêneo & Par $45^{\circ}$ & 1 & 2 & 10000 & 3227 & 25492 & 975873 & 2066 \\
\hline Heterogêneo & $\operatorname{Par} 45^{\circ}$ & 1 & 2 & 32000 & 3947 & 33655 & 1149743 & 2950 \\
\hline Heterogêneo & $\operatorname{Par} 45^{\circ}$ & 1 & 2 & 100000 & 5134 & 43748 & 1304089 & 3021 \\
\hline Heterogêneo & $\operatorname{Par} 45^{\circ}$ & 1 & 3 & 0 & 239 & 822 & 27495 & 79 \\
\hline Heterogêneo & Par $45^{\circ}$ & 1 & 3 & 32 & 319 & 1809 & 93550 & 408 \\
\hline Heterogêneo & $\operatorname{Par} 45^{\circ}$ & 1 & 3 & 100 & 442 & 2843 & 122886 & 322 \\
\hline Heterogêneo & $\operatorname{Par} 45^{\circ}$ & 1 & 3 & 320 & 792 & 6839 & 233365 & 347 \\
\hline Heterogêneo & $\operatorname{Par} 45^{\circ}$ & 1 & 3 & 1000 & 1275 & 11006 & 343859 & 310 \\
\hline Heterogêneo & $\operatorname{Par} 45^{\circ}$ & 1 & 3 & 3200 & 2056 & 18106 & 599716 & 775 \\
\hline Heterogêneo & Par $45^{\circ}$ & 1 & 3 & 10000 & 2718 & 24898 & 878116 & 1648 \\
\hline Heterogêneo & $\operatorname{Par} 45^{\circ}$ & 1 & 3 & 32000 & 3612 & 31049 & 1076203 & 2938 \\
\hline Heterogêneo & $\operatorname{Par} 45^{\circ}$ & 1 & 3 & 100000 & 5066 & 40924 & 1162879 & 2866 \\
\hline Heterogêneo & $\operatorname{Par} 45^{\circ}$ & 5 & 1 & 0 & 127 & 432 & 17264 & 73 \\
\hline Heterogêneo & $\operatorname{Par} 45^{\circ}$ & 5 & 1 & 32 & 260 & 1406 & 59493 & 164 \\
\hline Heterogêneo & $\operatorname{Par} 45^{\circ}$ & 5 & 1 & 100 & 378 & 2370 & 91381 & 63 \\
\hline Heterogêneo & $\operatorname{Par} 45^{\circ}$ & 5 & 1 & 320 & 750 & 6154 & 186694 & 66 \\
\hline Heterogêneo & Par $45^{\circ}$ & 5 & 1 & 1000 & 1373 & 11747 & 342408 & 84 \\
\hline Heterogêneo & $\operatorname{Par} 45^{\circ}$ & 5 & 1 & 3200 & 2201 & 18518 & 648209 & 413 \\
\hline Heterogêneo & $\operatorname{Par} 45^{\circ}$ & 5 & 1 & 10000 & 2786 & 22415 & 878976 & 2921 \\
\hline Heterogêneo & $\operatorname{Par} 45^{\circ}$ & 5 & 1 & 32000 & 3763 & 32989 & 1268014 & 4779 \\
\hline Heterogêneo & Par $45^{\circ}$ & 5 & 1 & 100000 & 5489 & 53324 & 2029852 & 5095 \\
\hline Heterogêneo & Par $45^{\circ}$ & 5 & 2 & 0 & 233 & 755 & 24150 & 65 \\
\hline Heterogêneo & Par $45^{\circ}$ & 5 & 2 & 32 & 285 & 1735 & 82919 & 299 \\
\hline Heterogêneo & $\operatorname{Par} 45^{\circ}$ & 5 & 2 & 100 & 365 & 2247 & 97820 & 165 \\
\hline Heterogêneo & Par $45^{\circ}$ & 5 & 2 & 320 & 682 & 5895 & 207785 & 151 \\
\hline Heterogêneo & $\operatorname{Par} 45^{\circ}$ & 5 & 2 & 1000 & 1145 & 10387 & 379496 & 386 \\
\hline Heterogêneo & $\operatorname{Par} 45^{\circ}$ & 5 & 2 & 3200 & 1864 & 16256 & 611691 & 1189 \\
\hline Heterogêneo & $\operatorname{Par} 45^{\circ}$ & 5 & 2 & 10000 & 2743 & 24050 & 876352 & 1709 \\
\hline Heterogêneo & Par $45^{\circ}$ & 5 & 2 & 32000 & 3771 & 31816 & 1142117 & 2932 \\
\hline Heterogêneo & $\operatorname{Par} 45^{\circ}$ & 5 & 2 & 100000 & 5168 & 43553 & 1395509 & 3231 \\
\hline Heterogêneo & $\operatorname{Par} 45^{\circ}$ & 5 & 3 & 0 & 300 & 1011 & 30790 & 64 \\
\hline Heterogêneo & Par $45^{\circ}$ & 5 & 3 & 32 & 291 & 1731 & 90130 & 436 \\
\hline Heterogêneo & $\operatorname{Par} 45^{\circ}$ & 5 & 3 & 100 & 390 & 2432 & 107810 & 310 \\
\hline Heterogêneo & $\operatorname{Par} 45^{\circ}$ & 5 & 3 & 320 & 658 & 5480 & 187613 & 163 \\
\hline Heterogêneo & $\operatorname{Par} 45^{\circ}$ & 5 & 3 & 1000 & 1164 & 10726 & 366594 & 438 \\
\hline Heterogêneo & $\operatorname{Par} 45^{\circ}$ & 5 & 3 & 3200 & 1816 & 16078 & 587241 & 1194 \\
\hline Heterogêneo & Par $45^{\circ}$ & 5 & 3 & 10000 & 2515 & 22080 & 803806 & 1579 \\
\hline Heterogêneo & $\operatorname{Par} 45^{\circ}$ & 5 & 3 & 32000 & 3430 & 28955 & 1036377 & 3044 \\
\hline Heterogêneo & $\operatorname{Par} 45^{\circ}$ & 5 & 3 & 100000 & 4717 & 38127 & 1147819 & 2784 \\
\hline Heterogêneo & Par Paralelo & 0 & 1 & 0 & 147 & 499 & 18317 & 72 \\
\hline Heterogêneo & Par Paralelo & 0 & 1 & 32 & 234 & 1281 & 54801 & 181 \\
\hline Heterogêneo & Par Paralelo & 0 & 1 & 100 & 342 & 2331 & 85215 & 58 \\
\hline Heterogêneo & Par Paralelo & 0 & 1 & 320 & 662 & 5747 & 183517 & 31 \\
\hline
\end{tabular}




\begin{tabular}{|c|c|c|c|c|c|c|c|c|}
\hline Heterogêneo & Par Paralelo & 0 & 1 & 1000 & 1283 & 9944 & 249346 & 33 \\
\hline Heterogêneo & Par Paralelo & 0 & 1 & 3200 & 2755 & 14718 & 309385 & 35 \\
\hline Heterogêneo & Par Paralelo & 0 & 1 & 10000 & 68576 & 341204 & 4802643 & 0 \\
\hline Heterogêneo & Par Paralelo & 0 & 1 & 32000 & 128521 & 597853 & 8791514 & 0 \\
\hline Heterogêneo & Par Paralelo & 0 & 1 & 100000 & 282854 & 1706804 & 28504236 & 11 \\
\hline Heterogêneo & Par Paralelo & 0 & 2 & 0 & 221 & 748 & 23510 & 52 \\
\hline Heterogêneo & Par Paralelo & 0 & 2 & 32 & 284 & 1571 & 82311 & 365 \\
\hline Heterogêneo & Par Paralelo & 0 & 2 & 100 & 382 & 2471 & 119944 & 478 \\
\hline Heterogêneo & Par Paralelo & 0 & 2 & 320 & 752 & 6830 & 235892 & 375 \\
\hline Heterogêneo & Par Paralelo & 0 & 2 & 1000 & 1370 & 10556 & 314165 & 430 \\
\hline Heterogêneo & Par Paralelo & 0 & 2 & 3200 & 2184 & 15951 & 598760 & 1321 \\
\hline Heterogêneo & Par Paralelo & 0 & 2 & 10000 & 57964 & 267881 & 14130217 & 25984 \\
\hline Heterogêneo & Par Paralelo & 0 & 2 & 32000 & 85186 & 398485 & 25295430 & 164125 \\
\hline Heterogêneo & Par Paralelo & 0 & 2 & 100000 & 174019 & 933491 & 63797647 & 605115 \\
\hline Heterogêneo & Par Paralelo & 0 & 3 & 0 & 377 & 1271 & 34479 & 42 \\
\hline Heterogêneo & Par Paralelo & 0 & 3 & 32 & 309 & 1781 & 97636 & 478 \\
\hline Heterogêneo & Par Paralelo & 0 & 3 & 100 & 411 & 2365 & 121330 & 552 \\
\hline Heterogêneo & Par Paralelo & 0 & 3 & 320 & 803 & 6421 & 231583 & 490 \\
\hline Heterogêneo & Par Paralelo & 0 & 3 & 1000 & 1436 & 11412 & 351923 & 851 \\
\hline Heterogêneo & Par Paralelo & 0 & 3 & 3200 & 2186 & 16703 & 693646 & 2269 \\
\hline Heterogêneo & Par Paralelo & 0 & 3 & 10000 & 44424 & 207653 & 10749917 & 19954 \\
\hline Heterogêneo & Par Paralelo & 0 & 3 & 32000 & 75304 & 354394 & 22277873 & 130252 \\
\hline Heterogêneo & Par Paralelo & 0 & 3 & 100000 & 134830 & 693894 & 46182101 & 393978 \\
\hline Heterogêneo & Par Paralelo & 1 & 1 & 0 & 142 & 504 & 18290 & 73 \\
\hline Heterogêneo & Par Paralelo & 1 & 1 & 32 & 244 & 1399 & 59462 & 197 \\
\hline Heterogêneo & Par Paralelo & 1 & 1 & 100 & 356 & 2445 & 105465 & 257 \\
\hline Heterogêneo & Par Paralelo & 1 & 1 & 320 & 645 & 5581 & 216410 & 297 \\
\hline Heterogêneo & Par Paralelo & 1 & 1 & 1000 & 1035 & 9433 & 439609 & 1294 \\
\hline Heterogêneo & Par Paralelo & 1 & 1 & 3200 & 1990 & 15297 & 753666 & 3432 \\
\hline Heterogêneo & Par Paralelo & 1 & 1 & 10000 & 2707 & 23522 & 1129393 & 4185 \\
\hline Heterogêneo & Par Paralelo & 1 & 1 & 32000 & 3591 & 30660 & 1319520 & 3956 \\
\hline Heterogêneo & Par Paralelo & 1 & 1 & 100000 & 4684 & 38517 & 1497926 & 5067 \\
\hline Heterogêneo & Par Paralelo & 1 & 2 & 0 & 267 & 874 & 26098 & 58 \\
\hline Heterogêneo & Par Paralelo & 1 & 2 & 32 & 287 & 1691 & 87753 & 410 \\
\hline Heterogêneo & Par Paralelo & 1 & 2 & 100 & 416 & 2720 & 122591 & 443 \\
\hline Heterogêneo & Par Paralelo & 1 & 2 & 320 & 740 & 5817 & 204010 & 315 \\
\hline Heterogêneo & Par Paralelo & 1 & 2 & 1000 & 1174 & 10504 & 382756 & 820 \\
\hline Heterogêneo & Par Paralelo & 1 & 2 & 3200 & 2022 & 16470 & 690609 & 2262 \\
\hline Heterogêneo & Par Paralelo & 1 & 2 & 10000 & 2716 & 22333 & 952285 & 3461 \\
\hline Heterogêneo & Par Paralelo & 1 & 2 & 32000 & 3392 & 27930 & 1051961 & 2906 \\
\hline Heterogêneo & Par Paralelo & 1 & 2 & 100000 & 4149 & 34114 & 1197633 & 3957 \\
\hline Heterogêneo & Par Paralelo & 1 & 3 & 0 & 341 & 1098 & 28228 & 38 \\
\hline Heterogêneo & Par Paralelo & 1 & 3 & 32 & 316 & 1851 & 102080 & 558 \\
\hline Heterogêneo & Par Paralelo & 1 & 3 & 100 & 440 & 2730 & 130474 & 539 \\
\hline
\end{tabular}




\begin{tabular}{|c|c|c|c|c|c|c|c|c|}
\hline Heterogêneo & Par Paralelo & 1 & 3 & 320 & 765 & 6108 & 225157 & 494 \\
\hline Heterogêneo & Par Paralelo & 1 & 3 & 1000 & 1242 & 10847 & 406148 & 1009 \\
\hline Heterogêneo & Par Paralelo & 1 & 3 & 3200 & 1881 & 17089 & 750040 & 2811 \\
\hline Heterogêneo & Par Paralelo & 1 & 3 & 10000 & 2559 & 21910 & 993515 & 4262 \\
\hline Heterogêneo & Par Paralelo & 1 & 3 & 32000 & 3232 & 25554 & 946858 & 2909 \\
\hline Heterogêneo & Par Paralelo & 1 & 3 & 100000 & 3989 & 31236 & 1117607 & 4222 \\
\hline Heterogêneo & Par Paralelo & 5 & 1 & 0 & 110 & 367 & 13504 & 59 \\
\hline Heterogêneo & Par Paralelo & 5 & 1 & 32 & 233 & 1331 & 55828 & 170 \\
\hline Heterogêneo & Par Paralelo & 5 & 1 & 100 & 333 & 2158 & 81310 & 76 \\
\hline Heterogêneo & Par Paralelo & 5 & 1 & 320 & 627 & 5628 & 168346 & 11 \\
\hline Heterogêneo & Par Paralelo & 5 & 1 & 1000 & 1109 & 10506 & 268151 & 11 \\
\hline Heterogêneo & Par Paralelo & 5 & 1 & 3200 & 1663 & 15207 & 409425 & 24 \\
\hline Heterogêneo & Par Paralelo & 5 & 1 & 10000 & 2298 & 19802 & 444858 & 13 \\
\hline Heterogêneo & Par Paralelo & 5 & 1 & 32000 & 2935 & 25930 & 562816 & 28 \\
\hline Heterogêneo & Par Paralelo & 5 & 1 & 100000 & 4106 & 36467 & 784188 & 35 \\
\hline Heterogêneo & Par Paralelo & 5 & 2 & 0 & 158 & 551 & 19014 & 67 \\
\hline Heterogêneo & Par Paralelo & 5 & 2 & 32 & 250 & 1470 & 80185 & 516 \\
\hline Heterogêneo & Par Paralelo & 5 & 2 & 100 & 350 & 2052 & 106499 & 568 \\
\hline Heterogêneo & Par Paralelo & 5 & 2 & 320 & 613 & 5162 & 252722 & 1120 \\
\hline Heterogêneo & Par Paralelo & 5 & 2 & 1000 & 1050 & 9986 & 503266 & 1368 \\
\hline Heterogêneo & Par Paralelo & 5 & 2 & 3200 & 1439 & 13284 & 744159 & 4094 \\
\hline Heterogêneo & Par Paralelo & 5 & 2 & 10000 & 1933 & 16974 & 921095 & 5969 \\
\hline Heterogêneo & Par Paralelo & 5 & 2 & 32000 & 2515 & 20672 & 928020 & 4432 \\
\hline Heterogêneo & Par Paralelo & 5 & 2 & 100000 & 3495 & 29225 & 1088218 & 4627 \\
\hline Heterogêneo & Par Paralelo & 5 & 3 & 0 & 217 & 726 & 23072 & 58 \\
\hline Heterogêneo & Par Paralelo & 5 & 3 & 32 & 272 & 1634 & 86237 & 516 \\
\hline Heterogêneo & Par Paralelo & 5 & 3 & 100 & 354 & 2178 & 94328 & 222 \\
\hline Heterogêneo & Par Paralelo & 5 & 3 & 320 & 618 & 5152 & 187817 & 273 \\
\hline Heterogêneo & Par Paralelo & 5 & 3 & 1000 & 1003 & 9150 & 339208 & 664 \\
\hline Heterogêneo & Par Paralelo & 5 & 3 & 3200 & 1309 & 11392 & 480016 & 1489 \\
\hline Heterogêneo & Par Paralelo & 5 & 3 & 10000 & 1768 & 14543 & 665913 & 3445 \\
\hline Heterogêneo & Par Paralelo & 5 & 3 & 32000 & 2481 & 19270 & 714194 & 2810 \\
\hline Heterogêneo & Par Paralelo & 5 & 3 & 100000 & 3552 & 27863 & 974274 & 4373 \\
\hline Homogêneo & Depleção & 0 & 1 & 0 & 81 & 302 & 15486 & 97 \\
\hline Homogêneo & Depleção & 0 & 1 & 32 & 222 & 1028 & 44475 & 155 \\
\hline Homogêneo & Depleção & 0 & 1 & 100 & 131 & 540 & 30425 & 194 \\
\hline Homogêneo & Depleção & 0 & 1 & 320 & 228 & 1101 & 51859 & 255 \\
\hline Homogêneo & Depleção & 0 & 1 & 1000 & 156 & 700 & 37364 & 239 \\
\hline Homogêneo & Depleção & 0 & 1 & 3200 & 131 & 570 & 31605 & 212 \\
\hline Homogêneo & Depleção & 0 & 1 & 10000 & 134 & 561 & 30631 & 219 \\
\hline Homogêneo & Depleção & 0 & 1 & 32000 & 149 & 601 & 31143 & 222 \\
\hline Homogêneo & Depleção & 0 & 1 & 100000 & 376 & 1827 & 63333 & 381 \\
\hline Homogêneo & Depleção & 0 & 2 & 0 & 65 & 283 & 14574 & 92 \\
\hline Homogêneo & Depleção & 0 & 2 & 32 & 254 & 1196 & 56833 & 311 \\
\hline
\end{tabular}




\begin{tabular}{|c|c|c|c|c|c|c|c|c|}
\hline Homogêneo & Depleção & 0 & 2 & 100 & 414 & 1932 & 81239 & 295 \\
\hline Homogêneo & Depleção & 0 & 2 & 320 & 548 & 2652 & 108289 & 360 \\
\hline Homogêneo & Depleção & 0 & 2 & 1000 & 333 & 1734 & 99678 & 671 \\
\hline Homogêneo & Depleção & 0 & 2 & 3200 & 267 & 1281 & 85263 & 841 \\
\hline Homogêneo & Depleção & 0 & 2 & 10000 & 107 & 366 & 27904 & 345 \\
\hline Homogêneo & Depleção & 0 & 2 & 32000 & 112 & 373 & 27647 & 341 \\
\hline Homogêneo & Depleção & 0 & 2 & 100000 & 136 & 533 & 39384 & 486 \\
\hline Homogêneo & Depleção & 0 & 3 & 0 & 76 & 281 & 15202 & 118 \\
\hline Homogêneo & Depleção & 0 & 3 & 32 & 417 & 1857 & 86263 & 447 \\
\hline Homogêneo & Depleção & 0 & 3 & 100 & 480 & 2182 & 87472 & 353 \\
\hline Homogêneo & Depleção & 0 & 3 & 320 & 602 & 2821 & 113132 & 458 \\
\hline Homogêneo & Depleção & 0 & 3 & 1000 & 346 & 1839 & 101200 & 636 \\
\hline Homogêneo & Depleção & 0 & 3 & 3200 & 319 & 1606 & 99473 & 898 \\
\hline Homogêneo & Depleção & 0 & 3 & 10000 & 115 & 401 & 29999 & 373 \\
\hline Homogêneo & Depleção & 0 & 3 & 32000 & 116 & 393 & 29765 & 366 \\
\hline Homogêneo & Depleção & 0 & 3 & 100000 & 177 & 703 & 47511 & 584 \\
\hline Homogêneo & Depleção & 1 & 1 & 0 & 72 & 290 & 14233 & 92 \\
\hline Homogêneo & Depleção & 1 & 1 & 32 & 242 & 1124 & 43932 & 141 \\
\hline Homogêneo & Depleção & 1 & 1 & 100 & 334 & 1577 & 64826 & 183 \\
\hline Homogêneo & Depleção & 1 & 1 & 320 & 509 & 2408 & 102353 & 374 \\
\hline Homogêneo & Depleção & 1 & 1 & 1000 & 459 & 2476 & 147047 & 929 \\
\hline Homogêneo & Depleção & 1 & 1 & 3200 & 217 & 1011 & 75913 & 878 \\
\hline Homogêneo & Depleção & 1 & 1 & 10000 & 128 & 511 & 37691 & 464 \\
\hline Homogêneo & Depleção & 1 & 1 & 32000 & 222 & 940 & 68290 & 853 \\
\hline Homogêneo & Depleção & 1 & 1 & 100000 & 162 & 620 & 43837 & 563 \\
\hline Homogêneo & Depleção & 1 & 2 & 0 & 82 & 270 & 14165 & 93 \\
\hline Homogêneo & Depleção & 1 & 2 & 32 & 326 & 1454 & 64266 & 301 \\
\hline Homogêneo & Depleção & 1 & 2 & 100 & 495 & 2163 & 86305 & 298 \\
\hline Homogêneo & Depleção & 1 & 2 & 320 & 621 & 2783 & 108482 & 353 \\
\hline Homogêneo & Depleção & 1 & 2 & 1000 & 287 & 1423 & 83867 & 608 \\
\hline Homogêneo & Depleção & 1 & 2 & 3200 & 551 & 2935 & 185231 & 1554 \\
\hline Homogêneo & Depleção & 1 & 2 & 10000 & 185 & 809 & 52855 & 600 \\
\hline Homogêneo & Depleção & 1 & 2 & 32000 & 158 & 689 & 48603 & 590 \\
\hline Homogêneo & Depleção & 1 & 2 & 100000 & 129 & 451 & 34125 & 427 \\
\hline Homogêneo & Depleção & 1 & 3 & 0 & 74 & 288 & 14176 & 85 \\
\hline Homogêneo & Depleção & 1 & 3 & 32 & 65 & 125 & 9311 & 113 \\
\hline Homogêneo & Depleção & 1 & 3 & 100 & 588 & 2595 & 105954 & 408 \\
\hline Homogêneo & Depleção & 1 & 3 & 320 & 718 & 3564 & 147810 & 619 \\
\hline Homogêneo & Depleção & 1 & 3 & 1000 & 475 & 2549 & 138519 & 838 \\
\hline Homogêneo & Depleção & 1 & 3 & 3200 & 524 & 2819 & 164423 & 1304 \\
\hline Homogêneo & Depleção & 1 & 3 & 10000 & 566 & 2999 & 200199 & 2099 \\
\hline Homogêneo & Depleção & 1 & 3 & 32000 & 99 & 275 & 20490 & 246 \\
\hline Homogêneo & Depleção & 1 & 3 & 100000 & 147 & 552 & 36690 & 442 \\
\hline Homogêneo & Depleção & 5 & 1 & 0 & 70 & 284 & 14504 & 94 \\
\hline
\end{tabular}




\begin{tabular}{|c|c|c|c|c|c|c|c|c|}
\hline Homogêneo & Depleção & 5 & 1 & 32 & 196 & 870 & 38693 & 158 \\
\hline Homogêneo & Depleção & 5 & 1 & 100 & 119 & 513 & 28061 & 181 \\
\hline Homogêneo & Depleção & 5 & 1 & 320 & 183 & 849 & 44704 & 235 \\
\hline Homogêneo & Depleção & 5 & 1 & 1000 & 191 & 854 & 44005 & 238 \\
\hline Homogêneo & Depleção & 5 & 1 & 3200 & 165 & 767 & 41244 & 249 \\
\hline Homogêneo & Depleção & 5 & 1 & 10000 & 139 & 582 & 35354 & 284 \\
\hline Homogêneo & Depleção & 5 & 1 & 32000 & 176 & 814 & 47024 & 375 \\
\hline Homogêneo & Depleção & 5 & 1 & 100000 & 235 & 1052 & 65839 & 626 \\
\hline Homogêneo & Depleção & 5 & 2 & 0 & 68 & 277 & 14032 & 95 \\
\hline Homogêneo & Depleção & 5 & 2 & 32 & 310 & 1360 & 63693 & 336 \\
\hline Homogêneo & Depleção & 5 & 2 & 100 & 380 & 1749 & 73764 & 303 \\
\hline Homogêneo & Depleção & 5 & 2 & 320 & 642 & 2979 & 119854 & 409 \\
\hline Homogêneo & Depleção & 5 & 2 & 1000 & 812 & 4383 & 206535 & 977 \\
\hline Homogêneo & Depleção & 5 & 2 & 3200 & 93 & 325 & 24774 & 306 \\
\hline Homogêneo & Depleção & 5 & 2 & 10000 & 102 & 349 & 26103 & 323 \\
\hline Homogêneo & Depleção & 5 & 2 & 32000 & 107 & 357 & 26072 & 323 \\
\hline Homogêneo & Depleção & 5 & 2 & 100000 & 165 & 662 & 43636 & 531 \\
\hline Homogêneo & Depleção & 5 & 3 & 0 & 77 & 288 & 14706 & 90 \\
\hline Homogêneo & Depleção & 5 & 3 & 32 & 59 & 85 & 6100 & 73 \\
\hline Homogêneo & Depleção & 5 & 3 & 100 & 397 & 1752 & 74658 & 292 \\
\hline Homogêneo & Depleção & 5 & 3 & 320 & 684 & 3155 & 127928 & 518 \\
\hline Homogêneo & Depleção & 5 & 3 & 1000 & 681 & 3895 & 190714 & 1103 \\
\hline Homogêneo & Depleção & 5 & 3 & 3200 & 547 & 2949 & 181951 & 1624 \\
\hline Homogêneo & Depleção & 5 & 3 & 10000 & 103 & 371 & 28349 & 349 \\
\hline Homogêneo & Depleção & 5 & 3 & 32000 & 127 & 457 & 29432 & 356 \\
\hline Homogêneo & Depleção & 5 & 3 & 100000 & 180 & 872 & 62925 & 798 \\
\hline Homogêneo & $\operatorname{Par} 45^{\circ}$ & 0 & 1 & 0 & 128 & 454 & 15086 & 69 \\
\hline Homogêneo & $\operatorname{Par} 45^{\circ}$ & 0 & 1 & 32 & 235 & 1371 & 54007 & 237 \\
\hline Homogêneo & Par $45^{\circ}$ & 0 & 1 & 100 & 330 & 2105 & 80258 & 191 \\
\hline Homogêneo & $\operatorname{Par} 45^{\circ}$ & 0 & 1 & 320 & 653 & 5301 & 161194 & 34 \\
\hline Homogêneo & $\operatorname{Par} 45^{\circ}$ & 0 & 1 & 1000 & 1268 & 9616 & 234964 & 13 \\
\hline Homogêneo & $\operatorname{Par} 45^{\circ}$ & 0 & 1 & 3200 & 2669 & 17984 & 436918 & 36 \\
\hline Homogêneo & Par $45^{\circ}$ & 0 & 1 & 10000 & 31248 & 156496 & 3384760 & 354 \\
\hline Homogêneo & Par $45^{\circ}$ & 0 & 1 & 32000 & 40922 & 213637 & 4602283 & 739 \\
\hline Homogêneo & $\operatorname{Par} 45^{\circ}$ & 0 & 1 & 100000 & 444998 & 4921588 & 73976738 & 1293 \\
\hline Homogêneo & Par $45^{\circ}$ & 0 & 2 & 0 & 234 & 754 & 21427 & 50 \\
\hline Homogêneo & $\operatorname{Par} 45^{\circ}$ & 0 & 2 & 32 & 232 & 1252 & 59846 & 354 \\
\hline Homogêneo & $\operatorname{Par} 45^{\circ}$ & 0 & 2 & 100 & 340 & 2104 & 95177 & 420 \\
\hline Homogêneo & $\operatorname{Par} 45^{\circ}$ & 0 & 2 & 320 & 673 & 5697 & 194621 & 97 \\
\hline Homogêneo & $\operatorname{Par} 45^{\circ}$ & 0 & 2 & 1000 & 1155 & 9678 & 253517 & 56 \\
\hline Homogêneo & Par $45^{\circ}$ & 0 & 2 & 3200 & 2391 & 15557 & 343890 & 63 \\
\hline Homogêneo & $\operatorname{Par} 45^{\circ}$ & 0 & 2 & 10000 & 49310 & 234301 & 6331670 & 0 \\
\hline Homogêneo & $\operatorname{Par} 45^{\circ}$ & 0 & 2 & 32000 & 66098 & 308168 & 11295093 & 6678 \\
\hline Homogêneo & Par $45^{\circ}$ & 0 & 2 & 100000 & 92489 & 472483 & 21369515 & 44660 \\
\hline
\end{tabular}




\begin{tabular}{|c|c|c|c|c|c|c|c|c|}
\hline Homogêneo & $\operatorname{Par} 45^{\circ}$ & 0 & 3 & 0 & 313 & 1003 & 26727 & 36 \\
\hline Homogêneo & Par $45^{\circ}$ & 0 & 3 & 32 & 229 & 1174 & 59672 & 372 \\
\hline Homogêneo & Par $45^{\circ}$ & 0 & 3 & 100 & 358 & 2163 & 101005 & 437 \\
\hline Homogêneo & $\operatorname{Par} 45^{\circ}$ & 0 & 3 & 320 & 653 & 5549 & 208105 & 278 \\
\hline Homogêneo & Par $45^{\circ}$ & 0 & 3 & 1000 & 1139 & 9783 & 272918 & 107 \\
\hline Homogêneo & $\operatorname{Par} 45^{\circ}$ & 0 & 3 & 3200 & 1765 & 14207 & 359976 & 242 \\
\hline Homogêneo & $\operatorname{Par} 45^{\circ}$ & 0 & 3 & 10000 & 37388 & 172754 & 5218118 & 0 \\
\hline Homogêneo & $\operatorname{Par} 45^{\circ}$ & 0 & 3 & 32000 & 47418 & 220649 & 8630115 & 9507 \\
\hline Homogêneo & $\operatorname{Par} 45^{\circ}$ & 0 & 3 & 100000 & 60680 & 287359 & 13785318 & 31352 \\
\hline Homogêneo & Par $45^{\circ}$ & 1 & 1 & 0 & 152 & 499 & 15372 & 58 \\
\hline Homogêneo & $\operatorname{Par} 45^{\circ}$ & 1 & 1 & 32 & 224 & 1285 & 50995 & 221 \\
\hline Homogêneo & $\operatorname{Par} 45^{\circ}$ & 1 & 1 & 100 & 332 & 1998 & 74818 & 160 \\
\hline Homogêneo & $\operatorname{Par} 45^{\circ}$ & 1 & 1 & 320 & 650 & 5370 & 163435 & 37 \\
\hline Homogêneo & $\operatorname{Par} 45^{\circ}$ & 1 & 1 & 1000 & 1098 & 8998 & 253650 & 22 \\
\hline Homogêneo & $\operatorname{Par} 45^{\circ}$ & 1 & 1 & 3200 & 1793 & 13872 & 400474 & 117 \\
\hline Homogêneo & $\operatorname{Par} 45^{\circ}$ & 1 & 1 & 10000 & 2564 & 20494 & 578617 & 741 \\
\hline Homogêneo & $\operatorname{Par} 45^{\circ}$ & 1 & 1 & 32000 & 3437 & 28858 & 809881 & 2020 \\
\hline Homogêneo & Par $45^{\circ}$ & 1 & 1 & 100000 & 4848 & 44029 & 1241721 & 3119 \\
\hline Homogêneo & $\operatorname{Par} 45^{\circ}$ & 1 & 2 & 0 & 254 & 776 & 20290 & 35 \\
\hline Homogêneo & $\operatorname{Par} 45^{\circ}$ & 1 & 2 & 32 & 224 & 1228 & 60454 & 372 \\
\hline Homogêneo & $\operatorname{Par} 45^{\circ}$ & 1 & 2 & 100 & 354 & 2212 & 97947 & 382 \\
\hline Homogêneo & Par $45^{\circ}$ & 1 & 2 & 320 & 626 & 4865 & 174099 & 187 \\
\hline Homogêneo & $\operatorname{Par} 45^{\circ}$ & 1 & 2 & 1000 & 1091 & 9301 & 284997 & 40 \\
\hline Homogêneo & Par $45^{\circ}$ & 1 & 2 & 3200 & 1644 & 14011 & 500600 & 679 \\
\hline Homogêneo & Par $45^{\circ}$ & 1 & 2 & 10000 & 2222 & 19155 & 690677 & 1191 \\
\hline Homogêneo & $\operatorname{Par} 45^{\circ}$ & 1 & 2 & 32000 & 2772 & 23509 & 771240 & 2094 \\
\hline Homogêneo & $\operatorname{Par} 45^{\circ}$ & 1 & 2 & 100000 & 3667 & 29662 & 814739 & 2152 \\
\hline Homogêneo & Par $45^{\circ}$ & 1 & 3 & 0 & 360 & 1133 & 27396 & 30 \\
\hline Homogêneo & Par $45^{\circ}$ & 1 & 3 & 32 & 229 & 1260 & 64755 & 406 \\
\hline Homogêneo & Par $45^{\circ}$ & 1 & 3 & 100 & 358 & 2107 & 101768 & 511 \\
\hline Homogêneo & $\operatorname{Par} 45^{\circ}$ & 1 & 3 & 320 & 643 & 5207 & 187360 & 275 \\
\hline Homogêneo & $\operatorname{Par} 45^{\circ}$ & 1 & 3 & 1000 & 1048 & 9130 & 286593 & 284 \\
\hline Homogêneo & $\operatorname{Par} 45^{\circ}$ & 1 & 3 & 3200 & 1561 & 13883 & 412328 & 347 \\
\hline Homogêneo & $\operatorname{Par} 45^{\circ}$ & 1 & 3 & 10000 & 1936 & 16637 & 551089 & 607 \\
\hline Homogêneo & $\operatorname{Par} 45^{\circ}$ & 1 & 3 & 32000 & 2540 & 20694 & 697571 & 2024 \\
\hline Homogêneo & $\operatorname{Par} 45^{\circ}$ & 1 & 3 & 100000 & 3438 & 26882 & 673914 & 1782 \\
\hline Homogêneo & $\operatorname{Par} 45^{\circ}$ & 5 & 1 & 0 & 100 & 353 & 11437 & 52 \\
\hline Homogêneo & Par $45^{\circ}$ & 5 & 1 & 32 & 197 & 1038 & 42331 & 200 \\
\hline Homogêneo & $\operatorname{Par} 45^{\circ}$ & 5 & 1 & 100 & 265 & 1518 & 61925 & 196 \\
\hline Homogêneo & $\operatorname{Par} 45^{\circ}$ & 5 & 1 & 320 & 481 & 3586 & 112759 & 70 \\
\hline Homogêneo & Par $45^{\circ}$ & 5 & 1 & 1000 & 810 & 6789 & 181117 & 18 \\
\hline Homogêneo & Par $45^{\circ}$ & 5 & 1 & 3200 & 1193 & 9728 & 290669 & 56 \\
\hline Homogêneo & Par $45^{\circ}$ & 5 & 1 & 10000 & 1592 & 12801 & 394548 & 311 \\
\hline Homogêneo & $\operatorname{Par} 45^{\circ}$ & 5 & 1 & 32000 & 2072 & 17249 & 532112 & 1141 \\
\hline
\end{tabular}




\begin{tabular}{|c|c|c|c|c|c|c|c|c|}
\hline Homogêneo & $\operatorname{Par} 45^{\circ}$ & 5 & 1 & 100000 & 2718 & 24941 & 799107 & 1795 \\
\hline Homogêneo & Par $45^{\circ}$ & 5 & 2 & 0 & 192 & 606 & 17842 & 52 \\
\hline Homogêneo & Par $45^{\circ}$ & 5 & 2 & 32 & 193 & 993 & 46632 & 282 \\
\hline Homogêneo & $\operatorname{Par} 45^{\circ}$ & 5 & 2 & 100 & 280 & 1715 & 76959 & 340 \\
\hline Homogêneo & $\operatorname{Par} 45^{\circ}$ & 5 & 2 & 320 & 464 & 3562 & 131555 & 95 \\
\hline Homogêneo & $\operatorname{Par} 45^{\circ}$ & 5 & 2 & 1000 & 837 & 7529 & 239649 & 145 \\
\hline Homogêneo & $\operatorname{Par} 45^{\circ}$ & 5 & 2 & 3200 & 1239 & 11427 & 384670 & 402 \\
\hline Homogêneo & $\operatorname{Par} 45^{\circ}$ & 5 & 2 & 10000 & 1765 & 15590 & 505788 & 503 \\
\hline Homogêneo & $\operatorname{Par} 45^{\circ}$ & 5 & 2 & 32000 & 2455 & 20689 & 681977 & 1647 \\
\hline Homogêneo & $\operatorname{Par} 45^{\circ}$ & 5 & 2 & 100000 & 3252 & 26300 & 706111 & 1914 \\
\hline Homogêneo & Par $45^{\circ}$ & 5 & 3 & 0 & 236 & 781 & 23771 & 68 \\
\hline Homogêneo & $\operatorname{Par} 45^{\circ}$ & 5 & 3 & 32 & 218 & 1207 & 57898 & 363 \\
\hline Homogêneo & $\operatorname{Par} 45^{\circ}$ & 5 & 3 & 100 & 296 & 1753 & 81049 & 409 \\
\hline Homogêneo & $\operatorname{Par} 45^{\circ}$ & 5 & 3 & 320 & 480 & 3704 & 154244 & 286 \\
\hline Homogêneo & Par $45^{\circ}$ & 5 & 3 & 1000 & 815 & 7228 & 258931 & 448 \\
\hline Homogêneo & $\operatorname{Par} 45^{\circ}$ & 5 & 3 & 3200 & 1206 & 10948 & 395106 & 677 \\
\hline Homogêneo & $\operatorname{Par} 45^{\circ}$ & 5 & 3 & 10000 & 1666 & 13808 & 503236 & 673 \\
\hline Homogêneo & Par $45^{\circ}$ & 5 & 3 & 32000 & 2320 & 18271 & 618977 & 1788 \\
\hline Homogêneo & $\operatorname{Par} 45^{\circ}$ & 5 & 3 & 100000 & 3097 & 22857 & 597466 & 1780 \\
\hline Homogêneo & Par Paralelo & 0 & 1 & 0 & 177 & 542 & 15437 & 32 \\
\hline Homogêneo & Par Paralelo & 0 & 1 & 32 & 192 & 990 & 42616 & 249 \\
\hline Homogêneo & Par Paralelo & 0 & 1 & 100 & 294 & 1819 & 72472 & 201 \\
\hline Homogêneo & Par Paralelo & 0 & 1 & 320 & 605 & 5072 & 157531 & 45 \\
\hline Homogêneo & Par Paralelo & 0 & 1 & 1000 & 1137 & 8896 & 224871 & 8 \\
\hline Homogêneo & Par Paralelo & 0 & 1 & 3200 & 2265 & 13552 & 262326 & 17 \\
\hline Homogêneo & Par Paralelo & 0 & 1 & 10000 & 50937 & 240609 & 3513838 & 0 \\
\hline Homogêneo & Par Paralelo & 0 & 1 & 32000 & 65379 & 306106 & 4703922 & 0 \\
\hline Homogêneo & Par Paralelo & 0 & 1 & 100000 & 119626 & 610331 & 10562744 & 0 \\
\hline Homogêneo & Par Paralelo & 0 & 2 & 0 & 300 & 956 & 22276 & 31 \\
\hline Homogêneo & Par Paralelo & 0 & 2 & 32 & 215 & 1172 & 58490 & 355 \\
\hline Homogêneo & Par Paralelo & 0 & 2 & 100 & 348 & 2087 & 105324 & 559 \\
\hline Homogêneo & Par Paralelo & 0 & 2 & 320 & 658 & 5496 & 194976 & 289 \\
\hline Homogêneo & Par Paralelo & 0 & 2 & 1000 & 1152 & 8893 & 241911 & 78 \\
\hline Homogêneo & Par Paralelo & 0 & 2 & 3200 & 1836 & 14244 & 406366 & 445 \\
\hline Homogêneo & Par Paralelo & 0 & 2 & 10000 & 40284 & 189050 & 7678068 & 4863 \\
\hline Homogêneo & Par Paralelo & 0 & 2 & 32000 & 57772 & 270746 & 15746753 & 64915 \\
\hline Homogêneo & Par Paralelo & 0 & 2 & 100000 & 81520 & 408860 & 25476090 & 176897 \\
\hline Homogêneo & Par Paralelo & 0 & 3 & 0 & 428 & 1365 & 28550 & 24 \\
\hline Homogêneo & Par Paralelo & 0 & 3 & 32 & 235 & 1265 & 69712 & 480 \\
\hline Homogêneo & Par Paralelo & 0 & 3 & 100 & 365 & 1961 & 105896 & 702 \\
\hline Homogêneo & Par Paralelo & 0 & 3 & 320 & 652 & 5297 & 200748 & 327 \\
\hline Homogêneo & Par Paralelo & 0 & 3 & 1000 & 1159 & 9272 & 278016 & 274 \\
\hline Homogêneo & Par Paralelo & 0 & 3 & 3200 & 1606 & 13024 & 419193 & 671 \\
\hline Homogêneo & Par Paralelo & 0 & 3 & 10000 & 32715 & 152060 & 6011403 & 4445 \\
\hline
\end{tabular}




\begin{tabular}{|c|c|c|c|c|c|c|c|c|}
\hline Homogêneo & Par Paralelo & 0 & 3 & 32000 & 48108 & 227641 & 12904385 & 45533 \\
\hline Homogêneo & Par Paralelo & 0 & 3 & 100000 & 61189 & 294435 & 17454453 & 100872 \\
\hline Homogêneo & Par Paralelo & 1 & 1 & 0 & 190 & 603 & 16662 & 46 \\
\hline Homogêneo & Par Paralelo & 1 & 1 & 32 & 201 & 1131 & 44974 & 227 \\
\hline Homogêneo & Par Paralelo & 1 & 1 & 100 & 307 & 1911 & 89547 & 467 \\
\hline Homogêneo & Par Paralelo & 1 & 1 & 320 & 534 & 4224 & 178322 & 381 \\
\hline Homogêneo & Par Paralelo & 1 & 1 & 1000 & 890 & 7982 & 315590 & 64 \\
\hline Homogêneo & Par Paralelo & 1 & 1 & 3200 & 1450 & 13507 & 560425 & 703 \\
\hline Homogêneo & Par Paralelo & 1 & 1 & 10000 & 2032 & 17656 & 667662 & 1157 \\
\hline Homogêneo & Par Paralelo & 1 & 1 & 32000 & 2605 & 20917 & 736400 & 1424 \\
\hline Homogêneo & Par Paralelo & 1 & 1 & 100000 & 3422 & 27480 & 868043 & 1957 \\
\hline Homogêneo & Par Paralelo & 1 & 2 & 0 & 321 & 1009 & 23483 & 28 \\
\hline Homogêneo & Par Paralelo & 1 & 2 & 32 & 227 & 1287 & 66018 & 437 \\
\hline Homogêneo & Par Paralelo & 1 & 2 & 100 & 340 & 1973 & 93364 & 423 \\
\hline Homogêneo & Par Paralelo & 1 & 2 & 320 & 579 & 4574 & 176677 & 141 \\
\hline Homogêneo & Par Paralelo & 1 & 2 & 1000 & 953 & 8669 & 277975 & 136 \\
\hline Homogêneo & Par Paralelo & 1 & 2 & 3200 & 1391 & 12772 & 443127 & 606 \\
\hline Homogêneo & Par Paralelo & 1 & 2 & 10000 & 1778 & 14648 & 484672 & 1041 \\
\hline Homogêneo & Par Paralelo & 1 & 2 & 32000 & 2372 & 18454 & 553039 & 1190 \\
\hline Homogêneo & Par Paralelo & 1 & 2 & 100000 & 2963 & 22632 & 600583 & 1309 \\
\hline Homogêneo & Par Paralelo & 1 & 3 & 0 & 420 & 1331 & 27359 & 15 \\
\hline Homogêneo & Par Paralelo & 1 & 3 & 32 & 240 & 1273 & 66538 & 426 \\
\hline Homogêneo & Par Paralelo & 1 & 3 & 100 & 358 & 1985 & 98656 & 482 \\
\hline Homogêneo & Par Paralelo & 1 & 3 & 320 & 597 & 4444 & 187332 & 364 \\
\hline Homogêneo & Par Paralelo & 1 & 3 & 1000 & 924 & 7888 & 277708 & 386 \\
\hline Homogêneo & Par Paralelo & 1 & 3 & 3200 & 1382 & 12365 & 469023 & 777 \\
\hline Homogêneo & Par Paralelo & 1 & 3 & 10000 & 1809 & 14819 & 581122 & 1611 \\
\hline Homogêneo & Par Paralelo & 1 & 3 & 32000 & 2378 & 18112 & 543039 & 1304 \\
\hline Homogêneo & Par Paralelo & 1 & 3 & 100000 & 2792 & 20258 & 538099 & 1599 \\
\hline Homogêneo & Par Paralelo & 5 & 1 & 0 & 110 & 340 & 10107 & 37 \\
\hline Homogêneo & Par Paralelo & 5 & 1 & 32 & 178 & 933 & 40847 & 244 \\
\hline Homogêneo & Par Paralelo & 5 & 1 & 100 & 253 & 1448 & 58284 & 192 \\
\hline Homogêneo & Par Paralelo & 5 & 1 & 320 & 430 & 3241 & 110673 & 49 \\
\hline Homogêneo & Par Paralelo & 5 & 1 & 1000 & 737 & 6689 & 187963 & 6 \\
\hline Homogêneo & Par Paralelo & 5 & 1 & 3200 & 1143 & 10563 & 280421 & 40 \\
\hline Homogêneo & Par Paralelo & 5 & 1 & 10000 & 1737 & 15774 & 387223 & 15 \\
\hline Homogêneo & Par Paralelo & 5 & 1 & 32000 & 2274 & 20257 & 432150 & 31 \\
\hline Homogêneo & Par Paralelo & 5 & 1 & 100000 & 2859 & 24652 & 518775 & 56 \\
\hline Homogêneo & Par Paralelo & 5 & 2 & 0 & 126 & 400 & 12699 & 61 \\
\hline Homogêneo & Par Paralelo & 5 & 2 & 32 & 200 & 1127 & 53392 & 332 \\
\hline Homogêneo & Par Paralelo & 5 & 2 & 100 & 271 & 1561 & 72325 & 284 \\
\hline Homogêneo & Par Paralelo & 5 & 2 & 320 & 443 & 3304 & 138521 & 258 \\
\hline Homogêneo & Par Paralelo & 5 & 2 & 1000 & 748 & 6767 & 261537 & 310 \\
\hline Homogêneo & Par Paralelo & 5 & 2 & 3200 & 1083 & 9487 & 390010 & 954 \\
\hline
\end{tabular}




\begin{tabular}{|l|l|c|c|c|c|c|c|c|}
\hline Homogêneo & Par Paralelo & 5 & 2 & 10000 & 1527 & 12716 & 566687 & 2214 \\
\hline Homogêneo & Par Paralelo & 5 & 2 & 32000 & 2023 & 15700 & 554921 & 1807 \\
\hline Homogêneo & Par Paralelo & 5 & 2 & 100000 & 2311 & 18104 & 545721 & 1647 \\
\hline Homogêneo & Par Paralelo & 5 & 3 & 0 & 132 & 427 & 13209 & 56 \\
\hline Homogêneo & Par Paralelo & 5 & 3 & 32 & 207 & 1155 & 58073 & 408 \\
\hline Homogêneo & Par Paralelo & 5 & 3 & 100 & 282 & 1630 & 75991 & 339 \\
\hline Homogêneo & Par Paralelo & 5 & 3 & 320 & 433 & 3007 & 129244 & 315 \\
\hline Homogêneo & Par Paralelo & 5 & 3 & 1000 & 713 & 6194 & 239366 & 465 \\
\hline Homogêneo & Par Paralelo & 5 & 3 & 3200 & 1059 & 8650 & 344666 & 662 \\
\hline Homogêneo & Par Paralelo & 5 & 3 & 10000 & 1468 & 11551 & 458237 & 1197 \\
\hline Homogêneo & Par Paralelo & 5 & 3 & 32000 & 1964 & 14784 & 485132 & 1382 \\
\hline Homogêneo & Par Paralelo & 5 & 3 & 100000 & 2503 & 18486 & 533227 & 1738 \\
\hline
\end{tabular}

Tabela A.2: Resultados das simulações - numérico 2

\begin{tabular}{|c|c|c|c|c|c|c|c|c|}
\hline Matriz & Malha & D & L & $K_{\text {frat }}$ & $\begin{array}{l}\text { Cortes de } \\
\text { Timestep }\end{array}$ & EBM (\%) & $\begin{array}{l}\text { Implicitude } \\
\text { Média (\%) }\end{array}$ & $\begin{array}{c}\text { Tempo de } \\
\text { Simulação } \\
\text { (s) }\end{array}$ \\
\hline Heterogêneo & Depleção & 0 & 1 & 0 & 2 & 0.3078 & 17.3972 & 125 \\
\hline Heterogêneo & Depleção & 0 & 1 & 32 & 17 & 0.0095 & 11.2724 & 175 \\
\hline Heterogêneo & Depleção & 0 & 1 & 100 & 25 & 0.0111 & 9.5050 & 173 \\
\hline Heterogêneo & Depleção & 0 & 1 & 320 & 55 & 0.0047 & 6.2497 & 224 \\
\hline Heterogêneo & Depleção & 0 & 1 & 1000 & 34 & 0.0043 & 10.2577 & 232 \\
\hline Heterogêneo & Depleção & 0 & 1 & 3200 & 34 & 0.0109 & 11.0344 & 208 \\
\hline Heterogêneo & Depleção & 0 & 1 & 10000 & 22 & 0.0279 & 15.9197 & 212 \\
\hline Heterogêneo & Depleção & 0 & 1 & 32000 & 38 & 0.0070 & 11.6036 & 234 \\
\hline Heterogêneo & Depleção & 0 & 1 & 100000 & 90 & 0.0069 & 5.6462 & 315 \\
\hline Heterogêneo & Depleção & 0 & 2 & 0 & 6 & 0.2917 & 20.6338 & 145 \\
\hline Heterogêneo & Depleção & 0 & 2 & 32 & 21 & 0.0072 & 8.3905 & 234 \\
\hline Heterogêneo & Depleção & 0 & 2 & 100 & 33 & 0.0055 & 7.6797 & 270 \\
\hline Heterogêneo & Depleção & 0 & 2 & 320 & 66 & 0.0160 & 6.4531 & 378 \\
\hline Heterogêneo & Depleção & 0 & 2 & 1000 & 113 & 0.0045 & 4.6111 & 542 \\
\hline Heterogêneo & Depleção & 0 & 2 & 3200 & 106 & 0.2608 & 5.5781 & 603 \\
\hline Heterogêneo & Depleção & 0 & 2 & 10000 & 113 & 0.4307 & 4.7286 & 873 \\
\hline Heterogêneo & Depleção & 0 & 2 & 32000 & 44 & 7.6047 & 2.5962 & 297 \\
\hline Heterogêneo & Depleção & 0 & 2 & 100000 & 48 & 8.1895 & 1.8576 & 168 \\
\hline Heterogêneo & Depleção & 0 & 3 & 0 & 4 & 0.2435 & 14.5058 & 123 \\
\hline Heterogêneo & Depleção & 0 & 3 & 32 & 22 & 0.0054 & 6.2099 & 251 \\
\hline Heterogêneo & Depleção & 0 & 3 & 100 & 55 & 0.0035 & 6.7940 & 296 \\
\hline Heterogêneo & Depleção & 0 & 3 & 320 & 89 & 0.0170 & 3.9646 & 486 \\
\hline Heterogêneo & Depleção & 0 & 3 & 1000 & 111 & 0.0041 & 5.2350 & 517 \\
\hline Heterogêneo & Depleção & 0 & 3 & 3200 & 83 & 0.0108 & 6.2487 & 614 \\
\hline Heterogêneo & Depleção & 0 & 3 & 10000 & 42 & 6.0113 & 3.4750 & 444 \\
\hline Heterogêneo & Depleção & 0 & 3 & 32000 & 269 & 0.4286 & 5.2343 & 1498 \\
\hline
\end{tabular}




\begin{tabular}{|c|c|c|c|c|c|c|c|c|}
\hline Heterogêneo & Depleção & 0 & 3 & 100000 & 54 & 8.2383 & 1.9667 & 146 \\
\hline Heterogêneo & Depleção & 1 & 1 & 0 & 7 & 0.3065 & 15.7284 & 140 \\
\hline Heterogêneo & Depleção & 1 & 1 & 32 & 18 & 0.2005 & 9.6725 & 160 \\
\hline Heterogêneo & Depleção & 1 & 1 & 100 & 21 & 0.0366 & 9.2208 & 175 \\
\hline Heterogêneo & Depleção & 1 & 1 & 320 & 80 & 0.0119 & 5.9921 & 270 \\
\hline Heterogêneo & Depleção & 1 & 1 & 1000 & 64 & 0.0055 & 7.4733 & 332 \\
\hline Heterogêneo & Depleção & 1 & 1 & 3200 & 62 & 0.0348 & 5.3549 & 376 \\
\hline Heterogêneo & Depleção & 1 & 1 & 10000 & 96 & 0.1027 & 4.6010 & 582 \\
\hline Heterogêneo & Depleção & 1 & 1 & 32000 & 60 & 7.6141 & 1.2805 & 213 \\
\hline Heterogêneo & Depleção & 1 & 1 & 100000 & 47 & 7.4429 & 1.5765 & 250 \\
\hline Heterogêneo & Depleção & 1 & 2 & 0 & 4 & 0.2982 & 16.3484 & 128 \\
\hline Heterogêneo & Depleção & 1 & 2 & 32 & 28 & 0.0059 & 5.9247 & 212 \\
\hline Heterogêneo & Depleção & 1 & 2 & 100 & 44 & 0.0021 & 6.3524 & 260 \\
\hline Heterogêneo & Depleção & 1 & 2 & 320 & 105 & 0.0126 & 3.0251 & 526 \\
\hline Heterogêneo & Depleção & 1 & 2 & 1000 & 174 & 0.0034 & 4.5812 & 589 \\
\hline Heterogêneo & Depleção & 1 & 2 & 3200 & 96 & 0.0148 & 5.3966 & 562 \\
\hline Heterogêneo & Depleção & 1 & 2 & 10000 & 112 & 0.1803 & 4.5134 & 791 \\
\hline Heterogêneo & Depleção & 1 & 2 & 32000 & 55 & 7.2326 & 2.3526 & 355 \\
\hline Heterogêneo & Depleção & 1 & 2 & 100000 & 66 & 8.0267 & 1.9676 & 220 \\
\hline Heterogêneo & Depleção & 1 & 3 & 0 & 5 & 0.2458 & 21.0077 & 166 \\
\hline Heterogêneo & Depleção & 1 & 3 & 32 & 27 & 0.0008 & 5.2387 & 227 \\
\hline Heterogêneo & Depleção & 1 & 3 & 100 & 47 & 0.0038 & 7.1312 & 285 \\
\hline Heterogêneo & Depleção & 1 & 3 & 320 & 88 & 0.0263 & 2.5723 & 610 \\
\hline Heterogêneo & Depleção & 1 & 3 & 1000 & 213 & 0.0035 & 4.6513 & 819 \\
\hline Heterogêneo & Depleção & 1 & 3 & 3200 & 702 & 0.0108 & 2.5945 & 1976 \\
\hline Heterogêneo & Depleção & 1 & 3 & 10000 & 204 & 0.0849 & 5.1223 & 1044 \\
\hline Heterogêneo & Depleção & 1 & 3 & 32000 & 46 & 8.2196 & 1.5452 & 128 \\
\hline Heterogêneo & Depleção & 1 & 3 & 100000 & 57 & 8.2545 & 1.8033 & 137 \\
\hline Heterogêneo & Depleção & 5 & 1 & 0 & 9 & 0.3003 & 20.1003 & 146 \\
\hline Heterogêneo & Depleção & 5 & 1 & 32 & 12 & 0.0084 & 12.6395 & 170 \\
\hline Heterogêneo & Depleção & 5 & 1 & 100 & 28 & 0.0148 & 9.2643 & 174 \\
\hline Heterogêneo & Depleção & 5 & 1 & 320 & 52 & 0.0219 & 8.9723 & 240 \\
\hline Heterogêneo & Depleção & 5 & 1 & 1000 & 77 & 0.0088 & 5.3924 & 272 \\
\hline Heterogêneo & Depleção & 5 & 1 & 3200 & 30 & 0.0146 & 12.5523 & 249 \\
\hline Heterogêneo & Depleção & 5 & 1 & 10000 & 45 & 0.0317 & 11.2920 & 282 \\
\hline Heterogêneo & Depleção & 5 & 1 & 32000 & 35 & 0.0142 & 7.7173 & 234 \\
\hline Heterogêneo & Depleção & 5 & 1 & 100000 & 67 & 0.0066 & 4.7252 & 344 \\
\hline Heterogêneo & Depleção & 5 & 2 & 0 & 5 & 0.3003 & 19.0468 & 129 \\
\hline Heterogêneo & Depleção & 5 & 2 & 32 & 18 & 0.0029 & 6.2867 & 194 \\
\hline Heterogêneo & Depleção & 5 & 2 & 100 & 38 & 0.0033 & 7.1811 & 236 \\
\hline Heterogêneo & Depleção & 5 & 2 & 320 & 118 & 0.0170 & 2.8890 & 512 \\
\hline Heterogêneo & Depleção & 5 & 2 & 1000 & 136 & 0.0078 & 4.9004 & 490 \\
\hline Heterogêneo & Depleção & 5 & 2 & 3200 & 116 & 0.0179 & 5.3513 & 580 \\
\hline Heterogêneo & Depleção & 5 & 2 & 10000 & 45 & 8.0289 & 1.4220 & 121 \\
\hline
\end{tabular}




\begin{tabular}{|c|c|c|c|c|c|c|c|c|}
\hline Heterogêneo & Depleção & 5 & 2 & 32000 & 37 & 8.2480 & 1.4324 & 101 \\
\hline Heterogêneo & Depleção & 5 & 2 & 100000 & 66 & 8.0903 & 1.6097 & 189 \\
\hline Heterogêneo & Depleção & 5 & 3 & 0 & 6 & 0.2448 & 20.7136 & 175 \\
\hline Heterogêneo & Depleção & 5 & 3 & 32 & 21 & 0.0043 & 5.9688 & 297 \\
\hline Heterogêneo & Depleção & 5 & 3 & 100 & 47 & 0.0074 & 6.1246 & 368 \\
\hline Heterogêneo & Depleção & 5 & 3 & 320 & 94 & 0.1604 & 6.7904 & 482 \\
\hline Heterogêneo & Depleção & 5 & 3 & 1000 & 159 & 0.3889 & 2.4273 & 1195 \\
\hline Heterogêneo & Depleção & 5 & 3 & 3200 & 184 & 0.3039 & 5.3735 & 1069 \\
\hline Heterogêneo & Depleção & 5 & 3 & 10000 & 34 & 8.1832 & 1.7672 & 143 \\
\hline Heterogêneo & Depleção & 5 & 3 & 32000 & 59 & 8.1518 & 1.8688 & 181 \\
\hline Heterogêneo & Depleção & 5 & 3 & 100000 & 61 & 8.2147 & 2.2778 & 185 \\
\hline Heterogêneo & $\operatorname{Par} 45^{\circ}$ & 0 & 1 & 0 & 30 & 0.0044 & 5.2926 & 100 \\
\hline Heterogêneo & $\operatorname{Par} 45^{\circ}$ & 0 & 1 & 32 & 84 & 0.0005 & 3.7915 & 298 \\
\hline Heterogêneo & $\operatorname{Par} 45^{\circ}$ & 0 & 1 & 100 & 151 & 0.0004 & 3.1091 & 430 \\
\hline Heterogêneo & $\operatorname{Par} 45^{\circ}$ & 0 & 1 & 320 & 539 & 0.0013 & 2.5070 & 851 \\
\hline Heterogêneo & Par $45^{\circ}$ & 0 & 1 & 1000 & 1251 & 0.0031 & 1.6396 & 1459 \\
\hline Heterogêneo & $\operatorname{Par} 45^{\circ}$ & 0 & 1 & 3200 & 2548 & 0.0022 & 1.0650 & 2087 \\
\hline Heterogêneo & Par $45^{\circ}$ & 0 & 1 & 10000 & 2660 & 0.0008 & 0.4762 & 8418 \\
\hline Heterogêneo & $\operatorname{Par} 45^{\circ}$ & 0 & 1 & 32000 & 4750 & 0.0009 & 0.5038 & 13754 \\
\hline Heterogêneo & Par $45^{\circ}$ & 0 & 1 & 100000 & 196761 & 0.0811 & 0.2597 & 191577 \\
\hline Heterogêneo & Par $45^{\circ}$ & 0 & 2 & 0 & 72 & 0.0048 & 4.6525 & 130 \\
\hline Heterogêneo & Par $45^{\circ}$ & 0 & 2 & 32 & 60 & 0.0007 & 3.7894 & 373 \\
\hline Heterogêneo & Par $45^{\circ}$ & 0 & 2 & 100 & 117 & 0.0002 & 3.1600 & 516 \\
\hline Heterogêneo & Par $45^{\circ}$ & 0 & 2 & 320 & 460 & 0.0013 & 2.3294 & 1036 \\
\hline Heterogêneo & Par $45^{\circ}$ & 0 & 2 & 1000 & 1109 & 0.0037 & 1.6223 & 1476 \\
\hline Heterogêneo & Par $45^{\circ}$ & 0 & 2 & 3200 & 2343 & 0.0025 & 0.9736 & 2392 \\
\hline Heterogêneo & $\operatorname{Par} 45^{\circ}$ & 0 & 2 & 10000 & 719 & 0.0009 & 0.1950 & 39509 \\
\hline Heterogêneo & $\operatorname{Par} 45^{\circ}$ & 0 & 2 & 32000 & 780 & 0.0012 & 0.1788 & 62089 \\
\hline Heterogêneo & Par $45^{\circ}$ & 0 & 2 & 100000 & 125208 & 0.1931 & 0.1697 & 417194 \\
\hline Heterogêneo & Par $45^{\circ}$ & 0 & 3 & 0 & 136 & 0.0049 & 3.8810 & 154 \\
\hline Heterogêneo & $\operatorname{Par} 45^{\circ}$ & 0 & 3 & 32 & 82 & 0.0011 & 4.0729 & 522 \\
\hline Heterogêneo & $\operatorname{Par} 45^{\circ}$ & 0 & 3 & 100 & 151 & 0.0003 & 3.0644 & 662 \\
\hline Heterogêneo & $\operatorname{Par} 45^{\circ}$ & 0 & 3 & 320 & 479 & 0.0017 & 2.4733 & 1087 \\
\hline Heterogêneo & $\operatorname{Par} 45^{\circ}$ & 0 & 3 & 1000 & 1238 & 0.0033 & 1.6138 & 1848 \\
\hline Heterogêneo & $\operatorname{Par} 45^{\circ}$ & 0 & 3 & 3200 & 1796 & 0.0022 & 1.1466 & 2349 \\
\hline Heterogêneo & Par $45^{\circ}$ & 0 & 3 & 10000 & 413 & 0.0005 & 0.2080 & 31695 \\
\hline Heterogêneo & $\operatorname{Par} 45^{\circ}$ & 0 & 3 & 32000 & 670 & 0.0026 & 0.1878 & 50840 \\
\hline Heterogêneo & Par $45^{\circ}$ & 0 & 3 & 100000 & 49149 & 0.1097 & 0.1841 & 223464 \\
\hline Heterogêneo & $\operatorname{Par} 45^{\circ}$ & 1 & 1 & 0 & 22 & 0.0039 & 5.2707 & 108 \\
\hline Heterogêneo & $\operatorname{Par} 45^{\circ}$ & 1 & 1 & 32 & 84 & 0.0006 & 3.8393 & 322 \\
\hline Heterogêneo & Par $45^{\circ}$ & 1 & 1 & 100 & 170 & 0.0005 & 3.2940 & 464 \\
\hline Heterogêneo & Par $45^{\circ}$ & 1 & 1 & 320 & 510 & 0.0015 & 2.4104 & 891 \\
\hline Heterogêneo & $\operatorname{Par} 45^{\circ}$ & 1 & 1 & 1000 & 1210 & 0.0027 & 1.6223 & 1505 \\
\hline Heterogêneo & $\operatorname{Par} 45^{\circ}$ & 1 & 1 & 3200 & 2135 & 0.0020 & 1.2041 & 2284 \\
\hline
\end{tabular}




\begin{tabular}{|c|c|c|c|c|c|c|c|c|}
\hline Heterogêneo & $\operatorname{Par} 45^{\circ}$ & 1 & 1 & 10000 & 3089 & 0.0019 & 1.1178 & 3256 \\
\hline Heterogêneo & Par $45^{\circ}$ & 1 & 1 & 32000 & 4467 & 0.0021 & 0.9678 & 4712 \\
\hline Heterogêneo & $\operatorname{Par} 45^{\circ}$ & 1 & 1 & 100000 & 6615 & 0.0018 & 0.8628 & 7170 \\
\hline Heterogêneo & $\operatorname{Par} 45^{\circ}$ & 1 & 2 & 0 & 59 & 0.0044 & 4.6008 & 125 \\
\hline Heterogêneo & $\operatorname{Par} 45^{\circ}$ & 1 & 2 & 32 & 78 & 0.0006 & 3.8489 & 379 \\
\hline Heterogêneo & $\operatorname{Par} 45^{\circ}$ & 1 & 2 & 100 & 135 & 0.0003 & 2.9448 & 479 \\
\hline Heterogêneo & $\operatorname{Par} 45^{\circ}$ & 1 & 2 & 320 & 441 & 0.0014 & 2.2524 & 910 \\
\hline Heterogêneo & $\operatorname{Par} 45^{\circ}$ & 1 & 2 & 1000 & 968 & 0.0027 & 1.7237 & 1356 \\
\hline Heterogêneo & $\operatorname{Par} 45^{\circ}$ & 1 & 2 & 3200 & 1766 & 0.0025 & 1.2081 & 2280 \\
\hline Heterogêneo & Par $45^{\circ}$ & 1 & 2 & 10000 & 2883 & 0.0031 & 0.7573 & 3268 \\
\hline Heterogêneo & $\operatorname{Par} 45^{\circ}$ & 1 & 2 & 32000 & 3164 & 0.0049 & 0.5629 & 3850 \\
\hline Heterogêneo & $\operatorname{Par} 45^{\circ}$ & 1 & 2 & 100000 & 3638 & 0.0057 & 0.4565 & 4858 \\
\hline Heterogêneo & $\operatorname{Par} 45^{\circ}$ & 1 & 3 & 0 & 132 & 0.0055 & 3.7892 & 162 \\
\hline Heterogêneo & $\operatorname{Par} 45^{\circ}$ & 1 & 3 & 32 & 79 & 0.0011 & 3.9778 & 440 \\
\hline Heterogêneo & Par $45^{\circ}$ & 1 & 3 & 100 & 140 & 0.0004 & 2.9073 & 528 \\
\hline Heterogêneo & $\operatorname{Par} 45^{\circ}$ & 1 & 3 & 320 & 457 & 0.0013 & 2.3797 & 1066 \\
\hline Heterogêneo & $\operatorname{Par} 45^{\circ}$ & 1 & 3 & 1000 & 951 & 0.0025 & 1.7857 & 1384 \\
\hline Heterogêneo & Par $45^{\circ}$ & 1 & 3 & 3200 & 1729 & 0.0023 & 1.2279 & 2355 \\
\hline Heterogêneo & $\operatorname{Par} 45^{\circ}$ & 1 & 3 & 10000 & 2155 & 0.0017 & 0.9110 & 3161 \\
\hline Heterogêneo & $\operatorname{Par} 45^{\circ}$ & 1 & 3 & 32000 & 2518 & 0.0025 & 0.6637 & 3702 \\
\hline Heterogêneo & $\operatorname{Par} 45^{\circ}$ & 1 & 3 & 100000 & 3030 & 0.0082 & 0.5023 & 4762 \\
\hline Heterogêneo & $\operatorname{Par} 45^{\circ}$ & 5 & 1 & 0 & 23 & 0.0038 & 5.3272 & 110 \\
\hline Heterogêneo & Par $45^{\circ}$ & 5 & 1 & 32 & 68 & 0.0006 & 4.0665 & 296 \\
\hline Heterogêneo & Par $45^{\circ}$ & 5 & 1 & 100 & 119 & 0.0005 & 3.3693 & 408 \\
\hline Heterogêneo & Par $45^{\circ}$ & 5 & 1 & 320 & 413 & 0.0011 & 2.6272 & 786 \\
\hline Heterogêneo & $\operatorname{Par} 45^{\circ}$ & 5 & 1 & 1000 & 904 & 0.0018 & 1.7810 & 1345 \\
\hline Heterogêneo & $\operatorname{Par} 45^{\circ}$ & 5 & 1 & 3200 & 1711 & 0.0014 & 1.3722 & 2436 \\
\hline Heterogêneo & Par $45^{\circ}$ & 5 & 1 & 10000 & 2214 & 0.0014 & 1.3079 & 3060 \\
\hline Heterogêneo & $\operatorname{Par} 45^{\circ}$ & 5 & 1 & 32000 & 3220 & 0.0019 & 1.1995 & 4193 \\
\hline Heterogêneo & Par $45^{\circ}$ & 5 & 1 & 100000 & 4939 & 0.0020 & 1.0274 & 6570 \\
\hline Heterogêneo & $\operatorname{Par} 45^{\circ}$ & 5 & 2 & 0 & 132 & 0.0054 & 3.7439 & 151 \\
\hline Heterogêneo & $\operatorname{Par} 45^{\circ}$ & 5 & 2 & 32 & 91 & 0.0008 & 3.8899 & 394 \\
\hline Heterogêneo & $\operatorname{Par} 45^{\circ}$ & 5 & 2 & 100 & 95 & 0.0005 & 3.1117 & 422 \\
\hline Heterogêneo & $\operatorname{Par} 45^{\circ}$ & 5 & 2 & 320 & 403 & 0.0008 & 2.3876 & 877 \\
\hline Heterogêneo & $\operatorname{Par} 45^{\circ}$ & 5 & 2 & 1000 & 838 & 0.0014 & 1.7545 & 1350 \\
\hline Heterogêneo & $\operatorname{Par} 45^{\circ}$ & 5 & 2 & 3200 & 1565 & 0.0019 & 1.3125 & 2174 \\
\hline Heterogêneo & $\operatorname{Par} 45^{\circ}$ & 5 & 2 & 10000 & 2354 & 0.0015 & 0.9661 & 3102 \\
\hline Heterogêneo & Par $45^{\circ}$ & 5 & 2 & 32000 & 2947 & 0.0023 & 0.7526 & 3780 \\
\hline Heterogêneo & $\operatorname{Par} 45^{\circ}$ & 5 & 2 & 100000 & 3554 & 0.0023 & 0.5814 & 4862 \\
\hline Heterogêneo & $\operatorname{Par} 45^{\circ}$ & 5 & 3 & 0 & 192 & 0.0050 & 3.2872 & 185 \\
\hline Heterogêneo & Par $45^{\circ}$ & 5 & 3 & 32 & 78 & 0.0011 & 4.0149 & 416 \\
\hline Heterogêneo & Par $45^{\circ}$ & 5 & 3 & 100 & 103 & 0.0005 & 3.0716 & 480 \\
\hline Heterogêneo & Par $45^{\circ}$ & 5 & 3 & 320 & 355 & 0.0008 & 2.4940 & 768 \\
\hline Heterogêneo & $\operatorname{Par} 45^{\circ}$ & 5 & 3 & 1000 & 855 & 0.0014 & 1.8708 & 1551 \\
\hline
\end{tabular}




\begin{tabular}{|c|c|c|c|c|c|c|c|c|}
\hline Heterogêneo & $\operatorname{Par} 45^{\circ}$ & 5 & 3 & 3200 & 1500 & 0.0017 & 1.4412 & 2119 \\
\hline Heterogêneo & $\operatorname{Par} 45^{\circ}$ & 5 & 3 & 10000 & 1902 & 0.0009 & 1.0785 & 2819 \\
\hline Heterogêneo & $\operatorname{Par} 45^{\circ}$ & 5 & 3 & 32000 & 2354 & 0.0014 & 0.8723 & 3465 \\
\hline Heterogêneo & $\operatorname{Par} 45^{\circ}$ & 5 & 3 & 100000 & 2670 & 0.0036 & 0.6579 & 4228 \\
\hline Heterogêneo & Par Paralelo & 0 & 1 & 0 & 45 & 0.0044 & 4.9103 & 113 \\
\hline Heterogêneo & Par Paralelo & 0 & 1 & 32 & 57 & 0.0007 & 4.2648 & 302 \\
\hline Heterogêneo & Par Paralelo & 0 & 1 & 100 & 118 & 0.0004 & 3.3282 & 405 \\
\hline Heterogêneo & Par Paralelo & 0 & 1 & 320 & 428 & 0.0019 & 2.4929 & 783 \\
\hline Heterogêneo & Par Paralelo & 0 & 1 & 1000 & 1097 & 0.0045 & 1.6089 & 1088 \\
\hline Heterogêneo & Par Paralelo & 0 & 1 & 3200 & 2586 & 0.0036 & 0.9187 & 1541 \\
\hline Heterogêneo & Par Paralelo & 0 & 1 & 10000 & 3448 & 0.0001 & 0.1889 & 23828 \\
\hline Heterogêneo & Par Paralelo & 0 & 1 & 32000 & 589 & 0.0014 & 0.1757 & 46819 \\
\hline Heterogêneo & Par Paralelo & 0 & 1 & 100000 & 55440 & 0.1113 & 0.1724 & 132005 \\
\hline Heterogêneo & Par Paralelo & 0 & 2 & 0 & 127 & 0.0056 & 4.0959 & 137 \\
\hline Heterogêneo & Par Paralelo & 0 & 2 & 32 & 62 & 0.0011 & 4.0278 & 518 \\
\hline Heterogêneo & Par Paralelo & 0 & 2 & 100 & 119 & 0.0003 & 3.2685 & 698 \\
\hline Heterogêneo & Par Paralelo & 0 & 2 & 320 & 509 & 0.0021 & 2.4986 & 1437 \\
\hline Heterogêneo & Par Paralelo & 0 & 2 & 1000 & 1116 & 0.0026 & 1.6328 & 2009 \\
\hline Heterogêneo & Par Paralelo & 0 & 2 & 3200 & 1839 & 0.0015 & 1.0986 & 3055 \\
\hline Heterogêneo & Par Paralelo & 0 & 2 & 10000 & 516 & 0.0004 & 0.2019 & 54127 \\
\hline Heterogêneo & Par Paralelo & 0 & 2 & 32000 & 702 & 0.0063 & 0.1910 & 87198 \\
\hline Heterogêneo & Par Paralelo & 0 & 2 & 100000 & 16353 & 0.0354 & 0.1962 & 205593 \\
\hline Heterogêneo & Par Paralelo & 0 & 3 & 0 & 278 & 0.0058 & 3.0675 & 196 \\
\hline Heterogêneo & Par Paralelo & 0 & 3 & 32 & 71 & 0.0008 & 4.3988 & 721 \\
\hline Heterogêneo & Par Paralelo & 0 & 3 & 100 & 84 & 0.0003 & 3.1958 & 795 \\
\hline Heterogêneo & Par Paralelo & 0 & 3 & 320 & 426 & 0.0018 & 2.5011 & 1508 \\
\hline Heterogêneo & Par Paralelo & 0 & 3 & 1000 & 1152 & 0.0025 & 1.6811 & 2503 \\
\hline Heterogêneo & Par Paralelo & 0 & 3 & 3200 & 1802 & 0.0014 & 1.1782 & 3646 \\
\hline Heterogêneo & Par Paralelo & 0 & 3 & 10000 & 521 & 0.0025 & 0.2197 & 43727 \\
\hline Heterogêneo & Par Paralelo & 0 & 3 & 32000 & 628 & 0.0036 & 0.2102 & 81640 \\
\hline Heterogêneo & Par Paralelo & 0 & 3 & 100000 & 7633 & 0.0321 & 0.2241 & 172222 \\
\hline Heterogêneo & Par Paralelo & 1 & 1 & 0 & 47 & 0.0049 & 4.9805 & 115 \\
\hline Heterogêneo & Par Paralelo & 1 & 1 & 32 & 70 & 0.0009 & 4.0423 & 329 \\
\hline Heterogêneo & Par Paralelo & 1 & 1 & 100 & 133 & 0.0005 & 3.2850 & 507 \\
\hline Heterogêneo & Par Paralelo & 1 & 1 & 320 & 391 & 0.0019 & 2.4551 & 881 \\
\hline Heterogêneo & Par Paralelo & 1 & 1 & 1000 & 790 & 0.0015 & 1.8089 & 1560 \\
\hline Heterogêneo & Par Paralelo & 1 & 1 & 3200 & 1777 & 0.0024 & 1.1504 & 2309 \\
\hline Heterogêneo & Par Paralelo & 1 & 1 & 10000 & 2390 & 0.0069 & 0.7876 & 3461 \\
\hline Heterogêneo & Par Paralelo & 1 & 1 & 32000 & 2913 & 0.0161 & 0.5348 & 3870 \\
\hline Heterogêneo & Par Paralelo & 1 & 1 & 100000 & 3473 & 0.0233 & 0.4288 & 4686 \\
\hline Heterogêneo & Par Paralelo & 1 & 2 & 0 & 163 & 0.0057 & 3.5805 & 147 \\
\hline Heterogêneo & Par Paralelo & 1 & 2 & 32 & 76 & 0.0009 & 4.1710 & 463 \\
\hline Heterogêneo & Par Paralelo & 1 & 2 & 100 & 132 & 0.0004 & 3.1098 & 555 \\
\hline Heterogêneo & Par Paralelo & 1 & 2 & 320 & 379 & 0.0019 & 2.3948 & 866 \\
\hline
\end{tabular}




\begin{tabular}{|c|c|c|c|c|c|c|c|c|}
\hline Heterogêneo & Par Paralelo & 1 & 2 & 1000 & 903 & 0.0023 & 1.8232 & 1474 \\
\hline Heterogêneo & Par Paralelo & 1 & 2 & 3200 & 1707 & 0.0017 & 1.1973 & 2220 \\
\hline Heterogêneo & Par Paralelo & 1 & 2 & 10000 & 2114 & 0.0060 & 0.8306 & 2948 \\
\hline Heterogêneo & Par Paralelo & 1 & 2 & 32000 & 2287 & 0.0091 & 0.6180 & 3214 \\
\hline Heterogêneo & Par Paralelo & 1 & 2 & 100000 & 2358 & 0.0135 & 0.5383 & 3961 \\
\hline Heterogêneo & Par Paralelo & 1 & 3 & 0 & 231 & 0.0058 & 2.8944 & 175 \\
\hline Heterogêneo & Par Paralelo & 1 & 3 & 32 & 77 & 0.0010 & 4.3648 & 539 \\
\hline Heterogêneo & Par Paralelo & 1 & 3 & 100 & 115 & 0.0003 & 3.1798 & 577 \\
\hline Heterogêneo & Par Paralelo & 1 & 3 & 320 & 392 & 0.0016 & 2.4469 & 905 \\
\hline Heterogêneo & Par Paralelo & 1 & 3 & 1000 & 918 & 0.0019 & 1.8415 & 1568 \\
\hline Heterogêneo & Par Paralelo & 1 & 3 & 3200 & 1452 & 0.0014 & 1.2971 & 2483 \\
\hline Heterogêneo & Par Paralelo & 1 & 3 & 10000 & 1748 & 0.0038 & 0.9015 & 3050 \\
\hline Heterogêneo & Par Paralelo & 1 & 3 & 32000 & 1846 & 0.0082 & 0.7016 & 3070 \\
\hline Heterogêneo & Par Paralelo & 1 & 3 & 100000 & 1910 & 0.0131 & 0.6217 & 3841 \\
\hline Heterogêneo & Par Paralelo & 5 & 1 & 0 & 17 & 0.0045 & 5.3207 & 91 \\
\hline Heterogêneo & Par Paralelo & 5 & 1 & 32 & 65 & 0.0011 & 4.1013 & 286 \\
\hline Heterogêneo & Par Paralelo & 5 & 1 & 100 & 107 & 0.0006 & 3.2996 & 393 \\
\hline Heterogêneo & Par Paralelo & 5 & 1 & 320 & 409 & 0.0017 & 2.5043 & 755 \\
\hline Heterogêneo & Par Paralelo & 5 & 1 & 1000 & 904 & 0.0029 & 1.7535 & 1176 \\
\hline Heterogêneo & Par Paralelo & 5 & 1 & 3200 & 1446 & 0.0034 & 1.3045 & 1729 \\
\hline Heterogêneo & Par Paralelo & 5 & 1 & 10000 & 1927 & 0.0027 & 0.9550 & 1988 \\
\hline Heterogêneo & Par Paralelo & 5 & 1 & 32000 & 2196 & 0.0011 & 0.7583 & 2317 \\
\hline Heterogêneo & Par Paralelo & 5 & 1 & 100000 & 2859 & 0.0009 & 0.5835 & 3250 \\
\hline Heterogêneo & Par Paralelo & 5 & 2 & 0 & 61 & 0.0051 & 4.7587 & 116 \\
\hline Heterogêneo & Par Paralelo & 5 & 2 & 32 & 64 & 0.0017 & 4.0454 & 363 \\
\hline Heterogêneo & Par Paralelo & 5 & 2 & 100 & 83 & 0.0010 & 3.1794 & 441 \\
\hline Heterogêneo & Par Paralelo & 5 & 2 & 320 & 339 & 0.0009 & 2.5648 & 935 \\
\hline Heterogêneo & Par Paralelo & 5 & 2 & 1000 & 785 & 0.0014 & 1.9116 & 1713 \\
\hline Heterogêneo & Par Paralelo & 5 & 2 & 3200 & 1051 & 0.0017 & 1.5011 & 2333 \\
\hline Heterogêneo & Par Paralelo & 5 & 2 & 10000 & 1273 & 0.0031 & 1.1028 & 2920 \\
\hline Heterogêneo & Par Paralelo & 5 & 2 & 32000 & 1468 & 0.0033 & 0.8527 & 2933 \\
\hline Heterogêneo & Par Paralelo & 5 & 2 & 100000 & 1975 & 0.0064 & 0.6870 & 3495 \\
\hline Heterogêneo & Par Paralelo & 5 & 3 & 0 & 113 & 0.0052 & 3.7621 & 137 \\
\hline Heterogêneo & Par Paralelo & 5 & 3 & 32 & 75 & 0.0013 & 4.2017 & 457 \\
\hline Heterogêneo & Par Paralelo & 5 & 3 & 100 & 93 & 0.0007 & 3.2563 & 444 \\
\hline Heterogêneo & Par Paralelo & 5 & 3 & 320 & 333 & 0.0008 & 2.6221 & 886 \\
\hline Heterogêneo & Par Paralelo & 5 & 3 & 1000 & 689 & 0.0012 & 1.9825 & 1511 \\
\hline Heterogêneo & Par Paralelo & 5 & 3 & 3200 & 769 & 0.0010 & 1.6254 & 2090 \\
\hline Heterogêneo & Par Paralelo & 5 & 3 & 10000 & 948 & 0.0025 & 1.2008 & 2324 \\
\hline Heterogêneo & Par Paralelo & 5 & 3 & 32000 & 1189 & 0.0031 & 0.8719 & 2764 \\
\hline Heterogêneo & Par Paralelo & 5 & 3 & 100000 & 1674 & 0.0103 & 0.7466 & 3574 \\
\hline Homogêneo & Depleção & 0 & 1 & 0 & 9 & 0.2359 & 20.3685 & 157 \\
\hline Homogêneo & Depleção & 0 & 1 & 32 & 33 & 0.0361 & 4.5952 & 249 \\
\hline Homogêneo & Depleção & 0 & 1 & 100 & 39 & 0.0540 & 7.0166 & 173 \\
\hline
\end{tabular}




\begin{tabular}{|c|c|c|c|c|c|c|c|c|}
\hline Homogêneo & Depleção & 0 & 1 & 320 & 92 & 0.0166 & 4.1032 & 266 \\
\hline Homogêneo & Depleção & 0 & 1 & 1000 & 54 & 0.0114 & 9.5552 & 249 \\
\hline Homogêneo & Depleção & 0 & 1 & 3200 & 44 & 0.0160 & 11.2343 & 224 \\
\hline Homogêneo & Depleção & 0 & 1 & 10000 & 47 & 0.0115 & 11.2851 & 228 \\
\hline Homogêneo & Depleção & 0 & 1 & 32000 & 48 & 0.0305 & 9.2857 & 219 \\
\hline Homogêneo & Depleção & 0 & 1 & 100000 & 105 & 0.0096 & 2.4005 & 324 \\
\hline Homogêneo & Depleção & 0 & 2 & 0 & 7 & 0.2339 & 22.5403 & 154 \\
\hline Homogêneo & Depleção & 0 & 2 & 32 & 54 & 0.0236 & 3.6334 & 333 \\
\hline Homogêneo & Depleção & 0 & 2 & 100 & 71 & 0.0354 & 2.2901 & 455 \\
\hline Homogêneo & Depleção & 0 & 2 & 320 & 114 & 0.0384 & 1.9601 & 589 \\
\hline Homogêneo & Depleção & 0 & 2 & 1000 & 183 & 0.0482 & 4.1268 & 554 \\
\hline Homogêneo & Depleção & 0 & 2 & 3200 & 96 & 0.8148 & 5.0845 & 510 \\
\hline Homogêneo & Depleção & 0 & 2 & 10000 & 40 & 8.2866 & 1.4313 & 117 \\
\hline Homogêneo & Depleção & 0 & 2 & 32000 & 40 & 8.2806 & 1.6442 & 125 \\
\hline Homogêneo & Depleção & 0 & 2 & 100000 & 55 & 8.2710 & 1.4977 & 165 \\
\hline Homogêneo & Depleção & 0 & 3 & 0 & 7 & 0.2132 & 22.1714 & 155 \\
\hline Homogêneo & Depleção & 0 & 3 & 32 & 53 & 0.0276 & 2.0117 & 378 \\
\hline Homogêneo & Depleção & 0 & 3 & 100 & 46 & 2.1751 & 2.1547 & 386 \\
\hline Homogêneo & Depleção & 0 & 3 & 320 & 113 & 0.8078 & 2.4062 & 548 \\
\hline Homogêneo & Depleção & 0 & 3 & 1000 & 173 & 0.1427 & 4.4820 & 489 \\
\hline Homogêneo & Depleção & 0 & 3 & 3200 & 116 & 0.4618 & 5.5162 & 503 \\
\hline Homogêneo & Depleção & 0 & 3 & 10000 & 42 & 8.2699 & 1.5244 & 105 \\
\hline Homogêneo & Depleção & 0 & 3 & 32000 & 43 & 8.2693 & 1.6769 & 107 \\
\hline Homogêneo & Depleção & 0 & 3 & 100000 & 49 & 7.9927 & 2.6452 & 201 \\
\hline Homogêneo & Depleção & 1 & 1 & 0 & 7 & 0.2391 & 21.6048 & 155 \\
\hline Homogêneo & Depleção & 1 & 1 & 32 & 40 & 0.1717 & 3.2868 & 221 \\
\hline Homogêneo & Depleção & 1 & 1 & 100 & 65 & 0.1786 & 2.4640 & 291 \\
\hline Homogêneo & Depleção & 1 & 1 & 320 & 102 & 0.1416 & 2.0255 & 424 \\
\hline Homogêneo & Depleção & 1 & 1 & 1000 & 245 & 0.0591 & 2.4386 & 564 \\
\hline Homogêneo & Depleção & 1 & 1 & 3200 & 79 & 0.3436 & 5.2013 & 314 \\
\hline Homogêneo & Depleção & 1 & 1 & 10000 & 46 & 8.0010 & 1.0775 & 125 \\
\hline Homogêneo & Depleção & 1 & 1 & 32000 & 57 & 7.3916 & 1.3542 & 242 \\
\hline Homogêneo & Depleção & 1 & 1 & 100000 & 53 & 8.0447 & 1.3391 & 141 \\
\hline Homogêneo & Depleção & 1 & 2 & 0 & 4 & 0.2335 & 18.4893 & 127 \\
\hline Homogêneo & Depleção & 1 & 2 & 32 & 24 & 0.0372 & 2.8082 & 309 \\
\hline Homogêneo & Depleção & 1 & 2 & 100 & 56 & 0.0601 & 1.8147 & 348 \\
\hline Homogêneo & Depleção & 1 & 2 & 320 & 83 & 0.0508 & 1.7440 & 510 \\
\hline Homogêneo & Depleção & 1 & 2 & 1000 & 134 & 0.0403 & 4.3497 & 417 \\
\hline Homogêneo & Depleção & 1 & 2 & 3200 & 336 & 0.6423 & 2.7914 & 798 \\
\hline Homogêneo & Depleção & 1 & 2 & 10000 & 52 & 7.2421 & 1.7968 & 211 \\
\hline Homogêneo & Depleção & 1 & 2 & 32000 & 45 & 7.9512 & 1.9868 & 180 \\
\hline Homogêneo & Depleção & 1 & 2 & 100000 & 51 & 8.2426 & 1.7189 & 132 \\
\hline Homogêneo & Depleção & 1 & 3 & 0 & 4 & 0.2377 & 18.0133 & 132 \\
\hline Homogêneo & Depleção & 1 & 3 & 32 & 1 & 7.6071 & 0.4232 & 36 \\
\hline
\end{tabular}




\begin{tabular}{|c|c|c|c|c|c|c|c|c|}
\hline Homogêneo & Depleção & 1 & 3 & 100 & 75 & 0.1133 & 1.9986 & 481 \\
\hline Homogêneo & Depleção & 1 & 3 & 320 & 173 & 0.7846 & 2.2186 & 687 \\
\hline Homogêneo & Depleção & 1 & 3 & 1000 & 246 & 0.6288 & 3.4759 & 691 \\
\hline Homogêneo & Depleção & 1 & 3 & 3200 & 270 & 0.9253 & 3.9968 & 843 \\
\hline Homogêneo & Depleção & 1 & 3 & 10000 & 247 & 1.5948 & 4.8369 & 982 \\
\hline Homogêneo & Depleção & 1 & 3 & 32000 & 35 & 8.2789 & 1.7821 & 81 \\
\hline Homogêneo & Depleção & 1 & 3 & 100000 & 42 & 8.1464 & 1.9418 & 147 \\
\hline Homogêneo & Depleção & 5 & 1 & 0 & 5 & 0.2282 & 18.0804 & 132 \\
\hline Homogêneo & Depleção & 5 & 1 & 32 & 24 & 0.0398 & 6.3621 & 234 \\
\hline Homogêneo & Depleção & 5 & 1 & 100 & 32 & 0.1058 & 9.7474 & 186 \\
\hline Homogêneo & Depleção & 5 & 1 & 320 & 78 & 0.0653 & 5.0382 & 226 \\
\hline Homogêneo & Depleção & 5 & 1 & 1000 & 92 & 0.0527 & 5.2703 & 229 \\
\hline Homogêneo & Depleção & 5 & 1 & 3200 & 56 & 0.0173 & 6.1989 & 230 \\
\hline Homogêneo & Depleção & 5 & 1 & 10000 & 42 & 0.0334 & 9.5169 & 231 \\
\hline Homogêneo & Depleção & 5 & 1 & 32000 & 39 & 0.0248 & 7.1697 & 245 \\
\hline Homogêneo & Depleção & 5 & 1 & 100000 & 58 & 0.0176 & 4.3568 & 312 \\
\hline Homogêneo & Depleção & 5 & 2 & 0 & 10 & 0.2285 & 20.8333 & 146 \\
\hline Homogêneo & Depleção & 5 & 2 & 32 & 33 & 0.0395 & 2.6195 & 301 \\
\hline Homogêneo & Depleção & 5 & 2 & 100 & 38 & 1.3565 & 1.8961 & 327 \\
\hline Homogêneo & Depleção & 5 & 2 & 320 & 100 & 0.0515 & 1.5597 & 528 \\
\hline Homogêneo & Depleção & 5 & 2 & 1000 & 277 & 0.5152 & 1.8610 & 903 \\
\hline Homogêneo & Depleção & 5 & 2 & 3200 & 26 & 8.2072 & 0.8639 & 81 \\
\hline Homogêneo & Depleção & 5 & 2 & 10000 & 34 & 8.2229 & 1.3908 & 95 \\
\hline Homogêneo & Depleção & 5 & 2 & 32000 & 34 & 8.2593 & 1.4197 & 94 \\
\hline Homogêneo & Depleção & 5 & 2 & 100000 & 57 & 8.1374 & 1.4538 & 170 \\
\hline Homogêneo & Depleção & 5 & 3 & 0 & 7 & 0.2230 & 18.2297 & 140 \\
\hline Homogêneo & Depleção & 5 & 3 & 32 & 1 & 7.8882 & 0.2307 & 27 \\
\hline Homogêneo & Depleção & 5 & 3 & 100 & 13 & 5.0110 & 1.5797 & 365 \\
\hline Homogêneo & Depleção & 5 & 3 & 320 & 101 & 1.1834 & 2.1057 & 697 \\
\hline Homogêneo & Depleção & 5 & 3 & 1000 & 343 & 0.2621 & 3.2632 & 1150 \\
\hline Homogêneo & Depleção & 5 & 3 & 3200 & 283 & 1.3336 & 4.0849 & 1065 \\
\hline Homogêneo & Depleção & 5 & 3 & 10000 & 32 & 8.2364 & 1.4350 & 119 \\
\hline Homogêneo & Depleção & 5 & 3 & 32000 & 38 & 8.1807 & 1.8260 & 123 \\
\hline Homogêneo & Depleção & 5 & 3 & 100000 & 102 & 8.2440 & 2.3352 & 307 \\
\hline Homogêneo & $\operatorname{Par} 45^{\circ}$ & 0 & 1 & 0 & 34 & 0.0057 & 3.7345 & 85 \\
\hline Homogêneo & Par $45^{\circ}$ & 0 & 1 & 32 & 70 & 0.0014 & 3.2409 & 239 \\
\hline Homogêneo & $\operatorname{Par} 45^{\circ}$ & 0 & 1 & 100 & 112 & 0.0007 & 2.9547 & 329 \\
\hline Homogêneo & $\operatorname{Par} 45^{\circ}$ & 0 & 1 & 320 & 357 & 0.0011 & 2.4884 & 700 \\
\hline Homogêneo & $\operatorname{Par} 45^{\circ}$ & 0 & 1 & 1000 & 890 & 0.0031 & 1.7651 & 1014 \\
\hline Homogêneo & $\operatorname{Par} 45^{\circ}$ & 0 & 1 & 3200 & 2190 & 0.0029 & 1.1675 & 1902 \\
\hline Homogêneo & Par $45^{\circ}$ & 0 & 1 & 10000 & 2286 & 0.0003 & 0.2919 & 13632 \\
\hline Homogêneo & $\operatorname{Par} 45^{\circ}$ & 0 & 1 & 32000 & 4708 & 0.0005 & 0.3039 & 18252 \\
\hline Homogêneo & $\operatorname{Par} 45^{\circ}$ & 0 & 1 & 100000 & 384444 & 0.0784 & 0.2038 & 348977 \\
\hline Homogêneo & Par $45^{\circ}$ & 0 & 2 & 0 & 137 & 0.0061 & 2.8978 & 116 \\
\hline
\end{tabular}




\begin{tabular}{|c|c|c|c|c|c|c|c|c|}
\hline Homogêneo & $\operatorname{Par} 45^{\circ}$ & 0 & 2 & 32 & 46 & 0.0023 & 3.1137 & 283 \\
\hline Homogêneo & Par $45^{\circ}$ & 0 & 2 & 100 & 91 & 0.0005 & 2.5615 & 443 \\
\hline Homogêneo & Par $45^{\circ}$ & 0 & 2 & 320 & 390 & 0.0014 & 2.0736 & 876 \\
\hline Homogêneo & $\operatorname{Par} 45^{\circ}$ & 0 & 2 & 1000 & 811 & 0.0025 & 1.5686 & 1265 \\
\hline Homogêneo & $\operatorname{Par} 45^{\circ}$ & 0 & 2 & 3200 & 2089 & 0.0027 & 0.9913 & 2035 \\
\hline Homogêneo & $\operatorname{Par} 45^{\circ}$ & 0 & 2 & 10000 & 977 & 0.0005 & 0.2000 & 28052 \\
\hline Homogêneo & $\operatorname{Par} 45^{\circ}$ & 0 & 2 & 32000 & 815 & 0.0011 & 0.1821 & 41553 \\
\hline Homogêneo & $\operatorname{Par} 45^{\circ}$ & 0 & 2 & 100000 & 4007 & 0.0054 & 0.1744 & 73297 \\
\hline Homogêneo & $\operatorname{Par} 45^{\circ}$ & 0 & 3 & 0 & 213 & 0.0060 & 2.4503 & 153 \\
\hline Homogêneo & $\operatorname{Par} 45^{\circ}$ & 0 & 3 & 32 & 41 & 0.0032 & 3.2919 & 302 \\
\hline Homogêneo & $\operatorname{Par} 45^{\circ}$ & 0 & 3 & 100 & 89 & 0.0007 & 2.5835 & 471 \\
\hline Homogêneo & $\operatorname{Par} 45^{\circ}$ & 0 & 3 & 320 & 370 & 0.0012 & 2.1925 & 1039 \\
\hline Homogêneo & $\operatorname{Par} 45^{\circ}$ & 0 & 3 & 1000 & 838 & 0.0023 & 1.6202 & 1389 \\
\hline Homogêneo & $\operatorname{Par} 45^{\circ}$ & 0 & 3 & 3200 & 1322 & 0.0020 & 1.1968 & 1869 \\
\hline Homogêneo & Par $45^{\circ}$ & 0 & 3 & 10000 & 292 & 0.0002 & 0.2155 & 23671 \\
\hline Homogêneo & $\operatorname{Par} 45^{\circ}$ & 0 & 3 & 32000 & 563 & 0.0007 & 0.1907 & 32748 \\
\hline Homogêneo & $\operatorname{Par} 45^{\circ}$ & 0 & 3 & 100000 & 844 & 0.0025 & 0.1865 & 47262 \\
\hline Homogêneo & Par $45^{\circ}$ & 1 & 1 & 0 & 53 & 0.0055 & 3.3446 & 89 \\
\hline Homogêneo & $\operatorname{Par} 45^{\circ}$ & 1 & 1 & 32 & 61 & 0.0014 & 3.1784 & 234 \\
\hline Homogêneo & Par $45^{\circ}$ & 1 & 1 & 100 & 92 & 0.0007 & 2.8431 & 333 \\
\hline Homogêneo & $\operatorname{Par} 45^{\circ}$ & 1 & 1 & 320 & 365 & 0.0013 & 2.4713 & 738 \\
\hline Homogêneo & Par $45^{\circ}$ & 1 & 1 & 1000 & 674 & 0.0021 & 1.9211 & 1085 \\
\hline Homogêneo & Par $45^{\circ}$ & 1 & 1 & 3200 & 1221 & 0.0023 & 1.5297 & 1586 \\
\hline Homogêneo & $\operatorname{Par} 45^{\circ}$ & 1 & 1 & 10000 & 1999 & 0.0020 & 1.4012 & 2132 \\
\hline Homogêneo & $\operatorname{Par} 45^{\circ}$ & 1 & 1 & 32000 & 2730 & 0.0022 & 1.2745 & 3242 \\
\hline Homogêneo & $\operatorname{Par} 45^{\circ}$ & 1 & 1 & 100000 & 3863 & 0.0020 & 1.1328 & 4788 \\
\hline Homogêneo & $\operatorname{Par} 45^{\circ}$ & 1 & 2 & 0 & 151 & 0.0065 & 2.6451 & 119 \\
\hline Homogêneo & $\operatorname{Par} 45^{\circ}$ & 1 & 2 & 32 & 56 & 0.0023 & 3.2556 & 272 \\
\hline Homogêneo & $\operatorname{Par} 45^{\circ}$ & 1 & 2 & 100 & 100 & 0.0006 & 2.4729 & 408 \\
\hline Homogêneo & Par $45^{\circ}$ & 1 & 2 & 320 & 302 & 0.0012 & 2.0662 & 674 \\
\hline Homogêneo & $\operatorname{Par} 45^{\circ}$ & 1 & 2 & 1000 & 794 & 0.0024 & 1.5969 & 1223 \\
\hline Homogêneo & $\operatorname{Par} 45^{\circ}$ & 1 & 2 & 3200 & 1319 & 0.0024 & 1.2357 & 1756 \\
\hline Homogêneo & $\operatorname{Par} 45^{\circ}$ & 1 & 2 & 10000 & 1753 & 0.0016 & 0.9421 & 2332 \\
\hline Homogêneo & $\operatorname{Par} 45^{\circ}$ & 1 & 2 & 32000 & 1856 & 0.0056 & 0.7462 & 2630 \\
\hline Homogêneo & $\operatorname{Par} 45^{\circ}$ & 1 & 2 & 100000 & 2139 & 0.0068 & 0.5624 & 2916 \\
\hline Homogêneo & $\operatorname{Par} 45^{\circ}$ & 1 & 3 & 0 & 263 & 0.0064 & 2.2049 & 169 \\
\hline Homogêneo & $\operatorname{Par} 45^{\circ}$ & 1 & 3 & 32 & 49 & 0.0033 & 3.2368 & 276 \\
\hline Homogêneo & Par $45^{\circ}$ & 1 & 3 & 100 & 79 & 0.0009 & 2.5325 & 433 \\
\hline Homogêneo & $\operatorname{Par} 45^{\circ}$ & 1 & 3 & 320 & 323 & 0.0011 & 2.1382 & 825 \\
\hline Homogêneo & $\operatorname{Par} 45^{\circ}$ & 1 & 3 & 1000 & 723 & 0.0019 & 1.7113 & 1196 \\
\hline Homogêneo & Par $45^{\circ}$ & 1 & 3 & 3200 & 1173 & 0.0013 & 1.3157 & 1656 \\
\hline Homogêneo & Par $45^{\circ}$ & 1 & 3 & 10000 & 1284 & 0.0016 & 1.0516 & 2023 \\
\hline Homogêneo & Par $45^{\circ}$ & 1 & 3 & 32000 & 1397 & 0.0036 & 0.8364 & 2612 \\
\hline Homogêneo & $\operatorname{Par} 45^{\circ}$ & 1 & 3 & 100000 & 1639 & 0.0068 & 0.6320 & 2884 \\
\hline
\end{tabular}




\begin{tabular}{|c|c|c|c|c|c|c|c|c|}
\hline Homogêneo & $\operatorname{Par} 45^{\circ}$ & 5 & 1 & 0 & 17 & 0.0061 & 3.9263 & 69 \\
\hline Homogêneo & Par $45^{\circ}$ & 5 & 1 & 32 & 45 & 0.0017 & 3.4354 & 200 \\
\hline Homogêneo & Par $45^{\circ}$ & 5 & 1 & 100 & 67 & 0.0009 & 3.0777 & 276 \\
\hline Homogêneo & $\operatorname{Par} 45^{\circ}$ & 5 & 1 & 320 & 194 & 0.0011 & 2.6519 & 485 \\
\hline Homogêneo & Par $45^{\circ}$ & 5 & 1 & 1000 & 399 & 0.0013 & 2.0574 & 819 \\
\hline Homogêneo & $\operatorname{Par} 45^{\circ}$ & 5 & 1 & 3200 & 641 & 0.0013 & 1.8305 & 1160 \\
\hline Homogêneo & $\operatorname{Par} 45^{\circ}$ & 5 & 1 & 10000 & 974 & 0.0012 & 1.6794 & 1497 \\
\hline Homogêneo & $\operatorname{Par} 45^{\circ}$ & 5 & 1 & 32000 & 1341 & 0.0020 & 1.5078 & 1967 \\
\hline Homogêneo & $\operatorname{Par} 45^{\circ}$ & 5 & 1 & 100000 & 1891 & 0.0020 & 1.5110 & 2870 \\
\hline Homogêneo & $\operatorname{Par} 45^{\circ}$ & 5 & 2 & 0 & 85 & 0.0060 & 3.0731 & 104 \\
\hline Homogêneo & Par $45^{\circ}$ & 5 & 2 & 32 & 35 & 0.0029 & 3.1800 & 212 \\
\hline Homogêneo & $\operatorname{Par} 45^{\circ}$ & 5 & 2 & 100 & 77 & 0.0010 & 2.6388 & 312 \\
\hline Homogêneo & $\operatorname{Par} 45^{\circ}$ & 5 & 2 & 320 & 198 & 0.0010 & 2.1864 & 512 \\
\hline Homogêneo & $\operatorname{Par} 45^{\circ}$ & 5 & 2 & 1000 & 504 & 0.0008 & 1.6441 & 926 \\
\hline Homogêneo & Par $45^{\circ}$ & 5 & 2 & 3200 & 822 & 0.0008 & 1.3735 & 1379 \\
\hline Homogêneo & $\operatorname{Par} 45^{\circ}$ & 5 & 2 & 10000 & 1132 & 0.0008 & 1.1166 & 1781 \\
\hline Homogêneo & $\operatorname{Par} 45^{\circ}$ & 5 & 2 & 32000 & 1527 & 0.0031 & 0.8765 & 2425 \\
\hline Homogêneo & Par $45^{\circ}$ & 5 & 2 & 100000 & 1847 & 0.0043 & 0.7071 & 2562 \\
\hline Homogêneo & $\operatorname{Par} 45^{\circ}$ & 5 & 3 & 0 & 125 & 0.0054 & 2.7952 & 135 \\
\hline Homogêneo & $\operatorname{Par} 45^{\circ}$ & 5 & 3 & 32 & 55 & 0.0036 & 3.1559 & 268 \\
\hline Homogêneo & $\operatorname{Par} 45^{\circ}$ & 5 & 3 & 100 & 74 & 0.0013 & 2.5791 & 346 \\
\hline Homogêneo & $\operatorname{Par} 45^{\circ}$ & 5 & 3 & 320 & 210 & 0.0008 & 2.2281 & 630 \\
\hline Homogêneo & Par $45^{\circ}$ & 5 & 3 & 1000 & 469 & 0.0008 & 1.7033 & 980 \\
\hline Homogêneo & $\operatorname{Par} 45^{\circ}$ & 5 & 3 & 3200 & 729 & 0.0006 & 1.4444 & 1404 \\
\hline Homogêneo & $\operatorname{Par} 45^{\circ}$ & 5 & 3 & 10000 & 888 & 0.0007 & 1.1938 & 1726 \\
\hline Homogêneo & Par $45^{\circ}$ & 5 & 3 & 32000 & 1122 & 0.0024 & 1.0485 & 2203 \\
\hline Homogêneo & $\operatorname{Par} 45^{\circ}$ & 5 & 3 & 100000 & 1271 & 0.0037 & 0.7468 & 2403 \\
\hline Homogêneo & Par Paralelo & 0 & 1 & 0 & 83 & 0.0064 & 3.1412 & 92 \\
\hline Homogêneo & Par Paralelo & 0 & 1 & 32 & 37 & 0.0016 & 3.1777 & 210 \\
\hline Homogêneo & Par Paralelo & 0 & 1 & 100 & 72 & 0.0005 & 2.7248 & 339 \\
\hline Homogêneo & Par Paralelo & 0 & 1 & 320 & 355 & 0.0014 & 2.1114 & 707 \\
\hline Homogêneo & Par Paralelo & 0 & 1 & 1000 & 869 & 0.0031 & 1.5194 & 997 \\
\hline Homogêneo & Par Paralelo & 0 & 1 & 3200 & 2005 & 0.0039 & 1.0407 & 1385 \\
\hline Homogêneo & Par Paralelo & 0 & 1 & 10000 & 755 & 0.0003 & 0.1940 & 17973 \\
\hline Homogêneo & Par Paralelo & 0 & 1 & 32000 & 1075 & 0.0005 & 0.1785 & 24135 \\
\hline Homogêneo & Par Paralelo & 0 & 1 & 100000 & 5131 & 0.0101 & 0.1732 & 47002 \\
\hline Homogêneo & Par Paralelo & 0 & 2 & 0 & 205 & 0.0069 & 2.4753 & 125 \\
\hline Homogêneo & Par Paralelo & 0 & 2 & 32 & 49 & 0.0026 & 3.4093 & 391 \\
\hline Homogêneo & Par Paralelo & 0 & 2 & 100 & 80 & 0.0009 & 2.6570 & 572 \\
\hline Homogêneo & Par Paralelo & 0 & 2 & 320 & 377 & 0.0015 & 2.1985 & 1176 \\
\hline Homogêneo & Par Paralelo & 0 & 2 & 1000 & 858 & 0.0025 & 1.5992 & 1556 \\
\hline Homogêneo & Par Paralelo & 0 & 2 & 3200 & 1424 & 0.0026 & 1.2032 & 2462 \\
\hline Homogêneo & Par Paralelo & 0 & 2 & 10000 & 810 & 0.0002 & 0.2095 & 32742 \\
\hline Homogêneo & Par Paralelo & 0 & 2 & 32000 & 670 & 0.0028 & 0.1872 & 54848 \\
\hline
\end{tabular}




\begin{tabular}{|c|c|c|c|c|c|c|c|c|}
\hline Homogêneo & Par Paralelo & 0 & 2 & 100000 & 2518 & 0.0167 & 0.1924 & 84343 \\
\hline Homogêneo & Par Paralelo & 0 & 3 & 0 & 323 & 0.0060 & 2.1145 & 173 \\
\hline Homogêneo & Par Paralelo & 0 & 3 & 32 & 43 & 0.0028 & 3.6291 & 489 \\
\hline Homogêneo & Par Paralelo & 0 & 3 & 100 & 57 & 0.0009 & 2.6894 & 639 \\
\hline Homogêneo & Par Paralelo & 0 & 3 & 320 & 337 & 0.0011 & 2.2838 & 1230 \\
\hline Homogêneo & Par Paralelo & 0 & 3 & 1000 & 864 & 0.0020 & 1.6910 & 1760 \\
\hline Homogêneo & Par Paralelo & 0 & 3 & 3200 & 1044 & 0.0016 & 1.3028 & 2474 \\
\hline Homogêneo & Par Paralelo & 0 & 3 & 10000 & 421 & 0.0012 & 0.2244 & 29008 \\
\hline Homogêneo & Par Paralelo & 0 & 3 & 32000 & 630 & 0.0047 & 0.1984 & 49651 \\
\hline Homogêneo & Par Paralelo & 0 & 3 & 100000 & 1286 & 0.0325 & 0.2187 & 64821 \\
\hline Homogêneo & Par Paralelo & 1 & 1 & 0 & 90 & 0.0059 & 3.0892 & 104 \\
\hline Homogêneo & Par Paralelo & 1 & 1 & 32 & 53 & 0.0022 & 3.1394 & 227 \\
\hline Homogêneo & Par Paralelo & 1 & 1 & 100 & 84 & 0.0010 & 2.5770 & 372 \\
\hline Homogêneo & Par Paralelo & 1 & 1 & 320 & 253 & 0.0008 & 2.0748 & 628 \\
\hline Homogêneo & Par Paralelo & 1 & 1 & 1000 & 575 & 0.0015 & 1.6754 & 1126 \\
\hline Homogêneo & Par Paralelo & 1 & 1 & 3200 & 1155 & 0.0015 & 1.2606 & 1861 \\
\hline Homogêneo & Par Paralelo & 1 & 1 & 10000 & 1519 & 0.0108 & 0.9345 & 2229 \\
\hline Homogêneo & Par Paralelo & 1 & 1 & 32000 & 1715 & 0.0210 & 0.7286 & 2374 \\
\hline Homogêneo & Par Paralelo & 1 & 1 & 100000 & 2192 & 0.0331 & 0.5425 & 3073 \\
\hline Homogêneo & Par Paralelo & 1 & 2 & 0 & 227 & 0.0067 & 2.3521 & 144 \\
\hline Homogêneo & Par Paralelo & 1 & 2 & 32 & 56 & 0.0025 & 3.3470 & 311 \\
\hline Homogêneo & Par Paralelo & 1 & 2 & 100 & 72 & 0.0009 & 2.4817 & 358 \\
\hline Homogêneo & Par Paralelo & 1 & 2 & 320 & 269 & 0.0006 & 2.1491 & 731 \\
\hline Homogêneo & Par Paralelo & 1 & 2 & 1000 & 614 & 0.0014 & 1.7270 & 1107 \\
\hline Homogêneo & Par Paralelo & 1 & 2 & 3200 & 975 & 0.0007 & 1.3368 & 1617 \\
\hline Homogêneo & Par Paralelo & 1 & 2 & 10000 & 1052 & 0.0051 & 1.0762 & 1668 \\
\hline Homogêneo & Par Paralelo & 1 & 2 & 32000 & 1205 & 0.0112 & 0.8385 & 2006 \\
\hline Homogêneo & Par Paralelo & 1 & 2 & 100000 & 1371 & 0.0207 & 0.6722 & 2267 \\
\hline Homogêneo & Par Paralelo & 1 & 3 & 0 & 321 & 0.0063 & 2.0992 & 176 \\
\hline Homogêneo & Par Paralelo & 1 & 3 & 32 & 44 & 0.0026 & 3.3239 & 323 \\
\hline Homogêneo & Par Paralelo & 1 & 3 & 100 & 58 & 0.0008 & 2.4381 & 397 \\
\hline Homogêneo & Par Paralelo & 1 & 3 & 320 & 239 & 0.0007 & 2.2221 & 688 \\
\hline Homogêneo & Par Paralelo & 1 & 3 & 1000 & 503 & 0.0009 & 1.7845 & 1002 \\
\hline Homogêneo & Par Paralelo & 1 & 3 & 3200 & 859 & 0.0005 & 1.3742 & 1562 \\
\hline Homogêneo & Par Paralelo & 1 & 3 & 10000 & 970 & 0.0029 & 1.1251 & 1807 \\
\hline Homogêneo & Par Paralelo & 1 & 3 & 32000 & 1015 & 0.0058 & 0.8757 & 2179 \\
\hline Homogêneo & Par Paralelo & 1 & 3 & 100000 & 1050 & 0.0167 & 0.6794 & 2023 \\
\hline Homogêneo & Par Paralelo & 5 & 1 & 0 & 17 & 0.0065 & 3.7053 & 67 \\
\hline Homogêneo & Par Paralelo & 5 & 1 & 32 & 36 & 0.0017 & 3.1709 & 194 \\
\hline Homogêneo & Par Paralelo & 5 & 1 & 100 & 62 & 0.0009 & 2.6602 & 252 \\
\hline Homogêneo & Par Paralelo & 5 & 1 & 320 & 166 & 0.0009 & 2.1883 & 464 \\
\hline Homogêneo & Par Paralelo & 5 & 1 & 1000 & 441 & 0.0011 & 1.6904 & 759 \\
\hline Homogêneo & Par Paralelo & 5 & 1 & 3200 & 759 & 0.0012 & 1.3901 & 1106 \\
\hline Homogêneo & Par Paralelo & 5 & 1 & 10000 & 1296 & 0.0016 & 1.0918 & 1588 \\
\hline
\end{tabular}




\begin{tabular}{|c|c|c|c|c|c|c|c|c|}
\hline Homogêneo & Par Paralelo & 5 & 1 & 32000 & 1584 & 0.0014 & 0.8533 & 1805 \\
\hline Homogêneo & Par Paralelo & 5 & 1 & 100000 & 1813 & 0.0010 & 0.7032 & 2471 \\
\hline Homogêneo & Par Paralelo & 5 & 2 & 0 & 28 & 0.0061 & 3.5250 & 76 \\
\hline Homogêneo & Par Paralelo & 5 & 2 & 32 & 47 & 0.0021 & 3.1964 & 232 \\
\hline Homogêneo & Par Paralelo & 5 & 2 & 100 & 61 & 0.0011 & 2.5811 & 295 \\
\hline Homogêneo & Par Paralelo & 5 & 2 & 320 & 178 & 0.0008 & 2.2005 & 536 \\
\hline Homogêneo & Par Paralelo & 5 & 2 & 1000 & 439 & 0.0008 & 1.7386 & 929 \\
\hline Homogêneo & Par Paralelo & 5 & 2 & 3200 & 600 & 0.0011 & 1.4553 & 1240 \\
\hline Homogêneo & Par Paralelo & 5 & 2 & 10000 & 840 & 0.0015 & 1.2319 & 2019 \\
\hline Homogêneo & Par Paralelo & 5 & 2 & 32000 & 974 & 0.0023 & 0.9753 & 1845 \\
\hline Homogêneo & Par Paralelo & 5 & 2 & 100000 & 1113 & 0.0063 & 0.8103 & 2045 \\
\hline Homogêneo & Par Paralelo & 5 & 3 & 0 & 32 & 0.0056 & 3.4617 & 78 \\
\hline Homogêneo & Par Paralelo & 5 & 3 & 32 & 50 & 0.0029 & 3.2383 & 270 \\
\hline Homogêneo & Par Paralelo & 5 & 3 & 100 & 62 & 0.0012 & 2.6307 & 309 \\
\hline Homogêneo & Par Paralelo & 5 & 3 & 320 & 144 & 0.0009 & 2.2580 & 535 \\
\hline Homogêneo & Par Paralelo & 5 & 3 & 1000 & 379 & 0.0008 & 1.8127 & 995 \\
\hline Homogêneo & Par Paralelo & 5 & 3 & 3200 & 487 & 0.0010 & 1.5160 & 1441 \\
\hline Homogêneo & Par Paralelo & 5 & 3 & 10000 & 667 & 0.0018 & 1.2444 & 1620 \\
\hline Homogêneo & Par Paralelo & 5 & 3 & 32000 & 873 & 0.0026 & 0.9924 & 2002 \\
\hline Homogêneo & Par Paralelo & 5 & 3 & 100000 & 1024 & 0.0085 & 0.9137 & 2269 \\
\hline
\end{tabular}

Tabela A.3: Resultados de Simulaçao - Produção

\begin{tabular}{|c|c|c|c|c|c|c|c|c|c|c|}
\hline Matriz & Malha & D & $\mathbf{L}$ & $K_{\text {frat }}$ & $N_{p}\left(m^{3}\right)$ & FR & $\begin{array}{l}\text { Dias para o } \\
\text { Breakthrough } \\
\text { de Água }\end{array}$ & $t_{D w}$ & $\begin{array}{c}\text { Dias para } \\
\mathbf{P}_{\mathrm{b}}\end{array}$ & $t_{D p b}$ \\
\hline Heterogêneo & Depleção & 0 & 1 & 0 & $1.45 \mathrm{E}+07$ & 0.048 & -1 & $-1.10 \mathrm{E}-05$ & 4050 & 0.044614137 \\
\hline Heterogêneo & Depleção & 0 & 1 & 32 & $1.31 \mathrm{E}+07$ & 0.043 & -1 & $-1.10 \mathrm{E}-05$ & 3600 & 0.039657011 \\
\hline Heterogêneo & Depleção & 0 & 1 & 100 & $1.31 \mathrm{E}+07$ & 0.043 & -1 & $-1.10 \mathrm{E}-05$ & 3569 & 0.03931552 \\
\hline Heterogêneo & Depleção & 0 & 1 & 320 & $1.31 \mathrm{E}+07$ & 0.043 & -1 & $-1.10 \mathrm{E}-05$ & 3591 & 0.039557868 \\
\hline Heterogêneo & Depleção & 0 & 1 & 1000 & $1.31 \mathrm{E}+07$ & 0.043 & -1 & $-1.10 \mathrm{E}-05$ & 3575 & 0.039381615 \\
\hline Heterogêneo & Depleção & 0 & 1 & 3200 & $1.31 \mathrm{E}+07$ & 0.043 & -1 & $-1.10 \mathrm{E}-05$ & 3600 & 0.039657011 \\
\hline Heterogêneo & Depleção & 0 & 1 & 10000 & $1.31 \mathrm{E}+07$ & 0.043 & -1 & $-1.10 \mathrm{E}-05$ & 3900 & 0.042961762 \\
\hline Heterogêneo & Depleção & 0 & 1 & 32000 & $1.31 \mathrm{E}+07$ & 0.043 & -1 & $-1.10 \mathrm{E}-05$ & 3792 & 0.041772052 \\
\hline Heterogêneo & Depleção & 0 & 1 & 100000 & $1.31 \mathrm{E}+07$ & 0.043 & -1 & $-1.10 \mathrm{E}-05$ & 3685 & 0.040593357 \\
\hline Heterogêneo & Depleção & 0 & 2 & 0 & $1.44 \mathrm{E}+07$ & 0.048 & -1 & $-1.10 \mathrm{E}-05$ & 4050 & 0.044614137 \\
\hline Heterogêneo & Depleção & 0 & 2 & 32 & $1.31 \mathrm{E}+07$ & 0.043 & -1 & $-1.10 \mathrm{E}-05$ & 3600 & 0.039657011 \\
\hline Heterogêneo & Depleção & 0 & 2 & 100 & $1.31 \mathrm{E}+07$ & 0.043 & -1 & $-1.10 \mathrm{E}-05$ & 3575 & 0.039381615 \\
\hline Heterogêneo & Depleção & 0 & 2 & 320 & $1.31 \mathrm{E}+07$ & 0.043 & -1 & $-1.10 \mathrm{E}-05$ & 3588 & 0.039524821 \\
\hline Heterogêneo & Depleção & 0 & 2 & 1000 & $1.30 \mathrm{E}+07$ & 0.043 & -1 & $-1.10 \mathrm{E}-05$ & 3600 & 0.039657011 \\
\hline Heterogêneo & Depleção & 0 & 2 & 3200 & $1.43 E+07$ & 0.047 & -1 & $-1.10 \mathrm{E}-05$ & 4000 & 0.044063345 \\
\hline Heterogêneo & Depleção & 0 & 2 & 10000 & $1.51 \mathrm{E}+07$ & 0.050 & -1 & $-1.10 \mathrm{E}-05$ & 4236 & 0.046663083 \\
\hline Heterogêneo & Depleção & 0 & 2 & 32000 & $3.98 \mathrm{E}+07$ & 0.132 & -1 & $-1.10 \mathrm{E}-05$ & -1 & $-1.10 \mathrm{E}-05$ \\
\hline Heterogêneo & Depleção & 0 & 2 & 100000 & $3.99 \mathrm{E}+07$ & 0.132 & -1 & $-1.10 \mathrm{E}-05$ & -1 & $-1.10 \mathrm{E}-05$ \\
\hline
\end{tabular}




\begin{tabular}{|c|c|c|c|c|c|c|c|c|c|c|}
\hline Heterogêneo & Depleção & 0 & 3 & 0 & $1.42 \mathrm{E}+07$ & 0.047 & -1 & $-1.10 \mathrm{E}-05$ & 4050 & 0.044614137 \\
\hline Heterogêneo & Depleção & 0 & 3 & 32 & $1.31 \mathrm{E}+07$ & 0.043 & -1 & $-1.10 \mathrm{E}-05$ & 3508 & 0.038643554 \\
\hline Heterogêneo & Depleção & 0 & 3 & 100 & $1.30 \mathrm{E}+07$ & 0.043 & -1 & $-1.10 \mathrm{E}-05$ & 3512 & 0.038687617 \\
\hline Heterogêneo & Depleção & 0 & 3 & 320 & $1.31 \mathrm{E}+07$ & 0.043 & -1 & $-1.10 \mathrm{E}-05$ & 3517 & 0.038742697 \\
\hline Heterogêneo & Depleção & 0 & 3 & 1000 & $1.30 \mathrm{E}+07$ & 0.043 & -1 & $-1.10 \mathrm{E}-05$ & 3516 & 0.038731681 \\
\hline Heterogêneo & Depleção & 0 & 3 & 3200 & $1.31 \mathrm{E}+07$ & 0.043 & -1 & $-1.10 \mathrm{E}-05$ & 3563 & 0.039249425 \\
\hline Heterogêneo & Depleção & 0 & 3 & 10000 & $3.98 \mathrm{E}+07$ & 0.132 & -1 & $-1.10 \mathrm{E}-05$ & -1 & $-1.10 \mathrm{E}-05$ \\
\hline Heterogêneo & Depleção & 0 & 3 & 32000 & $1.51 \mathrm{E}+07$ & 0.050 & -1 & $-1.10 \mathrm{E}-05$ & 3786 & 0.041705956 \\
\hline Heterogêneo & Depleção & 0 & 3 & 100000 & $3.99 \mathrm{E}+07$ & 0.132 & -1 & $-1.10 \mathrm{E}-05$ & -1 & $-1.10 \mathrm{E}-05$ \\
\hline Heterogêneo & Depleção & 1 & 1 & 0 & $1.45 E+07$ & 0.048 & -1 & $-1.10 \mathrm{E}-05$ & 4050 & 0.044614137 \\
\hline Heterogêneo & Depleção & 1 & 1 & 32 & $1.40 \mathrm{E}+07$ & 0.046 & -1 & $-1.10 \mathrm{E}-05$ & 3853 & 0.042444018 \\
\hline Heterogêneo & Depleção & 1 & 1 & 100 & $1.32 \mathrm{E}+07$ & 0.044 & -1 & $-1.10 \mathrm{E}-05$ & 3600 & 0.039657011 \\
\hline Heterogêneo & Depleção & 1 & 1 & 320 & $1.31 \mathrm{E}+07$ & 0.043 & -1 & $-1.10 \mathrm{E}-05$ & 3600 & 0.039657011 \\
\hline Heterogêneo & Depleção & 1 & 1 & 1000 & $1.31 \mathrm{E}+07$ & 0.043 & -1 & $-1.10 \mathrm{E}-05$ & 3582 & 0.039458726 \\
\hline Heterogêneo & Depleção & 1 & 1 & 3200 & $1.32 \mathrm{E}+07$ & 0.044 & -1 & $-1.10 \mathrm{E}-05$ & 3637 & 0.040064597 \\
\hline Heterogêneo & Depleção & 1 & 1 & 10000 & $1.35 \mathrm{E}+07$ & 0.045 & -1 & $-1.10 \mathrm{E}-05$ & 3720 & 0.040978911 \\
\hline Heterogêneo & Depleção & 1 & 1 & 32000 & $3.98 \mathrm{E}+07$ & 0.132 & -1 & $-1.10 \mathrm{E}-05$ & -1 & $-1.10 \mathrm{E}-05$ \\
\hline Heterogêneo & Depleção & 1 & 1 & 100000 & $3.97 E+07$ & 0.131 & -1 & $-1.10 \mathrm{E}-05$ & -1 & $-1.10 \mathrm{E}-05$ \\
\hline Heterogêneo & Depleção & 1 & 2 & 0 & $1.45 \mathrm{E}+07$ & 0.048 & -1 & $-1.10 \mathrm{E}-05$ & 4050 & 0.044614137 \\
\hline Heterogêneo & Depleção & 1 & 2 & 32 & $1.31 \mathrm{E}+07$ & 0.043 & -1 & $-1.10 \mathrm{E}-05$ & 3537 & 0.038963013 \\
\hline Heterogêneo & Depleção & 1 & 2 & 100 & $1.30 \mathrm{E}+07$ & 0.043 & -1 & $-1.10 \mathrm{E}-05$ & 3524 & 0.038819807 \\
\hline Heterogêneo & Depleção & 1 & 2 & 320 & $1.31 \mathrm{E}+07$ & 0.043 & -1 & $-1.10 \mathrm{E}-05$ & 3511 & 0.038676601 \\
\hline Heterogêneo & Depleção & 1 & 2 & 1000 & $1.30 \mathrm{E}+07$ & 0.043 & -1 & $-1.10 \mathrm{E}-05$ & 3577 & 0.039403647 \\
\hline Heterogêneo & Depleção & 1 & 2 & 3200 & $1.31 \mathrm{E}+07$ & 0.043 & -1 & $-1.10 \mathrm{E}-05$ & 3540 & 0.038996061 \\
\hline Heterogêneo & Depleção & 1 & 2 & 10000 & $1.39 \mathrm{E}+07$ & 0.046 & -1 & $-1.10 \mathrm{E}-05$ & 3790 & 0.04175002 \\
\hline Heterogêneo & Depleção & 1 & 2 & 32000 & $3.97 E+07$ & 0.131 & -1 & $-1.10 \mathrm{E}-05$ & -1 & $-1.10 \mathrm{E}-05$ \\
\hline Heterogêneo & Depleção & 1 & 2 & 100000 & $3.99 \mathrm{E}+07$ & 0.132 & -1 & $-1.10 \mathrm{E}-05$ & -1 & $-1.10 \mathrm{E}-05$ \\
\hline Heterogêneo & Depleção & 1 & 3 & 0 & $1.42 \mathrm{E}+07$ & 0.047 & -1 & $-1.10 \mathrm{E}-05$ & 4050 & 0.044614137 \\
\hline Heterogêneo & Depleção & 1 & 3 & 32 & $1.30 \mathrm{E}+07$ & 0.043 & -1 & $-1.10 \mathrm{E}-05$ & 3529 & 0.038874887 \\
\hline Heterogêneo & Depleção & 1 & 3 & 100 & $1.30 \mathrm{E}+07$ & 0.043 & -1 & $-1.10 \mathrm{E}-05$ & 3493 & 0.038478316 \\
\hline Heterogêneo & Depleção & 1 & 3 & 320 & $1.31 \mathrm{E}+07$ & 0.043 & -1 & $-1.10 \mathrm{E}-05$ & 3498 & 0.038533396 \\
\hline Heterogêneo & Depleção & 1 & 3 & 1000 & $1.30 \mathrm{E}+07$ & 0.043 & -1 & $-1.10 \mathrm{E}-05$ & 3485 & 0.03839019 \\
\hline Heterogêneo & Depleção & 1 & 3 & 3200 & $1.30 \mathrm{E}+07$ & 0.043 & -1 & $-1.10 \mathrm{E}-05$ & 3283 & 0.036164991 \\
\hline Heterogêneo & Depleção & 1 & 3 & 10000 & $1.34 \mathrm{E}+07$ & 0.044 & -1 & $-1.10 \mathrm{E}-05$ & 3600 & 0.039657011 \\
\hline Heterogêneo & Depleção & 1 & 3 & 32000 & $3.99 \mathrm{E}+07$ & 0.132 & -1 & $-1.10 \mathrm{E}-05$ & -1 & $-1.10 \mathrm{E}-05$ \\
\hline Heterogêneo & Depleção & 1 & 3 & 100000 & $3.99 E+07$ & 0.132 & -1 & $-1.10 \mathrm{E}-05$ & -1 & $-1.10 \mathrm{E}-05$ \\
\hline Heterogêneo & Depleção & 5 & 1 & 0 & $1.45 \mathrm{E}+07$ & 0.048 & -1 & $-1.10 \mathrm{E}-05$ & 4050 & 0.044614137 \\
\hline Heterogêneo & Depleção & 5 & 1 & 32 & $1.31 \mathrm{E}+07$ & 0.043 & -1 & $-1.10 \mathrm{E}-05$ & 3600 & 0.039657011 \\
\hline Heterogêneo & Depleção & 5 & 1 & 100 & $1.31 \mathrm{E}+07$ & 0.043 & -1 & $-1.10 \mathrm{E}-05$ & 3600 & 0.039657011 \\
\hline Heterogêneo & Depleção & 5 & 1 & 320 & $1.32 \mathrm{E}+07$ & 0.044 & -1 & $-1.10 \mathrm{E}-05$ & 3600 & 0.039657011 \\
\hline Heterogêneo & Depleção & 5 & 1 & 1000 & $1.31 \mathrm{E}+07$ & 0.043 & -1 & $-1.10 \mathrm{E}-05$ & 3600 & 0.039657011 \\
\hline Heterogêneo & Depleção & 5 & 1 & 3200 & $1.31 \mathrm{E}+07$ & 0.043 & -1 & $-1.10 \mathrm{E}-05$ & 3600 & 0.039657011 \\
\hline Heterogêneo & Depleção & 5 & 1 & 10000 & $1.32 \mathrm{E}+07$ & 0.044 & -1 & $-1.10 \mathrm{E}-05$ & 3600 & 0.039657011 \\
\hline Heterogêneo & Depleção & 5 & 1 & 32000 & $1.31 \mathrm{E}+07$ & 0.043 & -1 & $-1.10 \mathrm{E}-05$ & 3600 & 0.039657011 \\
\hline
\end{tabular}




\begin{tabular}{|c|c|c|c|c|c|c|c|c|c|c|}
\hline Heterogêneo & Depleção & 5 & 1 & 100000 & $1.31 \mathrm{E}+07$ & 0.043 & -1 & $-1.10 \mathrm{E}-05$ & 3548 & 0.039084187 \\
\hline Heterogêneo & Depleção & 5 & 2 & 0 & $1.45 \mathrm{E}+07$ & 0.048 & -1 & $-1.10 \mathrm{E}-05$ & 4050 & 0.044614137 \\
\hline Heterogêneo & Depleção & 5 & 2 & 32 & $1.31 \mathrm{E}+07$ & 0.043 & -1 & $-1.10 \mathrm{E}-05$ & 3553 & 0.039139267 \\
\hline Heterogêneo & Depleção & 5 & 2 & 100 & $1.31 \mathrm{E}+07$ & 0.043 & -1 & $-1.10 \mathrm{E}-05$ & 3600 & 0.039657011 \\
\hline Heterogêneo & Depleção & 5 & 2 & 320 & $1.31 \mathrm{E}+07$ & 0.043 & -1 & $-1.10 \mathrm{E}-05$ & 3556 & 0.039172314 \\
\hline Heterogêneo & Depleção & 5 & 2 & 1000 & $1.31 \mathrm{E}+07$ & 0.043 & -1 & $-1.10 \mathrm{E}-05$ & 3563 & 0.039249425 \\
\hline Heterogêneo & Depleção & 5 & 2 & 3200 & $1.31 \mathrm{E}+07$ & 0.043 & -1 & $-1.10 \mathrm{E}-05$ & 3585 & 0.039491773 \\
\hline Heterogêneo & Depleção & 5 & 2 & 10000 & $3.99 E+07$ & 0.132 & -1 & $-1.10 \mathrm{E}-05$ & -1 & $-1.10 \mathrm{E}-05$ \\
\hline Heterogêneo & Depleção & 5 & 2 & 32000 & $3.99 E+07$ & 0.132 & -1 & $-1.10 \mathrm{E}-05$ & -1 & $-1.10 \mathrm{E}-05$ \\
\hline Heterogêneo & Depleção & 5 & 2 & 100000 & $3.99 \mathrm{E}+07$ & 0.132 & -1 & $-1.10 \mathrm{E}-05$ & -1 & $-1.10 \mathrm{E}-05$ \\
\hline Heterogêneo & Depleção & 5 & 3 & 0 & $1.42 \mathrm{E}+07$ & 0.047 & -1 & $-1.10 \mathrm{E}-05$ & 4050 & 0.044614137 \\
\hline Heterogêneo & Depleção & 5 & 3 & 32 & $1.31 \mathrm{E}+07$ & 0.043 & -1 & $-1.10 \mathrm{E}-05$ & 3564 & 0.039260441 \\
\hline Heterogêneo & Depleção & 5 & 3 & 100 & $1.31 \mathrm{E}+07$ & 0.043 & -1 & $-1.10 \mathrm{E}-05$ & 3535 & 0.038940982 \\
\hline Heterogêneo & Depleção & 5 & 3 & 320 & $1.38 \mathrm{E}+07$ & 0.046 & -1 & $-1.10 \mathrm{E}-05$ & 3734 & 0.041133133 \\
\hline Heterogêneo & Depleção & 5 & 3 & 1000 & $1.49 \mathrm{E}+07$ & 0.049 & -1 & $-1.10 \mathrm{E}-05$ & 4039 & 0.044492963 \\
\hline Heterogêneo & Depleção & 5 & 3 & 3200 & $1.45 \mathrm{E}+07$ & 0.048 & -1 & $-1.10 \mathrm{E}-05$ & 3944 & 0.043446459 \\
\hline Heterogêneo & Depleção & 5 & 3 & 10000 & $3.99 \mathrm{E}+07$ & 0.132 & -1 & $-1.10 \mathrm{E}-05$ & -1 & $-1.10 \mathrm{E}-05$ \\
\hline Heterogêneo & Depleção & 5 & 3 & 32000 & $3.99 \mathrm{E}+07$ & 0.132 & -1 & $-1.10 \mathrm{E}-05$ & -1 & $-1.10 \mathrm{E}-05$ \\
\hline Heterogêneo & Depleção & 5 & 3 & 100000 & $3.99 \mathrm{E}+07$ & 0.132 & -1 & $-1.10 \mathrm{E}-05$ & -1 & $-1.10 \mathrm{E}-05$ \\
\hline Heterogêneo & Par $45^{\circ}$ & 0 & 1 & 0 & $3.92 E+07$ & 0.130 & 8100 & $8.92 \mathrm{E}-02$ & -1 & $-1.10 \mathrm{E}-05$ \\
\hline Heterogêneo & $\operatorname{Par} 45^{\circ}$ & 0 & 1 & 32 & $3.91 E+07$ & 0.129 & 7677 & 8.46E-02 & -1 & $-1.10 \mathrm{E}-05$ \\
\hline Heterogêneo & $\operatorname{Par} 45^{\circ}$ & 0 & 1 & 100 & $3.89 E+07$ & 0.129 & 7491 & $8.25 \mathrm{E}-02$ & -1 & $-1.10 \mathrm{E}-05$ \\
\hline Heterogêneo & Par $45^{\circ}$ & 0 & 1 & 320 & $3.88 \mathrm{E}+07$ & 0.128 & 7360 & $8.11 \mathrm{E}-02$ & -1 & $-1.10 \mathrm{E}-05$ \\
\hline Heterogêneo & $\operatorname{Par} 45^{\circ}$ & 0 & 1 & 1000 & $3.88 \mathrm{E}+07$ & 0.128 & 7302 & 8.04E-02 & -1 & $-1.10 \mathrm{E}-05$ \\
\hline Heterogêneo & Par $45^{\circ}$ & 0 & 1 & 3200 & $3.88 \mathrm{E}+07$ & 0.129 & 7291 & 8.03E-02 & -1 & $-1.10 \mathrm{E}-05$ \\
\hline Heterogêneo & Par $45^{\circ}$ & 0 & 1 & 10000 & $3.88 \mathrm{E}+07$ & 0.128 & 7300 & 8.04E-02 & -1 & $-1.10 \mathrm{E}-05$ \\
\hline Heterogêneo & $\operatorname{Par} 45^{\circ}$ & 0 & 1 & 32000 & $3.88 \mathrm{E}+07$ & 0.128 & 7222 & 7.96E-02 & -1 & $-1.10 \mathrm{E}-05$ \\
\hline Heterogêneo & Par $45^{\circ}$ & 0 & 1 & 100000 & $3.84 \mathrm{E}+07$ & 0.127 & 7213 & $7.95 \mathrm{E}-02$ & -1 & $-1.10 \mathrm{E}-05$ \\
\hline Heterogêneo & $\operatorname{Par} 45^{\circ}$ & 0 & 2 & 0 & $3.91 \mathrm{E}+07$ & 0.130 & 8055 & 8.87E-02 & -1 & $-1.10 \mathrm{E}-05$ \\
\hline Heterogêneo & $\operatorname{Par} 45^{\circ}$ & 0 & 2 & 32 & $3.89 E+07$ & 0.129 & 7178 & 7.91E-02 & -1 & $-1.10 \mathrm{E}-05$ \\
\hline Heterogêneo & $\operatorname{Par} 45^{\circ}$ & 0 & 2 & 100 & $3.86 \mathrm{E}+07$ & 0.128 & 6300 & $6.94 \mathrm{E}-02$ & -1 & $-1.10 \mathrm{E}-05$ \\
\hline Heterogêneo & $\operatorname{Par} 45^{\circ}$ & 0 & 2 & 320 & $3.78 \mathrm{E}+07$ & 0.125 & 4200 & $4.63 \mathrm{E}-02$ & -1 & $-1.10 \mathrm{E}-05$ \\
\hline Heterogêneo & Par $45^{\circ}$ & 0 & 2 & 1000 & $3.61 E+07$ & 0.119 & 636 & 7.01E-03 & -1 & $-1.10 \mathrm{E}-05$ \\
\hline Heterogêneo & $\operatorname{Par} 45^{\circ}$ & 0 & 2 & 3200 & $3.40 E+07$ & 0.113 & 50 & $5.49 \mathrm{E}-04$ & -1 & $-1.10 \mathrm{E}-05$ \\
\hline Heterogêneo & $\operatorname{Par} 45^{\circ}$ & 0 & 2 & 10000 & $2.97 E+07$ & 0.098 & 22 & $2.45 \mathrm{E}-04$ & -1 & $-1.10 \mathrm{E}-05$ \\
\hline Heterogêneo & Par $45^{\circ}$ & 0 & 2 & 32000 & $2.88 \mathrm{E}+07$ & 0.095 & 14 & $1.53 \mathrm{E}-04$ & -1 & $-1.10 \mathrm{E}-05$ \\
\hline Heterogêneo & $\operatorname{Par} 45^{\circ}$ & 0 & 2 & 100000 & $2.83 \mathrm{E}+07$ & 0.094 & 10 & $1.08 \mathrm{E}-04$ & -1 & $-1.10 \mathrm{E}-05$ \\
\hline Heterogêneo & Par $45^{\circ}$ & 0 & 3 & 0 & $3.91 \mathrm{E}+07$ & 0.129 & 8058 & $8.88 \mathrm{E}-02$ & -1 & $-1.10 \mathrm{E}-05$ \\
\hline Heterogêneo & $\operatorname{Par} 45^{\circ}$ & 0 & 3 & 32 & $3.88 \mathrm{E}+07$ & 0.128 & 6767 & $7.45 \mathrm{E}-02$ & -1 & $-1.10 \mathrm{E}-05$ \\
\hline Heterogêneo & Par $45^{\circ}$ & 0 & 3 & 100 & $3.83 E+07$ & 0.127 & 5483 & $6.04 \mathrm{E}-02$ & -1 & $-1.10 \mathrm{E}-05$ \\
\hline Heterogêneo & $\operatorname{Par} 45^{\circ}$ & 0 & 3 & 320 & $3.71 E+07$ & 0.123 & 2577 & $2.84 \mathrm{E}-02$ & -1 & $-1.10 \mathrm{E}-05$ \\
\hline Heterogêneo & $\operatorname{Par} 45^{\circ}$ & 0 & 3 & 1000 & $3.47 \mathrm{E}+07$ & 0.115 & 137 & $1.50 \mathrm{E}-03$ & -1 & $-1.10 \mathrm{E}-05$ \\
\hline Heterogêneo & Par $45^{\circ}$ & 0 & 3 & 3200 & $3.34 \mathrm{E}+07$ & 0.110 & 42 & 4.62E-04 & -1 & $-1.10 \mathrm{E}-05$ \\
\hline Heterogêneo & $\operatorname{Par} 45^{\circ}$ & 0 & 3 & 10000 & $3.04 E+07$ & 0.101 & 23 & $2.48 \mathrm{E}-04$ & -1 & $-1.10 \mathrm{E}-05$ \\
\hline
\end{tabular}




\begin{tabular}{|c|c|c|c|c|c|c|c|c|c|c|}
\hline Heterogêneo & $\operatorname{Par} 45^{\circ}$ & 0 & 3 & 32000 & $2.94 \mathrm{E}+07$ & 0.097 & 16 & 1.77E-04 & -1 & $-1.10 \mathrm{E}-05$ \\
\hline Heterogêneo & $\operatorname{Par} 45^{\circ}$ & 0 & 3 & 100000 & $2.82 \mathrm{E}+07$ & 0.093 & 12 & $1.34 \mathrm{E}-04$ & -1 & $-1.10 \mathrm{E}-05$ \\
\hline Heterogêneo & Par $45^{\circ}$ & 1 & 1 & 0 & $3.92 \mathrm{E}+07$ & 0.130 & 8250 & 9.09E-02 & -1 & $-1.10 \mathrm{E}-05$ \\
\hline Heterogêneo & $\operatorname{Par} 45^{\circ}$ & 1 & 1 & 32 & $3.91 E+07$ & 0.129 & 7967 & $8.78 \mathrm{E}-02$ & -1 & $-1.10 \mathrm{E}-05$ \\
\hline Heterogêneo & Par $45^{\circ}$ & 1 & 1 & 100 & $3.91 \mathrm{E}+07$ & 0.129 & 7800 & 8.59E-02 & -1 & $-1.10 \mathrm{E}-05$ \\
\hline Heterogêneo & $\operatorname{Par} 45^{\circ}$ & 1 & 1 & 320 & $3.91 \mathrm{E}+07$ & 0.129 & 7733 & $8.52 \mathrm{E}-02$ & -1 & $-1.10 \mathrm{E}-05$ \\
\hline Heterogêneo & Par $45^{\circ}$ & 1 & 1 & 1000 & $3.90 E+07$ & 0.129 & 7678 & $8.46 \mathrm{E}-02$ & -1 & $-1.10 \mathrm{E}-05$ \\
\hline Heterogêneo & Par $45^{\circ}$ & 1 & 1 & 3200 & $3.90 E+07$ & 0.129 & 7659 & 8.44E-02 & -1 & $-1.10 \mathrm{E}-05$ \\
\hline Heterogêneo & $\operatorname{Par} 45^{\circ}$ & 1 & 1 & 10000 & $3.90 \mathrm{E}+07$ & 0.129 & 7644 & $8.42 \mathrm{E}-02$ & -1 & $-1.10 \mathrm{E}-05$ \\
\hline Heterogêneo & Par $45^{\circ}$ & 1 & 1 & 32000 & $3.90 E+07$ & 0.129 & 7640 & $8.42 \mathrm{E}-02$ & -1 & $-1.10 \mathrm{E}-05$ \\
\hline Heterogêneo & $\operatorname{Par} 45^{\circ}$ & 1 & 1 & 100000 & $3.90 E+07$ & 0.129 & 7637 & $8.41 \mathrm{E}-02$ & -1 & $-1.10 \mathrm{E}-05$ \\
\hline Heterogêneo & $\operatorname{Par} 45^{\circ}$ & 1 & 2 & 0 & $3.91 \mathrm{E}+07$ & 0.130 & 8100 & 8.92E-02 & -1 & $-1.10 \mathrm{E}-05$ \\
\hline Heterogêneo & $\operatorname{Par} 45^{\circ}$ & 1 & 2 & 32 & $3.90 E+07$ & 0.129 & 7588 & 8.36E-02 & -1 & $-1.10 \mathrm{E}-05$ \\
\hline Heterogêneo & Par $45^{\circ}$ & 1 & 2 & 100 & $3.89 \mathrm{E}+07$ & 0.129 & 7017 & 7.73E-02 & -1 & $-1.10 \mathrm{E}-05$ \\
\hline Heterogêneo & Par $45^{\circ}$ & 1 & 2 & 320 & $3.85 \mathrm{E}+07$ & 0.127 & 5068 & $5.58 \mathrm{E}-02$ & -1 & $-1.10 \mathrm{E}-05$ \\
\hline Heterogêneo & $\operatorname{Par} 45^{\circ}$ & 1 & 2 & 1000 & $3.75 E+07$ & 0.124 & 2112 & $2.33 \mathrm{E}-02$ & -1 & $-1.10 \mathrm{E}-05$ \\
\hline Heterogêneo & Par $45^{\circ}$ & 1 & 2 & 3200 & $3.59 \mathrm{E}+07$ & 0.119 & 827 & $9.11 \mathrm{E}-03$ & -1 & $-1.10 \mathrm{E}-05$ \\
\hline Heterogêneo & $\operatorname{Par} 45^{\circ}$ & 1 & 2 & 10000 & $3.47 \mathrm{E}+07$ & 0.115 & 501 & $5.51 \mathrm{E}-03$ & -1 & $-1.10 \mathrm{E}-05$ \\
\hline Heterogêneo & Par $45^{\circ}$ & 1 & 2 & 32000 & $3.45 \mathrm{E}+07$ & 0.114 & 423 & 4.66E-03 & -1 & $-1.10 \mathrm{E}-05$ \\
\hline Heterogêneo & Par $45^{\circ}$ & 1 & 2 & 100000 & $3.50 E+07$ & 0.116 & 419 & 4.62E-03 & -1 & $-1.10 \mathrm{E}-05$ \\
\hline Heterogêneo & Par $45^{\circ}$ & 1 & 3 & 0 & $3.91 E+07$ & 0.129 & 8025 & $8.84 \mathrm{E}-02$ & -1 & $-1.10 \mathrm{E}-05$ \\
\hline Heterogêneo & $\operatorname{Par} 45^{\circ}$ & 1 & 3 & 32 & $3.89 E+07$ & 0.129 & 7354 & $8.10 \mathrm{E}-02$ & -1 & $-1.10 \mathrm{E}-05$ \\
\hline Heterogêneo & Par $45^{\circ}$ & 1 & 3 & 100 & $3.87 \mathrm{E}+07$ & 0.128 & 6425 & $7.08 \mathrm{E}-02$ & -1 & $-1.10 \mathrm{E}-05$ \\
\hline Heterogêneo & $\operatorname{Par} 45^{\circ}$ & 1 & 3 & 320 & $3.81 E+07$ & 0.126 & 3806 & 4.19E-02 & -1 & $-1.10 \mathrm{E}-05$ \\
\hline Heterogêneo & Par $45^{\circ}$ & 1 & 3 & 1000 & $3.68 \mathrm{E}+07$ & 0.122 & 1538 & 1.69E-02 & -1 & $-1.10 \mathrm{E}-05$ \\
\hline Heterogêneo & Par $45^{\circ}$ & 1 & 3 & 3200 & $3.54 \mathrm{E}+07$ & 0.117 & 769 & 8.47E-03 & -1 & $-1.10 \mathrm{E}-05$ \\
\hline Heterogêneo & $\operatorname{Par} 45^{\circ}$ & 1 & 3 & 10000 & $3.48 \mathrm{E}+07$ & 0.115 & 555 & $6.11 \mathrm{E}-03$ & -1 & $-1.10 \mathrm{E}-05$ \\
\hline Heterogêneo & $\operatorname{Par} 45^{\circ}$ & 1 & 3 & 32000 & $3.52 \mathrm{E}+07$ & 0.116 & 514 & 5.67E-03 & -1 & $-1.10 \mathrm{E}-05$ \\
\hline Heterogêneo & $\operatorname{Par} 45^{\circ}$ & 1 & 3 & 100000 & $3.56 \mathrm{E}+07$ & 0.118 & 524 & 5.77E-03 & -1 & $-1.10 \mathrm{E}-05$ \\
\hline Heterogêneo & $\operatorname{Par} 45^{\circ}$ & 5 & 1 & 0 & $3.92 E+07$ & 0.130 & 8375 & $9.23 \mathrm{E}-02$ & -1 & $-1.10 \mathrm{E}-05$ \\
\hline Heterogêneo & Par $45^{\circ}$ & 5 & 1 & 32 & $3.92 E+07$ & 0.130 & 8100 & 8.92E-02 & -1 & $-1.10 \mathrm{E}-05$ \\
\hline Heterogêneo & $\operatorname{Par} 45^{\circ}$ & 5 & 1 & 100 & $3.92 E+07$ & 0.130 & 8097 & $8.92 \mathrm{E}-02$ & -1 & $-1.10 \mathrm{E}-05$ \\
\hline Heterogêneo & Par $45^{\circ}$ & 5 & 1 & 320 & $3.92 E+07$ & 0.130 & 8069 & 8.89E-02 & -1 & $-1.10 \mathrm{E}-05$ \\
\hline Heterogêneo & $\operatorname{Par} 45^{\circ}$ & 5 & 1 & 1000 & $3.92 E+07$ & 0.130 & 8042 & $8.86 \mathrm{E}-02$ & -1 & $-1.10 \mathrm{E}-05$ \\
\hline Heterogêneo & $\operatorname{Par} 45^{\circ}$ & 5 & 1 & 3200 & $3.92 E+07$ & 0.130 & 8046 & 8.86E-02 & -1 & $-1.10 \mathrm{E}-05$ \\
\hline Heterogêneo & Par $45^{\circ}$ & 5 & 1 & 10000 & $3.92 \mathrm{E}+07$ & 0.130 & 8039 & $8.86 \mathrm{E}-02$ & -1 & $-1.10 \mathrm{E}-05$ \\
\hline Heterogêneo & $\operatorname{Par} 45^{\circ}$ & 5 & 1 & 32000 & $3.92 \mathrm{E}+07$ & 0.130 & 8036 & $8.85 \mathrm{E}-02$ & -1 & $-1.10 \mathrm{E}-05$ \\
\hline Heterogêneo & Par $45^{\circ}$ & 5 & 1 & 100000 & $3.92 E+07$ & 0.130 & 8032 & $8.85 \mathrm{E}-02$ & -1 & $-1.10 \mathrm{E}-05$ \\
\hline Heterogêneo & $\operatorname{Par} 45^{\circ}$ & 5 & 2 & 0 & $3.92 \mathrm{E}+07$ & 0.130 & 8198 & $9.03 \mathrm{E}-02$ & -1 & $-1.10 \mathrm{E}-05$ \\
\hline Heterogêneo & Par $45^{\circ}$ & 5 & 2 & 32 & $3.92 E+07$ & 0.130 & 8100 & $8.92 \mathrm{E}-02$ & -1 & $-1.10 \mathrm{E}-05$ \\
\hline Heterogêneo & $\operatorname{Par} 45^{\circ}$ & 5 & 2 & 100 & $3.91 E+07$ & 0.130 & 8009 & $8.82 \mathrm{E}-02$ & -1 & $-1.10 \mathrm{E}-05$ \\
\hline Heterogêneo & $\operatorname{Par} 45^{\circ}$ & 5 & 2 & 320 & $3.90 E+07$ & 0.129 & 7556 & 8.32E-02 & -1 & $-1.10 \mathrm{E}-05$ \\
\hline Heterogêneo & Par $45^{\circ}$ & 5 & 2 & 1000 & $3.88 \mathrm{E}+07$ & 0.128 & 5899 & $6.50 \mathrm{E}-02$ & -1 & $-1.10 \mathrm{E}-05$ \\
\hline Heterogêneo & $\operatorname{Par} 45^{\circ}$ & 5 & 2 & 3200 & $3.82 \mathrm{E}+07$ & 0.127 & 4080 & 4.49E-02 & -1 & $-1.10 \mathrm{E}-05$ \\
\hline
\end{tabular}




\begin{tabular}{|c|c|c|c|c|c|c|c|c|c|c|}
\hline Heterogêneo & Par $45^{\circ}$ & 5 & 2 & 10000 & $3.78 \mathrm{E}+07$ & 0.125 & 3279 & $3.61 \mathrm{E}-02$ & -1 & $-1.10 \mathrm{E}-05$ \\
\hline Heterogêneo & $\operatorname{Par} 45^{\circ}$ & 5 & 2 & 32000 & $3.76 \mathrm{E}+07$ & 0.124 & 3003 & 3.31E-02 & -1 & $-1.10 \mathrm{E}-05$ \\
\hline Heterogêneo & Par $45^{\circ}$ & 5 & 2 & 100000 & $3.77 \mathrm{E}+07$ & 0.125 & 2962 & $3.26 \mathrm{E}-02$ & -1 & $-1.10 \mathrm{E}-05$ \\
\hline Heterogêneo & $\operatorname{Par} 45^{\circ}$ & 5 & 3 & 0 & $3.92 \mathrm{E}+07$ & 0.130 & 8159 & 8.99E-02 & -1 & $-1.10 \mathrm{E}-05$ \\
\hline Heterogêneo & Par $45^{\circ}$ & 5 & 3 & 32 & $3.92 \mathrm{E}+07$ & 0.130 & 8081 & $8.90 \mathrm{E}-02$ & -1 & $-1.10 \mathrm{E}-05$ \\
\hline Heterogêneo & $\operatorname{Par} 45^{\circ}$ & 5 & 3 & 100 & $3.91 \mathrm{E}+07$ & 0.130 & 7965 & 8.77E-02 & -1 & $-1.10 \mathrm{E}-05$ \\
\hline Heterogêneo & Par $45^{\circ}$ & 5 & 3 & 320 & $3.90 \mathrm{E}+07$ & 0.129 & 7242 & 7.98E-02 & -1 & $-1.10 \mathrm{E}-05$ \\
\hline Heterogêneo & $\operatorname{Par} 45^{\circ}$ & 5 & 3 & 1000 & $3.86 \mathrm{E}+07$ & 0.128 & 5229 & 5.76E-02 & -1 & $-1.10 \mathrm{E}-05$ \\
\hline Heterogêneo & $\operatorname{Par} 45^{\circ}$ & 5 & 3 & 3200 & $3.81 E+07$ & 0.126 & 3890 & 4.29E-02 & -1 & $-1.10 \mathrm{E}-05$ \\
\hline Heterogêneo & Par $45^{\circ}$ & 5 & 3 & 10000 & $3.78 \mathrm{E}+07$ & 0.125 & 3346 & 3.69E-02 & -1 & $-1.10 \mathrm{E}-05$ \\
\hline Heterogêneo & $\operatorname{Par} 45^{\circ}$ & 5 & 3 & 32000 & $3.78 \mathrm{E}+07$ & 0.125 & 3176 & 3.50E-02 & -1 & $-1.10 \mathrm{E}-05$ \\
\hline Heterogêneo & $\operatorname{Par} 45^{\circ}$ & 5 & 3 & 100000 & $3.80 \mathrm{E}+07$ & 0.126 & 3193 & 3.52E-02 & -1 & $-1.10 \mathrm{E}-05$ \\
\hline Heterogêneo & Par Paralelo & 0 & 1 & 0 & $3.88 \mathrm{E}+07$ & 0.128 & 7711 & 8.49E-02 & -1 & $-1.10 \mathrm{E}-05$ \\
\hline Heterogêneo & Par Paralelo & 0 & 1 & 32 & $3.85 \mathrm{E}+07$ & 0.127 & 6784 & 7.47E-02 & -1 & $-1.10 \mathrm{E}-05$ \\
\hline Heterogêneo & Par Paralelo & 0 & 1 & 100 & $3.80 \mathrm{E}+07$ & 0.126 & 5400 & 5.95E-02 & -1 & $-1.10 \mathrm{E}-05$ \\
\hline Heterogêneo & Par Paralelo & 0 & 1 & 320 & $3.69 E+07$ & 0.122 & 2024 & $2.23 \mathrm{E}-02$ & -1 & $-1.10 \mathrm{E}-05$ \\
\hline Heterogêneo & Par Paralelo & 0 & 1 & 1000 & $3.47 \mathrm{E}+07$ & 0.115 & 85 & $9.38 \mathrm{E}-04$ & -1 & $-1.10 \mathrm{E}-05$ \\
\hline Heterogêneo & Par Paralelo & 0 & 1 & 3200 & $3.22 \mathrm{E}+07$ & 0.107 & 22 & 2.47E-04 & -1 & $-1.10 \mathrm{E}-05$ \\
\hline Heterogêneo & Par Paralelo & 0 & 1 & 10000 & $2.80 \mathrm{E}+07$ & 0.093 & 12 & $1.34 \mathrm{E}-04$ & -1 & $-1.10 \mathrm{E}-05$ \\
\hline Heterogêneo & Par Paralelo & 0 & 1 & 32000 & $2.70 E+07$ & 0.089 & 8 & $9.22 \mathrm{E}-05$ & -1 & $-1.10 \mathrm{E}-05$ \\
\hline Heterogêneo & Par Paralelo & 0 & 1 & 100000 & $2.64 \mathrm{E}+07$ & 0.087 & 6 & 6.77E-05 & -1 & $-1.10 \mathrm{E}-05$ \\
\hline Heterogêneo & Par Paralelo & 0 & 2 & 0 & $3.88 \mathrm{E}+07$ & 0.128 & 7432 & $8.19 \mathrm{E}-02$ & -1 & $-1.10 \mathrm{E}-05$ \\
\hline Heterogêneo & Par Paralelo & 0 & 2 & 32 & $3.83 E+07$ & 0.127 & 6427 & $7.08 \mathrm{E}-02$ & -1 & $-1.10 \mathrm{E}-05$ \\
\hline Heterogêneo & Par Paralelo & 0 & 2 & 100 & $3.76 E+07$ & 0.124 & 4608 & $5.08 \mathrm{E}-02$ & -1 & $-1.10 \mathrm{E}-05$ \\
\hline Heterogêneo & Par Paralelo & 0 & 2 & 320 & $3.60 E+07$ & 0.119 & 1111 & $1.22 \mathrm{E}-02$ & -1 & $-1.10 \mathrm{E}-05$ \\
\hline Heterogêneo & Par Paralelo & 0 & 2 & 1000 & $3.31 E+07$ & 0.110 & 79 & $8.68 \mathrm{E}-04$ & -1 & $-1.10 \mathrm{E}-05$ \\
\hline Heterogêneo & Par Paralelo & 0 & 2 & 3200 & $3.16 E+07$ & 0.105 & 30 & 3.29E-04 & -1 & $-1.10 \mathrm{E}-05$ \\
\hline Heterogêneo & Par Paralelo & 0 & 2 & 10000 & $2.88 \mathrm{E}+07$ & 0.095 & 17 & $1.89 \mathrm{E}-04$ & -1 & $-1.10 \mathrm{E}-05$ \\
\hline Heterogêneo & Par Paralelo & 0 & 2 & 32000 & $2.82 \mathrm{E}+07$ & 0.093 & 13 & $1.43 \mathrm{E}-04$ & -1 & $-1.10 \mathrm{E}-05$ \\
\hline Heterogêneo & Par Paralelo & 0 & 2 & 100000 & $2.60 E+07$ & 0.086 & 10 & $1.12 \mathrm{E}-04$ & -1 & $-1.10 \mathrm{E}-05$ \\
\hline Heterogêneo & Par Paralelo & 0 & 3 & 0 & $3.87 \mathrm{E}+07$ & 0.128 & 7317 & 8.06E-02 & -1 & $-1.10 \mathrm{E}-05$ \\
\hline Heterogêneo & Par Paralelo & 0 & 3 & 32 & $3.81 E+07$ & 0.126 & 6257 & $6.89 \mathrm{E}-02$ & -1 & $-1.10 \mathrm{E}-05$ \\
\hline Heterogêneo & Par Paralelo & 0 & 3 & 100 & $3.73 E+07$ & 0.123 & 4317 & 4.76E-02 & -1 & $-1.10 \mathrm{E}-05$ \\
\hline Heterogêneo & Par Paralelo & 0 & 3 & 320 & $3.54 \mathrm{E}+07$ & 0.117 & 771 & 8.49E-03 & -1 & $-1.10 \mathrm{E}-05$ \\
\hline Heterogêneo & Par Paralelo & 0 & 3 & 1000 & $3.24 E+07$ & 0.107 & 85 & $9.35 \mathrm{E}-04$ & -1 & $-1.10 \mathrm{E}-05$ \\
\hline Heterogêneo & Par Paralelo & 0 & 3 & 3200 & $3.19 \mathrm{E}+07$ & 0.105 & 37 & 4.10E-04 & -1 & $-1.10 \mathrm{E}-05$ \\
\hline Heterogêneo & Par Paralelo & 0 & 3 & 10000 & $2.99 \mathrm{E}+07$ & 0.099 & 23 & $2.51 \mathrm{E}-04$ & -1 & $-1.10 \mathrm{E}-05$ \\
\hline Heterogêneo & Par Paralelo & 0 & 3 & 32000 & $2.87 E+07$ & 0.095 & 17 & $1.91 \mathrm{E}-04$ & -1 & $-1.10 \mathrm{E}-05$ \\
\hline Heterogêneo & Par Paralelo & 0 & 3 & 100000 & $2.58 \mathrm{E}+07$ & 0.085 & 15 & $1.62 \mathrm{E}-04$ & -1 & $-1.10 \mathrm{E}-05$ \\
\hline Heterogêneo & Par Paralelo & 1 & 1 & 0 & $3.88 \mathrm{E}+07$ & 0.128 & 7612 & 8.39E-02 & -1 & $-1.10 \mathrm{E}-05$ \\
\hline Heterogêneo & Par Paralelo & 1 & 1 & 32 & $3.86 \mathrm{E}+07$ & 0.128 & 7137 & 7.86E-02 & -1 & $-1.10 \mathrm{E}-05$ \\
\hline Heterogêneo & Par Paralelo & 1 & 1 & 100 & $3.83 E+07$ & 0.127 & 6426 & $7.08 \mathrm{E}-02$ & -1 & $-1.10 \mathrm{E}-05$ \\
\hline Heterogêneo & Par Paralelo & 1 & 1 & 320 & $3.76 \mathrm{E}+07$ & 0.125 & 4500 & 4.96E-02 & -1 & $-1.10 \mathrm{E}-05$ \\
\hline Heterogêneo & Par Paralelo & 1 & 1 & 1000 & $3.62 E+07$ & 0.120 & 1594 & $1.76 \mathrm{E}-02$ & -1 & $-1.10 \mathrm{E}-05$ \\
\hline
\end{tabular}




\begin{tabular}{|c|c|c|c|c|c|c|c|c|c|c|}
\hline Heterogêneo & Par Paralelo & 1 & 1 & 3200 & $3.40 E+07$ & 0.112 & 690 & 7.60E-03 & -1 & $-1.10 \mathrm{E}-05$ \\
\hline Heterogêneo & Par Paralelo & 1 & 1 & 10000 & $3.25 \mathrm{E}+07$ & 0.107 & 469 & 5.17E-03 & -1 & $-1.10 \mathrm{E}-05$ \\
\hline Heterogêneo & Par Paralelo & 1 & 1 & 32000 & $3.18 \mathrm{E}+07$ & 0.105 & 425 & $4.68 \mathrm{E}-03$ & -1 & $-1.10 \mathrm{E}-05$ \\
\hline Heterogêneo & Par Paralelo & 1 & 1 & 100000 & $3.18 \mathrm{E}+07$ & 0.105 & 437 & $4.82 \mathrm{E}-03$ & -1 & $-1.10 \mathrm{E}-05$ \\
\hline Heterogêneo & Par Paralelo & 1 & 2 & 0 & $3.88 \mathrm{E}+07$ & 0.128 & 7500 & $8.26 \mathrm{E}-02$ & -1 & $-1.10 \mathrm{E}-05$ \\
\hline Heterogêneo & Par Paralelo & 1 & 2 & 32 & $3.85 \mathrm{E}+07$ & 0.127 & 6900 & 7.60E-02 & -1 & $-1.10 \mathrm{E}-05$ \\
\hline Heterogêneo & Par Paralelo & 1 & 2 & 100 & $3.80 E+07$ & 0.126 & 5971 & $6.58 \mathrm{E}-02$ & -1 & $-1.10 \mathrm{E}-05$ \\
\hline Heterogêneo & Par Paralelo & 1 & 2 & 320 & $3.70 E+07$ & 0.123 & 3704 & $4.08 \mathrm{E}-02$ & -1 & $-1.10 \mathrm{E}-05$ \\
\hline Heterogêneo & Par Paralelo & 1 & 2 & 1000 & $3.53 E+07$ & 0.117 & 1612 & $1.78 \mathrm{E}-02$ & -1 & $-1.10 \mathrm{E}-05$ \\
\hline Heterogêneo & Par Paralelo & 1 & 2 & 3200 & $3.35 E+07$ & 0.111 & 904 & $9.95 \mathrm{E}-03$ & -1 & $-1.10 \mathrm{E}-05$ \\
\hline Heterogêneo & Par Paralelo & 1 & 2 & 10000 & $3.26 E+07$ & 0.108 & 731 & 8.05E-03 & -1 & $-1.10 \mathrm{E}-05$ \\
\hline Heterogêneo & Par Paralelo & 1 & 2 & 32000 & $3.24 \mathrm{E}+07$ & 0.107 & 712 & 7.84E-03 & -1 & $-1.10 \mathrm{E}-05$ \\
\hline Heterogêneo & Par Paralelo & 1 & 2 & 100000 & $3.25 \mathrm{E}+07$ & 0.108 & 737 & $8.12 \mathrm{E}-03$ & -1 & $-1.10 \mathrm{E}-05$ \\
\hline Heterogêneo & Par Paralelo & 1 & 3 & 0 & $3.88 \mathrm{E}+07$ & 0.128 & 7500 & $8.26 \mathrm{E}-02$ & -1 & $-1.10 \mathrm{E}-05$ \\
\hline Heterogêneo & Par Paralelo & 1 & 3 & 32 & $3.84 \mathrm{E}+07$ & 0.127 & 6900 & 7.60E-02 & -1 & $-1.10 \mathrm{E}-05$ \\
\hline Heterogêneo & Par Paralelo & 1 & 3 & 100 & $3.80 \mathrm{E}+07$ & 0.126 & 5838 & $6.43 \mathrm{E}-02$ & -1 & $-1.10 \mathrm{E}-05$ \\
\hline Heterogêneo & Par Paralelo & 1 & 3 & 320 & $3.68 \mathrm{E}+07$ & 0.122 & 3635 & $4.00 \mathrm{E}-02$ & -1 & $-1.10 \mathrm{E}-05$ \\
\hline Heterogêneo & Par Paralelo & 1 & 3 & 1000 & $3.52 E+07$ & 0.116 & 1814 & $2.00 \mathrm{E}-02$ & -1 & $-1.10 \mathrm{E}-05$ \\
\hline Heterogêneo & Par Paralelo & 1 & 3 & 3200 & $3.37 \mathrm{E}+07$ & 0.111 & 1155 & 1.27E-02 & -1 & $-1.10 \mathrm{E}-05$ \\
\hline Heterogêneo & Par Paralelo & 1 & 3 & 10000 & $3.30 E+07$ & 0.109 & 1014 & $1.12 \mathrm{E}-02$ & -1 & $-1.10 \mathrm{E}-05$ \\
\hline Heterogêneo & Par Paralelo & 1 & 3 & 32000 & $3.30 E+07$ & 0.109 & 1008 & $1.11 \mathrm{E}-02$ & -1 & $-1.10 \mathrm{E}-05$ \\
\hline Heterogêneo & Par Paralelo & 1 & 3 & 100000 & $3.32 E+07$ & 0.110 & 1031 & $1.14 \mathrm{E}-02$ & -1 & $-1.10 \mathrm{E}-05$ \\
\hline Heterogêneo & Par Paralelo & 5 & 1 & 0 & $3.89 \mathrm{E}+07$ & 0.129 & 7800 & 8.59E-02 & -1 & $-1.10 \mathrm{E}-05$ \\
\hline Heterogêneo & Par Paralelo & 5 & 1 & 32 & $3.89 E+07$ & 0.129 & 7612 & 8.39E-02 & -1 & $-1.10 \mathrm{E}-05$ \\
\hline Heterogêneo & Par Paralelo & 5 & 1 & 100 & $3.89 \mathrm{E}+07$ & 0.129 & 7616 & 8.39E-02 & -1 & $-1.10 \mathrm{E}-05$ \\
\hline Heterogêneo & Par Paralelo & 5 & 1 & 320 & $3.89 E+07$ & 0.129 & 7648 & $8.42 \mathrm{E}-02$ & -1 & $-1.10 \mathrm{E}-05$ \\
\hline Heterogêneo & Par Paralelo & 5 & 1 & 1000 & $3.87 E+07$ & 0.128 & 7536 & 8.30E-02 & -1 & $-1.10 \mathrm{E}-05$ \\
\hline Heterogêneo & Par Paralelo & 5 & 1 & 3200 & $3.83 E+07$ & 0.127 & 6705 & 7.39E-02 & -1 & $-1.10 \mathrm{E}-05$ \\
\hline Heterogêneo & Par Paralelo & 5 & 1 & 10000 & $3.81 \mathrm{E}+07$ & 0.126 & 5639 & $6.21 \mathrm{E}-02$ & -1 & $-1.10 \mathrm{E}-05$ \\
\hline Heterogêneo & Par Paralelo & 5 & 1 & 32000 & $3.80 E+07$ & 0.126 & 5188 & $5.72 \mathrm{E}-02$ & -1 & $-1.10 \mathrm{E}-05$ \\
\hline Heterogêneo & Par Paralelo & 5 & 1 & 100000 & $3.81 \mathrm{E}+07$ & 0.126 & 5153 & $5.68 \mathrm{E}-02$ & -1 & $-1.10 \mathrm{E}-05$ \\
\hline Heterogêneo & Par Paralelo & 5 & 2 & 0 & $3.89 E+07$ & 0.129 & 7669 & $8.45 \mathrm{E}-02$ & -1 & $-1.10 \mathrm{E}-05$ \\
\hline Heterogêneo & Par Paralelo & 5 & 2 & 32 & $3.89 E+07$ & 0.129 & 7747 & 8.53E-02 & -1 & $-1.10 \mathrm{E}-05$ \\
\hline Heterogêneo & Par Paralelo & 5 & 2 & 100 & $3.89 E+07$ & 0.129 & 7697 & $8.48 \mathrm{E}-02$ & -1 & $-1.10 \mathrm{E}-05$ \\
\hline Heterogêneo & Par Paralelo & 5 & 2 & 320 & $3.89 E+07$ & 0.129 & 7798 & 8.59E-02 & -1 & $-1.10 \mathrm{E}-05$ \\
\hline Heterogêneo & Par Paralelo & 5 & 2 & 1000 & $3.87 \mathrm{E}+07$ & 0.128 & 7635 & $8.41 \mathrm{E}-02$ & -1 & $-1.10 \mathrm{E}-05$ \\
\hline Heterogêneo & Par Paralelo & 5 & 2 & 3200 & $3.85 \mathrm{E}+07$ & 0.127 & 6830 & $7.52 \mathrm{E}-02$ & -1 & $-1.10 \mathrm{E}-05$ \\
\hline Heterogêneo & Par Paralelo & 5 & 2 & 10000 & $3.83 E+07$ & 0.127 & 6069 & 6.69E-02 & -1 & $-1.10 \mathrm{E}-05$ \\
\hline Heterogêneo & Par Paralelo & 5 & 2 & 32000 & $3.84 \mathrm{E}+07$ & 0.127 & 5845 & $6.44 \mathrm{E}-02$ & -1 & $-1.10 \mathrm{E}-05$ \\
\hline Heterogêneo & Par Paralelo & 5 & 2 & 100000 & $3.84 E+07$ & 0.127 & 5909 & 6.51E-02 & -1 & $-1.10 \mathrm{E}-05$ \\
\hline Heterogêneo & Par Paralelo & 5 & 3 & 0 & $3.89 E+07$ & 0.129 & 7619 & 8.39E-02 & -1 & $-1.10 \mathrm{E}-05$ \\
\hline Heterogêneo & Par Paralelo & 5 & 3 & 32 & $3.89 E+07$ & 0.129 & 7721 & 8.51E-02 & -1 & $-1.10 \mathrm{E}-05$ \\
\hline Heterogêneo & Par Paralelo & 5 & 3 & 100 & $3.90 \mathrm{E}+07$ & 0.129 & 7784 & 8.57E-02 & -1 & $-1.10 \mathrm{E}-05$ \\
\hline Heterogêneo & Par Paralelo & 5 & 3 & 320 & $3.90 E+07$ & 0.129 & 7924 & 8.73E-02 & -1 & $-1.10 \mathrm{E}-05$ \\
\hline
\end{tabular}




\begin{tabular}{|c|c|c|c|c|c|c|c|c|c|c|}
\hline Heterogêneo & Par Paralelo & 5 & 3 & 1000 & $3.88 \mathrm{E}+07$ & 0.128 & 7878 & $8.68 \mathrm{E}-02$ & -1 & $-1.10 \mathrm{E}-05$ \\
\hline Heterogêneo & Par Paralelo & 5 & 3 & 3200 & $3.87 E+07$ & 0.128 & 7228 & 7.96E-02 & -1 & $-1.10 \mathrm{E}-05$ \\
\hline Heterogêneo & Par Paralelo & 5 & 3 & 10000 & $3.86 \mathrm{E}+07$ & 0.128 & 6594 & $7.26 \mathrm{E}-02$ & -1 & $-1.10 \mathrm{E}-05$ \\
\hline Heterogêneo & Par Paralelo & 5 & 3 & 32000 & $3.86 \mathrm{E}+07$ & 0.128 & 6468 & $7.13 E-02$ & -1 & $-1.10 \mathrm{E}-05$ \\
\hline Heterogêneo & Par Paralelo & 5 & 3 & 100000 & $3.87 E+07$ & 0.128 & 6556 & $7.22 \mathrm{E}-02$ & -1 & $-1.10 \mathrm{E}-05$ \\
\hline Homogêneo & Depleção & 0 & 1 & 0 & $1.41 \mathrm{E}+07$ & 0.047 & -1 & $-1.10 \mathrm{E}-05$ & 4200 & 0.046266513 \\
\hline Homogêneo & Depleção & 0 & 1 & 32 & $1.32 \mathrm{E}+07$ & 0.044 & -1 & $-1.10 \mathrm{E}-05$ & 3726 & 0.041045006 \\
\hline Homogêneo & Depleção & 0 & 1 & 100 & $1.33 \mathrm{E}+07$ & 0.044 & -1 & $-1.10 \mathrm{E}-05$ & 3788 & 0.041727988 \\
\hline Homogêneo & Depleção & 0 & 1 & 320 & $1.31 \mathrm{E}+07$ & 0.043 & -1 & $-1.10 \mathrm{E}-05$ & 3618 & 0.039855296 \\
\hline Homogêneo & Depleção & 0 & 1 & 1000 & $1.30 \mathrm{E}+07$ & 0.043 & -1 & $-1.10 \mathrm{E}-05$ & 3690 & 0.040648436 \\
\hline Homogêneo & Depleção & 0 & 1 & 3200 & $1.30 \mathrm{E}+07$ & 0.043 & -1 & $-1.10 \mathrm{E}-05$ & 3850 & 0.04241097 \\
\hline Homogêneo & Depleção & 0 & 1 & 10000 & $1.30 \mathrm{E}+07$ & 0.043 & -1 & $-1.10 \mathrm{E}-05$ & 3756 & 0.041375481 \\
\hline Homogêneo & Depleção & 0 & 1 & 32000 & $1.31 \mathrm{E}+07$ & 0.043 & -1 & $-1.10 \mathrm{E}-05$ & 3774 & 0.041573766 \\
\hline Homogêneo & Depleção & 0 & 1 & 100000 & $1.30 \mathrm{E}+07$ & 0.043 & -1 & $-1.10 \mathrm{E}-05$ & 3723 & 0.041011959 \\
\hline Homogêneo & Depleção & 0 & 2 & 0 & $1.41 \mathrm{E}+07$ & 0.047 & -1 & $-1.10 \mathrm{E}-05$ & 4200 & 0.046266513 \\
\hline Homogêneo & Depleção & 0 & 2 & 32 & $1.31 \mathrm{E}+07$ & 0.043 & -1 & $-1.10 \mathrm{E}-05$ & 3683 & 0.040571325 \\
\hline Homogêneo & Depleção & 0 & 2 & 100 & $1.32 \mathrm{E}+07$ & 0.044 & -1 & $-1.10 \mathrm{E}-05$ & 3623 & 0.039910375 \\
\hline Homogêneo & Depleção & 0 & 2 & 320 & $1.32 \mathrm{E}+07$ & 0.044 & -1 & $-1.10 \mathrm{E}-05$ & 3584 & 0.039480758 \\
\hline Homogêneo & Depleção & 0 & 2 & 1000 & $1.32 \mathrm{E}+07$ & 0.044 & -1 & $-1.10 \mathrm{E}-05$ & 3639 & 0.040086629 \\
\hline Homogêneo & Depleção & 0 & 2 & 3200 & $1.69 \mathrm{E}+07$ & 0.056 & -1 & $-1.10 \mathrm{E}-05$ & 4785 & 0.052710777 \\
\hline Homogêneo & Depleção & 0 & 2 & 10000 & $3.99 \mathrm{E}+07$ & 0.132 & -1 & $-1.10 \mathrm{E}-05$ & -1 & $-1.10 \mathrm{E}-05$ \\
\hline Homogêneo & Depleção & 0 & 2 & 32000 & $3.99 E+07$ & 0.132 & -1 & $-1.10 \mathrm{E}-05$ & -1 & $-1.10 \mathrm{E}-05$ \\
\hline Homogêneo & Depleção & 0 & 2 & 100000 & $3.99 \mathrm{E}+07$ & 0.132 & -1 & $-1.10 \mathrm{E}-05$ & -1 & $-1.10 \mathrm{E}-05$ \\
\hline Homogêneo & Depleção & 0 & 3 & 0 & $1.40 \mathrm{E}+07$ & 0.046 & -1 & $-1.10 \mathrm{E}-05$ & 4150 & 0.045715721 \\
\hline Homogêneo & Depleção & 0 & 3 & 32 & $1.31 \mathrm{E}+07$ & 0.043 & -1 & $-1.10 \mathrm{E}-05$ & 3642 & 0.040119676 \\
\hline Homogêneo & Depleção & 0 & 3 & 100 & $2.34 \mathrm{E}+07$ & 0.078 & -1 & $-1.10 \mathrm{E}-05$ & 6681 & 0.073596803 \\
\hline Homogêneo & Depleção & 0 & 3 & 320 & $1.68 \mathrm{E}+07$ & 0.056 & -1 & $-1.10 \mathrm{E}-05$ & 4641 & 0.051124497 \\
\hline Homogêneo & Depleção & 0 & 3 & 1000 & $1.36 \mathrm{E}+07$ & 0.045 & -1 & $-1.10 \mathrm{E}-05$ & 3739 & 0.041188212 \\
\hline Homogêneo & Depleção & 0 & 3 & 3200 & $1.52 E+07$ & 0.050 & -1 & $-1.10 \mathrm{E}-05$ & 3950 & 0.043512554 \\
\hline Homogêneo & Depleção & 0 & 3 & 10000 & $3.99 \mathrm{E}+07$ & 0.132 & -1 & $-1.10 \mathrm{E}-05$ & -1 & $-1.10 \mathrm{E}-05$ \\
\hline Homogêneo & Depleção & 0 & 3 & 32000 & $3.99 \mathrm{E}+07$ & 0.132 & -1 & $-1.10 \mathrm{E}-05$ & -1 & $-1.10 \mathrm{E}-05$ \\
\hline Homogêneo & Depleção & 0 & 3 & 100000 & $3.98 \mathrm{E}+07$ & 0.132 & -1 & $-1.10 \mathrm{E}-05$ & -1 & $-1.10 \mathrm{E}-05$ \\
\hline Homogêneo & Depleção & 1 & 1 & 0 & $1.42 \mathrm{E}+07$ & 0.047 & -1 & $-1.10 \mathrm{E}-05$ & 4200 & 0.046266513 \\
\hline Homogêneo & Depleção & 1 & 1 & 32 & $1.38 \mathrm{E}+07$ & 0.046 & -1 & $-1.10 \mathrm{E}-05$ & 3918 & 0.043160047 \\
\hline Homogêneo & Depleção & 1 & 1 & 100 & $1.39 \mathrm{E}+07$ & 0.046 & -1 & $-1.10 \mathrm{E}-05$ & 3909 & 0.043060904 \\
\hline Homogêneo & Depleção & 1 & 1 & 320 & $1.37 \mathrm{E}+07$ & 0.045 & -1 & $-1.10 \mathrm{E}-05$ & 3837 & 0.042267764 \\
\hline Homogêneo & Depleção & 1 & 1 & 1000 & $1.33 E+07$ & 0.044 & -1 & $-1.10 \mathrm{E}-05$ & 3721 & 0.040989927 \\
\hline Homogêneo & Depleção & 1 & 1 & 3200 & $1.46 \mathrm{E}+07$ & 0.048 & -1 & $-1.10 \mathrm{E}-05$ & 4200 & 0.046266513 \\
\hline Homogêneo & Depleção & 1 & 1 & 10000 & $3.99 \mathrm{E}+07$ & 0.132 & -1 & $-1.10 \mathrm{E}-05$ & -1 & $-1.10 \mathrm{E}-05$ \\
\hline Homogêneo & Depleção & 1 & 1 & 32000 & $3.98 \mathrm{E}+07$ & 0.132 & -1 & $-1.10 \mathrm{E}-05$ & -1 & $-1.10 \mathrm{E}-05$ \\
\hline Homogêneo & Depleção & 1 & 1 & 100000 & $3.99 \mathrm{E}+07$ & 0.132 & -1 & $-1.10 \mathrm{E}-05$ & -1 & $-1.10 \mathrm{E}-05$ \\
\hline Homogêneo & Depleção & 1 & 2 & 0 & $1.41 E+07$ & 0.047 & -1 & $-1.10 \mathrm{E}-05$ & 4200 & 0.046266513 \\
\hline Homogêneo & Depleção & 1 & 2 & 32 & $1.32 \mathrm{E}+07$ & 0.044 & -1 & $-1.10 \mathrm{E}-05$ & 3688 & 0.040626405 \\
\hline Homogêneo & Depleção & 1 & 2 & 100 & $1.33 \mathrm{E}+07$ & 0.044 & -1 & $-1.10 \mathrm{E}-05$ & 3689 & 0.04063742 \\
\hline
\end{tabular}




\begin{tabular}{|c|c|c|c|c|c|c|c|c|c|c|}
\hline Homogêneo & Depleção & 1 & 2 & 320 & $1.32 \mathrm{E}+07$ & 0.044 & -1 & $-1.10 \mathrm{E}-05$ & 3646 & 0.040163739 \\
\hline Homogêneo & Depleção & 1 & 2 & 1000 & $1.32 \mathrm{E}+07$ & 0.044 & -1 & $-1.10 \mathrm{E}-05$ & 3715 & 0.040923832 \\
\hline Homogêneo & Depleção & 1 & 2 & 3200 & $1.61 \mathrm{E}+07$ & 0.053 & -1 & $-1.10 \mathrm{E}-05$ & 4556 & 0.05018815 \\
\hline Homogêneo & Depleção & 1 & 2 & 10000 & $3.97 E+07$ & 0.131 & -1 & $-1.10 \mathrm{E}-05$ & -1 & $-1.10 \mathrm{E}-05$ \\
\hline Homogêneo & Depleção & 1 & 2 & 32000 & $3.98 \mathrm{E}+07$ & 0.132 & -1 & $-1.10 \mathrm{E}-05$ & -1 & $-1.10 \mathrm{E}-05$ \\
\hline Homogêneo & Depleção & 1 & 2 & 100000 & $3.99 \mathrm{E}+07$ & 0.132 & -1 & $-1.10 \mathrm{E}-05$ & -1 & $-1.10 \mathrm{E}-05$ \\
\hline Homogêneo & Depleção & 1 & 3 & 0 & $1.41 \mathrm{E}+07$ & 0.047 & -1 & $-1.10 \mathrm{E}-05$ & 4200 & 0.046266513 \\
\hline Homogêneo & Depleção & 1 & 3 & 32 & $3.98 \mathrm{E}+07$ & 0.132 & -1 & $-1.10 \mathrm{E}-05$ & -1 & $-1.10 \mathrm{E}-05$ \\
\hline Homogêneo & Depleção & 1 & 3 & 100 & $1.35 \mathrm{E}+07$ & 0.045 & -1 & $-1.10 \mathrm{E}-05$ & 3719 & 0.040967895 \\
\hline Homogêneo & Depleção & 1 & 3 & 320 & $1.67 \mathrm{E}+07$ & 0.055 & -1 & $-1.10 \mathrm{E}-05$ & 4645 & 0.05116856 \\
\hline Homogêneo & Depleção & 1 & 3 & 1000 & $1.60 \mathrm{E}+07$ & 0.053 & -1 & $-1.10 \mathrm{E}-05$ & 4411 & 0.048590854 \\
\hline Homogêneo & Depleção & 1 & 3 & 3200 & $1.74 \mathrm{E}+07$ & 0.058 & -1 & $-1.10 \mathrm{E}-05$ & 4800 & 0.052876015 \\
\hline Homogêneo & Depleção & 1 & 3 & 10000 & $2.06 \mathrm{E}+07$ & 0.068 & -1 & $-1.10 \mathrm{E}-05$ & 5852 & 0.064464674 \\
\hline Homogêneo & Depleção & 1 & 3 & 32000 & $3.99 \mathrm{E}+07$ & 0.132 & -1 & $-1.10 \mathrm{E}-05$ & -1 & $-1.10 \mathrm{E}-05$ \\
\hline Homogêneo & Depleção & 1 & 3 & 100000 & $3.99 \mathrm{E}+07$ & 0.132 & -1 & $-1.10 \mathrm{E}-05$ & -1 & $-1.10 \mathrm{E}-05$ \\
\hline Homogêneo & Depleção & 5 & 1 & 0 & $1.41 \mathrm{E}+07$ & 0.047 & -1 & $-1.10 \mathrm{E}-05$ & 4150 & 0.045715721 \\
\hline Homogêneo & Depleção & 5 & 1 & 32 & $1.32 \mathrm{E}+07$ & 0.044 & -1 & $-1.10 \mathrm{E}-05$ & 3763 & 0.041452592 \\
\hline Homogêneo & Depleção & 5 & 1 & 100 & $1.35 \mathrm{E}+07$ & 0.045 & -1 & $-1.10 \mathrm{E}-05$ & 3900 & 0.042961762 \\
\hline Homogêneo & Depleção & 5 & 1 & 320 & $1.33 \mathrm{E}+07$ & 0.044 & -1 & $-1.10 \mathrm{E}-05$ & 3878 & 0.042719413 \\
\hline Homogêneo & Depleção & 5 & 1 & 1000 & $1.33 \mathrm{E}+07$ & 0.044 & -1 & $-1.10 \mathrm{E}-05$ & 3746 & 0.041265323 \\
\hline Homogêneo & Depleção & 5 & 1 & 3200 & $1.31 \mathrm{E}+07$ & 0.043 & -1 & $-1.10 \mathrm{E}-05$ & 3765 & 0.041474624 \\
\hline Homogêneo & Depleção & 5 & 1 & 10000 & $1.32 \mathrm{E}+07$ & 0.044 & -1 & $-1.10 \mathrm{E}-05$ & 3860 & 0.042521128 \\
\hline Homogêneo & Depleção & 5 & 1 & 32000 & $1.31 \mathrm{E}+07$ & 0.043 & -1 & $-1.10 \mathrm{E}-05$ & 3806 & 0.041926273 \\
\hline Homogêneo & Depleção & 5 & 1 & 100000 & $1.31 \mathrm{E}+07$ & 0.043 & -1 & $-1.10 \mathrm{E}-05$ & 3687 & 0.040615389 \\
\hline Homogêneo & Depleção & 5 & 2 & 0 & $1.41 \mathrm{E}+07$ & 0.047 & -1 & $-1.10 \mathrm{E}-05$ & 4150 & 0.045715721 \\
\hline Homogêneo & Depleção & 5 & 2 & 32 & $1.32 \mathrm{E}+07$ & 0.044 & -1 & $-1.10 \mathrm{E}-05$ & 3707 & 0.040835705 \\
\hline Homogêneo & Depleção & 5 & 2 & 100 & $1.95 \mathrm{E}+07$ & 0.065 & -1 & $-1.10 \mathrm{E}-05$ & 5596 & 0.06164462 \\
\hline Homogêneo & Depleção & 5 & 2 & 320 & $1.32 \mathrm{E}+07$ & 0.044 & -1 & $-1.10 \mathrm{E}-05$ & 3672 & 0.040450151 \\
\hline Homogêneo & Depleção & 5 & 2 & 1000 & $1.55 \mathrm{E}+07$ & 0.051 & -1 & $-1.10 \mathrm{E}-05$ & 4323 & 0.047621461 \\
\hline Homogêneo & Depleção & 5 & 2 & 3200 & $3.99 E+07$ & 0.132 & -1 & $-1.10 \mathrm{E}-05$ & -1 & $-1.10 \mathrm{E}-05$ \\
\hline Homogêneo & Depleção & 5 & 2 & 10000 & $3.99 E+07$ & 0.132 & -1 & $-1.10 \mathrm{E}-05$ & -1 & $-1.10 \mathrm{E}-05$ \\
\hline Homogêneo & Depleção & 5 & 2 & 32000 & $3.99 E+07$ & 0.132 & -1 & $-1.10 \mathrm{E}-05$ & -1 & $-1.10 \mathrm{E}-05$ \\
\hline Homogêneo & Depleção & 5 & 2 & 100000 & $3.99 \mathrm{E}+07$ & 0.132 & -1 & $-1.10 \mathrm{E}-05$ & -1 & $-1.10 \mathrm{E}-05$ \\
\hline Homogêneo & Depleção & 5 & 3 & 0 & $1.41 \mathrm{E}+07$ & 0.047 & -1 & $-1.10 \mathrm{E}-05$ & 4200 & 0.046266513 \\
\hline Homogêneo & Depleção & 5 & 3 & 32 & $3.98 E+07$ & 0.132 & -1 & $-1.10 \mathrm{E}-05$ & -1 & $-1.10 \mathrm{E}-05$ \\
\hline Homogêneo & Depleção & 5 & 3 & 100 & $3.69 \mathrm{E}+07$ & 0.122 & -1 & $-1.10 \mathrm{E}-05$ & $1.08 \mathrm{E}+04$ & 0.118971033 \\
\hline Homogêneo & Depleção & 5 & 3 & 320 & $1.87 \mathrm{E}+07$ & 0.062 & -1 & $-1.10 \mathrm{E}-05$ & 5268 & 0.058031426 \\
\hline Homogêneo & Depleção & 5 & 3 & 1000 & $1.42 \mathrm{E}+07$ & 0.047 & -1 & $-1.10 \mathrm{E}-05$ & 3920 & 0.043182079 \\
\hline Homogêneo & Depleção & 5 & 3 & 3200 & $1.94 \mathrm{E}+07$ & 0.064 & -1 & $-1.10 \mathrm{E}-05$ & 5475 & 0.060311704 \\
\hline Homogêneo & Depleção & 5 & 3 & 10000 & $3.99 E+07$ & 0.132 & -1 & $-1.10 \mathrm{E}-05$ & -1 & $-1.10 \mathrm{E}-05$ \\
\hline Homogêneo & Depleção & 5 & 3 & 32000 & $3.99 E+07$ & 0.132 & -1 & $-1.10 \mathrm{E}-05$ & -1 & $-1.10 \mathrm{E}-05$ \\
\hline Homogêneo & Depleção & 5 & 3 & 100000 & $3.99 \mathrm{E}+07$ & 0.132 & -1 & $-1.10 \mathrm{E}-05$ & -1 & $-1.10 \mathrm{E}-05$ \\
\hline Homogêneo & Par $45^{\circ}$ & 0 & 1 & 0 & $3.74 \mathrm{E}+07$ & 0.124 & 5400 & 5.95E-02 & -1 & $-1.10 \mathrm{E}-05$ \\
\hline Homogêneo & $\operatorname{Par} 45^{\circ}$ & 0 & 1 & 32 & $3.73 E+07$ & 0.124 & 5336 & $5.88 \mathrm{E}-02$ & -1 & $-1.10 \mathrm{E}-05$ \\
\hline
\end{tabular}




\begin{tabular}{|c|c|c|c|c|c|c|c|c|c|c|}
\hline Homogêneo & $\operatorname{Par} 45^{\circ}$ & 0 & 1 & 100 & $3.73 E+07$ & 0.123 & 5307 & $5.85 \mathrm{E}-02$ & -1 & $-1.10 \mathrm{E}-05$ \\
\hline Homogêneo & $\operatorname{Par} 45^{\circ}$ & 0 & 1 & 320 & $3.72 \mathrm{E}+07$ & 0.123 & 5251 & $5.78 \mathrm{E}-02$ & -1 & $-1.10 \mathrm{E}-05$ \\
\hline Homogêneo & Par $45^{\circ}$ & 0 & 1 & 1000 & $3.71 \mathrm{E}+07$ & 0.123 & 5221 & $5.75 \mathrm{E}-02$ & -1 & $-1.10 \mathrm{E}-05$ \\
\hline Homogêneo & $\operatorname{Par} 45^{\circ}$ & 0 & 1 & 3200 & $3.74 \mathrm{E}+07$ & 0.124 & 5210 & $5.74 \mathrm{E}-02$ & -1 & $-1.10 \mathrm{E}-05$ \\
\hline Homogêneo & Par $45^{\circ}$ & 0 & 1 & 10000 & $3.71 \mathrm{E}+07$ & 0.123 & 5206 & $5.73 \mathrm{E}-02$ & -1 & $-1.10 \mathrm{E}-05$ \\
\hline Homogêneo & $\operatorname{Par} 45^{\circ}$ & 0 & 1 & 32000 & $3.71 E+07$ & 0.123 & 5180 & $5.71 \mathrm{E}-02$ & -1 & $-1.10 \mathrm{E}-05$ \\
\hline Homogêneo & Par $45^{\circ}$ & 0 & 1 & 100000 & $3.67 E+07$ & 0.121 & 5194 & $5.72 \mathrm{E}-02$ & -1 & $-1.10 \mathrm{E}-05$ \\
\hline Homogêneo & $\operatorname{Par} 45^{\circ}$ & 0 & 2 & 0 & $3.74 \mathrm{E}+07$ & 0.124 & 5400 & $5.95 \mathrm{E}-02$ & -1 & $-1.10 \mathrm{E}-05$ \\
\hline Homogêneo & $\operatorname{Par} 45^{\circ}$ & 0 & 2 & 32 & $3.73 E+07$ & 0.123 & 5234 & $5.77 \mathrm{E}-02$ & -1 & $-1.10 \mathrm{E}-05$ \\
\hline Homogêneo & $\operatorname{Par} 45^{\circ}$ & 0 & 2 & 100 & $3.71 \mathrm{E}+07$ & 0.123 & 4981 & $5.49 \mathrm{E}-02$ & -1 & $-1.10 \mathrm{E}-05$ \\
\hline Homogêneo & $\operatorname{Par} 45^{\circ}$ & 0 & 2 & 320 & $3.66 \mathrm{E}+07$ & 0.121 & 4200 & 4.63E-02 & -1 & $-1.10 \mathrm{E}-05$ \\
\hline Homogêneo & $\operatorname{Par} 45^{\circ}$ & 0 & 2 & 1000 & $3.56 E+07$ & 0.118 & 1612 & $1.78 \mathrm{E}-02$ & -1 & $-1.10 \mathrm{E}-05$ \\
\hline Homogêneo & Par $45^{\circ}$ & 0 & 2 & 3200 & $3.45 E+07$ & 0.114 & 59 & $6.54 \mathrm{E}-04$ & -1 & $-1.10 \mathrm{E}-05$ \\
\hline Homogêneo & Par $45^{\circ}$ & 0 & 2 & 10000 & $3.17 E+07$ & 0.105 & 24 & $2.69 \mathrm{E}-04$ & -1 & $-1.10 \mathrm{E}-05$ \\
\hline Homogêneo & $\operatorname{Par} 45^{\circ}$ & 0 & 2 & 32000 & $3.18 \mathrm{E}+07$ & 0.105 & 15 & $1.61 \mathrm{E}-04$ & -1 & $-1.10 \mathrm{E}-05$ \\
\hline Homogêneo & Par $45^{\circ}$ & 0 & 2 & 100000 & $3.19 E+07$ & 0.105 & 10 & $1.12 \mathrm{E}-04$ & -1 & $-1.10 \mathrm{E}-05$ \\
\hline Homogêneo & Par $45^{\circ}$ & 0 & 3 & 0 & $3.73 E+07$ & 0.124 & 5331 & $5.87 \mathrm{E}-02$ & -1 & $-1.10 \mathrm{E}-05$ \\
\hline Homogêneo & Par $45^{\circ}$ & 0 & 3 & 32 & $3.72 \mathrm{E}+07$ & 0.123 & 5100 & $5.62 \mathrm{E}-02$ & -1 & $-1.10 \mathrm{E}-05$ \\
\hline Homogêneo & Par $45^{\circ}$ & 0 & 3 & 100 & $3.69 \mathrm{E}+07$ & 0.122 & 4610 & $5.08 \mathrm{E}-02$ & -1 & $-1.10 \mathrm{E}-05$ \\
\hline Homogêneo & $\operatorname{Par} 45^{\circ}$ & 0 & 3 & 320 & $3.61 \mathrm{E}+07$ & 0.120 & 3209 & $3.53 \mathrm{E}-02$ & -1 & $-1.10 \mathrm{E}-05$ \\
\hline Homogêneo & $\operatorname{Par} 45^{\circ}$ & 0 & 3 & 1000 & $3.47 \mathrm{E}+07$ & 0.115 & 176 & $1.94 \mathrm{E}-03$ & -1 & $-1.10 \mathrm{E}-05$ \\
\hline Homogêneo & $\operatorname{Par} 45^{\circ}$ & 0 & 3 & 3200 & $3.41 E+07$ & 0.113 & 48 & $5.25 \mathrm{E}-04$ & -1 & $-1.10 \mathrm{E}-05$ \\
\hline Homogêneo & Par $45^{\circ}$ & 0 & 3 & 10000 & $3.24 \mathrm{E}+07$ & 0.107 & 24 & $2.68 \mathrm{E}-04$ & -1 & $-1.10 \mathrm{E}-05$ \\
\hline Homogêneo & $\operatorname{Par} 45^{\circ}$ & 0 & 3 & 32000 & $3.28 \mathrm{E}+07$ & 0.108 & 17 & $1.83 \mathrm{E}-04$ & -1 & $-1.10 \mathrm{E}-05$ \\
\hline Homogêneo & $\operatorname{Par} 45^{\circ}$ & 0 & 3 & 100000 & $3.29 E+07$ & 0.109 & 13 & $1.41 \mathrm{E}-04$ & -1 & $-1.10 \mathrm{E}-05$ \\
\hline Homogêneo & $\operatorname{Par} 45^{\circ}$ & 1 & 1 & 0 & $3.74 \mathrm{E}+07$ & 0.124 & 5515 & $6.08 \mathrm{E}-02$ & -1 & $-1.10 \mathrm{E}-05$ \\
\hline Homogêneo & $\operatorname{Par} 45^{\circ}$ & 1 & 1 & 32 & $3.74 \mathrm{E}+07$ & 0.124 & 5400 & $5.95 \mathrm{E}-02$ & -1 & $-1.10 \mathrm{E}-05$ \\
\hline Homogêneo & Par $45^{\circ}$ & 1 & 1 & 100 & $3.74 \mathrm{E}+07$ & 0.124 & 5400 & $5.95 \mathrm{E}-02$ & -1 & $-1.10 \mathrm{E}-05$ \\
\hline Homogêneo & $\operatorname{Par} 45^{\circ}$ & 1 & 1 & 320 & $3.73 E+07$ & 0.124 & 5317 & $5.86 \mathrm{E}-02$ & -1 & $-1.10 \mathrm{E}-05$ \\
\hline Homogêneo & $\operatorname{Par} 45^{\circ}$ & 1 & 1 & 1000 & $3.73 E+07$ & 0.123 & 5292 & $5.83 \mathrm{E}-02$ & -1 & $-1.10 \mathrm{E}-05$ \\
\hline Homogêneo & $\operatorname{Par} 45^{\circ}$ & 1 & 1 & 3200 & $3.73 E+07$ & 0.123 & 5289 & $5.83 \mathrm{E}-02$ & -1 & $-1.10 \mathrm{E}-05$ \\
\hline Homogêneo & $\operatorname{Par} 45^{\circ}$ & 1 & 1 & 10000 & $3.73 E+07$ & 0.123 & 5282 & $5.82 \mathrm{E}-02$ & -1 & $-1.10 \mathrm{E}-05$ \\
\hline Homogêneo & $\operatorname{Par} 45^{\circ}$ & 1 & 1 & 32000 & $3.73 E+07$ & 0.123 & 5278 & $5.81 \mathrm{E}-02$ & -1 & $-1.10 \mathrm{E}-05$ \\
\hline Homogêneo & $\operatorname{Par} 45^{\circ}$ & 1 & 1 & 100000 & $3.73 E+07$ & 0.123 & 5278 & $5.81 \mathrm{E}-02$ & -1 & $-1.10 \mathrm{E}-05$ \\
\hline Homogêneo & $\operatorname{Par} 45^{\circ}$ & 1 & 2 & 0 & $3.74 E+07$ & 0.124 & 5400 & $5.95 \mathrm{E}-02$ & -1 & $-1.10 \mathrm{E}-05$ \\
\hline Homogêneo & Par $45^{\circ}$ & 1 & 2 & 32 & $3.73 E+07$ & 0.124 & 5296 & $5.83 \mathrm{E}-02$ & -1 & $-1.10 \mathrm{E}-05$ \\
\hline Homogêneo & $\operatorname{Par} 45^{\circ}$ & 1 & 2 & 100 & $3.72 E+07$ & 0.123 & 5091 & $5.61 \mathrm{E}-02$ & -1 & $-1.10 \mathrm{E}-05$ \\
\hline Homogêneo & $\operatorname{Par} 45^{\circ}$ & 1 & 2 & 320 & $3.69 \mathrm{E}+07$ & 0.122 & 4500 & $4.96 \mathrm{E}-02$ & -1 & $-1.10 \mathrm{E}-05$ \\
\hline Homogêneo & $\operatorname{Par} 45^{\circ}$ & 1 & 2 & 1000 & $3.62 E+07$ & 0.120 & 2786 & 3.07E-02 & -1 & $-1.10 \mathrm{E}-05$ \\
\hline Homogêneo & $\operatorname{Par} 45^{\circ}$ & 1 & 2 & 3200 & $3.47 E+07$ & 0.115 & 568 & $6.26 \mathrm{E}-03$ & -1 & $-1.10 \mathrm{E}-05$ \\
\hline Homogêneo & $\operatorname{Par} 45^{\circ}$ & 1 & 2 & 10000 & $3.29 E+07$ & 0.109 & 356 & $3.92 \mathrm{E}-03$ & -1 & $-1.10 \mathrm{E}-05$ \\
\hline Homogêneo & $\operatorname{Par} 45^{\circ}$ & 1 & 2 & 32000 & $3.21 E+07$ & 0.106 & 292 & $3.22 \mathrm{E}-03$ & -1 & $-1.10 \mathrm{E}-05$ \\
\hline Homogêneo & $\operatorname{Par} 45^{\circ}$ & 1 & 2 & 100000 & $3.21 \mathrm{E}+07$ & 0.106 & 272 & $3.00 \mathrm{E}-03$ & -1 & $-1.10 \mathrm{E}-05$ \\
\hline Homogêneo & $\operatorname{Par} 45^{\circ}$ & 1 & 3 & 0 & $3.74 E+07$ & 0.124 & 5400 & $5.95 \mathrm{E}-02$ & -1 & $-1.10 \mathrm{E}-05$ \\
\hline
\end{tabular}




\begin{tabular}{|c|c|c|c|c|c|c|c|c|c|c|}
\hline Homogêneo & $\operatorname{Par} 45^{\circ}$ & 1 & 3 & 32 & $3.73 E+07$ & 0.123 & 5214 & $5.74 \mathrm{E}-02$ & -1 & $-1.10 \mathrm{E}-05$ \\
\hline Homogêneo & $\operatorname{Par} 45^{\circ}$ & 1 & 3 & 100 & $3.71 \mathrm{E}+07$ & 0.123 & 4892 & 5.39E-02 & -1 & $-1.10 \mathrm{E}-05$ \\
\hline Homogêneo & Par $45^{\circ}$ & 1 & 3 & 320 & $3.67 E+07$ & 0.121 & 3900 & $4.30 \mathrm{E}-02$ & -1 & $-1.10 \mathrm{E}-05$ \\
\hline Homogêneo & Par $45^{\circ}$ & 1 & 3 & 1000 & $3.56 \mathrm{E}+07$ & 0.118 & 1401 & $1.54 \mathrm{E}-02$ & -1 & $-1.10 \mathrm{E}-05$ \\
\hline Homogêneo & Par $45^{\circ}$ & 1 & 3 & 3200 & $3.39 E+07$ & 0.112 & 439 & $4.83 \mathrm{E}-03$ & -1 & $-1.10 \mathrm{E}-05$ \\
\hline Homogêneo & $\operatorname{Par} 45^{\circ}$ & 1 & 3 & 10000 & $3.27 E+07$ & 0.108 & 347 & $3.82 \mathrm{E}-03$ & -1 & $-1.10 \mathrm{E}-05$ \\
\hline Homogêneo & Par $45^{\circ}$ & 1 & 3 & 32000 & $3.24 \mathrm{E}+07$ & 0.107 & 316 & $3.48 \mathrm{E}-03$ & -1 & $-1.10 \mathrm{E}-05$ \\
\hline Homogêneo & $\operatorname{Par} 45^{\circ}$ & 1 & 3 & 100000 & $3.26 \mathrm{E}+07$ & 0.108 & 304 & $3.35 \mathrm{E}-03$ & -1 & $-1.10 \mathrm{E}-05$ \\
\hline Homogêneo & $\operatorname{Par} 45^{\circ}$ & 5 & 1 & 0 & $3.74 E+07$ & 0.124 & 5593 & $6.16 \mathrm{E}-02$ & -1 & $-1.10 \mathrm{E}-05$ \\
\hline Homogêneo & $\operatorname{Par} 45^{\circ}$ & 5 & 1 & 32 & $3.74 \mathrm{E}+07$ & 0.124 & 5458 & $6.01 \mathrm{E}-02$ & -1 & $-1.10 \mathrm{E}-05$ \\
\hline Homogêneo & $\operatorname{Par} 45^{\circ}$ & 5 & 1 & 100 & $3.74 \mathrm{E}+07$ & 0.124 & 5451 & $6.00 \mathrm{E}-02$ & -1 & $-1.10 \mathrm{E}-05$ \\
\hline Homogêneo & $\operatorname{Par} 45^{\circ}$ & 5 & 1 & 320 & $3.74 E+07$ & 0.124 & 5453 & $6.01 \mathrm{E}-02$ & -1 & $-1.10 \mathrm{E}-05$ \\
\hline Homogêneo & Par $45^{\circ}$ & 5 & 1 & 1000 & $3.74 \mathrm{E}+07$ & 0.124 & 5433 & $5.98 \mathrm{E}-02$ & -1 & $-1.10 \mathrm{E}-05$ \\
\hline Homogêneo & Par $45^{\circ}$ & 5 & 1 & 3200 & $3.74 \mathrm{E}+07$ & 0.124 & 5425 & $5.98 \mathrm{E}-02$ & -1 & $-1.10 \mathrm{E}-05$ \\
\hline Homogêneo & $\operatorname{Par} 45^{\circ}$ & 5 & 1 & 10000 & $3.74 \mathrm{E}+07$ & 0.124 & 5425 & $5.98 \mathrm{E}-02$ & -1 & $-1.10 \mathrm{E}-05$ \\
\hline Homogêneo & Par $45^{\circ}$ & 5 & 1 & 32000 & $3.74 \mathrm{E}+07$ & 0.124 & 5425 & $5.98 \mathrm{E}-02$ & -1 & $-1.10 \mathrm{E}-05$ \\
\hline Homogêneo & Par $45^{\circ}$ & 5 & 1 & 100000 & $3.74 \mathrm{E}+07$ & 0.124 & 5430 & $5.98 \mathrm{E}-02$ & -1 & $-1.10 \mathrm{E}-05$ \\
\hline Homogêneo & Par $45^{\circ}$ & 5 & 2 & 0 & $3.74 \mathrm{E}+07$ & 0.124 & 5469 & $6.02 \mathrm{E}-02$ & -1 & $-1.10 \mathrm{E}-05$ \\
\hline Homogêneo & Par $45^{\circ}$ & 5 & 2 & 32 & $3.74 \mathrm{E}+07$ & 0.124 & 5499 & $6.06 \mathrm{E}-02$ & -1 & $-1.10 \mathrm{E}-05$ \\
\hline Homogêneo & $\operatorname{Par} 45^{\circ}$ & 5 & 2 & 100 & $3.74 \mathrm{E}+07$ & 0.124 & 5483 & $6.04 \mathrm{E}-02$ & -1 & $-1.10 \mathrm{E}-05$ \\
\hline Homogêneo & $\operatorname{Par} 45^{\circ}$ & 5 & 2 & 320 & $3.73 E+07$ & 0.124 & 5400 & $5.95 \mathrm{E}-02$ & -1 & $-1.10 \mathrm{E}-05$ \\
\hline Homogêneo & $\operatorname{Par} 45^{\circ}$ & 5 & 2 & 1000 & $3.71 E+07$ & 0.123 & 5031 & $5.54 \mathrm{E}-02$ & -1 & $-1.10 \mathrm{E}-05$ \\
\hline Homogêneo & Par $45^{\circ}$ & 5 & 2 & 3200 & $3.66 \mathrm{E}+07$ & 0.121 & 3556 & $3.92 \mathrm{E}-02$ & -1 & $-1.10 \mathrm{E}-05$ \\
\hline Homogêneo & $\operatorname{Par} 45^{\circ}$ & 5 & 2 & 10000 & $3.60 \mathrm{E}+07$ & 0.119 & 2660 & $2.93 \mathrm{E}-02$ & -1 & $-1.10 \mathrm{E}-05$ \\
\hline Homogêneo & $\operatorname{Par} 45^{\circ}$ & 5 & 2 & 32000 & $3.56 \mathrm{E}+07$ & 0.118 & 2316 & $2.55 \mathrm{E}-02$ & -1 & $-1.10 \mathrm{E}-05$ \\
\hline Homogêneo & $\operatorname{Par} 45^{\circ}$ & 5 & 2 & 100000 & $3.57 E+07$ & 0.118 & 2214 & $2.44 \mathrm{E}-02$ & -1 & $-1.10 \mathrm{E}-05$ \\
\hline Homogêneo & Par $45^{\circ}$ & 5 & 3 & 0 & $3.74 \mathrm{E}+07$ & 0.124 & 5430 & $5.98 \mathrm{E}-02$ & -1 & $-1.10 \mathrm{E}-05$ \\
\hline Homogêneo & Par $45^{\circ}$ & 5 & 3 & 32 & $3.74 \mathrm{E}+07$ & 0.124 & 5476 & $6.03 \mathrm{E}-02$ & -1 & $-1.10 \mathrm{E}-05$ \\
\hline Homogêneo & $\operatorname{Par} 45^{\circ}$ & 5 & 3 & 100 & $3.74 \mathrm{E}+07$ & 0.124 & 5510 & $6.07 E-02$ & -1 & $-1.10 \mathrm{E}-05$ \\
\hline Homogêneo & $\operatorname{Par} 45^{\circ}$ & 5 & 3 & 320 & $3.73 E+07$ & 0.123 & 5378 & $5.92 \mathrm{E}-02$ & -1 & $-1.10 \mathrm{E}-05$ \\
\hline Homogêneo & $\operatorname{Par} 45^{\circ}$ & 5 & 3 & 1000 & $3.70 \mathrm{E}+07$ & 0.122 & 4511 & 4.97E-02 & -1 & $-1.10 \mathrm{E}-05$ \\
\hline Homogêneo & $\operatorname{Par} 45^{\circ}$ & 5 & 3 & 3200 & $3.65 E+07$ & 0.121 & 3218 & $3.54 \mathrm{E}-02$ & -1 & $-1.10 \mathrm{E}-05$ \\
\hline Homogêneo & $\operatorname{Par} 45^{\circ}$ & 5 & 3 & 10000 & $3.60 \mathrm{E}+07$ & 0.119 & 2631 & $2.90 \mathrm{E}-02$ & -1 & $-1.10 \mathrm{E}-05$ \\
\hline Homogêneo & $\operatorname{Par} 45^{\circ}$ & 5 & 3 & 32000 & $3.59 E+07$ & 0.119 & 2411 & $2.66 \mathrm{E}-02$ & -1 & $-1.10 \mathrm{E}-05$ \\
\hline Homogêneo & $\operatorname{Par} 45^{\circ}$ & 5 & 3 & 100000 & $3.61 E+07$ & 0.119 & 2344 & $2.58 \mathrm{E}-02$ & -1 & $-1.10 \mathrm{E}-05$ \\
\hline Homogêneo & Par Paralelo & 0 & 1 & 0 & $3.77 \mathrm{E}+07$ & 0.125 & 5700 & $6.28 \mathrm{E}-02$ & -1 & $-1.10 \mathrm{E}-05$ \\
\hline Homogêneo & Par Paralelo & 0 & 1 & 32 & $3.76 \mathrm{E}+07$ & 0.124 & 5163 & $5.69 \mathrm{E}-02$ & -1 & $-1.10 \mathrm{E}-05$ \\
\hline Homogêneo & Par Paralelo & 0 & 1 & 100 & $3.73 E+07$ & 0.124 & 4652 & $5.12 \mathrm{E}-02$ & -1 & $-1.10 \mathrm{E}-05$ \\
\hline Homogêneo & Par Paralelo & 0 & 1 & 320 & $3.68 \mathrm{E}+07$ & 0.122 & 3378 & $3.72 \mathrm{E}-02$ & -1 & $-1.10 \mathrm{E}-05$ \\
\hline Homogêneo & Par Paralelo & 0 & 1 & 1000 & $3.56 \mathrm{E}+07$ & 0.118 & 414 & $4.56 \mathrm{E}-03$ & -1 & $-1.10 \mathrm{E}-05$ \\
\hline Homogêneo & Par Paralelo & 0 & 1 & 3200 & $3.45 E+07$ & 0.114 & 29 & 3.17E-04 & -1 & $-1.10 \mathrm{E}-05$ \\
\hline Homogêneo & Par Paralelo & 0 & 1 & 10000 & $3.15 E+07$ & 0.104 & 14 & $1.49 \mathrm{E}-04$ & -1 & $-1.10 \mathrm{E}-05$ \\
\hline Homogêneo & Par Paralelo & 0 & 1 & 32000 & $3.12 \mathrm{E}+07$ & 0.103 & 9 & $9.79 \mathrm{E}-05$ & -1 & $-1.10 \mathrm{E}-05$ \\
\hline Homogêneo & Par Paralelo & 0 & 1 & 100000 & $3.09 E+07$ & 0.102 & 6 & $7.08 \mathrm{E}-05$ & -1 & $-1.10 \mathrm{E}-05$ \\
\hline
\end{tabular}




\begin{tabular}{|c|c|c|c|c|c|c|c|c|c|c|}
\hline Homogêneo & Par Paralelo & 0 & 2 & 0 & $3.77 E+07$ & 0.125 & 5574 & $6.14 \mathrm{E}-02$ & -1 & $-1.10 \mathrm{E}-05$ \\
\hline Homogêneo & Par Paralelo & 0 & 2 & 32 & $3.75 E+07$ & 0.124 & 5041 & 5.55E-02 & -1 & $-1.10 \mathrm{E}-05$ \\
\hline Homogêneo & Par Paralelo & 0 & 2 & 100 & $3.72 E+07$ & 0.123 & 4307 & 4.74E-02 & -1 & $-1.10 \mathrm{E}-05$ \\
\hline Homogêneo & Par Paralelo & 0 & 2 & 320 & $3.63 \mathrm{E}+07$ & 0.120 & 2348 & $2.59 \mathrm{E}-02$ & -1 & $-1.10 \mathrm{E}-05$ \\
\hline Homogêneo & Par Paralelo & 0 & 2 & 1000 & $3.46 \mathrm{E}+07$ & 0.114 & 113 & $1.24 \mathrm{E}-03$ & -1 & $-1.10 \mathrm{E}-05$ \\
\hline Homogêneo & Par Paralelo & 0 & 2 & 3200 & $3.41 \mathrm{E}+07$ & 0.113 & 36 & 3.97E-04 & -1 & $-1.10 \mathrm{E}-05$ \\
\hline Homogêneo & Par Paralelo & 0 & 2 & 10000 & $3.19 E+07$ & 0.106 & 19 & $2.14 \mathrm{E}-04$ & -1 & $-1.10 \mathrm{E}-05$ \\
\hline Homogêneo & Par Paralelo & 0 & 2 & 32000 & $3.19 E+07$ & 0.106 & 14 & 1.56E-04 & -1 & $-1.10 \mathrm{E}-05$ \\
\hline Homogêneo & Par Paralelo & 0 & 2 & 100000 & $3.16 \mathrm{E}+07$ & 0.105 & 11 & 1.19E-04 & -1 & $-1.10 \mathrm{E}-05$ \\
\hline Homogêneo & Par Paralelo & 0 & 3 & 0 & $3.77 E+07$ & 0.125 & 5435 & 5.99E-02 & -1 & $-1.10 \mathrm{E}-05$ \\
\hline Homogêneo & Par Paralelo & 0 & 3 & 32 & $3.74 \mathrm{E}+07$ & 0.124 & 4854 & 5.35E-02 & -1 & $-1.10 \mathrm{E}-05$ \\
\hline Homogêneo & Par Paralelo & 0 & 3 & 100 & $3.70 \mathrm{E}+07$ & 0.122 & 4109 & 4.53E-02 & -1 & $-1.10 \mathrm{E}-05$ \\
\hline Homogêneo & Par Paralelo & 0 & 3 & 320 & $3.59 E+07$ & 0.119 & 2012 & $2.22 \mathrm{E}-02$ & -1 & $-1.10 \mathrm{E}-05$ \\
\hline Homogêneo & Par Paralelo & 0 & 3 & 1000 & $3.41 \mathrm{E}+07$ & 0.113 & 113 & $1.25 \mathrm{E}-03$ & -1 & $-1.10 \mathrm{E}-05$ \\
\hline Homogêneo & Par Paralelo & 0 & 3 & 3200 & $3.43 E+07$ & 0.114 & 43 & 4.75E-04 & -1 & $-1.10 \mathrm{E}-05$ \\
\hline Homogêneo & Par Paralelo & 0 & 3 & 10000 & $3.24 \mathrm{E}+07$ & 0.107 & 25 & $2.78 \mathrm{E}-04$ & -1 & $-1.10 \mathrm{E}-05$ \\
\hline Homogêneo & Par Paralelo & 0 & 3 & 32000 & $3.27 \mathrm{E}+07$ & 0.108 & 19 & $2.05 \mathrm{E}-04$ & -1 & $-1.10 \mathrm{E}-05$ \\
\hline Homogêneo & Par Paralelo & 0 & 3 & 100000 & $3.25 \mathrm{E}+07$ & 0.108 & 15 & $1.65 \mathrm{E}-04$ & -1 & $-1.10 \mathrm{E}-05$ \\
\hline Homogêneo & Par Paralelo & 1 & 1 & 0 & $3.77 \mathrm{E}+07$ & 0.125 & 5609 & $6.18 \mathrm{E}-02$ & -1 & $-1.10 \mathrm{E}-05$ \\
\hline Homogêneo & Par Paralelo & 1 & 1 & 32 & $3.77 E+07$ & 0.125 & 5400 & 5.95E-02 & -1 & $-1.10 \mathrm{E}-05$ \\
\hline Homogêneo & Par Paralelo & 1 & 1 & 100 & $3.75 E+07$ & 0.124 & 4951 & 5.45E-02 & -1 & $-1.10 \mathrm{E}-05$ \\
\hline Homogêneo & Par Paralelo & 1 & 1 & 320 & $3.72 \mathrm{E}+07$ & 0.123 & 3978 & $4.38 \mathrm{E}-02$ & -1 & $-1.10 \mathrm{E}-05$ \\
\hline Homogêneo & Par Paralelo & 1 & 1 & 1000 & $3.63 E+07$ & 0.120 & 2113 & $2.33 \mathrm{E}-02$ & -1 & $-1.10 \mathrm{E}-05$ \\
\hline Homogêneo & Par Paralelo & 1 & 1 & 3200 & $3.46 \mathrm{E}+07$ & 0.115 & 705 & 7.77E-03 & -1 & $-1.10 \mathrm{E}-05$ \\
\hline Homogêneo & Par Paralelo & 1 & 1 & 10000 & $3.31 E+07$ & 0.110 & 436 & $4.80 \mathrm{E}-03$ & -1 & $-1.10 \mathrm{E}-05$ \\
\hline Homogêneo & Par Paralelo & 1 & 1 & 32000 & $3.22 \mathrm{E}+07$ & 0.107 & 374 & 4.12E-03 & -1 & $-1.10 \mathrm{E}-05$ \\
\hline Homogêneo & Par Paralelo & 1 & 1 & 100000 & $3.19 E+07$ & 0.106 & 362 & 3.99E-03 & -1 & $-1.10 \mathrm{E}-05$ \\
\hline Homogêneo & Par Paralelo & 1 & 2 & 0 & $3.77 E+07$ & 0.125 & 5567 & $6.13 \mathrm{E}-02$ & -1 & $-1.10 \mathrm{E}-05$ \\
\hline Homogêneo & Par Paralelo & 1 & 2 & 32 & $3.76 \mathrm{E}+07$ & 0.125 & 5316 & $5.86 \mathrm{E}-02$ & -1 & $-1.10 \mathrm{E}-05$ \\
\hline Homogêneo & Par Paralelo & 1 & 2 & 100 & $3.74 \mathrm{E}+07$ & 0.124 & 4707 & 5.19E-02 & -1 & $-1.10 \mathrm{E}-05$ \\
\hline Homogêneo & Par Paralelo & 1 & 2 & 320 & $3.69 \mathrm{E}+07$ & 0.122 & 3476 & $3.83 \mathrm{E}-02$ & -1 & $-1.10 \mathrm{E}-05$ \\
\hline Homogêneo & Par Paralelo & 1 & 2 & 1000 & $3.57 E+07$ & 0.118 & 1534 & $1.69 \mathrm{E}-02$ & -1 & $-1.10 \mathrm{E}-05$ \\
\hline Homogêneo & Par Paralelo & 1 & 2 & 3200 & $3.41 \mathrm{E}+07$ & 0.113 & 669 & 7.37E-03 & -1 & $-1.10 \mathrm{E}-05$ \\
\hline Homogêneo & Par Paralelo & 1 & 2 & 10000 & $3.30 E+07$ & 0.109 & 501 & $5.52 \mathrm{E}-03$ & -1 & $-1.10 \mathrm{E}-05$ \\
\hline Homogêneo & Par Paralelo & 1 & 2 & 32000 & $3.25 E+07$ & 0.108 & 460 & 5.07E-03 & -1 & $-1.10 \mathrm{E}-05$ \\
\hline Homogêneo & Par Paralelo & 1 & 2 & 100000 & $3.24 \mathrm{E}+07$ & 0.107 & 451 & 4.97E-03 & -1 & $-1.10 \mathrm{E}-05$ \\
\hline Homogêneo & Par Paralelo & 1 & 3 & 0 & $3.77 \mathrm{E}+07$ & 0.125 & 5571 & $6.14 \mathrm{E}-02$ & -1 & $-1.10 \mathrm{E}-05$ \\
\hline Homogêneo & Par Paralelo & 1 & 3 & 32 & $3.76 \mathrm{E}+07$ & 0.124 & 5329 & 5.87E-02 & -1 & $-1.10 \mathrm{E}-05$ \\
\hline Homogêneo & Par Paralelo & 1 & 3 & 100 & $3.74 \mathrm{E}+07$ & 0.124 & 4688 & $5.16 \mathrm{E}-02$ & -1 & $-1.10 \mathrm{E}-05$ \\
\hline Homogêneo & Par Paralelo & 1 & 3 & 320 & $3.67 E+07$ & 0.122 & 3357 & 3.70E-02 & -1 & $-1.10 \mathrm{E}-05$ \\
\hline Homogêneo & Par Paralelo & 1 & 3 & 1000 & $3.55 \mathrm{E}+07$ & 0.117 & 1317 & $1.45 \mathrm{E}-02$ & -1 & $-1.10 \mathrm{E}-05$ \\
\hline Homogêneo & Par Paralelo & 1 & 3 & 3200 & $3.41 E+07$ & 0.113 & 648 & 7.14E-03 & -1 & $-1.10 \mathrm{E}-05$ \\
\hline Homogêneo & Par Paralelo & 1 & 3 & 10000 & $3.33 E+07$ & 0.110 & 553 & 6.09E-03 & -1 & $-1.10 \mathrm{E}-05$ \\
\hline Homogêneo & Par Paralelo & 1 & 3 & 32000 & $3.30 E+07$ & 0.109 & 520 & 5.73E-03 & -1 & $-1.10 \mathrm{E}-05$ \\
\hline
\end{tabular}




\begin{tabular}{|c|c|c|c|c|c|c|c|c|c|c|}
\hline Homogêneo & Par Paralelo & 1 & 3 & 100000 & $3.29 E+07$ & 0.109 & 512 & $5.64 \mathrm{E}-03$ & -1 & $-1.10 \mathrm{E}-05$ \\
\hline Homogêneo & Par Paralelo & 5 & 1 & 0 & $3.78 \mathrm{E}+07$ & 0.125 & 5680 & $6.26 \mathrm{E}-02$ & -1 & $-1.10 \mathrm{E}-05$ \\
\hline Homogêneo & Par Paralelo & 5 & 1 & 32 & $3.78 \mathrm{E}+07$ & 0.125 & 5651 & $6.23 \mathrm{E}-02$ & -1 & $-1.10 \mathrm{E}-05$ \\
\hline Homogêneo & Par Paralelo & 5 & 1 & 100 & $3.78 \mathrm{E}+07$ & 0.125 & 5662 & $6.24 \mathrm{E}-02$ & -1 & $-1.10 \mathrm{E}-05$ \\
\hline Homogêneo & Par Paralelo & 5 & 1 & 320 & $3.77 \mathrm{E}+07$ & 0.125 & 5650 & $6.22 \mathrm{E}-02$ & -1 & $-1.10 \mathrm{E}-05$ \\
\hline Homogêneo & Par Paralelo & 5 & 1 & 1000 & $3.76 E+07$ & 0.124 & 5602 & $6.17 \mathrm{E}-02$ & -1 & $-1.10 \mathrm{E}-05$ \\
\hline Homogêneo & Par Paralelo & 5 & 1 & 3200 & $3.72 E+07$ & 0.123 & 4969 & $5.47 \mathrm{E}-02$ & -1 & $-1.10 \mathrm{E}-05$ \\
\hline Homogêneo & Par Paralelo & 5 & 1 & 10000 & $3.69 E+07$ & 0.122 & 4165 & $4.59 \mathrm{E}-02$ & -1 & $-1.10 \mathrm{E}-05$ \\
\hline Homogêneo & Par Paralelo & 5 & 1 & 32000 & $3.67 E+07$ & 0.121 & 3782 & 4.17E-02 & -1 & $-1.10 \mathrm{E}-05$ \\
\hline Homogêneo & Par Paralelo & 5 & 1 & 100000 & $3.67 \mathrm{E}+07$ & 0.121 & 3662 & $4.03 \mathrm{E}-02$ & -1 & $-1.10 \mathrm{E}-05$ \\
\hline Homogêneo & Par Paralelo & 5 & 2 & 0 & $3.78 E+07$ & 0.125 & 5680 & $6.26 \mathrm{E}-02$ & -1 & $-1.10 \mathrm{E}-05$ \\
\hline Homogêneo & Par Paralelo & 5 & 2 & 32 & $3.78 \mathrm{E}+07$ & 0.125 & 5700 & $6.28 \mathrm{E}-02$ & -1 & $-1.10 \mathrm{E}-05$ \\
\hline Homogêneo & Par Paralelo & 5 & 2 & 100 & $3.78 \mathrm{E}+07$ & 0.125 & 5700 & $6.28 \mathrm{E}-02$ & -1 & $-1.10 \mathrm{E}-05$ \\
\hline Homogêneo & Par Paralelo & 5 & 2 & 320 & $3.77 \mathrm{E}+07$ & 0.125 & 5700 & $6.28 \mathrm{E}-02$ & -1 & $-1.10 \mathrm{E}-05$ \\
\hline Homogêneo & Par Paralelo & 5 & 2 & 1000 & $3.75 E+07$ & 0.124 & 5582 & $6.15 \mathrm{E}-02$ & -1 & $-1.10 \mathrm{E}-05$ \\
\hline Homogêneo & Par Paralelo & 5 & 2 & 3200 & $3.73 E+07$ & 0.123 & 4970 & 5.47E-02 & -1 & $-1.10 \mathrm{E}-05$ \\
\hline Homogêneo & Par Paralelo & 5 & 2 & 10000 & $3.71 \mathrm{E}+07$ & 0.123 & 4335 & $4.78 \mathrm{E}-02$ & -1 & $-1.10 \mathrm{E}-05$ \\
\hline Homogêneo & Par Paralelo & 5 & 2 & 32000 & $3.70 E+07$ & 0.122 & 4071 & 4.48E-02 & -1 & $-1.10 \mathrm{E}-05$ \\
\hline Homogêneo & Par Paralelo & 5 & 2 & 100000 & $3.70 \mathrm{E}+07$ & 0.122 & 3993 & 4.40E-02 & -1 & $-1.10 \mathrm{E}-05$ \\
\hline Homogêneo & Par Paralelo & 5 & 3 & 0 & $3.78 \mathrm{E}+07$ & 0.125 & 5700 & $6.28 \mathrm{E}-02$ & -1 & $-1.10 \mathrm{E}-05$ \\
\hline Homogêneo & Par Paralelo & 5 & 3 & 32 & $3.78 \mathrm{E}+07$ & 0.125 & 5700 & $6.28 \mathrm{E}-02$ & -1 & $-1.10 \mathrm{E}-05$ \\
\hline Homogêneo & Par Paralelo & 5 & 3 & 100 & $3.78 E+07$ & 0.125 & 5700 & $6.28 \mathrm{E}-02$ & -1 & $-1.10 \mathrm{E}-05$ \\
\hline Homogêneo & Par Paralelo & 5 & 3 & 320 & $3.78 \mathrm{E}+07$ & 0.125 & 5732 & $6.31 \mathrm{E}-02$ & -1 & $-1.10 \mathrm{E}-05$ \\
\hline Homogêneo & Par Paralelo & 5 & 3 & 1000 & $3.76 E+07$ & 0.124 & 5615 & $6.19 \mathrm{E}-02$ & -1 & $-1.10 \mathrm{E}-05$ \\
\hline Homogêneo & Par Paralelo & 5 & 3 & 3200 & $3.74 \mathrm{E}+07$ & 0.124 & 5061 & $5.58 \mathrm{E}-02$ & -1 & $-1.10 \mathrm{E}-05$ \\
\hline Homogêneo & Par Paralelo & 5 & 3 & 10000 & $3.73 E+07$ & 0.123 & 4545 & $5.01 \mathrm{E}-02$ & -1 & $-1.10 \mathrm{E}-05$ \\
\hline Homogêneo & Par Paralelo & 5 & 3 & 32000 & $3.73 E+07$ & 0.123 & 4326 & 4.77E-02 & -1 & $-1.10 \mathrm{E}-05$ \\
\hline Homogêneo & Par Paralelo & 5 & 3 & 100000 & $3.73 E+07$ & 0.123 & 4262 & 4.69E-02 & -1 & $-1.10 \mathrm{E}-05$ \\
\hline
\end{tabular}




\section{Apêndice B. Tabelas com os Ajustes da Curva Logística}

Tabela B.1: Ajustes da curva logística do FR.

\begin{tabular}{|c|c|c|c|c|c|c|c|c|}
\hline Matriz & Malha & D & $\mathbf{L}$ & $y_{\min }$ & $y_{\operatorname{máx}}$ & $\boldsymbol{h}$ & $p_{i}$ & $x_{a}$ \\
\hline Heterogêneo & Par Paralelo & 0 & 1 & 0.09 & 0.13 & -0.97 & 3.42 & 4.45 \\
\hline Homogêneo & Par Paralelo & 0 & 1 & 0.10 & 0.12 & -1.10 & 3.47 & 4.38 \\
\hline Heterogêneo & Par Paralelo & 1 & 1 & 0.10 & 0.13 & -1.10 & 3.23 & 4.13 \\
\hline Homogêneo & Par Paralelo & 1 & 1 & 0.11 & 0.12 & -1.04 & 3.48 & 4.44 \\
\hline Heterogêneo & Par Paralelo & 5 & 1 & 0.13 & 0.13 & -1.58 & 3.32 & 3.96 \\
\hline Homogêneo & Par Paralelo & 5 & 1 & 0.12 & 0.13 & -1.18 & 3.52 & 4.37 \\
\hline Heterogêneo & Par Paralelo & 0 & 2 & 0.08 & 0.13 & -0.51 & 3.28 & 5.25 \\
\hline Homogêneo & Par Paralelo & 0 & 2 & 0.10 & 0.13 & -0.78 & 3.10 & 4.38 \\
\hline Heterogêneo & Par $45^{\circ}$ & 0 & 2 & 0.09 & 0.13 & -1.14 & 3.50 & 4.38 \\
\hline Homogêneo & $\operatorname{Par} 45^{\circ}$ & 0 & 2 & 0.10 & 0.12 & -1.36 & 3.43 & 4.16 \\
\hline Heterogêneo & Par Paralelo & 1 & 2 & 0.11 & 0.13 & -1.16 & 2.95 & 3.81 \\
\hline Homogêneo & Par Paralelo & 1 & 2 & 0.11 & 0.12 & -1.07 & 3.20 & 4.14 \\
\hline Heterogêneo & Par $45^{\circ}$ & 1 & 2 & 0.11 & 0.13 & -1.48 & 3.20 & 3.88 \\
\hline Homogêneo & $\operatorname{Par} 45^{\circ}$ & 1 & 2 & 0.11 & 0.12 & -1.24 & 3.50 & 4.31 \\
\hline Heterogêneo & Par Paralelo & 5 & 2 & 0.13 & 0.13 & -2.13 & 3.11 & 3.58 \\
\hline Homogêneo & Par Paralelo & 5 & 2 & 0.12 & 0.13 & -1.37 & 3.30 & 4.03 \\
\hline Heterogêneo & $\operatorname{Par} 45^{\circ}$ & 5 & 2 & 0.12 & 0.13 & -1.40 & 3.36 & 4.08 \\
\hline Homogêneo & Par $45^{\circ}$ & 5 & 2 & 0.12 & 0.12 & -1.31 & 3.58 & 4.35 \\
\hline Homogêneo & Par Paralelo & 0 & 3 & 0.11 & 0.13 & -0.75 & 2.73 & 4.06 \\
\hline Heterogêneo & $\operatorname{Par} 45^{\circ}$ & 0 & 3 & 0.09 & 0.13 & -0.64 & 3.38 & 4.95 \\
\hline Homogêneo & $\operatorname{Par} 45^{\circ}$ & 0 & 3 & 0.11 & 0.12 & -1.02 & 2.95 & 3.94 \\
\hline Heterogêneo & Par Paralelo & 1 & 3 & 0.11 & 0.13 & -1.20 & 2.81 & 3.64 \\
\hline Homogêneo & Par Paralelo & 1 & 3 & 0.11 & 0.12 & -1.07 & 3.06 & 3.99 \\
\hline Heterogêneo & Par $45^{\circ}$ & 1 & 3 & 0.12 & 0.13 & -1.70 & 2.91 & 3.50 \\
\hline Homogêneo & Par $45^{\circ}$ & 1 & 3 & 0.11 & 0.12 & -1.36 & 3.21 & 3.95 \\
\hline Heterogêneo & Par Paralelo & 5 & 3 & 0.13 & 0.13 & -13.74 & 3.01 & 3.08 \\
\hline Homogêneo & Par Paralelo & 5 & 3 & 0.12 & 0.13 & -1.56 & 3.19 & 3.84 \\
\hline Heterogêneo & $\operatorname{Par} 45^{\circ}$ & 5 & 3 & 0.13 & 0.13 & -1.60 & 3.11 & 3.73 \\
\hline Homogêneo & Par $45^{\circ}$ & 5 & 3 & 0.12 & 0.12 & -1.51 & 3.30 & 3.96 \\
\hline
\end{tabular}


Tabela B.2: Ajustes da curva logística do $t_{D w}$.

\begin{tabular}{|c|c|c|c|c|c|c|c|c|}
\hline Matriz & Malha & D & $\mathbf{L}$ & $y_{m i ́ n}$ & $y_{\text {máx }}$ & $\boldsymbol{h}$ & $p_{i}$ & $x_{a}$ \\
\hline Heterogêneo & Par Paralelo & 0 & 1 & 0.00 & 0.08 & -1.92 & 2.29 & 2.81 \\
\hline Homogêneo & Par Paralelo & 0 & 1 & 0.00 & 0.05 & -2.57 & 2.62 & 3.01 \\
\hline Heterogêneo & Par Paralelo & 1 & 1 & 0.00 & 0.08 & -1.63 & 2.60 & 3.21 \\
\hline Homogêneo & Par Paralelo & 1 & 1 & 0.00 & 0.06 & -1.39 & 2.79 & 3.51 \\
\hline Heterogêneo & Par Paralelo & 5 & 1 & 0.06 & 0.08 & -1.78 & 3.64 & 4.20 \\
\hline Homogêneo & Par Paralelo & 5 & 1 & 0.04 & 0.06 & -1.62 & 3.69 & 4.30 \\
\hline Heterogêneo & Par Paralelo & 0 & 2 & 0.00 & 0.07 & -2.11 & 2.16 & 2.64 \\
\hline Homogêneo & Par Paralelo & 0 & 2 & 0.00 & 0.05 & -2.09 & 2.46 & 2.94 \\
\hline Heterogêneo & $\operatorname{Par} 45^{\circ}$ & 0 & 2 & 0.00 & 0.08 & -2.09 & 2.57 & 3.05 \\
\hline Homogêneo & $\operatorname{Par} 45^{\circ}$ & 0 & 2 & 0.00 & 0.06 & -2.01 & 2.82 & 3.32 \\
\hline Heterogêneo & Par Paralelo & 1 & 2 & 0.01 & 0.08 & -1.44 & 2.45 & 3.15 \\
\hline Homogêneo & Par Paralelo & 1 & 2 & 0.00 & 0.06 & -1.42 & 2.63 & 3.33 \\
\hline Heterogêneo & Par $45^{\circ}$ & 1 & 2 & 0.00 & 0.08 & -1.51 & 2.66 & 3.32 \\
\hline Homogêneo & Par $45^{\circ}$ & 1 & 2 & 0.00 & 0.06 & -1.86 & 2.99 & 3.53 \\
\hline Heterogêneo & Par Paralelo & 5 & 2 & 0.06 & 0.09 & -2.15 & 3.51 & 3.98 \\
\hline Homogêneo & Par Paralelo & 5 & 2 & 0.04 & 0.06 & -1.60 & 3.59 & 4.21 \\
\hline Heterogêneo & Par $45^{\circ}$ & 5 & 2 & 0.03 & 0.09 & -1.41 & 3.09 & 3.80 \\
\hline Homogêneo & Par $45^{\circ}$ & 5 & 2 & 0.02 & 0.06 & -1.69 & 3.42 & 4.01 \\
\hline Homogêneo & Par Paralelo & 0 & 3 & 0.00 & 0.05 & -1.99 & 2.41 & 2.91 \\
\hline Heterogêneo & Par $45^{\circ}$ & 0 & 3 & 0.00 & 0.08 & -1.81 & 2.36 & 2.91 \\
\hline Homogêneo & Par $45^{\circ}$ & 0 & 3 & 0.00 & 0.05 & -3.13 & 2.59 & 2.90 \\
\hline Heterogêneo & Par Paralelo & 1 & 3 & 0.01 & 0.08 & -1.37 & 2.40 & 3.13 \\
\hline Homogêneo & Par Paralelo & 1 & 3 & 0.01 & 0.06 & -1.57 & 2.58 & 3.22 \\
\hline Heterogêneo & Par $45^{\circ}$ & 1 & 3 & 0.01 & 0.08 & -1.46 & 2.46 & 3.14 \\
\hline Homogêneo & Par $45^{\circ}$ & 1 & 3 & 0.00 & 0.06 & -1.95 & 2.73 & 3.24 \\
\hline Heterogêneo & Par Paralelo & 5 & 3 & 0.07 & 0.09 & -4.08 & 3.52 & 3.76 \\
\hline Homogêneo & Par Paralelo & 5 & 3 & 0.05 & 0.06 & -1.65 & 3.57 & 4.17 \\
\hline Heterogêneo & Par $45^{\circ}$ & 5 & 3 & 0.04 & 0.09 & -1.48 & 2.91 & 3.59 \\
\hline Homogêneo & $\operatorname{Par} 45^{\circ}$ & 5 & 3 & 0.03 & 0.06 & -1.54 & 3.22 & 3.87 \\
\hline
\end{tabular}

